\title{
Conventional roentgenograms of the cervical spine in anteflexion and retroflexion : a new method to optimize their clinical significance
}

Citation for published version (APA):

Majoie, H. J. M. (1998). Conventional roentgenograms of the cervical spine in anteflexion and retroflexion : a new method to optimize their clinical significance. [Doctoral Thesis, Maastricht University]. Universiteit Maastricht. https://doi.org/10.26481/dis.19981203hm

Document status and date:

Published: 01/01/1998

DOI:

10.26481/dis.19981203hm

Document Version:

Publisher's PDF, also known as Version of record

Please check the document version of this publication:

- A submitted manuscript is the version of the article upon submission and before peer-review. There can be important differences between the submitted version and the official published version of record.

People interested in the research are advised to contact the author for the final version of the publication, or visit the DOI to the publisher's website.

- The final author version and the galley proof are versions of the publication after peer review.

- The final published version features the final layout of the paper including the volume, issue and page numbers.

Link to publication

\footnotetext{
General rights rights.

- You may freely distribute the URL identifying the publication in the public portal. please follow below link for the End User Agreement:

www.umlib.nl/taverne-license

Take down policy

If you believe that this document breaches copyright please contact us at:

repository@maastrichtuniversity.nl

providing details and we will investigate your claim.
}

Copyright and moral rights for the publications made accessible in the public portal are retained by the authors and/or other copyright owners and it is a condition of accessing publications that users recognise and abide by the legal requirements associated with these

- Users may download and print one copy of any publication from the public portal for the purpose of private study or research.

- You may not further distribute the material or use it for any profit-making activity or commercial gain

If the publication is distributed under the terms of Article 25fa of the Dutch Copyright Act, indicated by the "Taverne" license above, 
CONVENTIONAL ROENTGENOGRAMS OF THE CERVIGAL SPINE IN ANTEFLEXION AND RETROFLEXION;

A NEW METHOD TO OPTIMIZE THEIR CLINICAL SIONTHCANCE 
ISEN $90-9012280-\mathrm{x}$

Printing: Drukkerij Groenevelt BV Landgraaf

Financial support: Cardiall, Gyberonics, Katwijk, Novartis, Novonordisk, Orihomed, Sanofi, Shering Plough, Welcome Glaxo, West, Yamanouchi, Van Laarschot (Harley-Davidson dealer) 


\title{
Conventional roentgenograms of the
} cervical spine in anteflexion and retroflexion; a new method to optimize their clinical significance

\author{
proefschrift
}

Ter verkrijging van de graad van doctor aan de Universiteit Maastricht, op gezag van de Rector Magnificus Prof. dr A.C. Nieuwenhuijzen Kruseman volgens besluit van het College van Decanen

In het openbaar te verdedigen op donderdag 3 december 1998 om 12.00 uur

door

H.J.M. Majoie 


\section{Promotoren:}

Prol. dr J.T. Wilmink

Prof. dr ir. P.A. van de Brandt

\section{Co-promotor:}

Dr M.W. Berfelo

\section{Beoordelingscommissie:}

Prof. dr J.M.J.P. wan der Linden (voorzitter)

Prof. dr E.A.M. Beuls

Prof. dr R. Braakman (em. hooglcraar, Berkel Enschot)

Prof. dr ir. J.D.F. Habbema (Erasmus Universiteit Rotterdam)

Dr H. van Mameren 
Aan mijn Ouders voor Willem 
What we call knowledge is merely awoher form of ignorance, organzed igmorance" A. Huxly 


\section{Contents}

INTRODUCTION AND AIM OF THE STUDY 13

PART I; REVIEW 15

AnATOMY 17

Vertebral segments and motion segments 17

Lower and middle cervical region $\left(\mathrm{C}_{7}\right.$ up to and including $\left.\mathrm{C}_{3}\right) \quad 17$ Intervertebral or apophyseal joint 17

Uncinate process and uncovertebral joints 17

Intervertebral disc 18

Ligaments 19

Upper cervical region $\left(\mathrm{C}_{2}\right.$ up to and including $\left.\mathrm{C}_{0}\right) \quad 20$

Spinal canal and contents 23

Normal linear and cross-sectional measurements 23

Normal effects of anteflexion and retroflexion upon vertebral

structures, canal and cord 24

Cord compression 25

Ageing and degenerative changes of the spine 26

DIAGNostic PROPERTIES OF IMAGING TECHNIQUES 29

The matter of a gold standard 29

Plain x-rays 30

Myclography 31

$\mathrm{CT}$ and $\mathrm{CT}$-myelography 32

Magnetic resonance imaging 34 .

Comment 36

REVIEW OF THE LITERATURE 39

History 39

Kinematic studies of the cervical spine 411

General aspects 41

1. The Cartesian method 43

2. The R-Centre method 54

3. The cervical spine studied as a complete structure 58

4. Cine-radiography 66

5. Three-dimensional reconstructions of bi-planar $x$-rays of the spine 68

Comment 73 
PART II; PRESENT KINEMATIC STUDY OF FUNCTION X-RAYS OF THE CERWICAL SPINE 75

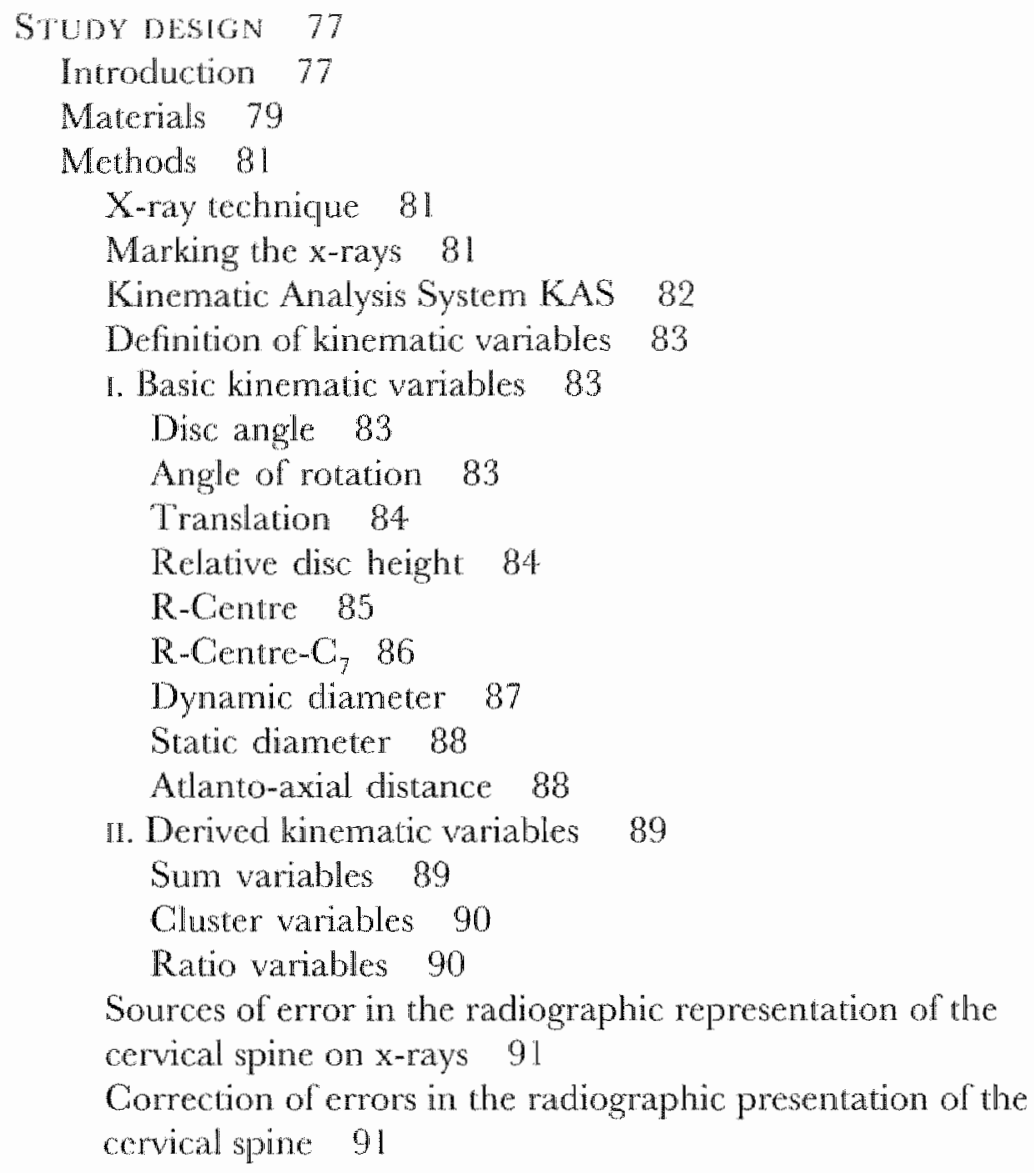

OBSERver VARIABHLITy 93

Introduction 93

Merhods 93

Results 96

Observer variability of the basic kinematic variables 96

Intra-observer variability of basic variables 96

Inter-observer variability of basic variables 96

Total observer variability or variance of

measurement noise of basic variables 97

Observer variability of the derived kinematic variables 100

Intra-observer variability of derived variables 100

Inter-observer variability of derived variables 100

Totall observer variability or variance of

measurement noise of derived variables 100 
Discussion 1.02

The intra-observer wariability 102

The inter-observer variability 102

Total observer variability or variance of measurement noise 103

EVALUATION OF DIAGNOSTIC PERFORMANCES OF KINEMATIC VARIABLES 05

Introduction 105

Methods 105

Univariate analysis 105

Logistic regression procedure 106

Selection of kinematic variables with diagnostic

sigmificance 106

ROC curves 108

ROC curves of different strategies: comparing

the areas under the curves 109

Selection of strategies 110

Split-sample method 111

Results 111

Age 111

Gender 113

Basic kinematic variables; differences between the study groups 114

Derived kinematic variables 1116

Sum variables 116

Cluster variables 117

Ratio variables 117

Selection of variables with diagnostic significance using the logistic regression procedure 118

Control group versus patient groups 1.18

Cervical myelopathy group versus herniated cervical disc groups 123

Patient group with hermiated disc at level $\mathrm{C}_{5}-\mathrm{C}_{0 ;}$ versus paticnt group with herniated disc at level $\mathrm{C}_{6}-\mathrm{C}_{7} \quad 127$

Control group versus herniated cervical disc groups 130

Control group versus cervical myelopathy group 132

Split-sample method 134

Discussion 136

Age 136

Gender 137

Paradoxical tilung 138

Basic kinematic variables 138

Angle of rotation 138 
Translation 140

Dynamic diameter in anteflexion and retroflexion 140

Disc height 140

R-Centre 141

R-Centre-C, 141

Static diameter $\quad 142$

Derived kinematic variables 142

Sum variables 142

Cluster variables 143

Ratio variables 143

GENERAL DISCUSSION 145

CONCLUSTONS 151

SUMMARY 153

SAMENVATTING 157

APPENDIX I 161

Age distribution: frequency tables 162

Age distribution: box plots 164

Gender distribution: frequency table 164

APPENDIX II 165

Angles of rotation 166

Translation 168

Disc heights in anteflexion 1.70

Disc heights in retroflexion 172

Dynamic diameters in anteflexion 174

Dynamic diameters in retroflexion 176

Cranial static diameters 178

Caudal static diameters 180

R-Gentres: $x$-comordinates 182

R-Centres: $y$-comordinates 184

$\mathrm{R}$-Centres- $\mathrm{C}_{7}: \mathrm{x}$-co-ordinates 186

$\mathrm{R}$-Centres-C;: y-Co-ordinates 188

R-Zero lines 190

Atlanto-axial distance in anteflexion and retroflexion 191 APPENDIX III 193

Sum variables 194

Ratio variables 196

REFERENCES 199

ACKNOWLEDGEMENTS 215 


\section{Chapter 1.}

\section{Introduction and aim of the study}

Since the advent of $\mathrm{x}$-ray imaging in 1895 , this technique has played an important part in medical practice. Computer-assisted methods such as CT-scanning and MR imaging, introduced in the last three decades, have provided hitherto unforeseen means to acquire highly detailed anatomical data. Differences in physical properties of anatomical structures are measured quantitatively; subsequently, these digitised differences are transformed into differences in grey-scale, which enable the composition of black and white images. It is remarkable, however, that attention is still almost exclusively focussed on the qualitative interpretation of these basically quantitative data: the doctor still handles diagnostic data in the same way as Vesalius (1514-1565) who opened the human body and described what he saw in a language that is still ours: a visually oriented qualifying language.

Neck pain, with or without neurological signs of spinal cord or nerve root compression, is very common: $23 \%-44 \%$ of the population suffer from neck pain on at least one occasion during their working life (Hult, 1954; Anderson, 1984; Lamberts, 1984; Dimberg et al., 1989; Bovim et al., 1994).

Sometimes a patho-physiological or patho-anatomical substrate is found and is subsequently held responsible for the patients' symptoms. Such findings may, however, also be present in individuals without complaints (Hussar et al., 1956). Frequently, despite the patients' symptoms, no abnormalities are found at all: the results of imaging studies are nogative in about $10-52 \%$ of these individuals (Hult, 1954; Lawrence, 1969; Ruggieri, 1995). One reason for this might be that the attention is almost exclusively focussed on the morphological information of the cervical spine.

The present study puts emphasis on the quantitative data obained from so-called function $x$-rays of the cervical spine: lateral $x$-rays of the cervical spine in anteflexion and in retroflexion. These films visualise differences in positions of the vertebral bodies with respect to each other. The observed linear and rotational displacements are described with the kinematic parameters distance and angle, thus providing quantitative information about functions of the cervical spine. 
This study will address the following questions:

1 Do kinematic studies of function $x$-rays of the cervical spine have clinical significance?

2 Do kinematic studies of function $x$-rays of the cervical spine contribute to the clinical diagnosis of individual patients?

The relevant anatomy of the cervical spine is presented in the first part of this study. Next, the diagnostic properties of static imaging techniques in the patient groups under study are described. A detailed review of the literature conceming kinematics of the cervical spine is discussed in a seperate section.

The second part presents the design and elaboration of the proper study, and can be summarised as follows.

Function x-rays of four different groups of individuals are analysed kinematically:

1. healthy individuals $(n=112)$

2. patients suffering from cervical myelopathy $(n=25)$

3. patients with a herniated disc at level $\mathrm{C}_{5}-\mathrm{C}_{6,}(\mathrm{n}=28)$

4. patients with a herniated disc at level $C_{60}-C_{7}(n=48)$

On both the anteflexion and retroflexion x-ray film, 43 predefined landmarks are identified and marked with a pencil. These markings serve to calculate the values of a large number of kinematic variables. A computer-assisted method has been developed to read and process these markings as accurately as possible.

An extensive observer variability study is performed to quantify the accuracy of the measuring procedure.

To gain insight into the kincmatic behaviour of the cervical spine, the statistically significant differences between the four study groups are analysed in depth.

The contribution of kinematics to the diagnosis of individual patients is cvaluated with the statistical method of logistic regression. This method cnables the selection of a subset of variables, which, as a subset, contains nearly all diagnostic information present in the studied patient groups. The values of observations of this selected subset serve to calculate the diagnostic probabilities for individual patients with respect to the diagnosis groups studied.

To test the quality of the calculated probabilistic diagnosis of future subjects, the results of the so-called split-sample method are presented and subsequently discussed. 
Part I

Review 



\section{Chapter 2. \\ Anatomy}

Kinematic studies of the spine are based on variables derived from anatomical landmarks on $x$-rays. This chapter discusses relevant aspects of the anatomy of the cervical spine.

\section{VERTEBRAL SEGMENTS AND MOTION SEGMENTS}

Lower and middle cervical region ( $C_{7}$ up to and including $C_{3}$ ) Junghanns $(1951,1952)$ proposed a division of the spine into vertebral segments on the one hand (i.e. vertebral body, vertebral arch, and spinous and transverse process) and motion segments on the other (i.e. intervertebral disc, zygapophyseal junction, flaval, interspinal, intertransverse and anterior and posterior longitudinal ligaments, the muscles attached to the spine included) (Braakman, 1967).

Nowadays it is common to use the term motion segments as it was defined by Schultz (1974): it describes the complex of two adjacent vertebra] bodies, the intervertebral disc and all the anterior and posterior ligaments and articular facet joint capsules that join them together.

These motion segments and vertebral segments delineate the virtual anatomical structures of the vertebral canal, the intervertebral foramina and the transverse foramina (Penning, 1960; Braakman, 1967).

\section{Intervertebral or apophyseal joint}

The apophyseal joint is diarthrotic with joint surfaces, synovial membrane, and capsule. The plane is directed perpendicular to the sagittal plane (at level $\mathrm{C}_{2}-\mathrm{C}_{3}$ this angle is $\pm 70-80^{\circ}$ ) and with an upward angle of $45^{\circ}$ with respect to the endplate of the body [Fig. 1]. In anteflexion, the joint opens dorsally; the joint surfaces remain in contact for approximately five $\mathrm{mm}$ in maximal anteflexion. Coupled movements (i.e. lateroflexion combined with rotation) are the result of the anatomical configuration of the apophyseal joints (Penning, 1960; Braakman, 1967; White, 1978; Lang, 1991).

Uncinate process and uncovertebral joints The uncinate process was first described by Vesalius in 'De humani corporis fabrica' (1543). 


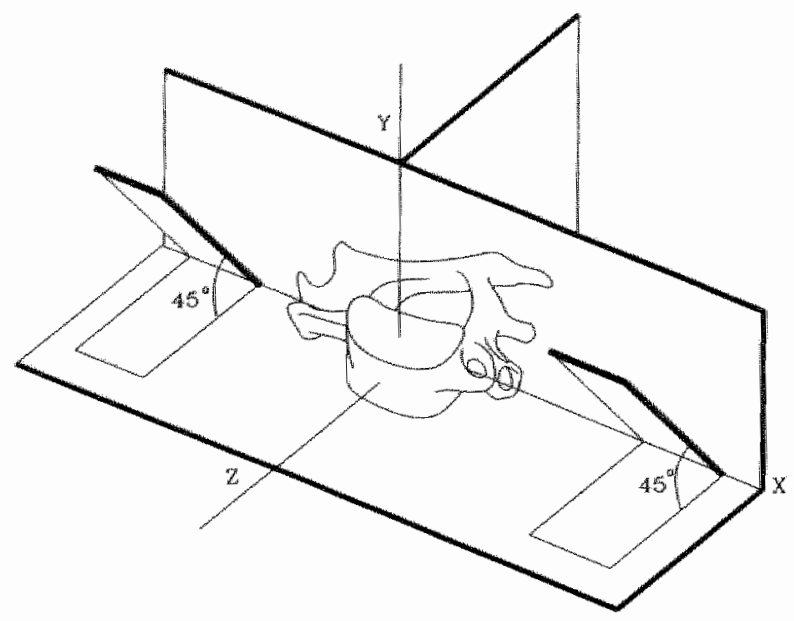

Fig. 1: Orimention of the interwentebal joind (White at al., 1978)

These processes extend from the postero-lateral margins of the upper surfaces of the bodies $\mathrm{C}_{3}-\mathrm{C}_{7}$. These posterolateral surfaces are congruent with the rounded lateral inferior surfaces of the adjacent wertebral bodies. Trolard (1893) (in Penning, 1960) called this lateral complex the uncovertebrat joint. He believed that this joint was a normal feature of the neck, whereas others (Hadley, 1956; Payne et al., 1957; Penning, 1960) considered it to be a sign of degeneration. According to Hall (1965) it is an adaptation to the upright posture. The uncovertebral joints promote stability of the cervical spine in a lateral direction (Hadley, 1956); they are covered with anulus tissue in which horizontal fissures may develop as the result of motion stress. After the age of 20 , a chondral lining, capsule and meniscus-like structure develops (Penning, 1960)/Fig. 2/.

\section{Intervertebral disc}

Each disc consists of a peripheral anulus fibrosis, which surrounds the nucleus pulposus. The amulus consists of concentric layers of collagen fibres, which run helicoidally from one vertebral body to the next, at an angle of approximately $60^{\circ}$ with the long axis, in alternating layers. The fibres of the anulus fibrosis are dorsally connected to the end-plates by a thin layer of hyaline cartilage. The ventral edge, however, is not covered by the cnd-plate: at this site, the fibres of the anulus are directly connected to the bony edges of the vertebral bodies (Penning, 1960).

Fluid exchange plays a major role in intervertebral disc mechanics (Schultz, 1974). The biomechanical properties of the nucleus pulposus, the gelatinous centre of the disc, are hydrostatically determined (Nachemson, $1975 \%$. 


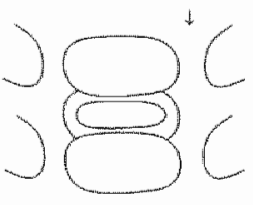

Nhes - borts

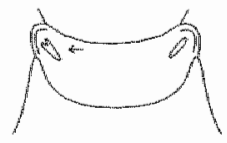

24. years

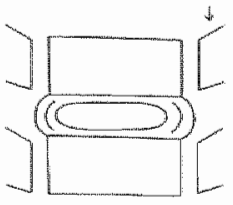

36 month: the

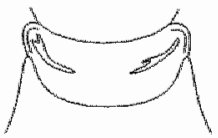

50 years: $\mathrm{C}_{2}-3$

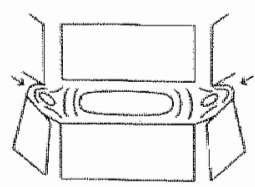

$\theta$ Hens

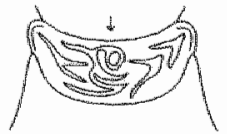

50 years: 6 6

Frontal section through mid-cendoral vegion

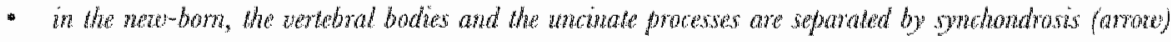

- at the age of 36 months, the uncinate processes (arrow) are flat

- at the age of 9 yedrs, the manate processes are raised at he end and the anulus bulges ouhard beyond the borders of synchondrosis; locat small fissures become wisible (atraw)

- at the age of 24 years: the talew hemianthosis' is well dofund

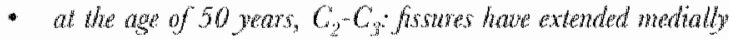

Frontal section through lowe central region

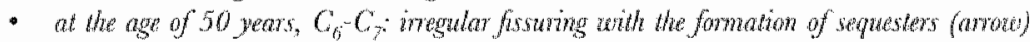

Fig. 2: unctiate process and intervertebral disc in ageing (Penuing, 1988)

According to Junghanns (1951), the location of the mucleus or 'Gallertkern' varies with posture.

\section{Ligaments}

The longitudinal ligaments cover the anterior and the posterior side of the vertebral bodies, and consist of fibres which bridge several segments Fig. 3]. The anterior ligament is connected to the vertebral body directly above or below the end-plates. The posterior ligament is stronger than the anterior ligament, contains more elastic fibres, and consists of two layers: the anterior or deep layer and the posterior or superficial layer. These two layers are loosely connected to each other. In the lateral part of the canal, the superficial layer joins the periradicular sheath of the nerve root at the level of the intervertebral disc; at the level of the vertebral bodies it joins the dura mater. In the lateral region, the epidural. venous plexus is embedded between the two layers of the posterior longitudinal ligament (Kubo et al., 1995).

The flaval ligaments run from the upper margin of the arch of one vertebra to the lower margin of the arch of the vertebra above. These ligaments are highly elastic. 


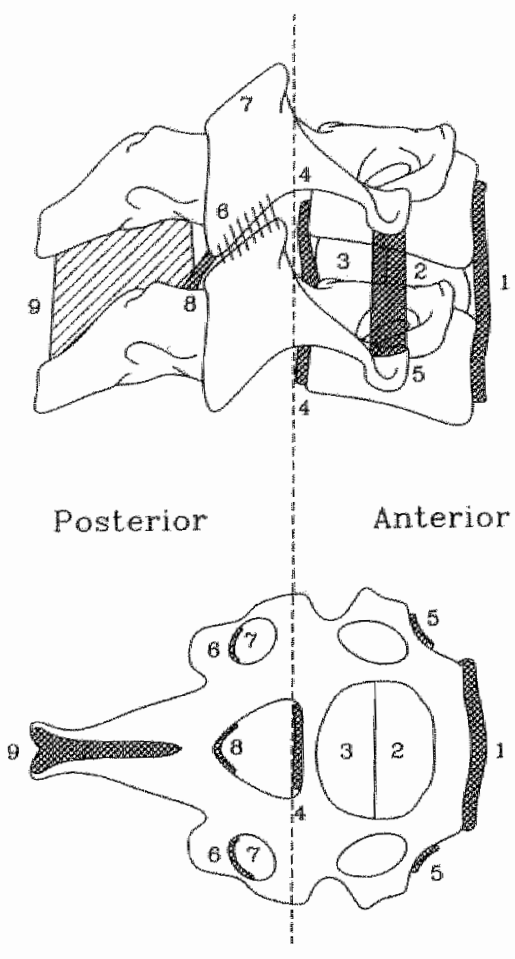

1. anterior Longitudinal ligament

2. wentral part of the anulus fibrosus

3. dorsal part of the aruulus frorasus

4. postorior longinutinat ligament

5. intertronsuerse ligument

6. copsular liganzent

7. focel joint

8. Aloval tiganlent

9. interspinous tiganents

Fig. 3: stabilising liguments (White et al., 1979)

The interspinal ligaments connect the spinous processes and consist mainly of collagen non-elastic fibres, orientated cranio-ventrally to caudodorsally and connected dorsally to the nuchal ligament.

The nuchal ligament is connected to the external occipital protuberance, the posterior tubercle of the attas, and the dorsal ends of the spinal processes of $\mathrm{C}_{2}-\mathrm{C}_{7}$. Elastic fibres within this thin ligament are sparse.

The intertransverse ligaments connect the transverse processes. These ligaments are very thin and provide moderate protection against lateroflexion (Ten Have, 1978).

In general, non-elastic ligaments (nuchal ligament and interspinal ligament) are considered to serve as passive inhibitors of movement, and elastic ligaments (flaval Jigament, longitudinal ligament and anulus fibrosus) as active inhibitors of movement (Penning, 1960, 1978; Braakman, 1967).

Upper cervicat region $\left(C_{2}\right.$, up to and including $C_{0}$ )

The upper cervical region consists of the occiput $\left(\mathrm{C}_{0}\right)$, the atlas $\left(\mathrm{C}_{1}\right)$, and the axis $\left(\mathrm{C}_{2}\right)$.

The occiput $\left(\mathrm{C}_{0}\right)$ is an integrated part of the cervical spine: the facilities for moving the cervical spine serve to move the head with respect to the 
environment. The visuo-spatial orientation of the quadruped is directed in line with the axis of the spine; to observe the environment, lateroflexion of the cervical spine is required. In the evolution from quadruped to biped, bipeds had to change the orientation of their senses over an angle of $90^{\circ}$ in order to assume an erect posture, thus enabling the acquisition of hand and eye comordination. The plane of the foramen magnum and the orientation of the clivus changed with respect to the erect cervical column [Fig. 4]. Observation of the environment is possible by rotating the head about the longitudinal axis of the cervical spine (Hall, 1965; Diethem, 1974; Schultz, 1974; Gutmann, 1981; Gracovetsky et al., 1984).

Movement in the cervical segments varies regionally. About $50 \%$ of headand-neck axial rotation occur at the $\mathrm{C}_{0}, \mathrm{C}_{1}, \mathrm{C}_{2}$ complex. The essential movement takes place between $\mathrm{C}_{0}$ and $\mathrm{C}_{2}$ with $\mathrm{C}_{1}$ functioning as a bony meniscoid structure between them. The axial rotation between $\mathrm{C}_{0}$ and $\mathrm{C}_{1}$ is virtually nihil, and there is no lateral bending between $C_{1}$ and $C_{2}$ (Braakman et al., 1971; Penning, 1978; White et al., 1978).

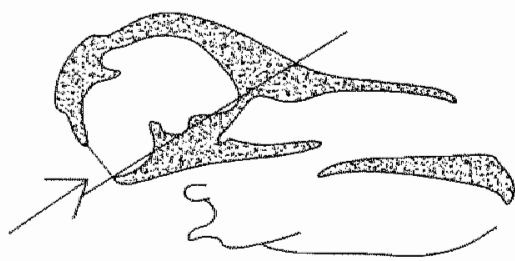

$\operatorname{dog}$

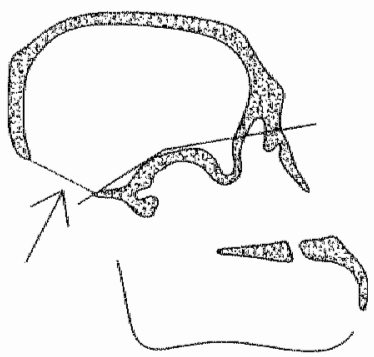

monkey

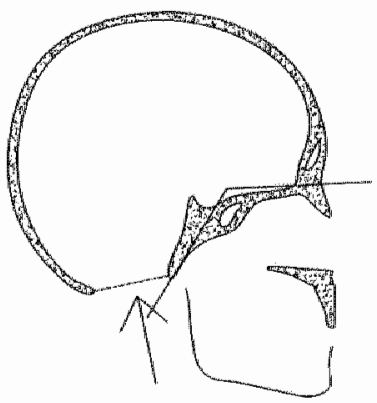

human

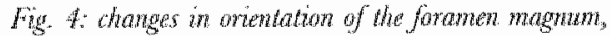
and clims dwring phylogerwests thustrated with a dog-. monky-, and heman stall (Guman, 1981)

human 
The axis $\left(\mathrm{C}_{2}\right)$ and the occiput $\left(\mathrm{C}_{0}\right)$ are directly connected by the apical ligaments, the paired alar ligaments, the tectorial membrane, and the cruciate ligaments [Fig. 5]. Indirect connections are formed by the anterior longitudinal ligament and the nuchal ligament.

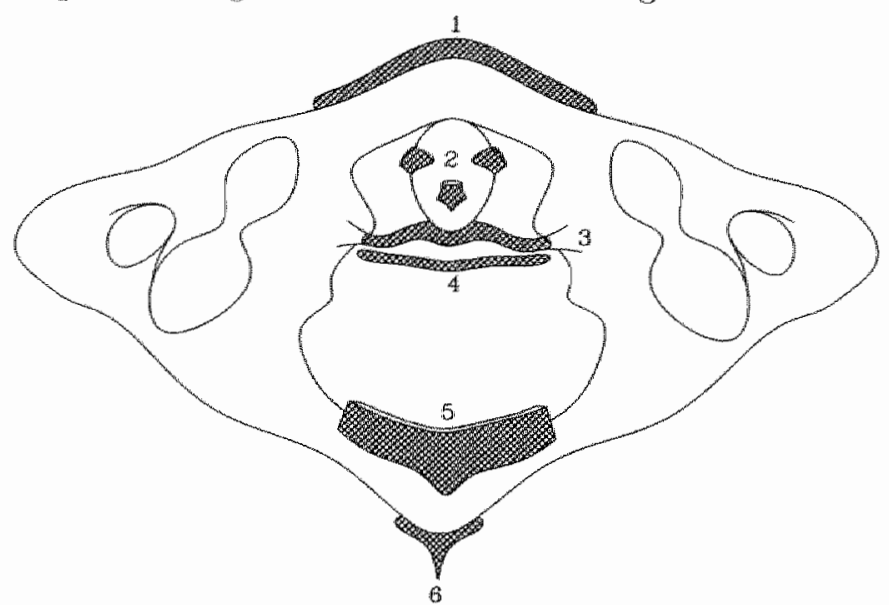

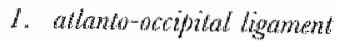

2. apical and alar ligaments

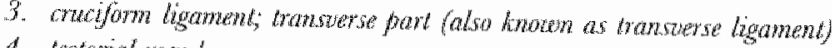

4. tectorial meminane?

5. posterior ailanto drecipital ligament

6. muchal ligament

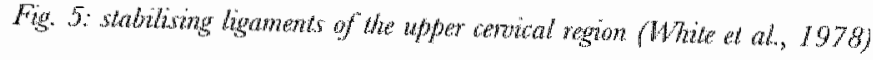

The atlas $\left(\mathrm{C}_{1}\right)$ is only loosely connected to $\mathrm{C}_{0}$ and $\mathrm{C}_{2}$ by the anterior and posterior atlanto-occipital and atlanto-odontoid membranes. $\mathrm{C}_{1}$ is indirectly connected to $\mathrm{C}_{22}$ and $\mathrm{C}_{0}$ by the longitudinal part of the cruciform ligaments (Braakman et al., 1971; Penning, 1978; White et al., 1978;

The mechanically most important ligaments of $\mathrm{C}_{0}, \mathrm{C}_{1}, \mathrm{C}_{2}$ complex are the alar ligaments and the tectorial membrane. Linear displacement in ante- or retroflexion motion between $\mathrm{C}_{0}, \mathrm{C}_{1}$ and $\mathrm{C}_{2}$ is controlled by these ligaments (Braakman et al., 1971; Penning, 1978; White et al., 1978; van 


\section{SPINAL CANAL AND CONTENTS}

Nomal linear and cross-sectional measurements

The spinal canal is defined anteriorly by the posterior longitudinal ligament and posteriorly by the flaval ligaments and laminae.

The (transverse) cross-section of the lower cervical canal is triangular in shape, the base of the triangle being greater than its height (Burrows, 1963; Braakman et al., 1971).

Measurements of the bony cervical canal, the arachnoid space and the spinal cord have been made by many authors (Boijsen, 1954; Wolf et al., 1956; Payne et al., 1957; Penning, 1960; Burrows, 1963; Penning et al., 1966; Babin, 1970). They stressed the large variability in measurements present in groups of healthy individuals [Table I].

It was also found that the diameter of the cervical canal was smaller in females than in males: Wolf et al. (1956) described a difference of $2 \mathrm{~mm}$.

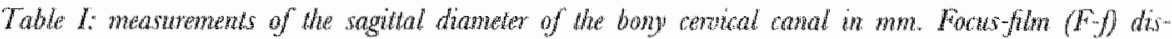
tance and number (n) of indionduls measued are preserted as described in the originat papors.

\begin{tabular}{|c|c|c|c|c|c|c|c|c|c|}
\hline Author & $F-f$ & $n$ & $C_{i}$ & $C_{2}$ & $c_{3}$ & $C_{d i}$ & $\mathrm{C}_{\xi}$ & $C_{6}$ & $c_{7}$ \\
\hline Boijsen (1954) & $1.5 \mathrm{~m}$ & 200 & $19-32$ & $16-27$ & $15-25$ & $14-24$ & $14-23$ & $14-23$ & $14-23$ \\
\hline Wolf et al. (1956) & $1.8 \mathrm{~m}$ & 72 & $16-30$ & $15-27$ & $13-22$ & $13-22$ & $12-21$ & $13-22$ & $12-22$ \\
\hline Payne et al. (1957) & $1.8 \mathrm{~m}$ & 90 & $16-26$ & $15-23$ & $13-22$ & $13-20$ & $12-22$ & $12-20$ & $12-20$ \\
\hline Penning (1960) & $1.5 \mathrm{~m}$ & 20 & $17-30$ & $15-24$ & $15-22$ & $14-21$ & $13-21$ & $13-22$ & $13-21$ \\
\hline Burrows (1963) & $1.8 \mathrm{~m}$ & 300 & $16-26$ & $15-25$ & $12-23$ & $12-22$ & $12-22$ & $12-21$ & $12-21$ \\
\hline Babin $(1970)$ & $1.5 \mathrm{~m}$ & 75 & $17-24$ & $14 \cdot 21$ & $12-19$ & $12-18$ & $12-18$ & $11-17$ & $12-17$ \\
\hline
\end{tabular}

In order to compensate for differences in radiological magnification and to improve the precision of the measurements, a spinal canal/vertebral body ratio was introduced (Pavlov et al., 1987; Herzog et al., 1991).

The shape of the cervical canal in the upper cervical region is circular (in contrast to the triangular shape at the lower cervical levels). At this level, the spinal cord has a diameter of $8-11 \mathrm{~mm}$ and the transverse part of the cruciform ligament is approximately $4 \mathrm{~mm}$ thick. The critical value of the sagitual diameter of the canal in the upper cervical region is therefore approximately $13 \mathrm{~mm}$ (Spierings et al., 1982). 
The sagittal dianeter decreases from the foramen magnum down to $\mathrm{C}_{3}$ and then remains nearly constant. The transverse diameter of the canal varies, thus reflecting the cervical enlargement of the cord Braakman et al., 1971); the diameter is maximal at level $\mathrm{C}_{5}$.

The mobility of the spinal cord was studied by Jinout (1959) and by Penning et al. (1966). They describe that the spinall cord follows the shortest possible route through the spinal canal, whatever the posture of the spinal column. The surrounding arachnoid space was found to be smaller in retroflexion as compared to the midposition or anteflexion posture.

The spinal cord is anchored to the dura by strong offshoots of the denticulate ligament. This ligament runs like a band to each side of the cord; the ventral nerve root lying in front of this structure, the dorsal nerve root behind it.

The ventral and dorsal nerve rootlets are attached to the spinal cord in different ways. The ventral nerve root is formed by a grouping of rootlets that emerge from an elliptical area on the anterior surface of the spinal cord. The dorsal rootlets are thicker than the ventral ones; they enter the spinal cord along the posterolateral sulcus in a linear fashion.

At the lower cervical spine, the dorsal and ventral rootlets run down about a distance of one disc height before they enter the intervertebral foramen. The rootlets pass obliquely laterally and caudally in the spinal canal. At the entrance of the root sleeve there are two ostia, one for the ventral (or motor) and one for the dorsal (or sensory) root; they are separated by the interradicular septum, which is part of the dura. The dorsal nerve root, including its swelling - the spinal ganglion-, is larger than the ventral root. The two roots, each in a separate dural sheath, unite beyond the ganglion to form a spinal nerve (Lang, 1991; Kubo, 1994).

Normal effects of anteflexion and retrolexion upon vertebral struchures, canal and cond According to Kraemer et al. (1989), the range of motion tends to be smaller in males than in females in the same age group, with the exception of levels $C_{1}$ and $C_{2}$ in retroflexion, and $C_{7}$ in both ante- and retroflexion. Ten Have (1978) could not find any relationship between gender, degenerative changes and mobility.

The cervical lordosis was found to be less pronounced in females than in males (Weh et al., 1990). According to Harrison et al. (1996) this difference is not significant. After the age of 50 , the lordosis increases in females and decreases in males (Boreadis Borden et al., 1960).

The spinal canal is longer in ante- than in retroflexion. This phenomenon can be understood by the fact that the axes of movement of the individual motion segments are positioned anteriorly with respect to the spinal canal (Penning, 1960; Braakman, 1967). The maximal length in- 
crease of the anterior border is $10 \%$, of the posterior border $55 \%$ (Penning, 1978). The cord adapts itself to the varying length of the spinal canal. In retroflexion, it is compressed axially, while transverse folds appear on its surface; its cross-sectional diameter becomes larger. In anteflexion, the smooth outline is restored. The diameter of the bony canal is smaller in retroflexion than in anteftexion (Penning et al, 1966; Bechar, 1971; de Graaff, 1982).

In retroflexion, the posterior and anterior margins of the arachnoid space are folded. The folding on the posterior side is caused by folding of the dura mater and the flaval ligaments (Payne et al., 1957; Braakman et al., 1971; Ten Have, 1978; White et al., 1978; the folding on the anterior side is caused by step-formation between the vertebral bodies and folding of the dura. In this position, the nerve roots are slack (Braakman et al., 1971; White et al., 1978; de Graaff, 1982). In anteftexion, the flaval ligaments, dura and nerve roots are stretched; there may be a slight stepformation at the ventral border of the cervical canal Virchow, 1928; Dittmar, 193\%; Braakman et al., 1971).

\section{Cord compression}

The relationship between a disc bulge, bulging of the flaval ligaments and antero-posterior canal diameter in response to tension-compression forces and combined loading in ante- and retroflexion was tested by Chen et al. (1994). The cervical spinal canal diameter was assessed in vitro by measuring the distance between markers on the posterior longitudinal ligament and on the flaval ligament. The author demonstrated spinal canal enlargement in anteflexion and compression. In retroflexion and compression, bulging of the flaval ligaments contributed significantly to canal encroachment (10\% of the original canal diameter, which averaged 11 $m m$.

Nipping of the cord by canal narrowing in retroftexion is called the pincer-mechanism (Penning et al., 1966). In retrohexion, the posterior-inferior edge of the upper vertebral body approaches the lamina of the lower vertebral body, which diminishes sagittal canal diameter by $1-2 \mathrm{~mm}$. This may result in cord compression if the spinal canal is already narrow (de Graaff, 1982). Function x-rays (especially in retroflexion) should be made whenever myelopathy, as the result of cord compression, is suspected (Penning et al., 1966; Bechar et al., 1971). An acquired sagittal diameter of less than 11-1.2 mm results in deformation of the cord. Patients with a reduction of $30 \%$ or more of the cross-sectional area of the cord usually show clinical signs and symptoms of cord involvement (Penning et al., 1986; Braakman, 1994). 
The incidence of asymptomatic disc protrusion varies with age: asymptomatic disc protrusions are found in $20 \%$ of individuals aged $45-54$ years and in $57 \%$ of individuals older than 64 years (Teresi et al, 1987; Braakman, 1994).

Biological events within the disc are mentioned by Nachemson (1975). Histological factors play a role fibrillation of the nucleus, ruptures in the anulus, cartilaginous degeneration in the end-plates, and microfractures in subchondral bone), as well as chemical factors (decrease in water content and mucopolysaccharides, and an increase in collagen).

Anatomical changes due to age are usually qualified as 'degenerative'. These changes, however, are the result of physiological processes and should, therefore, not be looked upon as abnormal. Hult (1954) presented a study in which these so-called degenerative changes (disc space narrowing, vertebral body end-plate sclerosis or osteophyte formation) were present in 5\% of asymptomatic individuals in the age group 25-29, and in $90 \%$ aged 55-59. Lawrence (1969) described degenerative changes present at routine autopsies in $10 \%$ of the individuals in the age group 20 29 , and in more than $96 \%$ of the group over the age of 60 . Nordquist (1964) described histological changes in the spinal cord due to ageing: he mentioned a slight decrease in the subarachnoid space and in the sagittal diameter of the spinal cord.

Age exerts its influence on the anatomy and mobility of the cervical spine. With increasing age, for example, cervical lordosis increases (Kraemer et al. 1989), and overall mobility decreases (Lenshoek, 1958; Kottke et al., 1959; Jones, 1960; Weh et al., 1990).

Degenerative changes are the main cause of restricted mobility (Ten Have, 1978). Leaving these degenerative changes aside, no correlation between age and mobility is found.

Paradoxical tilting (a retroflexion position of the atlas during anteflexion of the spine) may be found in individuals who are younger than 40 years (Kraemer et al, 1989); the amplitude of tilting decreases as age in-
creases.

In older age groups, dorsal and ventral intervertebral disc height diminishes at levels $\mathrm{C}_{5}-\mathrm{C}_{6}$ and $\mathrm{C}_{6}-\mathrm{C}_{7}$. In younger individuals, gliding is a normal phenomenon, especially in the mid-cervical region (Hadley, 1956; Penning, 1964); these gliding motions appear to facilitate degeneration
(Hadley, 1956; Weh et al., 1990).

Penning (1988) stated that the range of motion in ante-retroflexion manoewvres is most pronounced in the mid-cervical region; however, early
degeneration is more prominent at the lower levels $\mathrm{C}_{57}-\mathrm{C}_{6}$ and $\mathrm{C}_{6}-\mathrm{C}_{7}$. He 
explained this phenomenon by pointing at the differences in development and ageing of the mid- and lower cervical levels fsee Fig. 2]. At birth, there is already a difference in height of the articular processes. As a result, the uncinate processes and uncovertebral joints of the mid- and lower cervical region will show a different development between the ages of 9 and 21 , resulting in different kinematic behaviour. After the age of 21, the discs of the upper cervical region seem to be resistant to dissolution; regular fissuring starting at the well-developed uncovertebral joints transforms the disc into a diarthrotic structure with intact cartilaginous endplates and preserved disc height. Ar the lower levels fissuring tends to start centrally, following an irregular course leading to early radiological disc narrowing and other signs of disc degeneration. 



\section{Chapter 3.}

\section{Diagnostic properties of imaging techniques}

In the present study, function $x$-rays of four different groups of individuals are analysed kinematically: healthy individuals, patients with a hemiated disc at level $\mathrm{C}_{6}-\mathrm{C}_{7}$, patients with a herniated disc at level $\mathrm{C}_{5}-\mathrm{C}_{6}$, and patients with a cervical myclopathy. This chapter discusses the imaging techniques utilised in these patient groups.

\section{THE MATTER OF A GOLD STANDARD}

The diagnostic value of imaging techniques is beyond any question of doubt. However, these techniques sometimes fail to demonstrate changes, which might explain the patients' symptoms. Depending on the technique employed, no explanation of symptoms is found in $10-52 \%$ of cases (Hult, 1954; Lawrence, 1969; Ruggieri, 1995). On the other hand, abnormalities are often visible on images of individuals without clinical signs or symptoms. Depending on age and type of 'pathology' described, abnormalities are found in 3-95\%! (Hussar et al., 1956; Friedenberg et al., 1973; Gore et al., 1986; Penning et al., 1986; Teresi et al., 1987; Boden et al., 1990; Ruggieri, 1995).

One reason for this might be that clinical signs and symptoms are not exclusively the consequence of mechanical factors resulting from morphological changes. Nerve root compression as the result of a herniated disc, for example, may not be the only cause of radiculopathy in all circumstances: secondary chemical or immunological changes maty also contribute to the clinical manifestations. In situations like these, spontaneous recovery may occur while the signs of compression seen on imaging may persist (Grafin et al., 1991; Milette et al., 1995; Ruggieri, 1995).

A patient will not usually be operated on when imaging techniques fail to demonstrate any abnormality. Only a few studies are reported in which the decision to operate on a patient was made purely on the basis of clinical grounds (Hirsch et al., 1963; Esperen et al, 1984; Kosteljanetz et al. 1984). The latter authors found that the myelographic diagnosis of a herniated lumbar disc (seen as an indentation of the contrast column) correlated well with the presence of a herniated lumbar disc at surgery $(73-$ $87 \%$. In cases with normal myelographic findings, only $5 \%$ showed a disc herniation at surgery. 
Similarly, surgical findings are not necessarily conclusive. The surgeon may verify the presence of anatomical changes, but frequently he will be unable to state whether these findings should be considered as symptomatic or as asymptomatic. The relationship between the pathological findings and the presence of the climical symptoms should not be taken for granted. Surgery may reveal disc pathology, which is not related to the clinical picture, and removal of an apparently symptomatic lesion may fail to relieve the clinical signs and symptoms. Even a negative surgical exploration may result in a significant improvement in the clinical manifestations (Deyo et al., 1994). In the study by Hirsch et al. (1963), 96\% of the patients with a lumbar radiculopathy improved when a hemiated disc was found and removed. Howev$\mathrm{er}, 70 \%$ of the patients in whom no abnormalities were found at surgery also improved. Similar findings are reported by Kosteljanetz et al. (1984).

Conclusion: it is impossible to establish an unblemished gold standard for imaging techniques. Combining the results of imaging techniques and surgical findings with clinical signs and symptoms is probably the best way to reduce the chance of mis-diagnosis.

\section{PIAIN X-RAYS}

Plain $x$-rays serve to identify bony structures (vertebral bodies and contours of the foramina). The spinal cord, nerve roots, discs, and ligaments cannot be visualised. X-rays are thus useful for imaging bony structures but are of little use in diagnosing the presence and effect of a hemiated disc. They can also be used to measure the antero-posterior diameter of the cervical canal in cases of myelopathy suspected to be due to narrowing of the spinal canal. Function $x$-rays provide additional information on the dynamic diameter of the cervical canal in ante-and retroflexion and on the behaviour of the spine in different postures (Chapter 2, Anatomy - Spinal canal -- Cord compression).

Degenerative changes of the cervical spine, such as spondylosis and/or spondylarthrosis, are well depicted on plain films, but are often seen in the absence of clinical symptoms. Hult (1954) did not find a correlation between cervicobrachialgia and signs of dise degeneration. In a stucly by Hussar et al. (1956), bony spurs of the vertebral bodies combined with disc space narrowing and narrowed intervertebral foramina did not correlate with back- or neck-pain either. Lawrence (1969), however, found an increased incidence of pain in the neck, shoulders or upper extremities in cases of severe disc degeneration only.

In a study of asymptomatic individuals, the incidence of degenerative 
changes of the cervical spine increased with age, being present in $75 \%$ of individuals in the 7th decade (Friedenberg et al, 1963). According to Gore et al. (1986), in $95 \%$ of asymptomatic males, aged $60-65$, and $70 \%$ of asymptomatic females aged 60-65, plain $x$-rays of the cervical spine showed disc space narrowing, vertebral end-plate sclerosis or osteophytes.

Measurements of the anteroposterior diameter of the spinal canal are useful when narrowing of the spinal canal is suspected to be the cause of cervical myelopathy. An anteroposterior diameter of less than $12.5 \mathrm{~mm}$ is likely to result in compression of the cord (Penning et al., 1966; Nurick, 1972; Yu et al., 1986; Braakman, 1994). Bechar et al. (1971) studied plain $x$-rays of 100 healthy individuals and of 11 patients with cervical myelopathy. The minimal diameter of the cervical spinal canal was determined in the neutral position and in retroflexion. In the myelopathy group, the average canal diameter was significantly smaller than in the control group. In the retroflexion posture, narrowing of the spinal canal was found both in the controll group and, more pronounced, in the patient group. These results are in agreement with those of Penning et al. (1966) who performed in vitro ante- and retroflexion myelograms on twenty-three spines from patients who died from a non-neurological disease.

Herzog et al. (1991) analysed the sensitivity and predictive value of different methods for measuring the cervical canal diameter. He used the Torg ratio (also referred to as the Paolov ratio; Pavlov et al., 1987). This ratio is defined as the antero-posterior diameter of the cervical canal divided by the antero-posterior diameter of the vertebral body. It was demonstrated that the Torg ratio was highly sensitive, but also that its positive predictive value was poor. Herzog propagated the Torg ratio for screening purposes in cases in which the magnification factor of the $\mathrm{x}$-rays is unknown. A Torg ratio of less than 0.8 or a sagittal canal diameter of less than $12.5 \mathrm{~mm}$ was considered as abnormal.

Conclusion: plain $x$-rays are not suitable for demonstrating the causes of cervical radiculopathy. Narrowing of the spinal canal as a potential cause of cervical myelopathy, on the other hand, can accurately be assessed by measuring the antero-posterior mid sagittal diameter of the canal on plain $\mathrm{x}$-rays in the retroflexion posture.

\section{MYELOGRAPHY}

After intrathecal injection of a contrast medium $x$-rays are taken of the cervical spine. These films show the outline of the spinal cord and nerve rootlets within the contours of the dural tube and root sleeves, respectively, 
in relation to the surrounding bony structures. A mass lesion within the spinal canal, such as a herniated disc, may distort these structures, thus providing diagnostic information. An extradural lesion localised exclusively in the foramen may not be visualised. This situation occurs regularly in the lumbar region, but appears to be very rare in the cervical spine.

The injection of an intrathecal contrast medium by lumbar or cervical puncture is an unpleasant experience for the patient: additionally, up to $30 \%$ may experience side effects such as headache and dizziness. These side effects are attributed to a CSF leak or to an irritating effect of the contrast agent on the cerebral cortex.

Fox et al. (1975) described the diagnostic significance of cervical nerve root and root sleeve deformities on myelography. The size and shape of a cervical root sleeve deformity did not correlate with presence or absence of symptoms, although larger defects were more likely to have clinical significance than smaller ones. Furthermore, it was shown that non-visualisation or elevation of rootlets had a slightly greater clinical significance than other rootlet features such as medial deviation or spread of rootlets.

Penning et al. (1986) reported typical findings in various causes of cervical radiculopathy. In disc herniation, a soft tissue mass was observed occluding the entrance to the intervertebral foramen. As a rule, this mass extended below and sometimes above the level of the disc, thus causing an elongated indentation in the dural sac. Such a dural indentation was not usually found in foraminal narrowing due to osteophyte formation: instead, the swollen nerve rootlets at the foraminal entrance caused a circumscribed contrast defect confined to the affected level.

Narrowing of the spinal canal causing cervical myelopathy is easily diagnosed when a myelographic block is present. In a study by Sobel et al. (1984), myelography agreed with surgical results with regard to the degree of canal stenosis in $89 \%$ of the levels studied; the degree of stenosis was underestimated in $11 \%$.

Conclusion: the presence of soft tissue masses in the spinal canal which distort the dural sac and its content or bony narrowing of the spinal canal can easily be diagnosed with myelography. However, such deformations are not always related to clinical symptoms. A further disadvantage is the invasive nature of the procedure.

\section{CT AND CT-MYELOGRAPHY}

Computed tomography (CT) provides images, which are grey-scale representations of the different $x$-ray densities of tissues. The $x$-ray tube moves 
around the patient in the axial plane, thus providing cross-sectional curs.

CI yields accurate information about the bony structures of the spinal column; however, the content of the cervical spinal canall as well as soft disc hemiations will not be visualised adequately. Intravenous contrast injection can improve the definition of a hemiated cervical disc. The definition of a disc hermiation and its effect upon the spinal cond and nevve roots can be enhanced by CSF opacification with intrathecal contrast. For this reason, $\mathrm{CT}$ is often combined with myelography to evaluate radicular syndromes and chinical signs of cervical myelopathy. $A$ disadvantage of CT-myelography is the invasive nature of the investigation and also the inability to obtain images directly in the sagitall plane. If it is felt necessary to perform anteflexion-retroflexion studies by C T-myelography, the postures in the scanner gantry will be less natural than those achieved in erect function studies with plain $\mathrm{x}$-rays.

Sobel et al. (1984) assessed the diagnostic accuracy of CT-myelography, using the surgical findings as the gold standard for comparison. Myelography and CT-myelography were concondant in $80 \%$ of the levels studied when establishing the degree of canal and foraminal stenosis.

Daniels et al. (1984) retrospectively studied a heterogeneous group of patients with a cervical radicular syndrome. The clinical diagnosis served as the gold standard. He found that plain CT as well as CT-myelography is more accurate than conventional myelography in the identification of lesions causing cervical radiculopathy. However, the use of intrathecal contrast was not randomised and the study group was small $(n=24)$.

The value of conventional myelography and GT-myelography in radiculopathy and cervical myelopathy was studied by Yu et al. (1986). He found that the diagnostic information derived from conventional myclography was equivalent to CT-myelography in patients with radiculopathy. In cases of myelopathy, CT-myelography yielded the best results, especially when there was a dilution or obstruction of the contrast medium. However, pathological movement and bulging of the flaval ligaments could not be visualised as accurately with G T-myelography as with conventional myelography in the retroflexion position.

Penning et al. (1986) assessed CT-myelographic findings relative to climical signs of nerve-root and spinal cond involvement $(n=80)$. When CT-myclography showed occlusion of the foramen by the solt tissue mass of a hemiated disc, there was a 100\% correlation with the side of the symptoms. Nerwe root swelling at the entrance of a narrowed interverte. bral foramen showed a poorer correlation but still predicted the side of clinical symptoms of radiculopathy correctly in the majority of cases. A third group was formed by those with a mediolateral disc protrusion on CT-myelography, which did not occlude the foraminal entrance but of- 
ten indented or displaced the spinal cord. In these cases, conventional myelography was normal or showed only minor changes. Correlation of the CT-myelographic findings with the side of the clinical symptoms was very poor: it was concluded that GT-myelography provides almost no additional diagnostic information in the presence of a normal conventional myelogram. In the case of an abnormal myelogram, however, CT-myelography was useful in defining and differentiating a myelographic lesion. The analysis of images in patients with cervical myelopathy demonstrated that a reduction of the cross-sectional area of the spinal cord by at least $30 \%$ is accompanied by signs and symptoms of long tracts.

Conclusion: $\mathrm{CT}$ is superior to conventional $\mathrm{x}$-rays in visualising bony changes due to cervical spondylosis and the resultant encroachment on foramen and spinal canal. The cross-sectional images provided by CT are, furthermore, not hampered by the possibilities of anatomical structures being superimposed. CT literally adds a new dimension to plain and myelographic spinal imaging. The greater sensitivity of CT, however, resullts in even more irrelevant anatomical features being detected.

\section{MAGNETIC RESONANCE IMAGING}

Magnetic resonance (MR) imaging allows the reconstruction of highly detailed images of soft tissue structures such as the spinal cord and emerging nerves. The soft tissue resolution in MR imaging is considerably better than in $x$-ray $\mathrm{CT}$, and can be tailored to the clinical query by appropriate weighting (" $\Gamma_{1}$-weighted and $T_{2}$-weighted'). The plane of imaging can be freely selected. MR imaging is the investigational tool of first choice in the cvaluation of the clinical picture of cervical myelopathy because of its non-invasive character and its accuracy in delineating the spinal cord with emerging nerve roots. However, MR imaging is less useful in the evaluation of cervical radiculopathy: this imaging modality is unable to make a clear distinction between a 'hard disc' or bony spur and a soft herniated disc (Brown et al., 1988; Larsson et al., 1989; Mehalic et al., 1990; Braakman, 1994\%. The reliability of MR imaging is highly dependent on the scamning technique, which should, therefore, be specified when assessing diagnostic accuracy (Reul et al. 1995).

To evaluate the clinical significance of MR imaging in degenerative disc disease and spondylosis, "Teresi et al. (1987) studied a group of individuals asymptomatic for neck and arm pain (35 retrospectively and 65 prospectively); $20 \%$ of these 100 individuals aged $45-54$ years and $57 \%$ older than 64 years of age seem to have bulging or hemiated cervical discs. Spinal cord impingement was observed in $16 \%$ of the subjects un- 
der the age of 64 years and in $26 \%$ of those older than 64 years. Cord compression was seen in $7 \%$, however, the percentage reduction of the cross-sectional area of the spinal cord never exceeded $16 \%$.

Boden et al. (1990) examined the MR images of 63 healthy volunteers. These were randomly mixed with images of 37 patients who had symptomatic lesions of the cervical spine. Subsequently, these 100 images were subjected to interpretation by three neuroradiologists independently. The images were interpreted as abnomal in $19 \%$ of the asymptomatic subjects: $14 \%$ of those who were under 40 years of age and $28 \%$ of those who were older than 40 years. Of the subjects younger than 40 years of age, $10 \%$ showed a herniated disc and $4 \%$ suffered from foraminal stenosis. Of the subjects who were over $40,5 \%$ demonstrated a herniated disc, $3 \%$ a bulging disc and $20 \%$ suffered from foraminal stemosis. Narrowing of a disc space and the presence of spurs or disc degeneration were also recorded in $25 \%$ of the individuals who were younger than 40 years, and in almost $60 \%$ of those who were older.

This prevalence of abnormal MR images of the cervical spine as rellated to age in asymptomatic individuals emphasises the absolute necessity of matching the findings of diagnostic tests with clinical signs and symptoms.

Brown et al. (1988) studied a group of 34 patients: 50 abnomal findings were demonstrated with MR imaging, CT-myelography and plain CTscans (cervical herniated discs, canal stenosis and intramedullary lesions). The imaging findings were confirmed at surgery in $88 \%$ of the MR imaging studies, in $81 \%$ of the CT-myelographic studies, in $58 \%$ of the myelographic studies without CT-scanning, and in only $50 \%$ of the plain CTscans.

Larsson et al. (1989) evaluated mydography, CT-myelography and MR imaging in 26 patients with radiculopathy and/or myelopathy. The sensitivity and specificity of the three techniques were more or less the same with respect to radiculopathy. "The information on the narrowing of the subarachnoid space also appeared to be in agreement. It is difficult to distinguish between bony spurs and soft disc herniations using MR imag. ing. The combination of MR imaging and plain x-rays or CT, however, does provide adequate information.

For the diagnosis of cervical myelopathy, MR imaging as well as CT-myelography provide highly sensitive information. A reduction of the cross-sectional cord area of $30 \%$ or more, or a cross-sectional area of less than 60 $\mathrm{mm}^{2}$, results in the clinical signs of cervical myelopathy (Penning et al., 1986; Yu et al., 1986). The severity of compression correlates with the severity of the clinical picture of cervical spondylotic myelopathy (Bechar et 
al., 1971; Nurick, 1972, Badami et al., 1984; Penning et al, 1986; Yu et a., 1986; Braakman, 1994). If the transverse area of the cord is smaller than $30 \mathrm{~mm}^{2}$ the spinal cord will be irreversibly damaged (Fujwara et al., 1989). The $\mathrm{T}_{2}$-weighted $\mathrm{MR}$ image shows increased signal intensity at the point of maximal compression. The high signal intensity detected on preoperative MR imaging, however, does not correlate with the severity of myelopathy or surgical outcome (Mehalic et al., 1990; Yone et al., 1992).

Conclusion: MR imaging is as sensitive as CT-myelography in the identification of the site of a pathological lesion within the spinal canal, but is not as specific with respect to the nature of the lesion. CT makes a better distinction then MR between a soft disc hemiation and a bony spur occluding the foramen.

The diagnostic significance of the imaging techniques discussed is presented semi-quantitatively in Table $\mathrm{II}$.

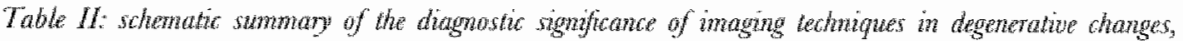
radiculopathy, and molopathy.

\begin{tabular}{llll}
\hline & Degenerative changes & Radiculopathy & Myelopathy \\
\hline Plain x-ralys & ++ & - & ++ \\
Myelography & + & +++ & +++ \\
CT & +++ & +- & ++ \\
CT-myelography & +++ & +++ & +++ \\
MR imaging & + & ++ & +++ \\
\hline
\end{tabular}

\section{COMMEN}

In cervical myelopathy plain films predict onset of cord compression when the $\mathrm{AP}$ diameter of the bony spinal canal is less than $12.5 \mathrm{~mm}$. Long unat signs stant to develop when MR images or CT-myelography show a reduction of the cross-sectional cord area of $30 \%$ or more, or a cross-sectional area of less than $60 \mathrm{~mm}^{2}$. Increased sigmal intensities on $\mathrm{T}_{2}$-weighted $\mathrm{MR}$ images indicates the area of maximal cord compression.

In patients with radiculopathy, the best diagnostic images at present are provided by myelography/CT-myelography, but the procedure is invasive. MR imaging may serve as a non-invasive alternative, but then it often proves to be difficult to distinguish between bony and soft causes of root compression. In these cases additional plain $x$-rays or $C T$ are useful. 
Despite sophisticated CT and MR imaging techniques, which are mainly morphologically oriented, the cause of cervicobrachialgia remains unexplained in about $10-20 \%$ of patients.

For this reason, it may be worthwhile paying attention to so-called function $\mathrm{x}$-rays in order to gather additional quantitative information. Kinematics provide the tools to evaluate these function $x$-rays. 



\section{Chapter 4. \\ Review of the literature}

The cervical spine has been studied extensively, also with respect to its kinematic behaviour.

In order to gain an impression about the development of knowledge in kinematics of the spine, an extensive literature search was performed. The most important data source was MEDLINE, an electronic data system that allows multiple search strategies of the Dutch, English, French and German literature. The following key words were used with reference to the cervical spine: cervical, spine, function $x$-ray, kinematics, reliability, measurement, biomechanics, cine, cinematography, three-dimensional, vertebral bodies, disc height, vertebral canal.

Additionally, article references were searched for further relevant literature. Studies, which were considered to be relevant to the above-mentioned subject, were selected. Studies concerning the lumbar spine were only included when elucidating developments in kinematic knowledge of the spine.

The following review is presented in two parts. In the first part (Histovy), kinematic studies of the spine are presented in historical perspective. The second part (Kinematic studies of the cenvical spine) presents a review of the literature focussing on specific kinematic methods:

1. The Cartesian method

2. The R-Centre method

3. The cervical spine studied as a complete structure

4. Cineradiography

5. 3-D reconstructions of bi-planar $x$-rays of the spine

\section{HISTORY}

Comprehensive reviews of the literature have been given by Bakke (1931), Elward (1939), Andersson et al. (1940), Rolander (1966), Luysell (1969), Troup et al. (1968), and Keessen (1988).

Weber (1827, quoted by Elward, 1939) was probably the first to actually measure movements of the human vertebral column. He inserted metal pins in the spinous and transverse processes in three osteoligamentous preparations of the spine, and then studied the motion of the pins while bending and stretching the specimens manually. He concluded that the 
greatest degree of movement in all directions could be found in the region of the cervical spine. Weber also studied the spinal motion of three healthy young men. He placed a ruler between their teeth and the various angles between this ruler and a horizontal plane were taken as a measure of the mobility of the spine. (Quoted by Bakke, 1931).

Meyer (1873, quoted by Bakke, 1931) studied the movements of the spine in a strict mid-sagittal plane: he sawed a specimen in two and nailed the sacrum and promontorium to a table. Ante- and retroflexion movements of the spine and of the individual motion segments could thus be studied in detail. He noted that the curve of the cervical spine in extreme anteflexion could become kyphotic, contrary to the curve of the lumbar spine.

Lovett (1903) mentioned in his study that the articular processes are not involved in torsional movements of the spine while Fick (1904) stated that the intervertebral disc determines the amount of movement and the articular processes its direction. These studies were done on osteoligamentous preparations of the spine. Both authors compared the spine with an elastic rod, the Aexibility of which is in all directions directly proportional to the square of the length and inversely proportional to the square of the area in cross-section.

In 1909 Virchow (quoted by Elward, 1939) presented the first of his studies on ante- and retroflexion movements of the human spine in the sagittal plane, describing primarily the atlanto-axial articulation. The degree and range of motion were represented by geometrical diagrams in conjunction with anatomical models.

Nogvorodsky (1911) (quoted by Andersson et al., 1940) presented the intersegmental range of motion of the individual motion segments of the spine in a study of four specimens.

Strasser (1913) (quoted by Rolander, 1966) stressed the importance of studying individual motion segments. He defined the neutral position of a vertebral body in a motion segment as the position adopted by that body when not affected by muscular or external forces.

The earliest reference in the literature to $x$-ray examinations of human spine movements is probably from Virchow (1919) (in Elward, 1939). He published a brief comparative review of anatomical and roentgenological findings in the cervical spine. 
Müller (1922) studied intact anatomical preparations, focussing on lateroflexion of the spine. To do so, he injected formalin intravascularly; the related muscles contracted and caused lateroflexion of the spine. He found that the lumbar spine curved most and the cervical spine least, while the thoracic spine remained straight (described by Bakke, 1931).

Gradually, more refined methods were introduced to study the kinematics of the human spine. For obvious reasons, the clinicians were looking for methods suited to examining the spine in living individuals. Fixing external markers to the skin gave some idea of movement but these methods failed with respect to accuracy and reproducibility. Stokes et al. (1987) demonstrated that surface measurements differ by about $25 \%$ from radiographic measurements.

Other techniques such as inclinometers (Locbl, 1967; Mayer et al., 1984; Chiarello et al., 1993), goniometers (Youdas et al,, 1992; Chiarello et al., 1993) protractors (Troup et al., 1968), and video registration of external landmarks using video-canneras (Roozmon et al., 1993; Robinson et al., 1993) provide valuable information about kinematics of the spine as an integrated structure. The precision of the measuring devices, when analysing the spine in this way seems to be acceptable. However, information about inter- and intra-rater differences in the measurements is limited. The major weakness of these methods lies in the fact that the clinical significance of the measurements in terms of limits of normal values and relationships of abnormal findings with specific clinical syndromes, has not been established.

In 1895, Roentgen discovered x-rays. These x-rays proved especially suitable for visualising the skeleton in vivo. Within 4 decades, this technique was applied to kinematic studies of the spine.

Virchow (1928) was the first to present a study of the cervical spine in which $\mathrm{x}$-rays were used to obtain kinematic data. He described the examination by these $x$-rays as 'delicate' and pointed out that the direction of the central beam was of great importance with respect to the photographic depiction of the spine. Both remarks still hold true.

KINEMATIC STUDIES OF THE CERVICAL SPINE

General aspects

A diversity of technical factors are brought into practise to obtain function $x$-rays of the cervical spine. These different methods exert their effect on the photographic depiction of the spine and thus on the results of kinematic examinations. 
The spatial relationship between the $x$-ray tube, film, and object is frequently not described, and if so varies widely (Colachis et al, 1965: object-focus distance $=190.5 \mathrm{~cm}$; Arlen, 1977 and 1978 : focus-firn distance $=2.50 \mathrm{~m}$; van Mameren, 1988: focus - fum distance $=1.25 \mathrm{~m}$; Weh et al. 1990; focus-film distance $=1.5 \mathrm{~m}$; Vortman, 1992: focus-film distance $=1.35 \mathrm{~m}$, object film distance $=20-25 \mathrm{~cm}$.

Jones (1960) and Ketessen et al. (1984) pointed out that the radiographic depiction of the spine in antelexion and retroflexion may vary, depending on whether the subject is standing or situng. However, a description of these postures is frequently not presented. X-rays are sometimes taken in both standing and sitting postures (Buetri Bäum1, 1954; Jones, 1960, and sometimes only in a standing (Vortman, 1992) or sitting posture Boreadis Borden et al., 1960). In some studies, the trunk is fixed (Buetri Bauml, 1954, Dvorak et al, 1991), in others the head (lai et al., 1993). Varying definitions of the neutral position are presented: a comfortable/relaxed posture (Ditmar, 1931; Gutmann, 1981); fixing the eyes on a mark on the wall at eye-level (Boreadis Bordon et al., 1960; Arlen, 1977, 1978; Kraemer et al, 1989; Weh et al., 1990; keeping the head horizontal Vortman, 1992); occlusion plane of the teeth horizontal (de Seze et al., 1951, Buett Bäuml, 1954), or lower margin of the orbita in the same horizontal plane as the external auditory meatus (Penning, 1964). Also poorly described are the instructions given to the subjects on how to assume a specific posture (anteflexion, retroflexion, or neutral position). The anteflexion manoeuvre has been defined as 'bringing the chin to the manubrium sterni' (de Sèze et al. 1951; Buetri Bäuml 1954; Jones 1960; Penning, 1964; Arlen, 1977, 1978; van Mameren, 1988; Weh et al., 1990; Vortman, 1992). Some authors prefer a differentiation of "anteflexion' into anteflexion of the upper cervical spine (the "chin-in manoeuvre"), and global anteftexion without 'chin-in' Jones, 1960; Lxwit et al., 1963; Gutmann, 1981; Kraemer et al., 1989). Instructions for retrofexion are even less frequently described. Weh et al. (1990) defined the retroftexion manoenvre as mozmg the head backwards as far as possible; de Seze et al.(1951), Buetti Bäuml (1954), and Arlen (1977, 1978) as looking backwards as far as possible, while Vortman (1992) instructed the subjects to retroflect with the mouth open. Fineman et al.(1963) pointed out that the normal lordotic configuration of the cervical spine might change into linear or kyphotic one when lowering the chin only slightly.

These different instructions result in different ranges of anteflexion and retroflexion, thus demonstrating the need for standardisation [Table III]. 


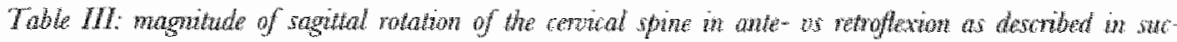
cesticie shides.

\begin{tabular}{|c|c|c|c|c|c|}
\hline author & anteflexion & retrofiexion & levels & $\begin{array}{l}\text { wivol } \\
\text { vitro }\end{array}$ & $\begin{array}{l}\text { ante/retroflexion } \\
\text { procedure }\end{array}$ \\
\hline Weber (1827) & $75^{\prime \prime}$ & $75^{\circ}$ & $\mathrm{C}_{11} \cdot \mathrm{C}_{7}$ & in vitro & procedure described \\
\hline Fick (1904) & $90^{\prime \prime}$ & $90^{\circ}$ & $\mathrm{C}_{0} \cdot \mathrm{C}_{7}$ & in vitro & procedure described \\
\hline Bakke (1931) & $16^{\prime \prime}$ & $64^{\circ}$ & $C_{1}-C_{7}$ & in vivo & no procedure described \\
\hline de Sèze et al. (1951) & $33^{\circ}$ & $59.5^{\circ}$ & $\mathrm{C}_{2} \mathrm{C}_{7}$ & in vivo & procedure described \\
\hline Kottke et al. (1959) & $50^{\circ}$ & $45^{\circ}$ & $\mathrm{C}_{1}^{2}+\mathrm{C}_{7}$ & in vivo & no procedure described \\
\hline
\end{tabular}

\section{The Cartesian method}

The displacement of an object in one plane is the result of a linear and/or rotational displacement and is defined in a so-called Cartesian co-ordinate system with an $\mathrm{x}$ - and $\mathrm{y}$-axis. Linear displacement is quantified as a distance along these axes and is defined by differences in the $\mathrm{x}$ - and $\mathrm{y}$-co-ordinates. Rotation occurs when the distance between every single point of the body and a reference-point remains constant. This reference-point is called the centre of rotation. The line connecting a point of the body and this centre of rotation is called the respective radius. Rotational displacement is present when the radius changes its position. The angle between the original radius and the radius in its new position is the so-called angle of rotation.

The following paragraph presents a chronological review of Cartesian methods applied to kinematic studies of the cervical spine.

Virchow (1928) was one of the first to use function $x$-rays to study motion patterns of the cervical spine. He compared the positions of the vertebral bodies on an anteflexion $\mathrm{x}$-ray with the respective positions on a retroflexion $x$-ray by copying the vertebral bodies and pedicles onto transparent paper. On both the anteflexion and retroflexion transparencies, lines were drawn through specific points on the respective vertebral bodies. Then he superimposed the contours of the respective lower vertebral bodies in a motion segment, demonstrating in this way that the lines through the points on the upper vertebral bodies deviated from one another. The angle between these two lines is equivalent to the sagittal rotation, which occurred within this motion segment [Fig. 6].

He noted that the cervical spine becomes straight in the anteflexion position while so-called positive step-formation may occur. 


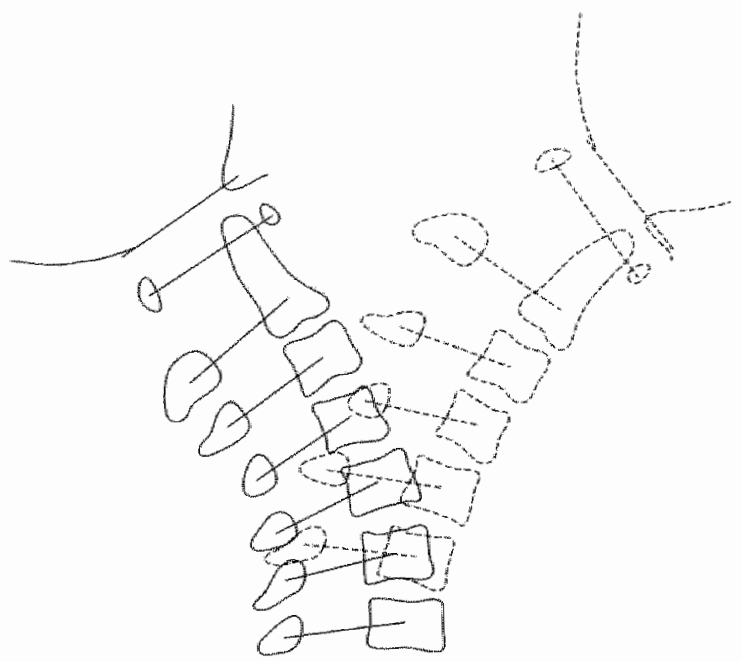

Fig. 6. rotation (Throhot, $1928)$

Dittmar (1931) used the same method for the entire spine. He also studled the spine in a neutral position as well as in lateroflexion. Contrary to Virchow, he found a kyphotic posture of the cervical spine in maximal anteftexion. He also described positive step-formation in anteflexion, but negative step-formation in retroflexion [Fig. 7].

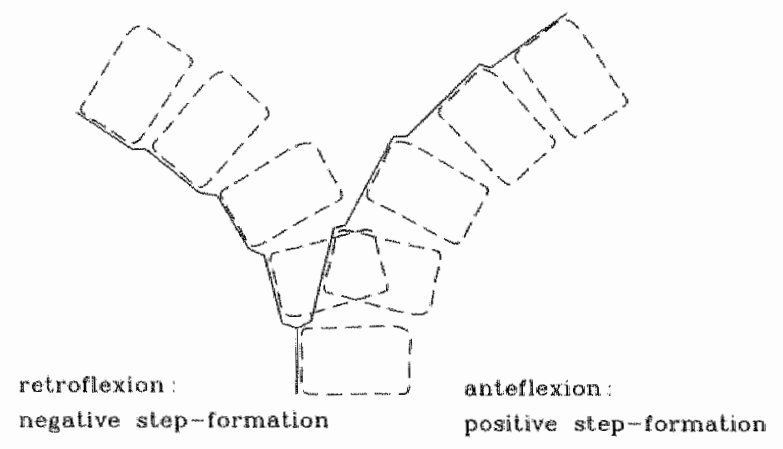

Fig. 7. schomatic reproduction of step fompation an ante, awd retroflexion (Ditmar, 1931)

Bakke (1931) studied the x-rays of 44 healthy young men and women in ante-, retro-, and lateroflexion postures. He drew lines through the upper and lower borders of the vertebral bodies and measured the angles between adjacent vertebral bodies [Fig. 8].

He found that the angular range of motion of the entire cervical spine was $30.5^{\circ}$, of which $16.3^{\circ}$ were due to anteflexion and $64.2^{\circ}$ to retroflexion. The maximum measuring error was stated to be $2^{\circ}$ or less. 
Fig. 8: angulation (Bakke 1931)

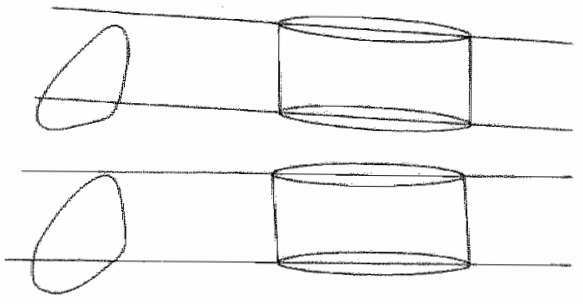

Another method to measure displacements of vertebral bodies visualised on function $x$-rays, was introduced by Begg et al. (1949). The retroflexion $\mathrm{x}$-ray is placed on a viewing-box and covered with a transparent sheet. The anteflexion film is positioned on top of it in such a way that the outlines of the sacrum on both films becomes superimposed. A line is drawn along the top margin of the upper film on the transparent paper, thus creating a base-line. Subsequently, the other vertebral bodies are superimposed and new lines are drawn along the top margin of the upper film /Fig. 9], thus defining the positions of the vertebral bodies with respect to each other and the angles of rotation in ante- and retroflexion.

Fig. 9: superpostation of respertive corpora in onder to measure intersegmental rotation (Begg ot al., 1949)

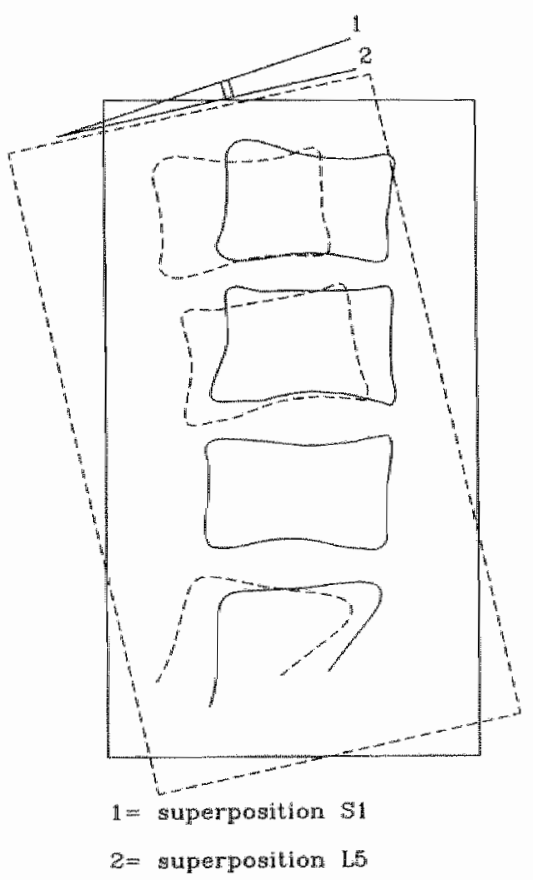

De Sèze et al.(1951) kinematically described function x-rays of the cervical spine. He analysed three postures: anteflexion, retroftexion and neutral posture. The anteflexion and retroflexion $x$-rays respectively, were 


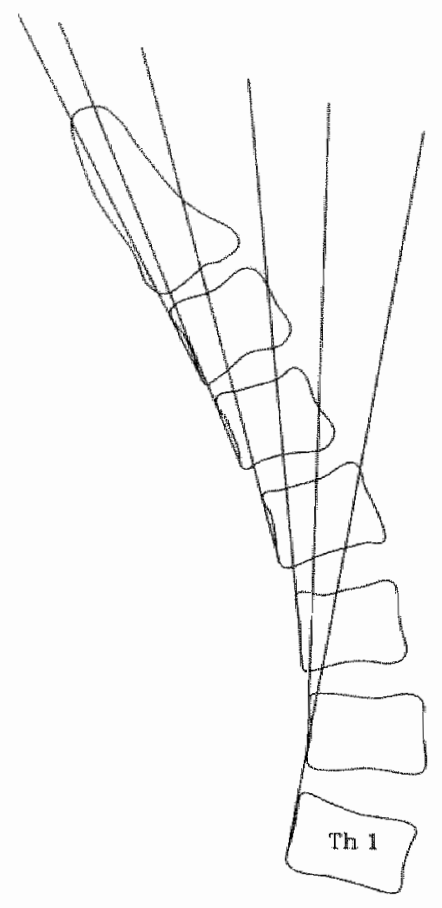

Fig. 10: angulation (de Size at at, 1951)

superimposed on the neutral $x$-ray. Angles of rotation were defined as the angles between the two lines tangent to the respective posterior borders of two adjacent vertebral bodies /Fig. $10 \%$.

The range of motion from the neutral position to the maximal retroflexion position proved to be twice as large as the range of motion from the neutral position to the maximal anteflexion posture. The neutral position was defined as the horizontal occlusion plane of the teeth.

Buetti-Bäuml (1954) defined the anteflexion, retroflexion and the neutral position of the cervical spine in essentially the same way as de Seze. His method of marking the $x$-rays and measuring the angles of rotation were also identical. He found mobility to be equally distributed among the different segments of motion. He also noted that restricted mobility in one segment caused complaints related to the superior adjacent segment. Rotation was found to be less when disc degeneration was present.

Aho et al. (1955) described the mobility of the cervical motion segments by defining the intersegmental angulation. To do so, he determined the inclination of each vertebral body with respect to a base-line through two fixed points on each body [Fig. II and 12]. 


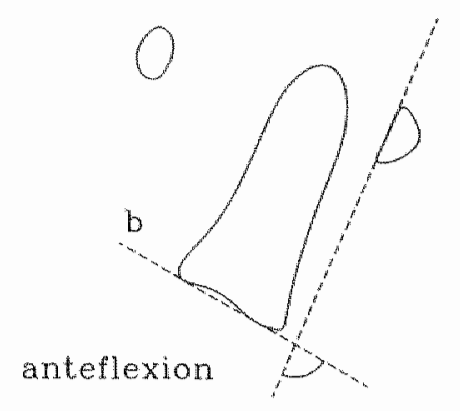

Fig. 11: anguhation $C_{1}-C_{2}, b=$ base-line (Aho et al, 1955)
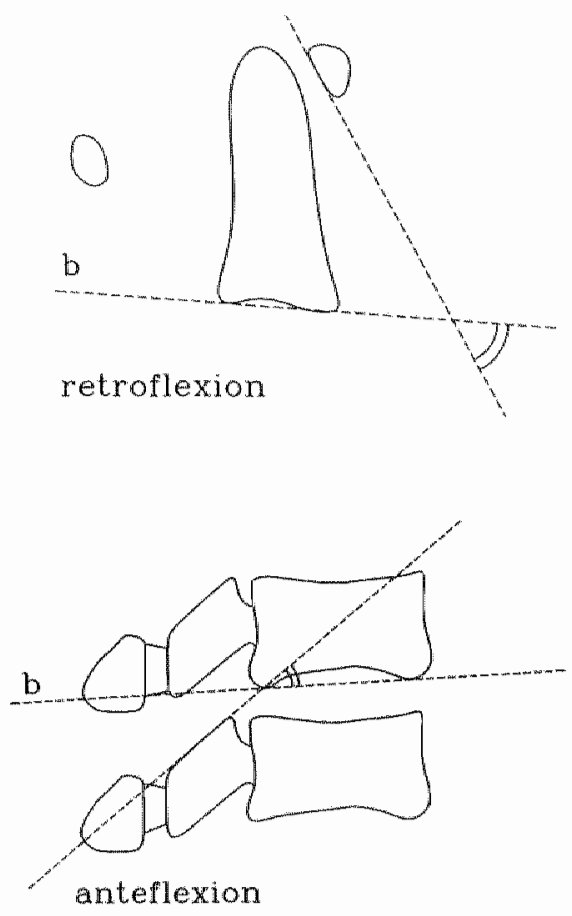

Fig. 12: angulation $\mathrm{C}_{2}-\mathrm{C}_{7} ; b=$ base line (Ato at al, 1955)

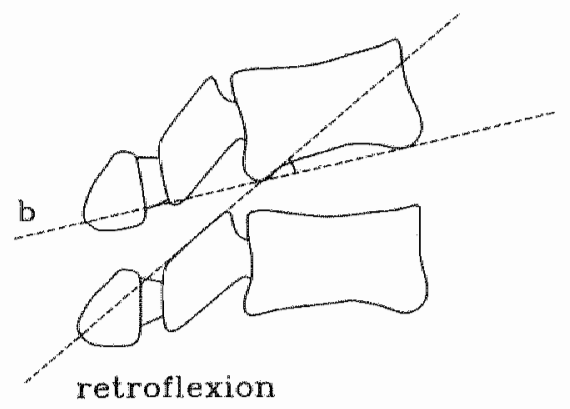


He found displacement to be equally distributed amongst the different segments of motion in healthy individuals. Reduced mobility in one segment was compensated by increased mobility in the segment above. In contrast to earlier studies, translation - or so-called sliding motions-were not observed in the healthy group. However, in the presence of disc degeneration and related to its severity, linear displacements or sliding movements were found to be present, as well as angulation in the neutral position; disc degeneration might also result in an increase or in a decrease of the range of motion.

Kottke et al. (1959) reported that the range of motion between the atlas and $\mathrm{C}_{7}$ was more or less equal from a neutral position to maximal anteflexion and to maximal retroflexion $\left(50^{\circ}\right.$ vs $45^{\circ}$, respectively). However, a definition of this neutral position was not given. Step-formation was found to be present in both the anteflexion and retroftexion posture; the inclination of the apophyseal facets was considered to be responsible for this phenomenon. He measured angulation between vertebral bodies by drawing a tangent to the inferior border of the respective vertebral bodies. The angles between these lines determined the sagittal rotation of the bodies with respect to each other. The atlas was defined by a line through the inferior margin of the anterior and posterior arch; the skull by a line from the tubercle of the root of the zygoma and the postero-lateral tubercle of the foramen magnum. Anteflexion-retroffexion movement between occiput and atlas, determined in this way, varied between $0^{\circ}$ and $22^{\circ}$ [Fig. 13 ].

In describing the angle of rotation of two successive vertebral bodies with respect to each other, Penning (1960) re-introduced the method that was first described by Begg et al. (1949) [Fig. 14].

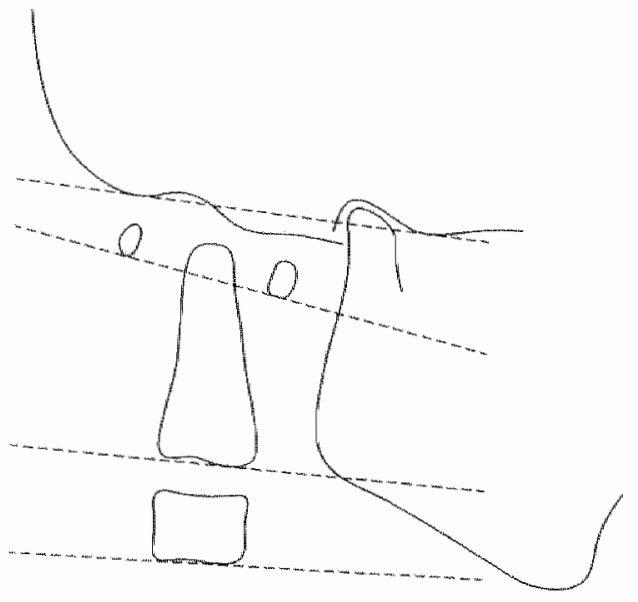


Fig. 14: rotation after Begg et al. (1949). Line I is the nesult of superparition of $S_{4}$, nexi $L_{5}$ is superimposed as illustrated in the figure, resulting in line 2

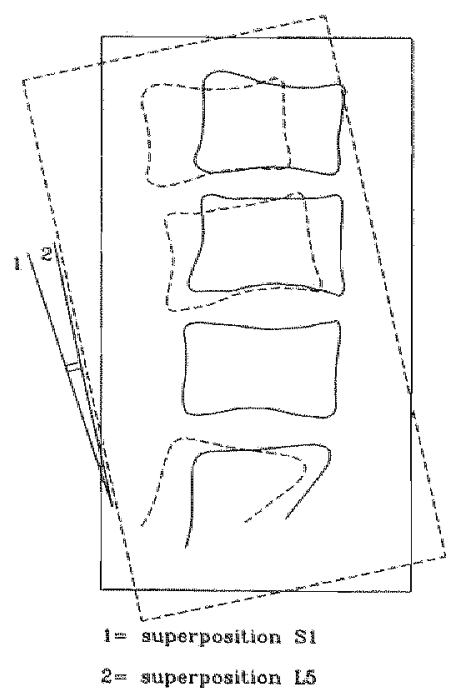

To differentiate more accurately between normal and abnormal postures, Penning (1964) studied the cervical spine in healthy individuals and in patients with a diversity of cervical pathology. Special attention was paid to conditions as olisthesis, angulation, and arcuate kyphosis. He concluded that movements are equally distributed among the different segments of motion in healthy individualls. He also found that so-called step formation can be present, especially in the younger age groups.

Lewit et al. (1963) was one of the first to describe the paradoxical movement in the upper cervical spine. This phenomenon is defined by a retroflexion position of the atlas during anteflexion of the spine and is called: inversion (Arlen, 1977; van Mameren, 1988), 'Atlas-kippen' (Gutmann, 1981; Weh et al., 1990), or paradoxical tilting (Kraemer et al., 1989). Lewit et al. studied 5 different positions (erect position; nodding and bending forward in a sitting position; bending forward while supine; bending backward while sitting, and while prone) in 50 healthy individuals. The pattern of forward and backward tilting of the atlas during antc- and retroflexion manoeuvres proved to be quite variable, both in different positions as well as in different individuals. Three marker lines were used to determine the range of motion in the antlanto-occipital and antlanto-axial segments: a line from the basion (dorsal end of the clivus) to the opisthion (dorsal border of the foramen magnum), a line through the middlle of the anterior and posterior arch of the atlas, and a third line drawn from the caudal border of the transverse process to the caudal border of the spinous process of the axis. The position of these three lines with respect to each other determined the range of motion in the antlanto-occipital and antlanto-axial segments in the different postures [Fig. 157. 


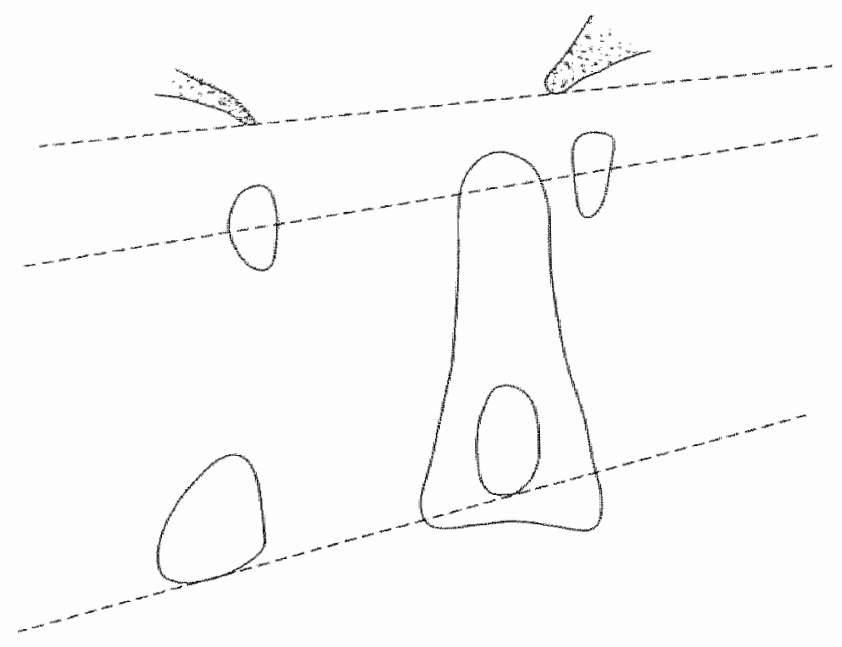

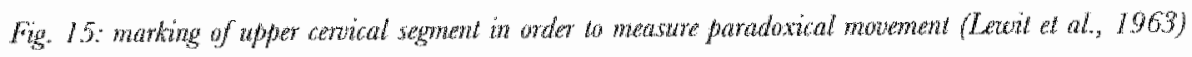

The total range of movement of the atlanto-occipital segment was found to be $15.2^{\circ}$, and of the atlanto-axial segment $16.5^{\circ}$.

Ball et al.(1964) subjected fresh osteoligamentous preparations of patients without a history of neck-complaints to a standardised load (4 kg). To measure the resulting angulation, pins were inserted into the vertebrad bodies perpendicularly. It was shown that the extent of angulation depended on the Hexibility of the ligaments, especially the flaval ligaments. The distribution of cervical movement followed a distinct pattern, angular deflexion being invariably less at the $\mathrm{C}_{2}-\mathrm{C}_{3}$ and $\mathrm{C}_{y}$-Th, levels than at the other levels. The total amount of angulation was $65^{\circ}-110^{\circ}$. Disc degeneration was associated with restricted movement at the affected level. Segmental immobilisation did not result in increased mobility of the unaffected parts, this in contrast to the findings of Rolander (1966) who studied lumbar specimens.

Dicthelm (1974) stated that the natural posture (or, as Fick called it, the 'Eigenform') of the spine is only partly explained by the shape of the vertebral bodies. According to the results of his study, tensions in the spinal ligaments and the intervertebral discs play an additional role. Movements were found to be equally distributed over the motion segments. Step formation was a common finding in individuals younger than 10 years.

Arlen (1977) described the paradoxical flexion of the upper cervical motion segment $\mathrm{C}_{0}, \mathrm{C}_{1}$. The investigator drew attention to the age-related significance of this paradoxical movement. The author used the atlas and the McGregor (or palato-occipital) line to determine the angle of rotation [Fig. 16$]$. 
Fig. 16: paradowical mowement in the upper cervical segment (Arlen, 1977)

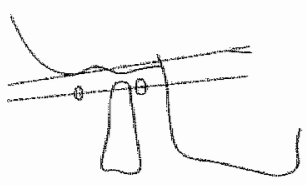

reeutarel posilion

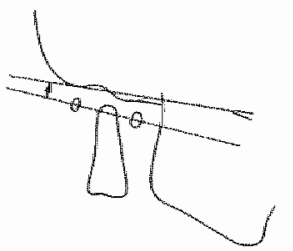

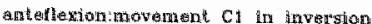

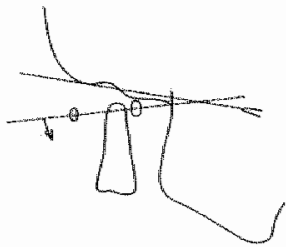

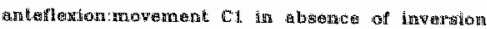

Arlen (1978) postulated that mobility of the upper cervical spine was less if paradoxical movement at the upper cervical level was absent. In this study, lines connecting inferior-anterior comers of the corpora and the inferior edge of the vertebral arches for marking $\mathrm{C}_{3}$ up to and including $\mathrm{C}_{2}$ were added to the marking procedure of $\mathrm{C}_{0}-\mathrm{C}_{1}$ /in Fig. 167. A base-line was constructed. Intersegmental angles of rotation in ante-, and retroflexion and in neutral position were derived from the angles formed by the marking lines and the base-line [Fig. 17 ].

Fig. 17: angugutation $\mathrm{C}_{\mathrm{g}}-\mathrm{C}_{\mathrm{g}}($ Arten, 1979)

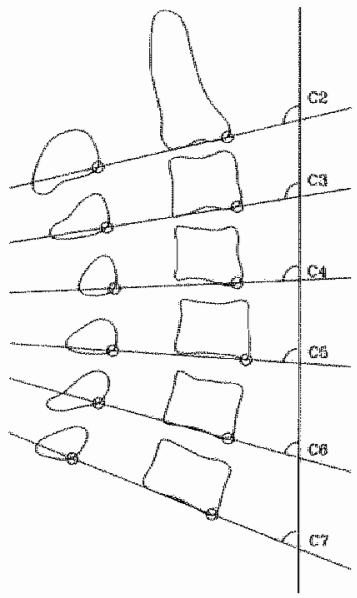


Dupuis et al.(1985) used the following method to measure horizontal displacement within a motion segment. He marked the angular points of the vertebral bodies. On each vertebral body, a line $\mathrm{a}$ and b, respectively, /Fig. 187) was drawn from the superior posterior angular point to the inferior posterior angular point. A third line (c) was drawn from the lower landmark of the upper vertebral body parallel to line (b) of the lower body. The distance between these lines was considered to be the horizontal displacement of these vertebral bodies with respect to each other. This procedure was repeated for each motion segment in both the anteflexion and retroflexion posture. To correct for differences in magnification, the horizontal displacement was expressed as a percentage of the mid-body width $(W)$.

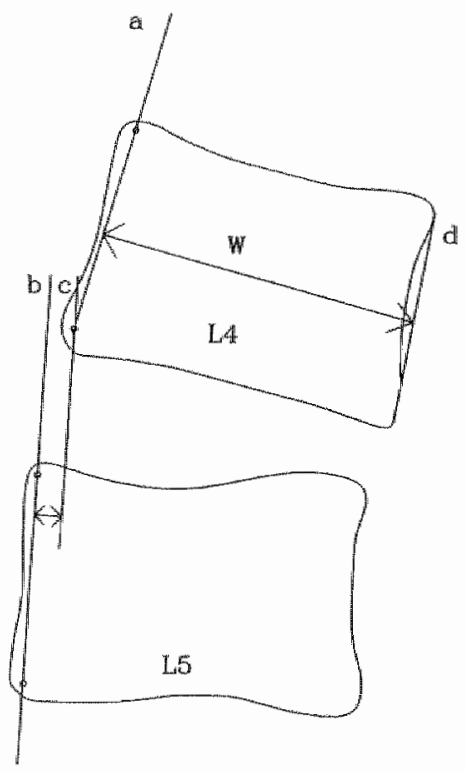

Fig. 18: horizonal displacement (Detpuis et al., 1985)

Stokes et al. (1987) used the same method as Dupuis to measure horizontal displacement but also rellated this displacement to the degree of angulation present in each motion segment: he found a positive correlation. This horizontal displacement/angulation ratio was significantly reduced in symptomatic levels.

Dvorak et al. (1988) paid some attention to observer variations and compared the method of Buetti-Bäuml (1954) with the method used by Penning (1960). Both so-called active function $x$-rays (films made of anteflexion and retroflexion postures assumed by the patient himself) and passive function x-rays (the investigator induces the photographed postures) of 28 healthy individuals and 31 patients were analysed by three observers. He 
demonstrated that the method of Penning was more precise (especially with respect to the passive $\mathrm{x}$-rays) and less time consuming.

Berfelo (1989) used a computer-assisted method to analyse function $\mathrm{x}$-rays of the lumbar spine. In a motion segment, a Cartesian co-ordinate system is projected in such a way that the $\mathrm{x}$-axis runs through the superior-anterior and posterior corners of the lower vertebral body, the $y$-axis perpendicular to it through the posterior-superior corner. Angulation was defined as the angle between the $\mathrm{x}$-axis and the line connecting the inferior comers of the upper vertebral body. Horizontal displacement was measured with a modified method originally introduced by Hagelstam (1949): the sum of the absolute values of the $\mathrm{x}$-co-ordinate of the posterior-inferior angular point of a body in the anteflexion and retroflexion position, respectively, is defined as translation $(\mathrm{X}-\mathrm{X})$ [Fig. 19].

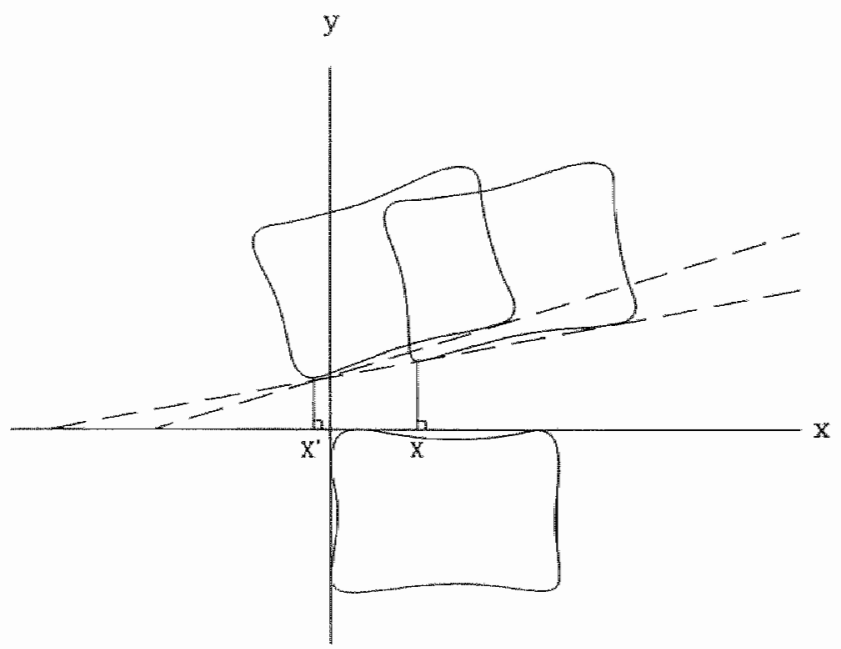

Fig. 19: horzontal disphacment or marshation according to Beffeto (1989)

Holmes et al.(1994) measured the full range of motion of the motion segments $\mathrm{C}_{6}-\mathrm{C}_{7}$ up to and including $\mathrm{C}_{2}-\mathrm{C}_{3}$ in 78 normal subjects and in 50 patients with myelopathy in a Chinese population. The four corners of the superior vertebral body of a motion segment were marked on both the anteflexion and the retroflexion $\mathrm{x}$-ray. A line was drawn through the superior corners, delineating the superior surface of the vertebral body, and another line through the inferior comers, delineating the inferior surface. Next, these films were arranged in such a way that the inferior vertebral body of the same motion segment became superimposed. The angle between the lines representing the superior surface of the upper vertebral body was measured as well as the angle between the lines representing the inferior 
surface. Due to errors in photographic depiction as well as in marking the anatomical landmarks and in measuring the kinematic variables on the $x-$ rays, slight differences between these two angles were found. The average value of the measured angles was, therefore, taken as the corrected total range of motion within the motion segment in question [Fig. 20].

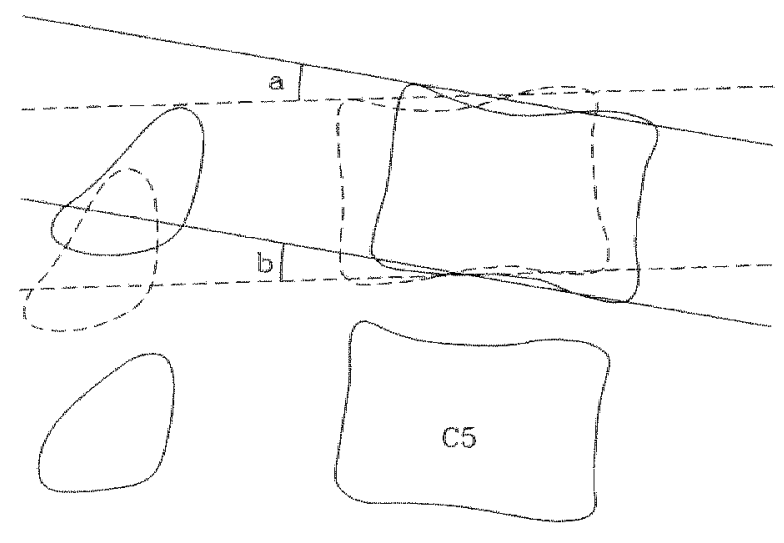

Fig. 20: intersegmental rolation (Holmes, 1994); the ther values of the range of mothon a and $b$ are aneraged, givengs the range of motion at a particular level

Holmes supported the method of Begg to measure the range of motion within a motion segment, but claimed that his averaging technique was more precise, especially with $\mathrm{x}$-rays of poor quality. The results of his study demonstrated that the total range of motion decreases with increasing age; also, that the emphasis of angular motion moves from level $\mathrm{C}_{5}-\mathrm{C}_{60}$ to $\mathrm{C}_{4}-\mathrm{C}_{5}$, both in healthy individuals concomitant with ageing, and in patients with myelopathy.

\section{The R-Centre method}

Rosenberg (1955) introduced the theorem of Euler' in clinical practice to study function $x$-rays of the spine kinematically. This theorem states that "any displacement of a rigid body in one plane, though actually resulting from combined rotations and linear displacements, can be described as if it results from pure rotation only about one axis perpendicular to that plane'. In other words: not the actual events are described but only the resultant displacement. The point of intersection of the axis of rotation with the plane is called the resultant centre of rotation

' Euler L.: Fomulaw generales pro transhatone quaqunque corporum rigidorum. Nonn Comment. Petrop. 20,189, 1776 (Procedings of S1.Pelersburg 1776). Reprinted in Eteri Opera Omnia (2), rol.9, Basel, 1968. 


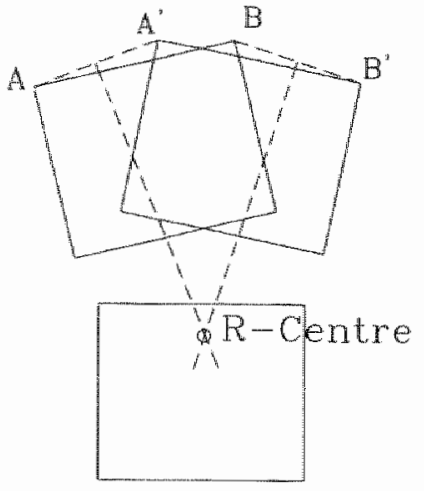

Fig, 21 . deterynination of the $R-C$ ewe

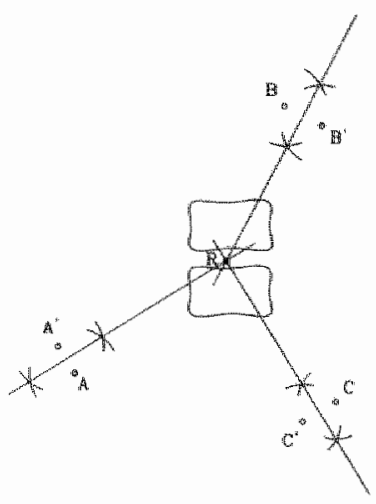

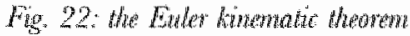
(Rosenberg, 1955). The the perperdiculo bisectors intersed at owe point $R_{3}$ the $R$-Combe.

(R-Centre). The so-called R-Centre is found as the intersection of perpendicular bisectors of lines connecting corresponding points of a body before (A and B) and after (A' and $\left.B^{\prime}\right)$ displacement /Fig. 21].

Rosenberg studied the postures of the lumbar spine in lateral bending, using the R-Centre method to analyse the function $x$-rays of 30 subjects. The $\mathrm{x}$-ray taken in lateroftexion was placed on top of the film taken in the upright position (front view) in such a way that the contours of the first lumbar body became superimposed. With the films held in this position, three holes were pierced $(A, B, C)$ with a small needle leaving three corresponding pinholes in both films. Subsequently, the films were arranged in such a way that the second lumbar vertebral body became superimposed. The needle was again inserted through each of the three existing holes of the upper $x$-ray to pierce the underlying film in its new position (A', B', C'). The difference in position between the first set and the second set of three pinholes, both now visible in the underlying $x$-ray, determines the change in position of the second lumbar vertebral body with respect to the first lumbar body. Three lines are drawn to connect each pair of corresponding pinpoints. The perpendicular bisectors of these three lines intersect at one point, the R-Centre. The change in position of the second lumbar vertebral body with respect to the first lumbar body can now be described as if it is the result of pure rotation only about the centre of rotation, $\mathrm{R}$ / Fig. 22$]$.

Rosenberg described the results of his study semi-quantitatively: the R-Centre of a motion segment tends to lie in or near the intervertebral disc. 


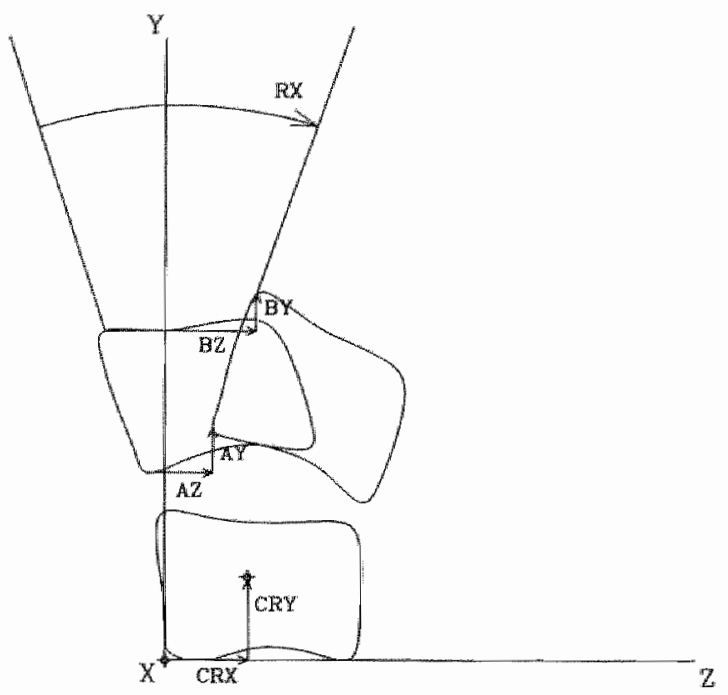

Fig. 23: intersegmental angulation $(R X)$ and horizonlal displachent $\mathrm{Z}$ (AZ and BZJ, Diontak el al. (1991)

Amevo et al. (1991) evaluated the reliability of conventional techniques for the determination of the R-Centres of cervical motion segments by comparing the results obtained by two observers and by the same observer on two separate occasions. It was found that the mean location of an R-Centre in a population could be determined quite accurately. However, the technique was not reliable for the determination of an $\mathrm{R}$-Centre in a given subject (variation up to $38 \%$ ). A qualitative analysis suggested that the identification of the radiographic images of the vertebral bodies and their tracings was the greatest source of error for this technique. Using stricter criteria for recognising and tracing the landmarks on the vertebral bodies improved the results of the observer variability study.

Dvorak et al. (1991) used a computer-assisted method to determine intervertebral translation, angulation, and centres of rotation for cervical spine motion segments. Four tangents were drawn to the four sides of each vertebral body. The intersections of these lines were considered to represent the four comers of the body. The lower vertebral body of each individual motion segment on the ante- and retroflexion $x$-ray was superimposed. A co-ordinate system was located with its origin at the posterior-inferior body comer of the lower vertebral body, the $x$-axis running through both the posterior- and anterior-inferior comer. Translation of the posterior-inferior comer $(A)$ and the posterior-superior corner $(B)$ of the upper vertebral body were defined by the horizontal displacements of these markers to (AZ) and $(\mathrm{BZ})$, respectively. To determine the angulation, the angle $(\mathrm{RX})$ between the dorsal tangents was measured [Fig. 237. 
Both the translation and angulation variables showed rather high standard deviations in repeated measurements. To reduce these standard deviations, a translation/rotation ratio was introduced. The rationale for this procedure was not given. It may be that this procedure results in smaller standard deviations: however, a higher power of diagnostic discrimination is not demonstrated. There is another shortcoming: translation and rotation are independent variables which are assumed to be normally distributed; for this reason this ratio itself cannot be normally distributed.

Vortman (1992) analysed the motion patterns of the lower cervical segments in 36 healthy individuals and in 21 patients with disc space narrowing at $\mathrm{C}_{5}-\mathrm{C}_{60}$. He studied the $\mathrm{x}$-rays of both actively and passively produced anteflexion and retroflexion postures. To construct the respective centres of rotation a rather elaborate procedure was used. A co-ordinate system was constructed for each vertebral body: the $\mathrm{x}$-axis running through the inferior-anterior comer of the body and tangent to the superior margin of the arch; the $y$-axis perpendicular to it and tangent to the inferior-anterior corner of same body. Co-ordinate systems were constructed for all vertebral bodies on both the ante- and retroflexion x-rays [Fig. 21$]$.

Then, the anteflexion $x$-ray was positioned on a viewing box with adhesive tape. The outline of the anteflexion film itself was drawn on the viewing box. The retroflexion $x$-ray was superimposed in such a way that the co-ordinate systems of the lower vertebral body of the motion segment

foig. 24: wegnental co-ardinate spstern (Forman, 1992)

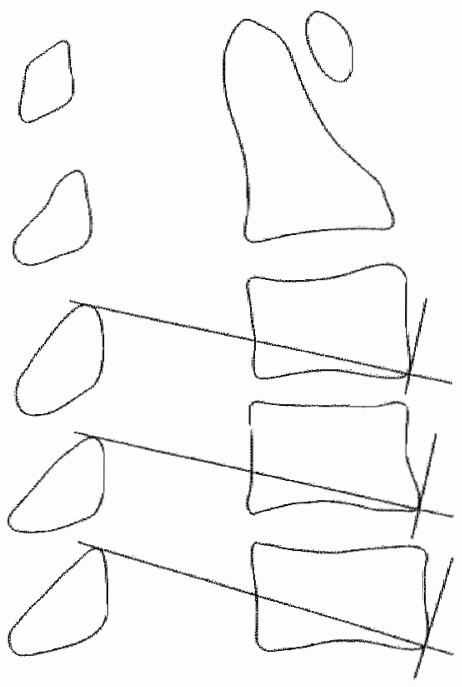



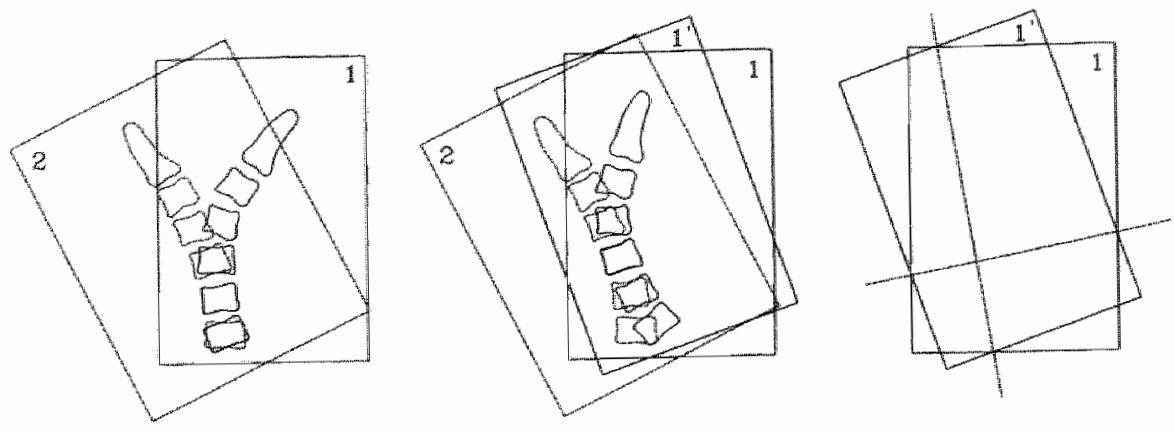

Fig 25 procedure of detemination of the R-Comtre (Vorman, 1992)

under investigation became superimposed. After fixing the retroflexion film in this position, the anteflexion $x$-ray was removed, leaving behind only its outline on the viewing box. The next step in the procedure was now to superimpose the anteflexion film on the fixed retroflexion film in such a way that the co-ordinate system of the upper vertebral body became superimposed. Subsequently, the outline of the anteflexion film in its new position was copied onto the viewing box. To determine the R-Centre of the motion segment under investigation, lines were drawn through the opposite corresponding points of intersection of the lines delineating the outlines of the films in the ante- and retroflexion position. The intersection of these two perpendicular lines is the R-Centre [Fig. 257.

The results of this study show that the centres of rotation are located in an oval area, in the lower vertebral body of each segment: the spread in the antero-posterior direction is about half the spread in cranio-caudal direction. With increasing age, the centres tend to move caudally.

In patients with disc space narrowing, however, the centres are found in a position further cranial than expected on the basis of the actual age of these individuals.

\section{The revaicat spine studied as a complete structure}

The concept of the cervical spine moving as an integrated chain of motion segments is not a new one. Many authors have described the curvature of the cervical spine in anteflexion, retroftexion and in the mid-position (Dittmar, 1931; Buetti-Bäuml, 1954; De Sèze et al., 1951; Jones, 1960; Boreadis Borden et al., 1960; Fineman et al., 1963; Diethelm, 1974; Penning, 1960; Gutmann, 1981; Dimnet et all, 1982; Weh et al., 1990; Gay, 1993).

Boreadis Borden (1960) studied the relationship between the cervical curvature, age and gender, and also the relationship between the cervical and thoraco-lumbar curvature. A specific relationship was not found. 


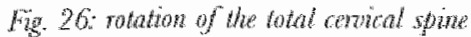
Coluchis at al., 1965$)$

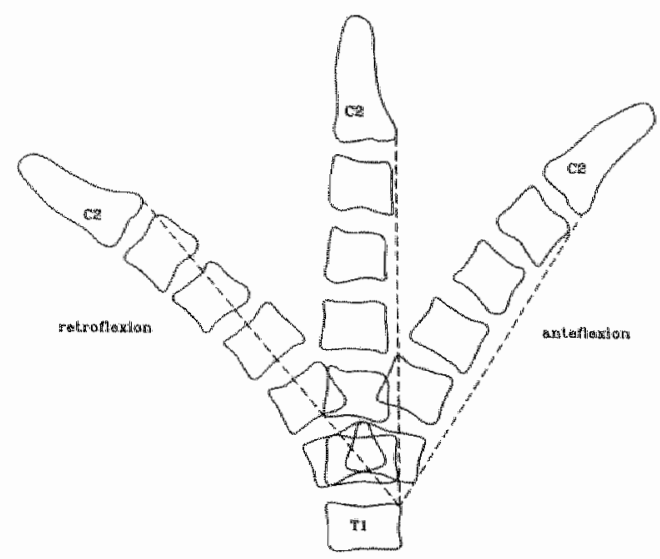

Following the suggestions of others (Bakke, 1931; Jones, 1960), Fineman et al. (1963) demonstrated that the shape of the cervical curve was dependent on the posture of the patient: a slight lowering of the chin could make the lordotic curve disappear in normal individuals without previous injuries.

Colachis et al. (1965) evaluated the cervical spine in neutral position and in ante- and retroflexion position from the second cervical to the first thoracic vertebral body. The contours and the corners of the bodies were marked. The anterior length of the spine in different positions was determined as the sum of the heights of the vertebral bodies and the intervertebral discs anteriorly; the posterior length was defined correspondingly. In order to measure the total rotation, a line was drawn from the ventralsuperior corner of $\mathrm{Th}_{1}$ to the ventral-inferior comer of $\mathrm{C}_{22}$. Then the $\mathrm{x}$ rays depicting the three different positions were superimposed. The angle between the above-mentioned lines on the antefexion film and on the retroflexion $x$-ray was considered to represent the total rotation as a result of the anteflexion-retroflexion manoeuvre [Fig. 26 ].

With respect to the midposition, maximal anteflexion requires more intervertebral motion than maximal retroftexion. To explain this difference, the authors point at the slight retroflexion posture in the neutral position. Regretfully, no further details on neutral-position-definition were given. These findings contrast with the results of other investigators (Virchow, 1928; Bakke, 1931; de Sèze et al., 1951; Diethelm, 1974) who found that the differences between the natural midposition and anteflexion were less than the differences between this midposition and retroflexion.

Another method to describe the spine as an integrated chain of motion segments was postulated by Veleanu et al. (1975). The translation, as well as the angulation of the different vertebral bodies, was described relative 


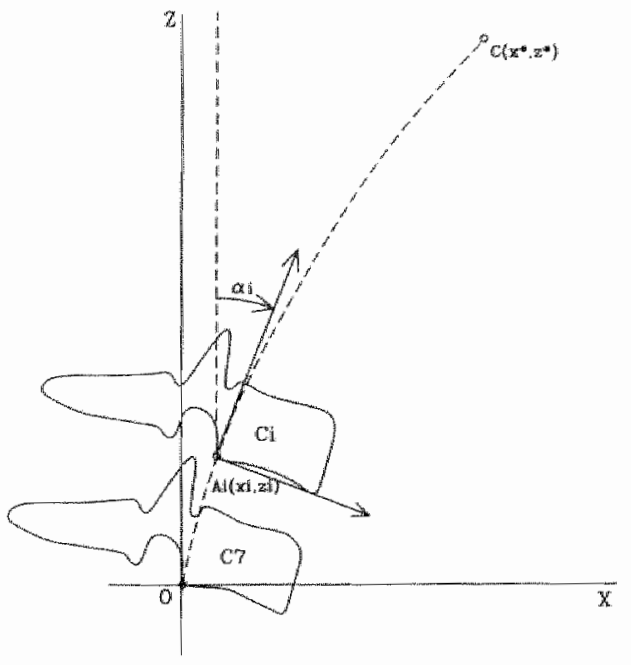

fig. 27: arientation of the co-ordinale spstem (Veleanu et al., 1975)

to the position of $\mathrm{C}_{7}$. $\mathrm{X}$-rays were taken in ante- and retroflexion and in neutral position. In each position, the contours of the vertebral bodies were copied on a transparent sheet superimposing the contours of $\mathrm{C}_{7}$. The posterior-inferior corner of each vertebral body, as well as the centre of gravity $(C)$ of the head (defined to be positioned in the centre of the meatus acusticus extermus), were marked. The origin of the co-ordinate system was projected in the posterior-inferior corner of $\mathrm{C}_{7}\left[\mathrm{Fig}_{\mathrm{g}} .27\right]$.

The relation between the $x$-co-ordinates of the vertebral bodies $\left(x_{i}\right)$ and the $x$-co-ordinates of the centres of gravity $\left(\mathrm{x}^{*}\right)$ are presented in a graph in anteflexion, in the neutral position and in retroflexion. $[F \mathrm{~g} .28]$

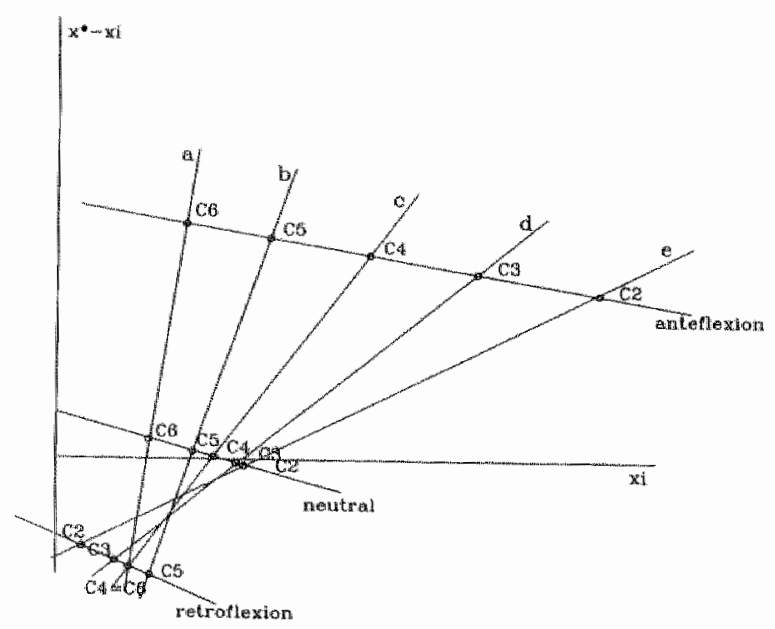

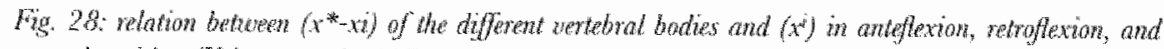
wethal position (Veluam et al., 1975) 


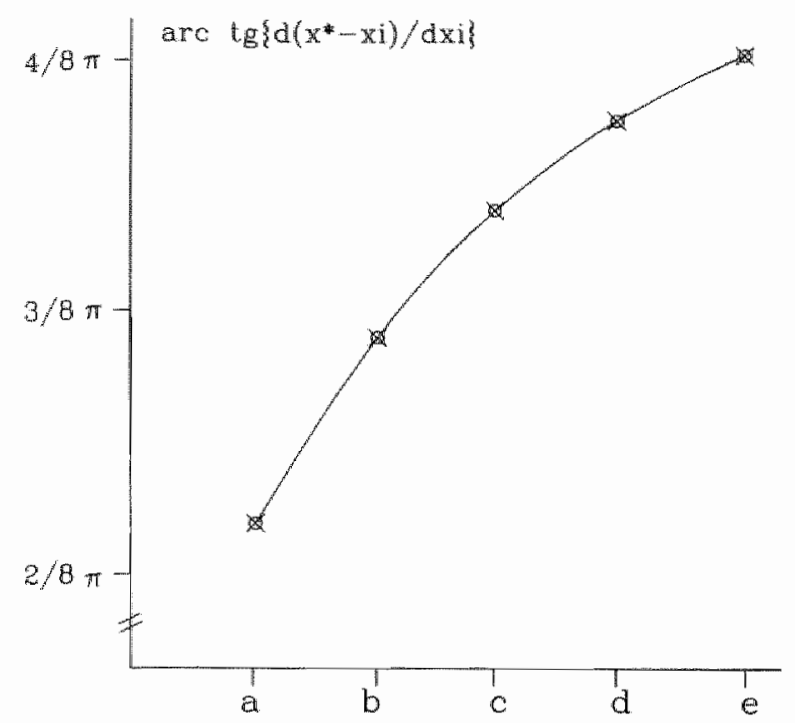

Fig. 29: inclination of the thes $(a, b, \ldots$ e) (Voleanu et at, 1975)

In non-pathological conditions, there seems to be a linear dependence of the $x$-co-ordinates of the vertebral bodies with respect to the $x$-co-ordinate of the centre of gravity of the head. For each vertebral body, the relative $\mathrm{x}$-co-ordinates on the lines representing the three postures were connected, resulting in another series of straight lines $(a, b, \ldots . . e)$. The angulations of these lines are presented relative to each other in another graph, showing the so-called inclination. [Fig. 29]

This inclination seems to be continuous and non-linear in normal conditions. In pathological conditions, the inclination showed discontinuous variations. With this method, the authors were able to discriminate between pathological and non-pathological conditions, albeit for a rather small population (20 healthy individuals versus 3 patients).

Wackenheim (1975) described a more practical method for analysing function $x$-rays of the cervical spine. He traced the contours of the vertebral body of $\mathrm{C}_{7}$. Next, a continuing line tangent to the posterior surface of the vertebral bodies was drawn, from $\mathrm{C}_{7}$ up to the top of the dens. The skull was marked with the Chamberlain line $/ F \mathrm{~g}$. 307. The anteftexion, retroflexion, and midposition $x$-rays were superpositioned with $\mathrm{C}_{7}$ as reference. As a result, the three Chamberlain lines marking the skull form a triangle. In normal individuals, this triangle proved to be equilateral. Any deformation of the triangle indicates a disharmonious movement. 


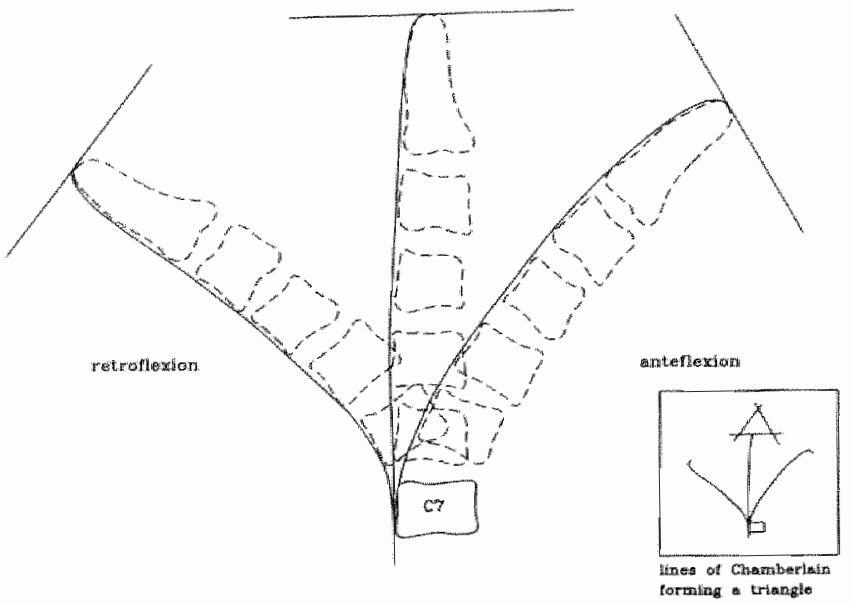

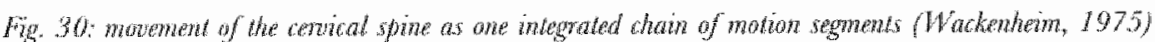

Gutmann (1981) analysed kinematically the anteflexion, retroftexion and mid-position postures on x-rays. He defined the mid-position of the cervical spine as the posture at rest, in which the patient is looking straight forward.

Special attention was paid to the $\mathrm{C}_{0}-\mathrm{C}_{1}$, and $\mathrm{C}_{1}-\mathrm{C}_{2}$ segments. Evaluating the three methods of Buetti-Bäuml, Penning, and Arlen, Gutmann developed a technique with specific advantages: no need to indicate delicate marking points on the films, the possibility to analyse $\mathrm{C}_{0}-\mathrm{C}_{1}$, and $\mathrm{C}_{1}-\mathrm{C}_{2}$, and no need to use large $x$-rays. Anatomical references on the films were marked not with points but with lines: the upper cervical segment was defined by the palato-occipital or McGregor line and the clivus-tangential line, the clivus-dens angle, and a line through the prominence of the dorsal arc $[\mathrm{Fig} .31]$.

The author propagated the idea of the spine moving as a complete structure. His analydical method, however, was primarily focussed on the propertics of single segments of motion. The properties of these motion segments were put together in a motion diagram represenung the complete cervical spine. The method of Wackenheim, which is more in agreement with the concept of the spine moving as a complete structure, was rejected by Gutmann because this approach, in his opinion, does not account for small movements.

In a study on cervical spine motion in a sagittal plane, Dimnet et al. (1982) emphasised the importance of the contour of the cervical spine. He determined the angulations and centres of rotation of individual motion segments with respect to $\mathrm{C}_{7}$. From full retroflexion to full anteflexion, five intermediate positions were studied (PI-P5) /Fig. 327. 


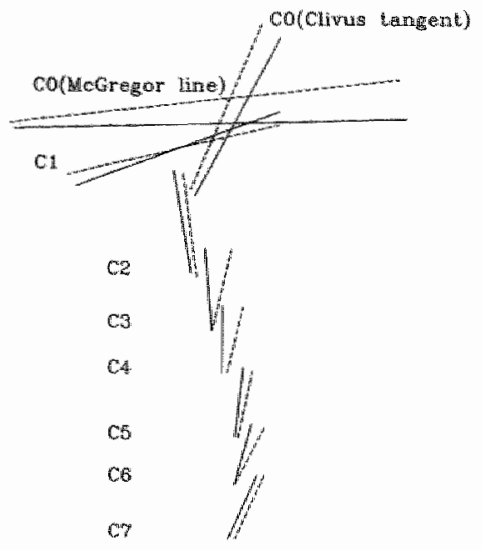

intersigenental rotation:

metreall position (continuous lines)

va anteflexion fenched lines

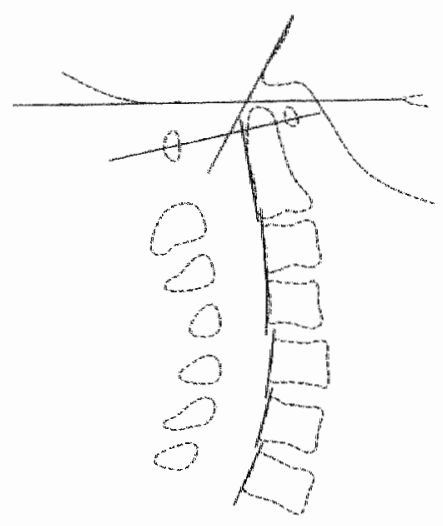

londmartivis

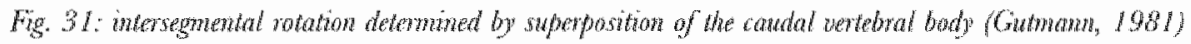
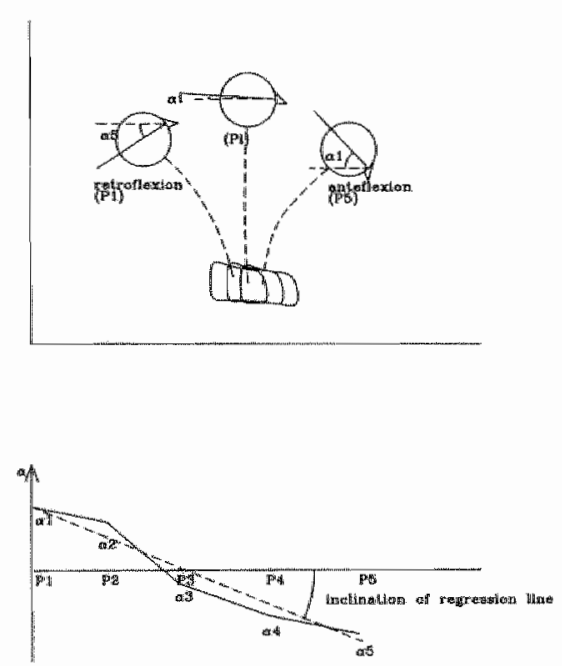

Fog 32. andulation of the thead in froe successine porthons (rotation in respect of $C_{y}$. In the graph below, the angtalitons are plotent aguinst the different positions $(P 1-P 5)$; a regression line is constructed (Dimnet at at., 1982)
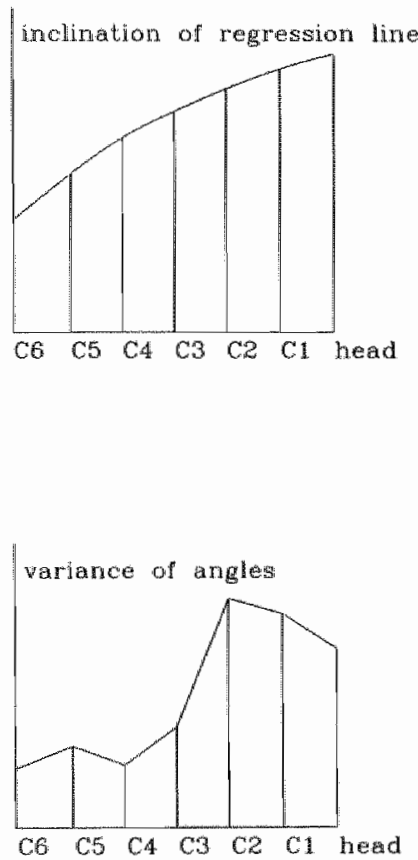

Fogs.33: an regression line as presended in (fig.32)

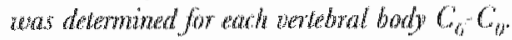
The inclinations of these regression thes are presented in the upper graph. The loxwer graph presents the variance of the measuremexts of angulat wion for ench wetebral body (Dhinnet et al., 1989) 
For each position, the angulation of each vertebral body relative $10 C_{7}$ was projected in a graph. The slope of the regression line, representing these angulations, and the variance of the angulations were measured. The inclination of these regression lines were plotted in a second graph, together with the variances of the angulations [Fig. 32 and 337 .

Next, the centre of rotation of each vertebral body relative to $\mathrm{C}_{7}$ was determined for each of the five intermediate steps of motion between anteand retroflexion (Pl-P5) [Fig. 34 ].

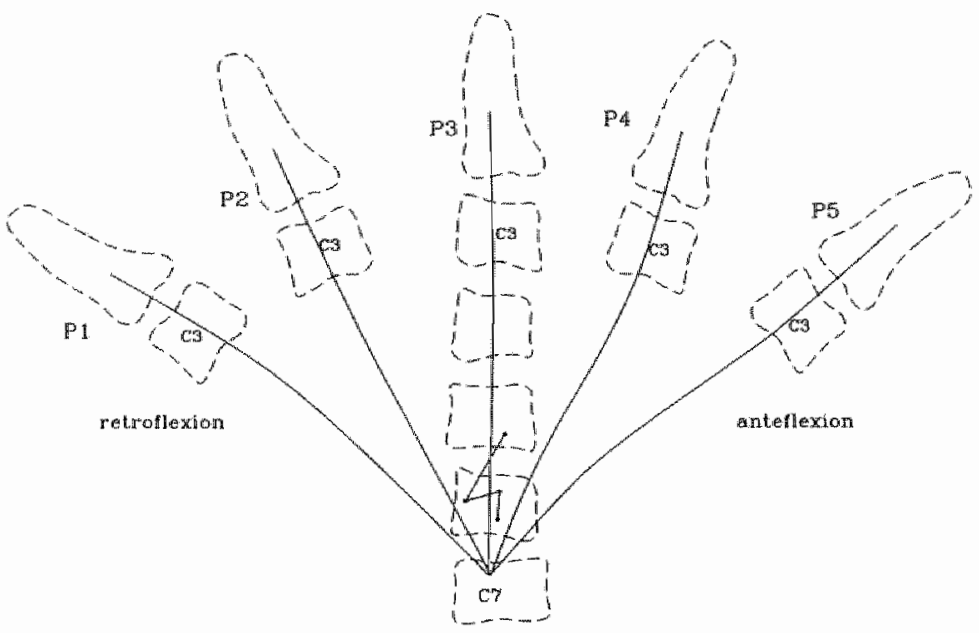

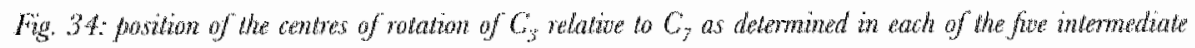
positions of motion (PI-P5). (Dimnet et al., 1982)

The $x$-rays of 6 healthy individuals and of 6 patients (patients with consolidated cervical fractures or surgical fusions, or patients with neckpain only) were analysed.

In patients, a decrease of motion relative to $\mathrm{C}_{7}$ was found for all vertebral bodies. Motion also becomes less continuous (the variances of the measurements of the angles of rotation in steps (PI-P5) increase; the centres of rotation also become spread over a larger area. In the motion segments themselves, there is also a reduction of motion, most pronounced in the lower cervical segments. Dimnet concluded that his merhod was capable of identifying functional abnormalities in patients with neck pain. However, it is obvious that the number of individuals studied is too small to justify such a general conclusion. 
Berfelo (1989, 1993) analysed function x-rays of the lumbar spine using a computer assisted method that enables the quantification of a large number of kinematic variables ( $\mathrm{n}=96, \mathrm{c}$.g. vertebral body height, antero-posterior diameter vertebral body, disc height, translation, angulation, R-Centres of individual motion segments and relative to $S_{1}$, length of lumbar spine, wedgeshaped vertebral body). Amongst these, a new kinematic concept the R-Zero line" was introduced, which acknowledges to the notion that the lumbar spine behaves as an integrated chain of motion segments. [Fg. 35]. This concept quantifies the kinematic situation in which the lumbar spine has carried out half the amount of rotation and translation needed to complete displacement from anteflexion to retroflexion or vice-versa

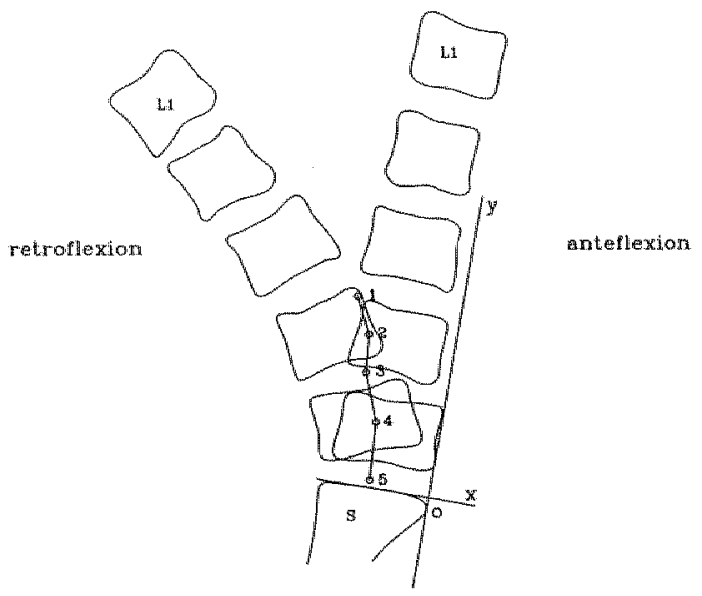

Fig. 35: wentres of rotation relative to 5, (Berfolo, 1989$)$

It was demonstrated that this $\mathrm{R}$-Zero line was configured characteristically in the patient groups studied (control group, $n=62$; herniated lumbar disc $L_{4}-L_{5,} n=47$; herniated disc $L_{5}-S_{1}, n=34 ;$ lysis/olisthesis, $n=21$ ).

To evaluate the diagnostic significance of combinations of kinematic variables, a computer programme based on a stepwise discriminant analysis was used. From the large number of variables $(n=96)$, a small subset $(n=7)$ was selected that contained (nearly) all diagnostic information that was present in the patient groups studied. The values of obscrvations of the selected subset served to calculate diagnostic probabilities for individual patients. Of the calculated probabilistic diagnoses, $87 \%$ was correct for individuals in the control group, $90 \%$ for patients with a spondylolisthesis and $75 \%$ for patients with a herniated lumbar disc. The kinematic analysis method presented in this study demonstrated that kinematic studies have clinical relevance for individual patients. 


\section{Cine-radiography}

Fielding $(1957,1964)$ presented a study of cervical spine motion based on cineroentgenography. He considered this method to be an adjunct to standard $\mathrm{x}$-rays. Although the $\mathrm{x}$-ray dose is low $(3-6$ roentgen $/ \mathrm{min})$, the author warned about the cumulative effect of prolonged exposure. One also has to decide whether to sacrifice anatomical details for motion or motion for anatomical details (Gutmann, 1956; Fielding, 1964).

Jones (1960) stressed the importance of this kind of investigation and pointed out that particular positions and particular movements which produced symptomatology could be recorded at the moment of their occurrence.

Van Mameren (1988) studied motion patterns of the cervical spine in 10 healthy individuals with cine-radiography. Both the ante- and retroflexion manoeuvres took about 10 seconds and were filmed with a speed of $4 \mathrm{im}$ ages per second; thus producing two times 40 pictures. In each picture 40 anatomical landmarks were indicated with a small dot. These landmarks were digitised and read into a computer, using specifically written software that executed an averaging procedure to diminish the errors in marking and reading these landmarks [Fig. 36, 37, 38, 39].

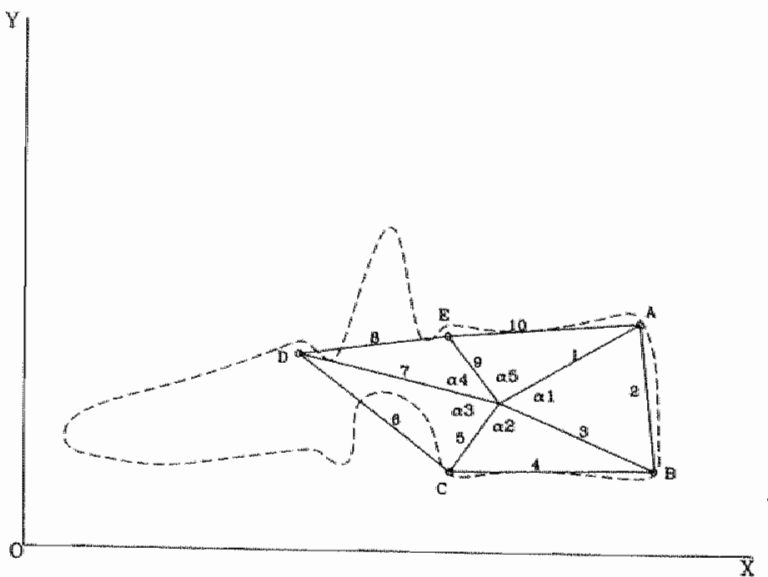

Fig. 36: makting procedure I fon Mameren el al, 1990). The poritron of a vertebral body was indiated wath five points, one at ead comer of the body itself and one on the spinal process. These fove points represent a pentongle from which the mathenatical sentre was determined. The mean zalue of the $x-$ and" $y-c 0$ ordinates of the fore comer-points of the pentongle thefore the $x$-and $y-c 0$ ordinate of this mathematical contre. The length of the tines connecting these fore points and the length of the lanes conneding the mathematical

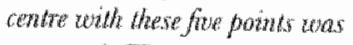
measured. The angles between the Whes diverging from the mathematical weatre were also measured. This procerture is used to detemine the abow'mentioned dimensions of each wertetwat bodly, an each frame of the fitm. Subsequently, the mean whutes per fith are calculated for cach wertebral body and these are used to design a senplate representing the 'meon wettebral body?" 
Fig. 37: manking prowedwe If fom

Mameren at at, 1990). The new step in the procedwe is to correct the shape of the wertorat hody $A B C D E$ atelicted on wach frame of the fon, for marking errors and for enow due the phatographic distartion. To do so, the lemplate of vertebral bodp $A B C D E$ is rataled froty to find the best fit wath the terphlate of the romesponding

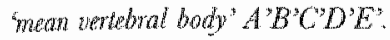

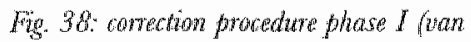
Mameren at at, 1990). If a makking poin of a sertebrat body, for example $B$, dereates more than 7 mm from the comesponding marking point $B$ ' of the

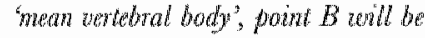
roplaned by point $B^{\prime}$.

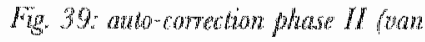
Mameren ot al, 1990 . If a maknig poind of a arebrat body, for axmple $A$. dewates tess than 1 mm from the conesponding mathong poind $A^{\prime}$ of the "mean vertebral body", a mee makng poind A' will be canstructed al equal distances betem A and $A$.
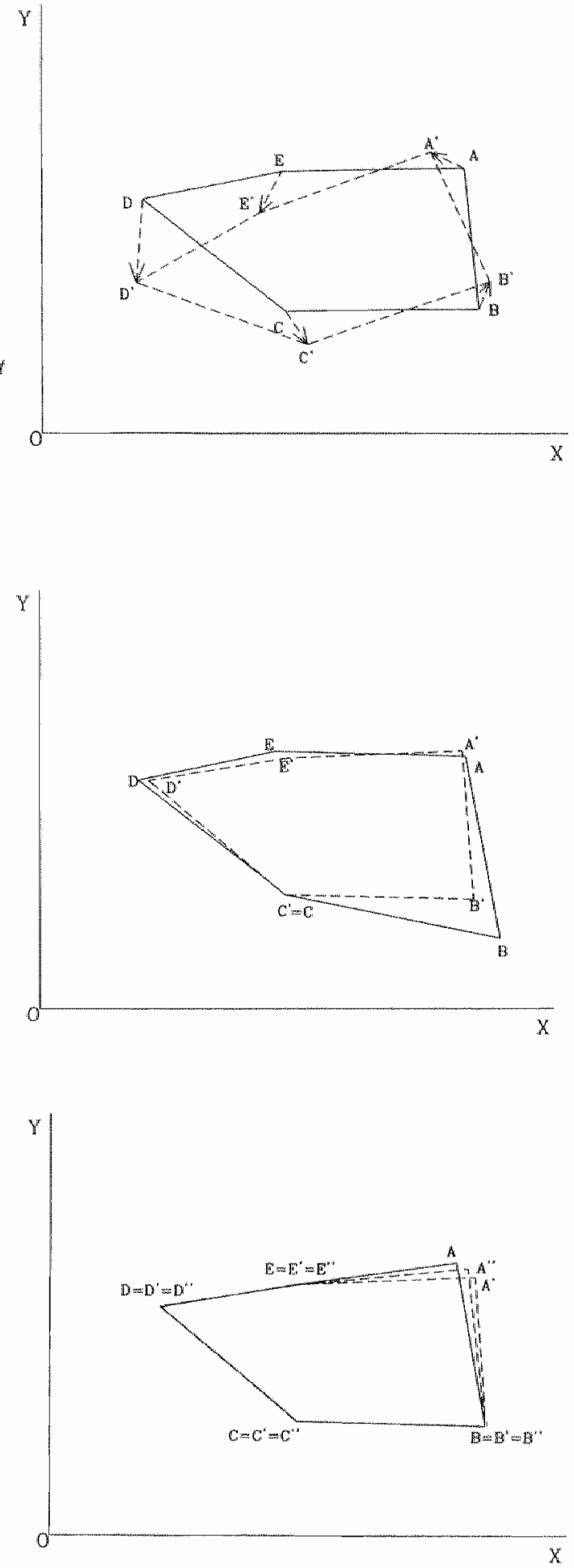
The inter-observer variance was not determined, nor was the ability of this method to discriminate between motion patterns of healthy individuals and motion patterns of patients.

The normal range of motion was found to be large. The construction of centrodes was only reliable within certain limits when non-consecutive frames of films were used. The averaged position of the constructed centrodes showed smaller variability than mentioned in the literature.

Distortion of the intervertebral disc (gliding and tilting) was regarded as a variable of motion. The absolute values of this variable showed large variability. In the upper part of the spine, more gliding than tilting was observed; in the caudal segments the opposite was found.

Both ante- and retroflexion of the cervical spine started and ended in the caudal part of the cervical spine, never in the mid-cervical part. At the end of the anteflexion manoeuvre of the cervical spine, some retroflexion was noticed within block $\mathrm{C}_{0}-\mathrm{C}_{2}$. During the retroflexion manocuvre, retroflexion in segment $\mathrm{C}_{1}-\mathrm{C}_{2}$ was always accompanied by anteflexion within segment $\mathrm{C}_{0}-\mathrm{C}_{1}$.

Inversion was also found to be a normal phenomenon within the caudal part of the cervical spine (in segment $\mathrm{C}_{6}-\mathrm{C}_{7}$ and less frequently in segment $\left.\mathrm{C}_{5}-\mathrm{C}_{6}\right)$.

\section{Three-dimensional reconstmetions of bi-planar $x$-rays of the spine}

Photogrammetry is a technique for measuring movement in three dimensions. Reflective markers are attached to parts of the body. Filming these markers during movement with two or more cameras in different positions enables a three-dimensional reconstruction of the movements. A major disadvantage of this method is the large number of markers needed to identify the object.

In other methods, emitting light diodes in the infrared region of the spectrum were used (accuracy $3-5 \mathrm{~mm}$ and $1 \%$ ). Acoustic waves were also used (accuracy $1 \mathrm{~mm}$ ). However, none of these methods have been subjected to in-depth clinical evaluation.

Proper definitions of items used in kinematics in general and in three-dimensional investigations in particular have been presented by White et al. (1978).

Lysell (1969) was the first to study joint movements of the cervical spine in three dimensions using plain $x$-rays. He examined the segments $\mathrm{C}_{3}-\mathrm{Th}_{1}$ in 28 autopsy specimens (aged 11-67), using a custom-made three-dimensional radiodiagnostic apparatus. The vertebral bodies were marked with four steel balls. Motion in a sagittal-, frontal- and horizontal plane was studied [Fig. 40]. 

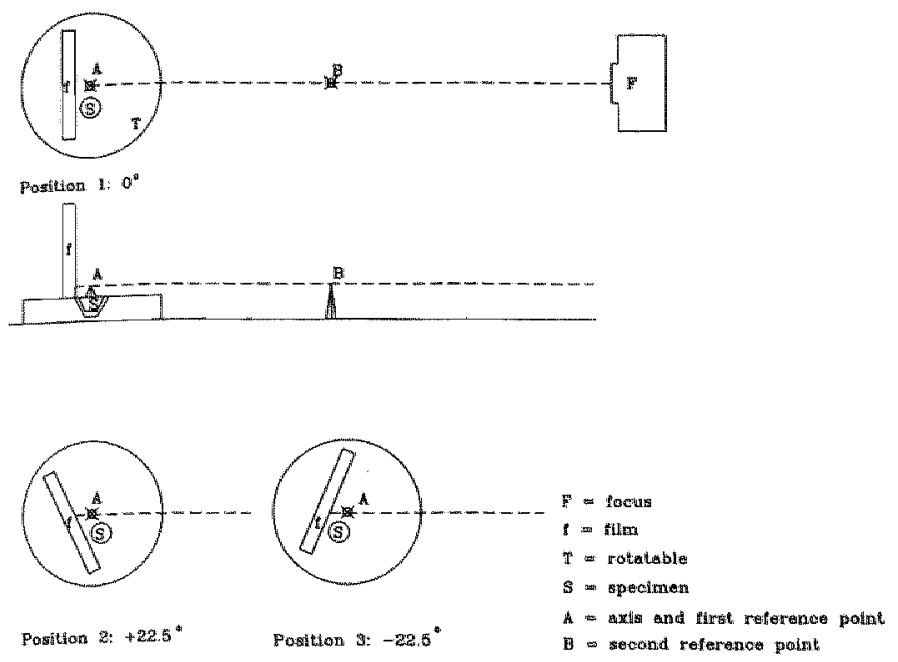

Fig. 10: three-dimensional apparatus according to Lyell. The x-ray beam is projected through points of

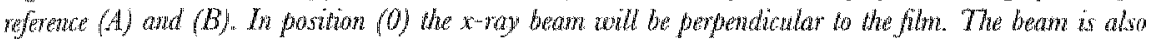
perpondicutar to the axis of rotation (A) of the rotatable (T). The specannen (S) in fixed to the rota table as shown. Fiths are made in three different positions $\left(0^{\circ}, 22.5^{\circ}\right.$, antd $-22.5 \%$. (Lysell, 1969)

In ante- and retroflexion movements in the sagittal plane, the centre of rotation was found to be located in the subjacent vertebral body. For segment $\mathrm{C}_{2}-\mathrm{C}_{3}$, this axis was positioned more caudally than for the lower vertebral bodies. Motion patterns in lateroflexion and rotations in a horizontal plane were similar: both motions were always combined. Segment $\mathrm{C}_{32}-\mathrm{C}_{3}$ shows the largest rotation combined with lateroflexion and the largest lateroftexion if combined with rotation; the conditions for segment $\mathrm{C}_{7}-\mathrm{Th}_{1}$ were the opposite (meaning that freedom of motion is largest in the upper part of the cervical spine). The centre of rotation was found in the anterior region of the moving vertebral body.

Studying degenerated specimen versus non-degenerated specimen, it was found that the total range of motion in any plane was not affected by degeneration. The pattern of motion was only influenced in the sagittal plane in such a way that at level $\mathrm{C}_{5}-\mathrm{C}_{65}$ anteflexion was reduced in relation to retroflexion.

Panjabi et al. (1971) published a mathematical approach to three-dimensional kinematic analyses of the spine. The displacement of a rigid body is represented by rotation and translation. Basically, until 1971, there were two methods for describing these displacements. First, the vector method describing displacement as rotation and translation in an $x-y-z-$ co-ordinate system. The second method describes displacement as if 


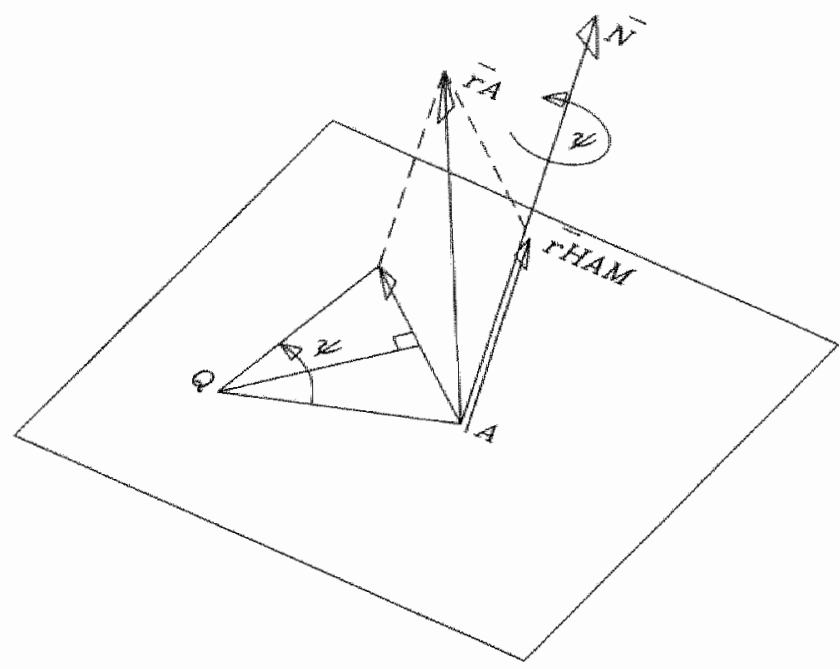

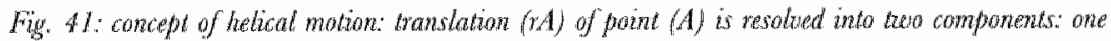
component (rHAM) paratel to the helical axis of twotion (N) and ane component perpendicular to $(\mathrm{N}$ )

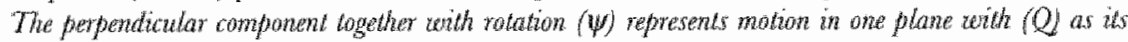

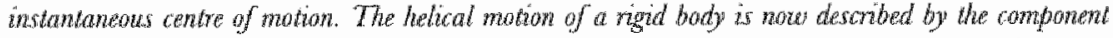

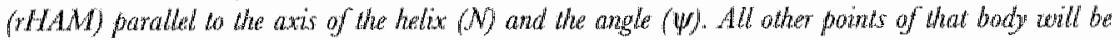

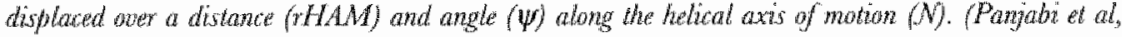
$1991)$

resulting from pure rotation only (Euler theorem). The measuring errors inherent to these methods increase disproportionately with an increasing number of variables and marking-points on the films. Describing motion of an irregularly shaped body as displacement about an axis in a certain direction (so-called helical motion) reduces the measuring errors. Displacement in this concept is defined by two vectors: linear displacement in one direction, combined with rotational displacement about the axis of this direction. All particles of the body move along these two axes of motion with the same displacement whatever marking point is chosen [Fig. 41).

This concept is less sensitive with respect to errors than both the Cartesian vector method and $R$-Centre method, as was demonstrated in vitro. A major advantage is its independence of whatever marking-point on the moving rigid body is chosen.

Selvik (1974) developed a three-dimensional method for determining the position of radio-opaque markers in an object: the co-ordinates of an object in three-dimensional space were determined using markers on a test cage. The markers on this cage functioned as calibration points and were depicted on the same x-ray as the object itself [Fig. 42$]$. 


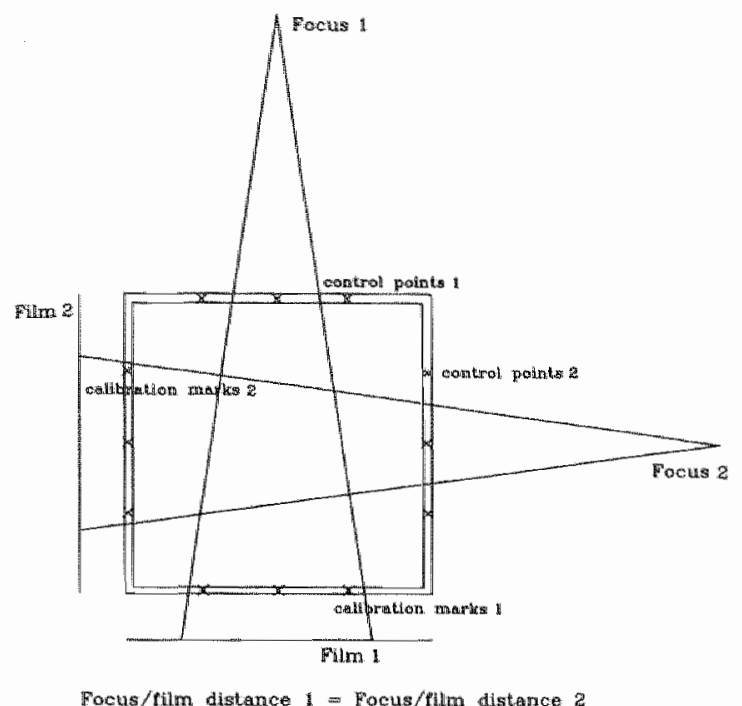

Fig. 42: schematic cross-section of the lest rage (Sebri, 1974)

The precision of locating the markings on the $x$-ray was evaluated, as well as the influence of deliberately introducing errors in the co-ordinates of an object in this test cage. The precision of locating the position of the object on the x-ray with respect to the reference markers on the test cage was also analysed together with the influence of deliberately introducing an error in the co-ordinates of the test cage. Finally, a total error analysis and an intra-observer analysis were performed. Three non-collinear markers were used. Displacement was analysed with the Euler method. The precision in determining rotation angles was found to be $0.1^{\circ}$. The precision in translation was about one-tenth of a millimetre.

Brown et al. (1976) used the same method as Selvik, but introduced a special rectangular reference frame to support the film cassettes at right angles, and to mount the required reference and calibration markers. In this way, the orientation of the two films, the projected marking-points of the object to be investigated, and the location of the two point sources ( $x$ ray tubes) were known in terms of a common co-ordinate system.

Considering the end-plates as an ellipse, the upper and lower end-plates were marked in the centre. Two other markers were placed at the inferior margin of the pedicles. The inferior margin of the spinous process served as an additional marking target. A mathematical approach was presented to locate the individual vertebral bodies in the reference frame. The original co-ordinates of the markers were converted in a common co-ordinate sys- 
tem by equivallent transformation. In this way, comparison of different $x$ rays with respect to the $\mathrm{x}$ - and $\mathrm{y}$-co-ordinates was possible. The errors in marking the four landmarks were less than $0.1 \mathrm{~cm}$. The accuracy of the system was tested by using mechanical models and autopsy specimens. To determine the clinical applicability of this procedure, a set of $x$-rays of a patient with scoliosis was analysed. These data did not differ significanty from data derived from measuring the Cobb's angle by standard methods. Further studies have to be done to evaluate the relevance of this method for motion anallyses and its significance for patient-groups.

Panjabi et al. (1981) presented a method specifically designed for measurements of three-dimensional motions of human spine segments in vitro. A motion transducer system was used measuring six translatory components of motion of three spheres attached non-collinearly to the moving body, relative to a fixed co-ordinate system. The apparatus consisted of a measuring jig and six uniaxial translation measuring devices. The jig was made of three non-collinearly arranged balls rigidly attached to each other and to the moving body. Data gathered with this apparatus were used to define the instantaneous helical axis of motion. In this way, the complex six degree-of-freedom motion was conveniently visualised by simple translation along and rotation about one single axis in space. The overall accuracy was very high: the averaged error in translation was 0.06 $\mathrm{mm}$ or $0.4 \%$, the averaged error in rotation $0.02^{\circ}$ or $0.9 \%$. Attention was paid to the situation in which pure translation occurs, because the helical axis will then lie in infinity. Adjustments were also needed in cases in which the helical axis was parallel to one of the global axes. [Fig. 43]

Plamondon et al. (1992), using the Euler-method, demonstrated that the precision in measurements could be improved by positioning the landmarks as lar apart as possible. Varying the location of a marking-point by about 2 $\mathrm{mm}$ resulted in rotation varying by about $2^{\circ}$ and translation by about $1 \mathrm{~mm}$.

To optimise the precision in measurements, Lee et al. (1993) implanted markers made of vitallium into the posterior or anterior surfaces of vertebral bodies.

Anterior-posterior translation, axial rotation and ante- and retroftexion in the sagittal plane were analysed in vitro (segment $\mathrm{C}_{4}-\mathrm{C}_{5}$ ), and in one patient. This method showed a high precision as one might expect: in translation $0.07 \mathrm{~mm}$, in axial rotation $0.08^{\circ}$, and in flexion $0.14^{\circ}$. The feasibility of the technique in vivo was demonstrated in two more patients (Lee, 1994). However, a major draw-back is the necessity for surgery. The number of volunteers was limited; general conclusions cannot be drawn. 

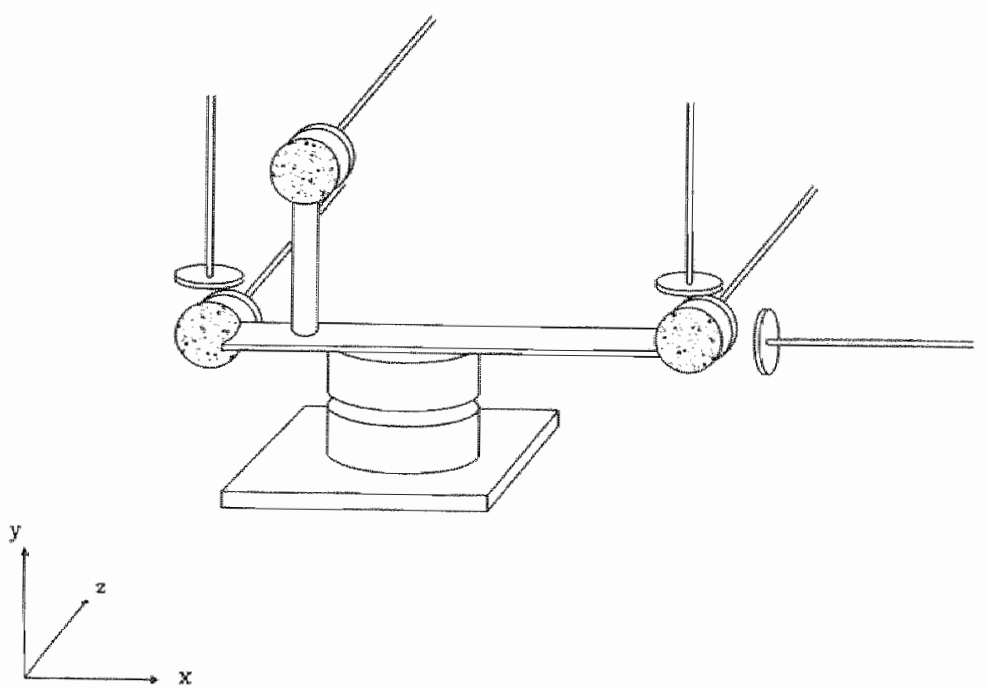

Fig. 43; measurng device consisting of three wherical balls strongdy athaded to each other and to the

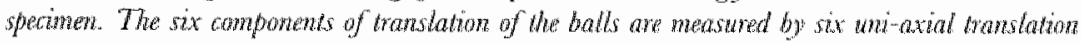

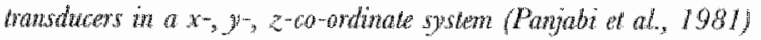

Iai (1993) analysed axial rotation in the upper cervical spine in 20 healthy volunteers, using biplanar $x$-rays. The subject's head was fixed and the trunk rotated in the reference frame while biplanar $\mathrm{x}$-rays were obtained. Almost all $(80 \%)$ cervical axial rotation took place at $\mathrm{C}_{1}-\mathrm{C}_{2}$, only $4 \%$ of the rotation occurred at $\mathrm{C}_{0}-\mathrm{C}_{1}$. As axial rotation at $\mathrm{C}_{1}-\mathrm{C}_{2}$ increased, there was an increase in rotation at $\mathrm{C}_{0}-\mathrm{C}_{1}$ in the opposite direction. The instantaneous axis of axial rotation was located anterior to the foramen magnum at the $\mathrm{C}_{0}-\mathrm{C}_{1}$ level, and in the central portion of the dens at the $\mathrm{C}_{1}-\mathrm{C}_{2}$ level. In axial rotation, with the exception of segment $\mathrm{C}_{1}-\mathrm{C}_{2}$, the entire spine and occiput showed lateral bending in the same direction as the rotation. The average bending angle in the opposite direction at level $\mathrm{C}_{1}-\mathrm{C}_{2}$ was $11^{\circ}$.

\section{Comment}

In cervicobrachialgia imaging techniques often fail to demonstrate morphological changes, which might explain the patient's complaints. To gather additional information about the functions of the spine, so-called function $x$-rays can be made. Usually, a lateral $x$-ray is made in the anteflexion posture and another one in retroflexion. On these films, anatomical landmarks of the cervical spine are indicated, thus defining the dimensions of the cervical spine on the one hand and differences in posture on the other. Subsequently, these so-called function x-rays are analysed kinematically, meaning that the dimensions and differences in postures 
are quantificd by measuring the distances and angles between the related landmarks on the films. Thus far, these studies have not resulted in the development of diagnostic tools with clinical significance for individual patients. One reason for this can be that the attention is almost exclusively focussed on the properties of single segments of motion, disregarding the fact that the spine behaves as an integrated chain of motion segments and as a complete structure. Another reason can be found in the study designs and technical procedures applied which vary widely. These different methods may have a major impact on the photographic depiction of the spine and thus on the results of the kinematic studies. This can explain why the reported observations are ambiguous. And above all, it is now generally accepted that each study inevitably faces large variances of observations, which are mainly physiological. To improve upon these matters a different approach was decided upon as will be elucidated in the present kinematic study. (Part II, "Present kinematic study of function $\mathrm{x}$-rays of the cervical spine'.) 
Part II

Present kinematic study of function $x$-rays

of the cervical spine 



\section{Chapter 5. \\ Study design}

\section{INTRODUCTION}

The present study aims to provide an answer to the following questions: 1 Do kinematic studies of function $x$-rays of the cervical spine have dinical significance?

2 Do kinematic studies of function $\mathrm{x}$-rays of the cervical spine contribute to clinical diagnosis of individual patients?

For this purpose, function x-rays of four different groups of individuals are analysed kinematically. The kinematic data derived from the x-rays of a control group serve as a reference: these data are compared with the data of three different groups of patients: patients suffering from cervical myelopathy, patients with a cervical radiculopathy due to a herniated disc at level $\mathrm{C}_{5}-\mathrm{C}_{6}$ and patients with a herniated disc at level $\mathrm{C}_{6}-\mathrm{C}_{7}$.

Cervical myelopathy is defined as spinall cord dysfunction caused by compression of the spinal cord and/or its vascular supply. The clinical picture is polymorphic. The onset is usually characterised by irradiating pain in the shoulder region. Further signs and symptoms may evolve synmetrically or asymmetrically. Spasticity will become manifest when the transverse area of the cord has been reduced by one-third. Commonly, the lower limbs are affected earlier than the upper limbs. Evolving muscular weakness will show a radicular distribution and frequently affects several segments. Spasticity in the upper limbs is rarely accompanied by lasciculations. Sensory disturbances are often non-specific and not invariably radicular: they may show a patchy or glove-like distribution. Damage to the spinocerebellar tracts results in ataxic disturbances. (Clarke et al, 1956; Crandall et al., 1966; Hughes, 1978; Lunsford et al., 1980; de Graaff, 1982; Mumenthaler, 1990; Cusick, 1991; Wilmink, 1991; Law et al., 1994).

Cenvical radiculopathy in general refers to any affliction that compromises the cervical nerve roots. The clinical picture of radiculopathy is characterised by the acute or subacute onset of pain in the shoulder and arm. Commonly, an acute torticollis develops with limitation of movements and a constrained position of the head. Later, pain irradiates more or less into the dermatome supplied by the affected nerve root. Specific movements, 
particularly straining, coughing, sneezing, and stretching the extended arm backwards provokes the irradiating pain. The affected nerve root often shows corresponding localised paraesthesias, or even sensory loss. There may be muscular weakness, muscular atrophy and diminished tendon reflexes corresponding to the affected nerve root Mumenthaler, 1990).

Progressive degeneration of the cervical spine due to physical stress and ageing causes reactive changes in the bone and soft tissues which may result in formation of hypertrophic spurs or osteophytes (hard disc). These osteophytes may also lead to the gradual onset of a radicular syndrome. Radicular syndromes are less often caused by trauma, benign or malignant neoplasms, inflammatory processes, infections, and metabolic or vascular diseases (Ruggieri, 1995).

In the present study, radiculopathy is associated with compression of the nerve root by a posterolaterall soft disc protrusion or extrusion. This is the most common cause of radiculopathy.

On both the anteflexion and retroffexion x-ray film, 43 predefined landmarks are identified and marked with a pencil. These markings serve to calculate the values of a large number of kinematic variables. These kinematic measuring procedures are rather time-consuming and subject to different types of error. Therefore, a computer-assisted method was developed to address both aspects. A specific software programme was written to enable the kinematic analysis of function x-rays of the cervical spine. (See paragraph 'Kinematic Analysis System KAS'.)

Acknowledging the concept of the cervical spine being a complete and integrated structure, the variable $\mathrm{R}-\mathrm{Cientre}-\mathrm{C}_{7}$ is introduced. Furthermore, so-called derived kincmatic variables are defined which refer also to the complete structure of the cervical spine. A description of these variables is given in the paragraph 'Definition of kinematic variables'.

An observer variability study has been carried out to evaluate the accuracy of the measurements and to identify different types of error. Six different observers anallysed six sets of $x$-rays on six different occasions. The design and results of the observer variability study are presented in chapter 6: 'Observer variability'.

The collected data were statistically analysed as follows.

Significant differences between the patient groups with respect to age and gender were evaluated with a One Way Analysis of Variance and the Pearson Chi-square test, respectively.

The effect of age and gender on the values of observations on the de- 
fined variables was evaluated by calculating the Pearson correlation coefficient, and using the Independent t-test, respectively. The Pearson correlation coefficient was also calculated to evaluate the correlation between the values of observation of the respective kinematic variables. Significant differences between the study groups with respect to the values of observations on the respective variables was evaluated with a One Way Analysis of Variance and a Kruskal-Wallis test. All tests were run at a level of significance $\alpha=0.05$, tested double-sided.

The statistical techniques, mentioned above, are commonly used to evaluate kinematic studies of the spine. This customary approach, however, has thus far not resulted in the development of diagnostic tools with clinical significance for individual patients. For this reason, we called upon the procedure of logistic regression. This method enables the selection of a limited number of variables, which, as a subset, contain nearly all diagnostic information that is present in the study groups. The values of observations in the selected subsets of variables serve to calculate the probabilistic diagnosis for individual patients with respect to these study groups. A more detailed description is given in the paragraph 'Logistic regression procedure', see chapter 7: 'Evaluation of diagnostic performances of kinematic variables'. The number of correctly allocated subjects can be looked upon as a measure of the quality of the probabilistic diagnosis rule.

However, this study design is subject to a particular bias: the calculated diagnostic probability is partly based on information provided by the subject himself. A so-called split-sample method is used to eliminate this bias.

All measurements were performed by the author personally.

\section{Materials}

Function $x$-rays of four different groups of individuals are analysed kinematically. The kinematic data from the $x$-rays of the control group serve as a reference and are compared with the data of the patient groups. The following groups are analysed:

- control group $(n=112)$

- patients suffering from cervical myelopathy $(n=25)$

- patients with a hemiated disc at level $\mathrm{C}_{5}-\mathrm{C}_{6}(\mathrm{n}=28)$

- patients with a herniated disc at level $\mathrm{C}_{6}-\mathrm{C}_{7}(\mathrm{n}=48)$

All subjects were informed about the nature of the study and gave their informed consent. 


\section{Inclusion criteria}

\section{Control group}

The control group was accumulated over a two years period. The individuals from this group had never suffered from neck pain, cervical trauma, or from a radicular disorder of the upper extremities. They practised different occupations (e.g. construction workers as well as clerical employees) and were living in the region of Limburg and Brabant. They were not matched with the patient groups for age or gender.

\section{Cervical myelopathy group}

This patient group demonstrated the clinical signs and symptoms of cervical myelopathy. A detailed description of this syndrome is presented in the introduction to this section. Furthermore the patients met one or more of the following morphometric criteria:

- Sagittal diameter of the cervical canall less than $12 \mathrm{~mm}$ on plain $\mathrm{x}$-rays

- Reduction of the transverse area of the cervical spinal cord by at least one-third on CT-myelography or MRI

- Intramedullary hyperintense lesion(s) as a sign of myelomalacia on MRI

For the diagnosis of cervical myelopathy, surgical findings are not conclusive and have not, therefore, been used as inclusion criteria.

\section{Cervical herniated disc group}

These patients all presented with the clinical picture of cervical radiculopathy. The reader is referred to the introduction of this section for a detailed description of this clinical entity. The level of the herniated disc was determined on the basis of the clinical history, physical examination and radiological findings on plain $x$-ray or $\mathrm{CT}$, combined with $\mathrm{CT}$-myelography or MRI. The diagnosis of a herniated disc was confirmed by surgery. The patients were operated on using an anterior approach: perforation of the posterior longitudinal ligament was found in all cases as well as the presence of free disc fragments within the spinal canal.

Patients who suffered from a radicular disorder but met the radiological criteria of cervical myelopathy were classified in the category of cervical myelopathy.

The individuals from the patient groups visited the outpatient department of a neurosurgical clinic in 'Zuicl-Limburg' as a consecutive series over a five-year period. They were all operated on in the same hospital. 


\section{Exclusion criteria}

- herniated cervical discs at multiple levels $(n=1)$

- a previous operation on the cervical spine $(n=4)$

- function $x$-rays which did not meet the requirements set by the roentgenological protocol (e.g. no measuring coin present on the films $(n=6)$, no visualisation of $C_{6}$ and/or $C_{7}(n=10)$, function x-rays not representing the mid-sagittal plane $(\mathrm{n}=1))$

\section{METHODS}

\section{$X$-roy technique}

Lateral $x$-rays are taken with the patient in a standing position, carrying a weight of $5 \mathrm{~kg}$ in each hand in order to depress the shoulders and visualise the vertebral body of $\mathrm{C}_{7}$.

The anteflexion and retroflexion manoeuvre is performed actively (instruction for anteflexion: 'touch the chest with your nose'; instruction for retroflexion: 'look up and as far back as possible').

The focus-film distance is kept as close to constant as possible and varies between 70 and $96 \mathrm{~cm}$. The distance between the cervical spine and the $\mathrm{x}$-ray also varies to some degree, due to the varying width of the shoulders of the subjects. The central beam is focussed on level $\mathrm{C}_{3}-\mathrm{C}_{4}$. To enable correction for differences in magnification, a measuring coin (Dutch one-guilder piece; diameter $2.5 \mathrm{~mm}$ ) is fixed with tape to the midline of the patient's neck.

\section{Marking the x-raps [Fig. 44]}

On the lower cervical spine, the four corners of the vertebrall bodies and the anterior-superior and anterior-inferior corners of the spinous processes are marked.

The markings on $\mathrm{C}_{2}$ are placed on the inferior comers of the body; subsequently the odontoid process is marked with three points, one on the top, one on the anterior surface of the odontoid process and one on its posterior surface in such a way that the circle through these three points coincides as closely as possible with the superior outline of the odontoid. The anterior and posterior borders of $\mathrm{C}_{2}$ are now defined by the lines through the anterior-inferior point of the body anteriorly tangent to the circle representing the odontoid, and the line through the posterior-inferior point of the body posteriorly tangent to this same circle.

Markings on $\mathrm{C}_{1}$ are placed on the superior and inferior comers of the anterior and posterior arch, respectively. 

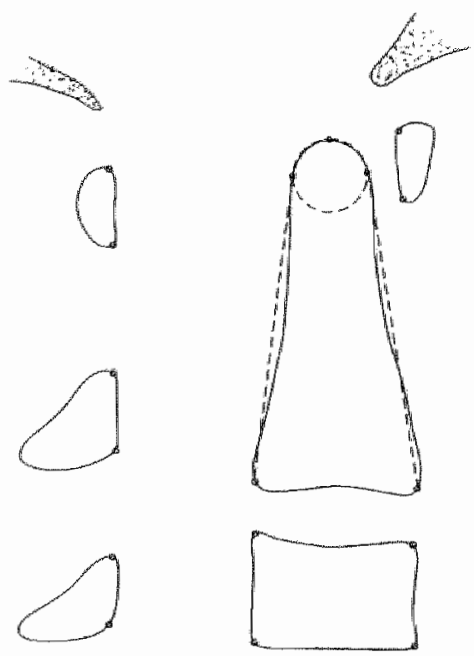

Fig. 44: mathing the $x$-rays

The skull is marked by three arbitrarily chosen points in the midline on one $x$-ray. These points are copied to the other $x$-ray by superimposing the pictures.

The measuring coin is marked at its maximum diameter. This diameter, relative to the known diameter of the coin, permits calculation of the magnification factor.

In all, 43 marking points are defined on each $x$-ray.

\section{Kinematic Anabyis System KAS}

KAS is a computerised Kinematic Analysing System with the following components: an IBM-compatible desktop computer (386 DX and up, 40 Mb harddisk and $2 \mathrm{Mb}$ RAM), a backlit digitiser with cursor (Graphtec digitiser, resolution $0.1 \mathrm{~mm}$ ) and software written in Fortran 5.1 for kinematic analyses of the cervical spine.

The measuring procedure is as follows. The $\mathrm{x}$-ray with the markings on it is taped to the digitiser. The cursor is positioned above the markings; their $\mathrm{x}$ - and $y$-co-ordinates are transmitted to the computer by push-button and are converted to a common co-ordinate system by equivalent transformation. The values of the variables are subsequently derived from the co-ordinates of the marking-points in each $\mathrm{x}$-ray by simple computation. 


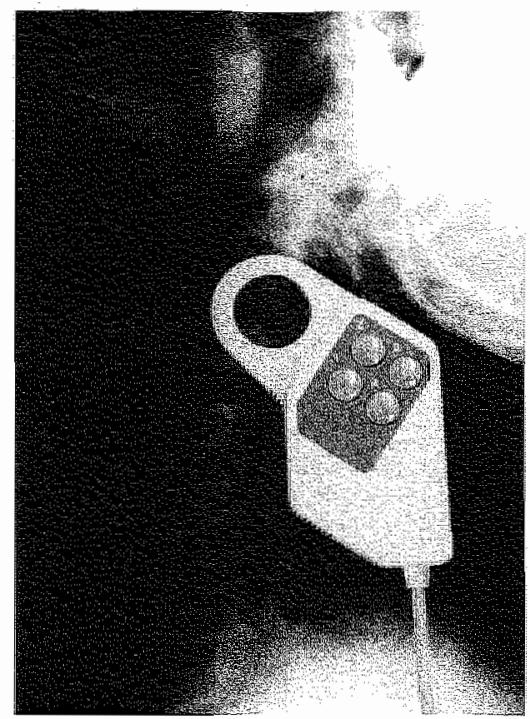

\section{Pholo 1: Finomatic Analysis System KAS}

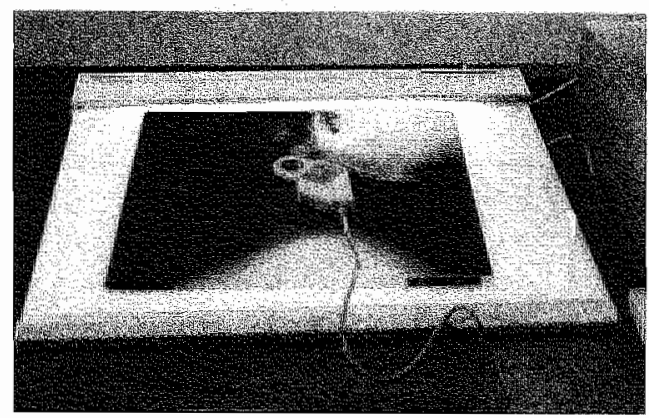

Defmition of kinematic variables

\section{Basic kinematic variables}

Disc angle

This is the angle between the line connecting the superior angular points of a vertebral body and the line connecting the inferior angular points of the vertebral body above it. This angle is called positive if it diverges to the ventral side and negative if it diverges to the dorsal side. [Fig. 45]

\section{Angle of rotation}

This is the difference between the disc angle in ante-versus retroflexion [ar]. The angle of rotation is called positive when the divergence of the disc angle increases to the ventral side on the retroflexion $x$-ray with respect to the anteflexion $x$-ray, and is negative in the opposite situation.

Fig. 45: dise angle $(=\alpha)$

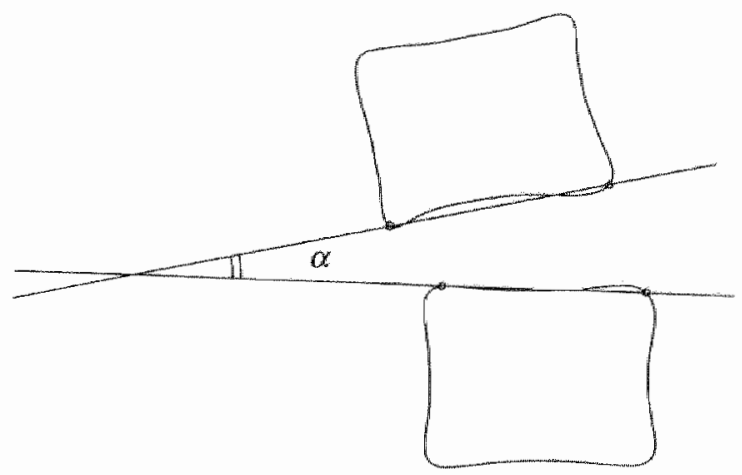




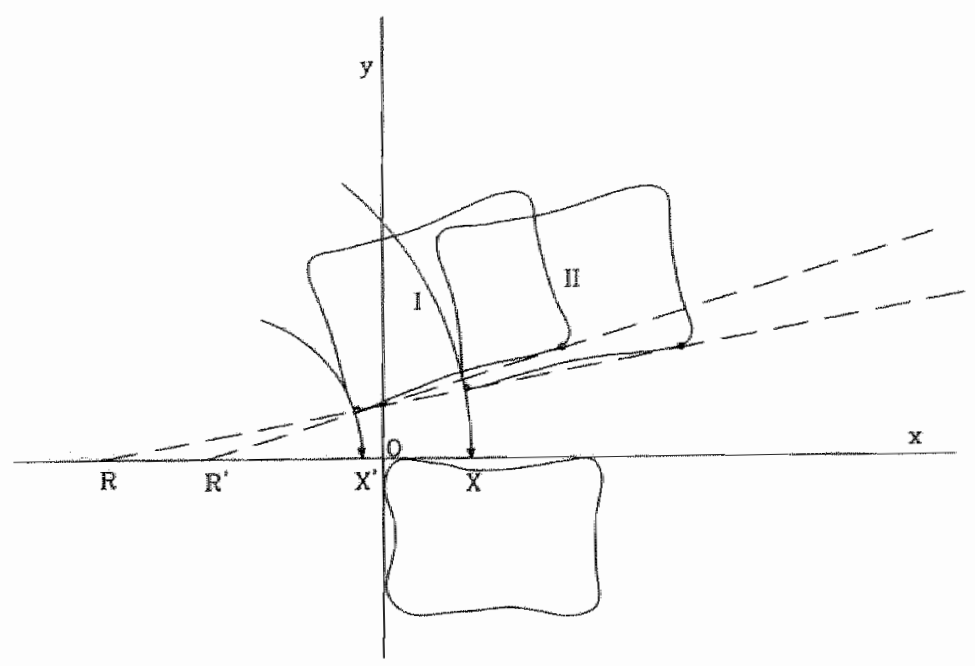

Fig. 46: Manslation $\left(X^{2}-X\right)$

Translation

Translation is defined as described by Hagelstam (1949).

Figure [46] presents the situation in which a vertebral body changes its position with respect to the underlying vertebral body from position (I) into position (II) . A co-ordinate system is projected with the $\mathrm{x}$-axis running through the upper border of the underlying vertebral body, the $y$ axis perpendicular to it. The origin $(O)$ is positioned in the dorsal corner of the body.

A perpendicular line from the dorsocaudal corner of the upper vertebral body in position $(I)$ intersects the $x$-axis at $\left(X^{\prime}\right)$. The distance $\left(O x^{\prime}\right)$ is called the relative displacement of body (I) with respect to the underlying body. In position (II), the relative displacement is $(\mathrm{Ox})$. The translation $[\mathrm{l}]$ of the body - shifting from position (I) to position (II) - is defined as the sum of the relative displacements, being $(X ' X)$. Relative values are given as a percentage of the length of the caudal border of the body (I).

Relative dise height

The method described by Berfelo (1989) was used. This method defines the disc height independent of the degree of rectangularity of the disc. The intervertebral disc is delineated by the superior border of a vertebral body and the inferior border of the adjacent body. Line (a) bisects the middle of the ventral and dorsal borders; line (b) bisects the middle of the superior and inferior borders of the disc. The intersection of line (a) and (b) is called the Mathematical Centre (MG) of the disc. The perpendicular to 
Fig. 47; disc height $(A-B)$

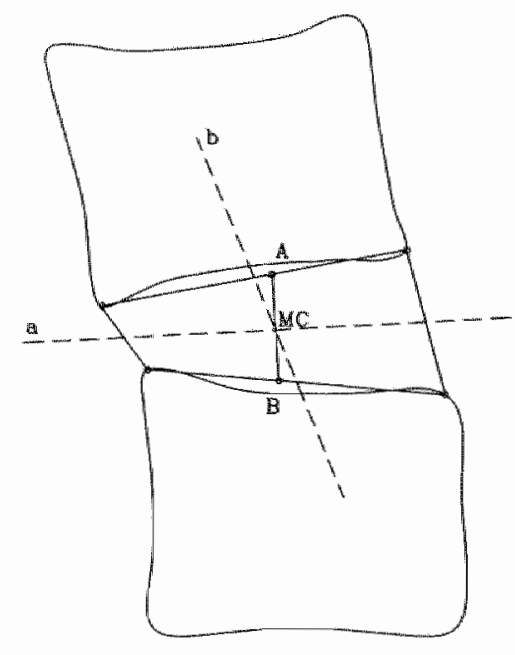

line (a) through MG intersects the superior border of the disc at (A) and the inferior border at $(B)$. The distance $(A B)$ is defined as disc height. To enable comparison of different disc heights from different patients, a relative disc height is given as a fraction of the length of the inferior border of the upper vertebral body for the anteflexion $\mathrm{x}$-ray $[d h l]$ and for the retroflexion $x$-ray, respectively [dh2]. [Fig. 47]

\section{R-Centre}

According to Euler's theorem, the displacement of a body in one plane being the result of combined linear and rotational displacements - can be described as if it is the result of pure rotation about one centre of rotation. This centre of rotation is called the Resultant-Centre of rotation or R-Centre. Rosenberg (1955) introduced this theorem in dinical practice, analysing kinematically function $x$-rays of the lumbar spine.

To detemine the $R$-Centre of a vertebral body in the anteflexion and retroflexion position with respect to the underlying vertebral body (thus in one motion segment), the function $x$-rays are positioned in such a way that the lower vertebral bodies become superimposed. Then, at least two markings on the body in anteflexion are connected with the corresponding points of the body in the retroflexion position. Perpendicular bisectors of these connecting lines intersect in one point, the R-Centre $/ F \mathrm{~g} .487 . \mathrm{A}$ co-ordinate system is projected with the x-axis running through the upper comers of the lower vertebral body of the motion segment, the $y$-axis perpendicular to it. The origo is positioned in the dorsal corner of the verrebral body. The $\mathrm{x}$ - and $\mathrm{y}$-co-ordinates of the R-Centre $[x R$, and $y R]$ are given as fractions of the caudal border of the upper vertebral body. 


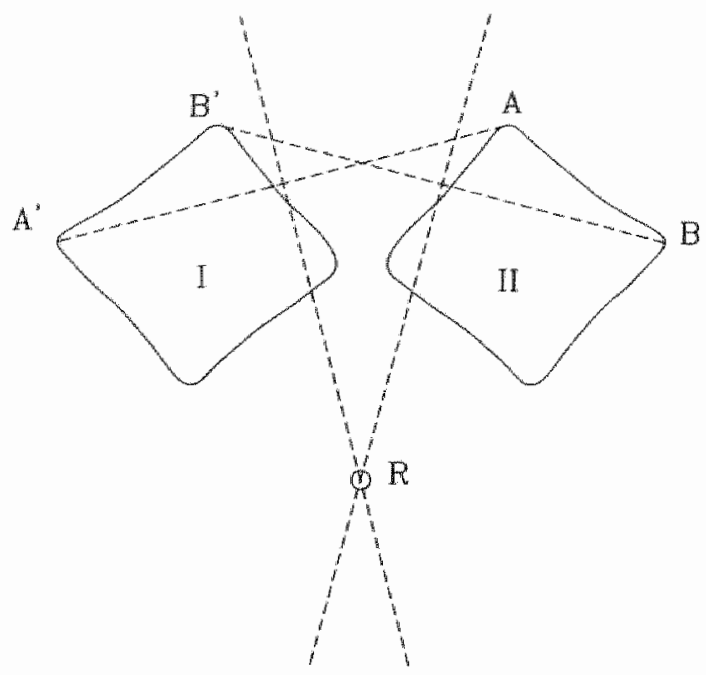

Fig. 48:R-Centure

The kinematic information, provided by an R-Centre, is related to one single motion segment only. Each R-Centre is positioned in its own coordinate system and thus cannot provide information about the complete cervical spine. To improve upon this basic limitation of commonly determined R-Centres, a new kinematic variable is defined, the R-Centre- $\mathrm{C}_{7}$.

\section{R-Centre-C7}

For each vertebral body, the difference between the anteflexion and retroflexion posture is determined with respect to a common reference, namely $C_{7}$, in essentially the same way as $\mathrm{R}$-Centres are determined in the individual motion segments. $A$ co-ordinate system is projected with the $\mathrm{x}$-axis running through the upper corners of the vertebral body of $\mathrm{C}_{7}$ the $y$-axis perpendicular to it. The origo $(O)$ is positioned in the ventral comer of the body.

The $\mathrm{x}$-co-ordinates $[x R 7]$ are given as fractions of the caudal border of the vertebral body $\mathrm{C}_{6}$; the $\mathrm{y}$-co-ordinates $[p R 7]$ of the respective $\mathrm{R}$-Centres- $\mathrm{C}_{7}$ are given as fractions of the length of the spine (length cervical spine is defined as the distance from the superior border of $\mathrm{C}_{6}$ up to the inferior border of $\left.\mathrm{C}_{2}\right)$. The $\mathrm{x}$ - and $y$-co-orclinates of the $\mathrm{R}$-Centres with respect to vertebral body $\mathrm{C}_{7}$ are defined in one co-ordinate system and can thus be interrelated. The line that connects the R-Centres- $C_{\text {, }}$ is called the R-Zero line [Fig. 49] which represents the kinematic mid-position of the cervical spine between anteftexion and retroflexion with respect to $\mathrm{C}_{7}$, representing the situation in which the cervical spine as a whole has consumed half the amount of rotations and linear displacements required to carry out the anteffexion-retroftexion manoeuvre (Berfelo, 1989). 
Fis. 19: the the contecting the $R$ Centres of the respective atertedral bodies with respect to $C_{7}$ is called the R-Zorw line.

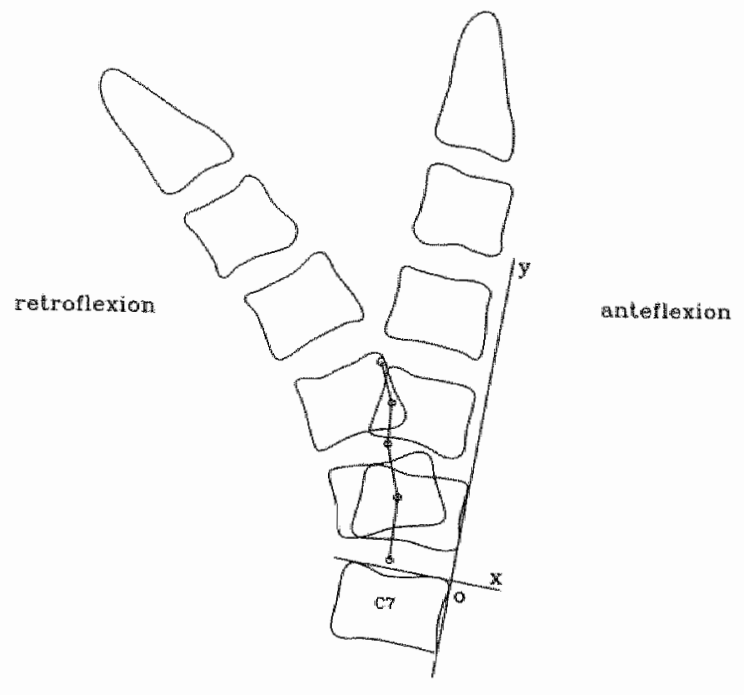

Dynamic diameter

Distance between the superior angular point of an arch and the inferior angular point of the adjacent vertebral body. These diameters are given in absolute values, for both the anteflexion and retroflexion $x$-rays as $[d d I]$ and $[d d 2]$, respectively [Fig. 50].

Fig. 50: dynomic diameter (on antefexion $A-B$, in retroftemion $\left.A-B^{3}\right)$

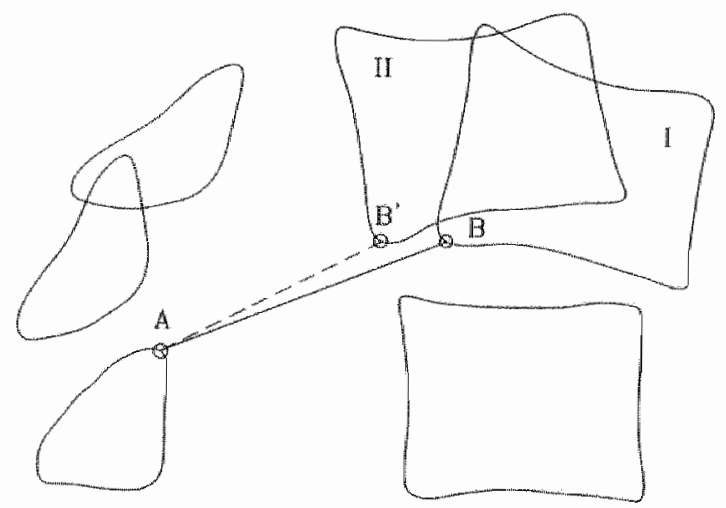

The dynamic diameter of the spinal canal at level $\mathrm{C}_{1}-\mathrm{C}_{2}$ is defined as the shortest distance between the inferior corner of the dorsal arch of $\mathrm{C}_{1}$ and the posterior dorsal border of the odontoid process [Fig. 51]. 


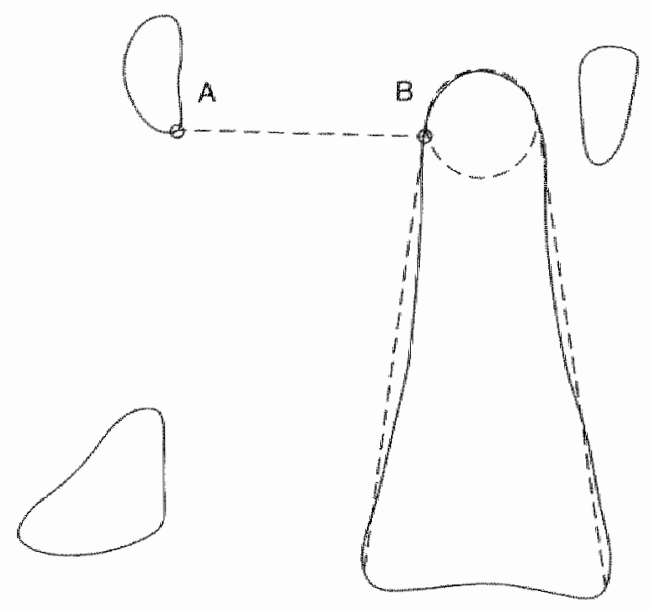

Fig. 51: dymamic dameter (A-B)

Static diameter

Distance between superior angular point of the spinous process and the posterior-superior angular point of the vertebral body is called the cranial static diameter $[s d h]$. The distance between the inferior angular point of the spinous process and posterior-inferior angular point of the vertebral body is also measured as the caudal static diameter $[s d l]$. These diameters are given in absolute values for the anteflexion x-ray only. [Fig. 52$]$

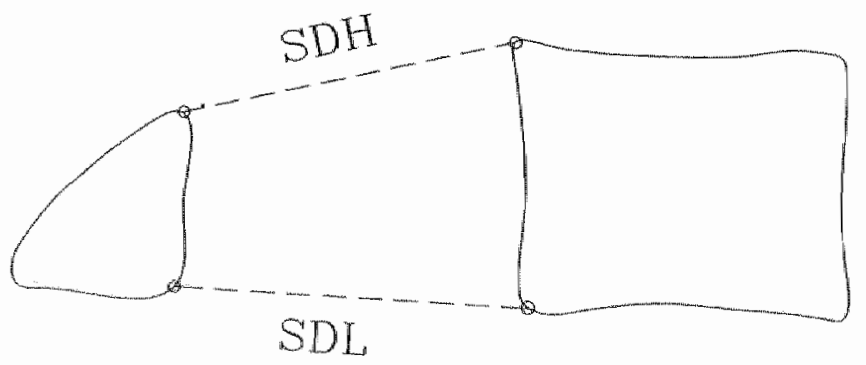

fory. 52: static dianneter

Adanto-axial distance

This is the shortest distance between the dorsal border of the ventral arch of $\mathrm{C}_{1}$ and the line, which delineates the ventral border of $\mathrm{C}_{2}$. These distances are given in absolute values ( $\mathrm{mm}$ ), of both the anteflexion and retroflexion $x$-rays, as [aal] and [aa2], respectively. [Fig. 53] 
Fig- 53: alanto-axial distance

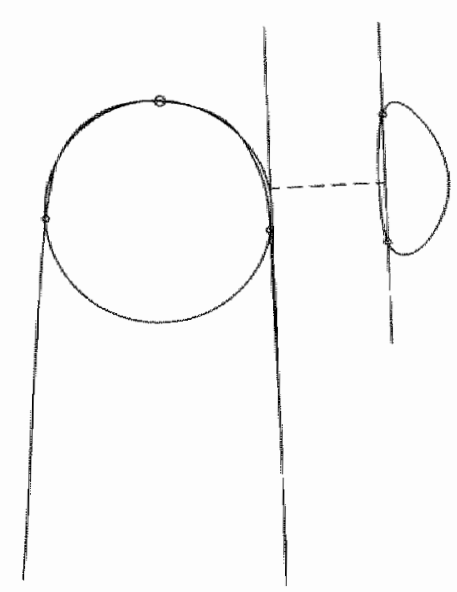

\section{Derized kinematic variables}

To gain insight into the kinematic behaviour of the spine, it is customary to study individual motion segments. By doing so, one disregards the fact that the spine behaves as an integrated chain of motion segments and as a complete structure. This might be one reason why kinematic studies of motion segments have not resulted in the development of diagnostic tools for individual patients. Berfelo (1989), on the other hand, demonstrated in lumbar spine motion studies that combinations of variables, which also describe the spine as an integrated structure, do have diagnostic significance for individual patients.

To characterise the cervical spine as an integrated structure, the variable $\mathrm{R}-\mathrm{Centre}_{\mathrm{f}} \mathrm{C}_{\mathrm{j}}$ was introduced as described previously. In the next paragraph so-called derived kinematic variables will be defined, which also reflect the integrated structure of the cervical spine.

\section{Sum variables}

The following sum variables are defined:

- Sum rotation $[$ Sum ar]: sum of the angles of rotation within the individual motion segments $\mathrm{C}_{6}-\mathrm{C}_{7}$ up 10 and including $\mathrm{C}_{0}-\mathrm{C}_{1}$

- Sum translation [Stom $\mathrm{kr}$ : sum of the translations within the individual motion segments $\mathrm{C}_{6}-\mathrm{C}_{7}$ up to and including $\mathrm{C}_{0}-\mathrm{C}_{1}$

- Sum disc heights in anteflexion [Sum dhl]: sum of disc heights of the segments $\mathrm{C}_{6}-\mathrm{C}_{7}$ up to and including $\mathrm{C}_{2}-\mathrm{C}_{3}$ in anteflexion

- Sum disc height in retroflexion /Sum dh2]: sum of disc heights of the segments $\mathrm{C}_{6}-\mathrm{C}_{7}$ up to and including $\mathrm{C}_{2}-\mathrm{C}_{3}$ in retroflexion

- Sum superior static diameter [Sum sdh]: sum of superior static sagital diameters of $\mathrm{C}_{6}$ up to and including $\mathrm{C}_{2}$

- Sum inferior static diameter /Sum sdl]? sum of inferior static sagittal diameters of $\mathrm{C}_{6}$ up to and including $\mathrm{C}_{2}$ 
- Sum dynamic diameter in anteflexion [Sum dd/]: sum of dynamic diameters in anteflexion of segments $\mathrm{C}_{3} \mathrm{C}_{3}$ up to and including $\mathrm{C}_{1}-\mathrm{C}_{2}$

- Sum dynamic diameter in retroflexion /Sum dd27: sum of dynamic diameters in retroflexion of segments $C_{6}-C_{7}$ up 10 and including $C_{1}-C_{2}$

\section{Cluster variables}

Van Mameren (1988) found distinct kinematic patterns in different parts of the cervical spine using cinematographic techniques. Due to its nature, the present study is unable to describe sequences of motion in individual motion segments or pairs of motion segments. However, the graphic representations of the mean values of the kinematic variables in the study groups suggest distinct patterns in different parts of the cervical spine Graphs 1-13, Appendix II). Therefore, the following clusters of variables were defined for further evaluation:

- Sum rotation of segments $\mathrm{C}_{1}-\mathrm{C}_{2}$ and $\mathrm{C}_{0}-\mathrm{C}_{1}$ /SmarCo-2]

- Sum rotation of segments $\mathrm{C}_{2}-\mathrm{C}_{3}$ up to and including $\left.\mathrm{C}_{0}-\mathrm{C}_{1} / 5 \operatorname{mar} C O-3\right]$

- Sum rotation of segments $\mathrm{C}_{6}-\mathrm{C}_{7}$ up to and including $\mathrm{C}_{2}-\mathrm{C}_{3} /$ Smar $\mathrm{C} 3-6$ )

- Sum of x-co-ordinates of R-Centres of $\mathrm{C}_{2}$ up to and including $\mathrm{C}_{0}$ with respect to $\left.\mathrm{C}_{7} / S m R 7 \times 0-2\right]$

- Sum of $x$-co-ordinates of $R$-Centres of $\mathrm{C}_{5}$ up to and including $\mathrm{C}_{2}$ with respect to $\left.\mathrm{C}_{7} / \operatorname{Sm} R 7 \times 2-5\right\rangle$

- Sum of $\mathrm{x}$-co-ordinates of $\mathrm{R}$-Centres of $\mathrm{C}_{5}$ and $\mathrm{C}_{6}$ with respect to $\mathrm{C}_{7}$ $\operatorname{Sin} R 7 \times 5-67$

- Sum of $y$-co-ordinates of R-Gentres of $\mathrm{C}_{2}$ up to and including $\mathrm{C}_{0}$ with respect to $\mathrm{C},[\mathrm{SmR} 7 y 0-2]$

- Sum of y-co-ordinates of R-Centres of $\mathrm{C}_{5}$ up to and including $\mathrm{C}_{2}$ with respect to $\mathrm{C}_{7} / \mathrm{SmR7y2-5]}$

- Sum of y-co-ordinates of $R$-Centres of $C_{5}$ and $C_{6}$ with respect to $C_{7}$ SmR7) $5-6]$

- Sum ranslation of $\mathrm{C}_{2}$ up to and including $\mathrm{C}_{0} / \operatorname{Sm} \operatorname{TrCO-2]}$

- Sum translation of $\mathrm{C}_{6}$ up to and including $\left.\mathrm{C}_{3} / \operatorname{Sm} \operatorname{Tr} \mathrm{C} 3-6\right]$

Ravio variables

Pathology is often characterised by unequal distribution of motion amongst the successive segments (Aho et al., 1955; Berfelo, 1989; Holmes et al., 1994). Therefore, the following ratio variables were defined:

- Segmental rotation /ar/ expressed as a fraction of the sum-rotation $/ \mathrm{sr}$ :

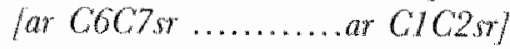

- Segmental rotation /ar] expressed as a fraction of the rotation in the adjacent upper segment

Cangle of rotation $C_{6}-C_{7}$ with respect to $C_{5}-C_{6}$ is given as far $C 67 C .567$, etc)

Another ratio mentioned in the literature is the segmental translation versus rotation. This variable was propagated because of its low observer variability (Dvorak, 1991). 
- Translation-rotation ratios of $\mathrm{C}_{6}-\mathrm{C}_{7}$ up to and including $\mathrm{C}_{0}-\mathrm{C}_{1}$ : [trar6] [trarl]

Sources of error in the radiographic representation of the cenvical spine on $x-r o y s$ Ideally, a lateral $x$-ray should represent the mid-sagittal projection of the cervical spinal canal. Due to variations in the anatomical architecture (e.g. scoliosis) and due to deviations from the mid-sagittal plane during the anteflexion and retroftexion manoeuvre, such an ideal x-ray will never be obtained. The projection of the vertebral bodies is also dependent on the spatial relationship between the x-ray tube, subject and film, which may change between the two exposures.

Correction of errors in the radiographic presentation of the cervical spine It is impossible to correct all errors mentioned above. However, assuming that the anteflexion $\mathrm{x}$-ray is correct, a relative correction of differences in wedge-shape and magnification of the vertebral bodies on the retroflexion $x$-ray is feasible. Berfelo (1989) described these mathematical correction techniques extensively. The same techniques are used in the present study. 



\section{Chapter 6. \\ Observer variability}

\section{INTRODUCTION}

The results of diagnostic procedures are dependent on various factors, including the methods applied. In imaging techniques, the technique itself as well as the interpretation are liable to observer variability and may diminish the reliability of diagnostic procedures (Yerushalmy et al., 1950; Garland, 1959; Adams et al., 1969; Andersson et al., 1981; Saraste et al., 1985; Deyo et al., 1985; Frymoyer et al., 1986; Wilmink et al., 1988).

Variation will be present when one and the same $\mathrm{x}$-ray is interpreted by different observers: so-called inter-observer variability. Variation will also be present when one observer analyses the same $\mathrm{x}$-ray on different accasions: so-called intra-obsenver variability.

An observer variability study quantifies the accuracy of the measuring procedure, enabling comparison with other measuring techniques. To gain insight into the extent of the observer variability in this study, six observers marked and measured the function $x$-rays of the cervical spine of six different patients on six different occasions. To gain insight into the impact of the observer variability on the measured values of variables this variability is given as a fraction of the total spread of the measured values of the variables in the population. This approach enables furthermore the comparison of the results of the present study with the results obtained likewise in a kinematic study of the lumbar spine (Berfelo, 1989).

"The impact of observer variability on the clinical relevance of the successive kinematic variables will be addressed in the paragraph 'Discussion' at the end of this chapter.

\section{METHODS}

All x-rays were made following a strict protocol, by a team of two radiologists and two radiographers. The procedure was standardised as far as possible with respect to the radiographic technique, film format, film type, developing process, distance between $x$-ray tube and film, direction of the central beam, positioning of the patient and postures to be photographed.

From a total number of 80 sets of function $x$-rays ( 40 from healthy individuals and 40 from patients with brachialgia and/or spinal cord symptoms), six sets were randomly selected for further analysis. In retrospect, 
it was found that three sets belonged to healthy individuals and the other three sets to patients.

Six different observers analysed these six sets six times with an interval of at least wo hours. Four observers were familiar with the interpretation of $x$-rays (two radiologists, one neurosurgeon, and one neurologist); the other wo observers were a civil engineer and a medical student. All observers were instructed according to the guidelines described in the paragraph "Marking the x-rays" in chapter 5: "Present study design".

The anteflexion-and retroflexion $x$-rays were taped on the backlit digitiser and covered with a transparent sheet. The observer marked the previously described 43 lancmarks on the transparent foil, recorded these markings with the cursor, and transmitted them to the computer. In this way, each set of $x$-rays was marked and recorded six times by each observer, on six different occasions.

On the supposition that the measured $x$-rays are selected at random and that the observers are a representative sample from a larger pool of observers, a Two-Way Analysis of Variance with random effect (ANOVA) can be used to calculate the variance of observation.

In a statistical model, the true value ( $T$ ) of a variable is the hypothetical mean value of an infinite number of observations on that specific variable. When $h$ observations are made by $j$ observers $\left(O_{j}\right)$ on $i$ patients $(P)$ under conditions which are as close to being uniform as possible, the measured value, $\mathrm{X}$, will differ to some extent from the overall mean value, $T$ (Kleinbaum et al, 1988):

$$
X=T+P_{i}+O_{j}+P_{i j}+E_{i j}
$$

(P) is the patient man effect. This effect can be looked upon as the mean deviation of the $i$-th patient with respect to the global nean. The distribution is assumed to be nomal with zero as mean and with $\sigma^{2}$ patman as variance.

(O) is the observer main ffect and can be looked upon as the mean deviation of the $j$-th observer with respect to the global mean. The distribution is assumed to be normal with zero as mean and $\sigma^{2}$ ansin as variance.

$\left(\mathrm{PO}_{i j}\right)$ is the effect of interaction. This interaction effect describes the mean difference of observer $\left(O_{j}\right)$ when measuring patient $\left(\mathbf{P}_{i}\right)$ with respect to the global mean, after correction for the patient main effect and observer main of fect. This interaction effect deals with the situation in which observers may 
make errors when measuring a specific patient (so-called patient-related errors). The distribution of this interaction effect is assumed to be normal with zero as mean and $\sigma^{2}$ pw as variance.

$\left(\mathrm{E}_{i j}\right)$ is the enror or intra-obsenter effect; it can be looked upon as an estimate of the error that will result after correction for the three effects mentioned before $\left(\left(\mathrm{P}_{\mathrm{j}}\right),\left(\mathrm{O}_{\mathrm{i}}\right),(\mathrm{PO}, \mathrm{j})\right)$. This error will occur when one observer measures one patient several times, and is called the intra-observer effect. The distribution of this error or intra-obsener effect is assumed to be nomal with zero as mean and $\sigma^{2}{ }_{i m m a}$ as variance.

The four random variables $\left(\mathrm{P}_{i}\right),\left(\mathrm{O}_{j}\right),(\mathrm{PO}$,$) and \left(\mathrm{E}_{i j}\right)$ are assumed to be mutually independent.

The total variance of the measured value $(X)$ is given by the equation (Kleinbaum et al., 1988):

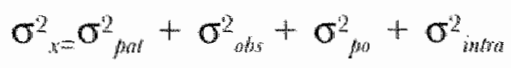

The diagnostic value of a variable is determined by various factors including the signal-to-noise ratio. The signal is the patient-effect described by $\sigma_{\text {patt }}^{2}$. The noise is caused by the measuring procedure itself, and results in both an inter- and intra-observer effect, described by the respective variances.

The intra-obsever variance is represented by: $\sigma^{2}$ iutra

The inter-obsener vaniance is represented by: $\sigma^{2}{ }_{\text {imer }}$; $\sigma_{\text {inter }}^{2}=\sigma_{\text {sids }}^{2}+\sigma^{2}$

The variance of the measurement noise, $\sigma^{2}$ masaswranent mases, is given as:

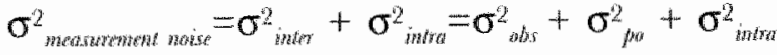

The proportion of the variance of an observation, due to intra-observer variability, will be represented by $\left(\mathrm{P}_{\mathrm{ini}}\right)$; and the proportion of the variance of an observation, due to inter-observer variability, by $\left(\mathrm{P}_{\text {incer }}\right)$. The proportion of the variance of an observation due to the total observer variability is given as $\left(\mathrm{P}_{\text {intratinter }}\right)$. 


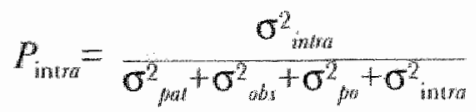

$$
\begin{aligned}
& P_{\text {inter }}=\frac{\sigma^{2}+\sigma_{p o s}^{2}}{\sigma_{p a t s}^{2}+\sigma_{b b s}^{2}+\sigma_{p o}^{2}+\sigma_{\text {irrotza }}^{2}}
\end{aligned}
$$

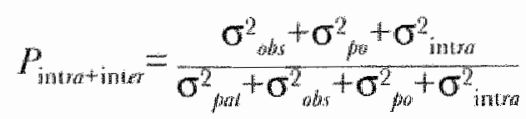

\section{RESULTS}

\section{Observer zariability of the basic kinematic tariables}

Table IV presents $\left(\mathrm{P}_{\text {inta }}\right),\left(\mathrm{P}_{\text {inter }}\right)$, and $\left(\mathrm{P}_{\text {intratinter }}\right)$ of the basic variables.

Intra-observer variability of basic wariables

The mean value for $\left(\mathrm{P}_{\text {intia }}\right)$ of the measured values of all basic variables is 0.33 , meaning that approximately $1 / 3$ of the total variance of observations is the result of intra-observer variability. The dynamic diameter in anteflexion at level $\mathrm{C}_{1}-\mathrm{C}_{2}$ [ddl $\left.\quad \mathrm{C} 1 \mathrm{C} 2\right]$ shows the lowest value of ( $\mathrm{P}_{\text {intrat }}$ ) (0.06); the highest value of $\left(\mathrm{P}_{\mathrm{intr}}\right),(0.98)$, is found for the $\mathrm{x}$-co-ordinate of the intersegmental $\mathrm{R}$-centre at level $\mathrm{C}_{1}-\mathrm{C}_{2}[\times \mathrm{R}$ ClC2]

The intra-observer variability for the $\mathrm{x}$ - and $\mathrm{y}$-co-ordinates of the rotation centres determined in the individual motion segments ( $[\mathrm{xR}]$ and $[y R]$, respectively) is somewhat thigher than the overall mean value of $\left(\mathrm{P}_{\text {inman }}\right)$ : mean value $\left(\mathrm{P}_{\text {intra }}\right)[\mathrm{xR}]$ is 0.51 ; mean value $\left(\mathrm{P}_{\mathrm{imra}}\right)[\mathrm{yR}]$ is 0.64 . However, the $x$ - and $y$-co-ordinates of the rotation centres determined with respect to $\mathrm{C}_{7}$ ( $[\mathrm{xR} 7]$ and [yR7], respectively) show higher accuracy: mean value $\left(\mathrm{P}_{\text {inera }}\right)[x R 7]$ is 0.23 and mean value $\left(\mathrm{P}_{\text {imtra }}\right)[y R 7]$ is 0.40 .

The $\left(\mathbf{P}_{\text {inta }}\right)$ of the variable atlanto-axial distance in anteflexion [aal] and retroflexion [aa2] is 0.50 and 0.37 , respectively.

\section{Inter-observer variability of basic variables}

$\left(P_{\text {imer }}\right)$ presents the proportion of the variance of observations due to inter-observer variability. The mean value for $\left(P_{\text {imer }}\right)$ is 0.14 , meaning that approximately $1 / 7$ of the total variance of observations is due to inter-observer variability. The highest $\left(\mathrm{P}_{\text {inter }}\right)$ values $(0.5)$ are found for dise height at level $\mathrm{C}_{4}-\mathrm{C}_{5}$ measured in anteflexion [ $\mathrm{dh} \cdot \mathrm{C} 4 \mathrm{C} 5$ ]; the lowest values $(<0.01)$ are found for the $x$ - and $y$-co-ordinate of the intersegmental R-Centres at level $\mathrm{C}_{1}-\mathrm{C}_{2}$ [xR ClC2] and [y $\mathrm{ClC2}$ ].

The variables, angle of rotation [ar], translation [tr], dynamic diameter 
$[d d]$, static diameter $[\mathrm{sd}]$, and $\mathrm{x}$ - and $\mathrm{y}$-co-ordinates of the rotation centres of both the individual motion segments and of the vertebral bodies with respect to $C_{7}([x R],[y R],[x R 7]$ and $[y R 7])$ are far less subject to inter-observer variability than the disc height [dh], and atlanto-axial distance [aa].

The inter-observer variation for the $x$ - and $y$-co-ordinates of rotation centres determined in the inclividual motion segments and with respect to $\mathrm{C}_{7}$ show even smaller values than the overall mean value of $\left(\mathrm{P}_{\text {mer }}\right)$ (mean value $\left(\mathrm{P}_{\text {inter }}\right)[\mathrm{xR}]$ is 0.04 ; mean value $\left(\mathrm{P}_{\text {iner }}\right)[\mathrm{y}]$ is 0.12 ; mean value $\left(\mathrm{P}_{\text {inter }}\right)[x R 7]$ is 0.04 and mean value $\left(P_{\text {imeer }}\right)$ [yR7] is 0.07).

The $\left(P_{\text {inner }}\right)$ of the variable atlanto-axial distance in anteflexion and retroflexion is 0.37 and 0.3 , respectively.

Total observer variability or variance of measurement noise of basic variables

The proportion of the variance of an observation due to the total observer variability or measurement noise is ( $\mathrm{P}_{\text {intratimex }}$ ). The mean value for $\left(\mathrm{P}_{\text {inuatimier }}\right)$ is 0.46 , meaning that approximately half of the total variance of observations can be explained by measurement noise. Highest values of $\left(\mathrm{P}_{\text {imratinier }}\right)(0.98)$ are found for the $\mathrm{x}$-comrlinate of the intersegmental $\mathrm{R}$ centre at level $\mathrm{C}_{1}-\mathrm{C}_{2}[\mathrm{xR} \quad \mathrm{C} 1 \mathrm{C} 2]$; the lowest values $(0.12)$ are found for the dynamic diameter in anteflexion at level $\mathrm{C}_{1}-\mathrm{C}_{2}$ [ddl $\mathrm{C}$ 1 C2]. The $\left(P_{\text {intratinter }}\right)$ for the $x$ - and $y$-co-ordinates of rotation centres determined in the individual motion segments is somewhat higher than the overall mean value of $\left(\mathrm{P}_{\text {intratintex }}\right)$ : mean value $\left(\mathrm{P}_{\text {innat inter }}\right)[\mathrm{xR}]$ is 0.56 and the mean value $\left(\mathrm{P}_{\text {intratinic }}\right)[\mathrm{yR}]$ is 0.76 . The measurements of the $\mathrm{x}$ - and $\mathrm{y}$-co-ordinates of the rotation centres determined with respect to $\mathrm{C}_{7}$, however, show better results: mean value $\left(\mathrm{P}_{\text {intrat inte }}\right)[\times R 7]$ is 0.27 and mean value $\left(\mathrm{P}_{\text {intratimer }}\right)[\mathrm{yR} 7]$ is 0.47 . The measurements of the diameter of the cervical spinal canal also show better results: the mean $\left(P_{\text {intratintes }}\right)$ of the $d y$ namic diameter [dd] is 0.28 for both the ante- and retroflexion posture; the $\left(\mathrm{P}_{\text {intratinten }}\right)$ of the static diameter [sd] is 0.33 .

The $\left(\mathbb{P}_{\text {intratimer }}\right)$ of the variable atlanto-axial distance in anteflexion and retroflexion is 0.87 and 0.66 , respectively. 


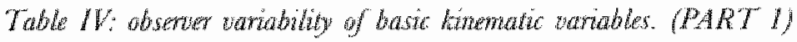

Basic kinematic Pintra+inter Pintra
variables

Angle of rotation
ar $\mathrm{COC} 1$
ar $\mathrm{C} 1 \mathrm{C} 2$
ar $\mathrm{C} 2 \mathrm{C3}$
ar $\mathrm{C} 3 \mathrm{C} 4$
ar $\mathrm{C} 4 \mathrm{C5}$
ar $\mathrm{C} 5 \mathrm{C} 6$
ar $\mathrm{C} 6 \mathrm{C} 7$

0.22

0.19

0.03

0.77

0.56

0.20

0.36

0.29

0.07

0.47

0.46

0.02

0.13

0.10

0.03

0.45

0.38

0.51

0.43

0.07

0.08

Disc height in anteflexion

$\begin{array}{llll}\text { dh1 } \mathrm{C} 2 \mathrm{C} 3 & 0.57 & 0.24 & 0.32 \\ \text { dh1 } \mathrm{C} 3 \mathrm{C} 4 & 0.23 & 0.09 & 0.14 \\ \text { dh1 C4C5 } & 0.80 & 0.31 & 0.50 \\ \text { dh1 C5C6 } & 0.52 & 0.20 & 0.32 \\ \text { dh1 C6C7 } & 0.39 & 0.22 & 0.17\end{array}$

Disc height in retroflexion

dh2 $\mathrm{C} 2 \mathrm{C} 3$

0.65

0.34

0.31

dh2 $\mathrm{C} 3 \mathrm{C} 4$

0.34

0.15

0.20

dhe $\mathrm{C4C5}$

0.52

0.24

0.29

dh2 $\mathrm{C} 5 \mathrm{C} 6$

0.85

0.40

0.45

dhe $\mathrm{C} 6 \mathrm{C} 7$

0.15

0.09

0.06

Translation

ir $\mathrm{COC} 1$

tr $\mathrm{C} 1 \mathrm{C2} 2$

0.68

0.35

0.33

tr $\mathrm{C}_{2} \mathrm{C}_{3}$

0.63

0.48

0.15

tr $\mathrm{C}_{3} \mathrm{C} 4$

0.50

0.38

0.12

tr $\mathrm{C} 4 \mathrm{C} 5$

0.35

0.30

0.05

tr $\mathrm{C} 5 \mathrm{C} 6$

0.28

0.26

0.02

0.62

0.50

0.73

0.68

0.13

0.05

Fotation Centre of a motion segment, $x$-co-ordinate

$\begin{array}{llll}\times R C O C 1 & 0.96 & 0.89 & 0.07 \\ \times R C 1 C 2 & 0.98 & 0.98 & 0.00 \\ \times A C 2 C 3 & 0.75 & 0.72 & 0.02 \\ \times A C 3 C 4 & 0.21 & 0.18 & 0.03 \\ \times R C 4 C 5 & 0.28 & 0.24 & 0.04 \\ \times R C 5 C 6 & 0.20 & 0.17 & 0.03 \\ \times R C 6 C 7 & 0.51 & 0.40 & 0.11\end{array}$

Fotation Centre of a motion segment, $y$-co-ordinate

$y R \mathrm{COC}_{1}$

yR $\mathrm{C} 1 \mathrm{C2}$

yR $\mathrm{C}_{2} \mathrm{C} 3$

yR C $3 C 4$

yR $\mathrm{C} 4 \mathrm{C5}$

y $\mathrm{R}$ C5C6

yR $\mathrm{CGC7}$
0.94

0.93

0.86

0.53

0.70

0.59

0.76
0.82

0.93

0.70

0.44

0.56

0.40

0.64
0.12

0.00

0.16

0.09

0.14

0.19

0.11 
Table W. obserwer variabilib of basic himomatic nariabler. (PART 2)

\begin{tabular}{l}
$\begin{array}{l}\text { Basickinematic } \\
\text { variables }\end{array}$ \\
\hline
\end{tabular}

Rotation Centre with respect to $C_{7 *} \times$ co-ordinate

$\begin{array}{llll}\text { XR7 C0 } & 0.19 & 0.14 & 0.05 \\ \times R 7 \mathrm{C1} & 0.17 & 0.13 & 0.05 \\ \text { XR7 C2 } & 0.15 & 0.11 & 0.04 \\ \text { XR7 C3 } & 0.14 & 0.11 & 0.04 \\ \text { XR7 C4 } & 0.15 & 0.11 & 0.04 \\ \text { XR7 C5 } & 0.18 & 0.13 & 0.05 \\ \text { XR7 C6 } & 0.95 & 0.93 & 0.02\end{array}$

Rotation Centre with respect to $C_{7}, y$-co-ordinate

$\begin{array}{llll}\text { yRT CO } & 0.41 & 0.29 & 0.12 \\ \text { yRT C1 } & 0.39 & 0.35 & 0.04 \\ \text { yRT C2 } & 0.67 & 0.57 & 0.10 \\ \text { yRT C3 } & 0.43 & 0.37 & 0.06 \\ \text { yRT C4 } & 0.44 & 0.35 & 0.09 \\ \text { yR7 C5 } & 0.26 & 0.20 & 0.06 \\ \text { yR7 C6 } & 0.71 & 0.69 & 0.02\end{array}$

Dynamic diameter in anteflexion

$\begin{array}{llll}\text { dd1 } \mathrm{C} 1 \mathrm{C} 2 & 0.12 & 0.06 & 0.06 \\ \text { dd1 } \mathrm{C} 2 \mathrm{C} 3 & 0.35 & 0.22 & 0.14 \\ \text { dd1 } \mathrm{C} 3 \mathrm{C} 4 & 0.35 & 0.23 & 0.12 \\ \text { dd1 } \mathrm{C} 4 \mathrm{C} 5 & 0.40 & 0.25 & 0.15 \\ \text { dd1 } \mathrm{C} 5 \mathrm{C} 6 & 0.32 & 0.24 & 0.08 \\ \text { dd1 } \mathrm{C} 6 \mathrm{C} 7 & 0.23 & 0.17 & 0.06\end{array}$

Dynamic diameter in retroftexion

$\begin{array}{llll}\text { dd2 } \mathrm{C} 1 \mathrm{C} 2 & 0.21 & 0.13 & 0.08 \\ \text { dd2 } \mathrm{C} 2 \mathrm{C} 3 & 0.36 & 0.23 & 0.13 \\ \text { dd2 } \mathrm{C} 3 \mathrm{C} 4 & 0.26 & 0.17 & 0.09 \\ \mathrm{dd2} \mathrm{C} 4 \mathrm{C5} & 0.26 & 0.17 & 0.08 \\ \mathrm{dd2} \mathrm{C5C6} & 0.27 & 0.19 & 0.07 \\ \mathrm{dd2} \mathrm{C} 6 \mathrm{C} 7 & 0.26 & 0.20 & 0.06\end{array}$

Static diameter spinal canal, caudal border

$\begin{array}{llll}\text { sdll C1 } & 0.27 & 0.19 & 0.08 \\ \text { sdl C2 } & 0.33 & 0.23 & 0.10 \\ \text { sdl C3 } & 0.32 & 0.22 & 0.10 \\ \text { sdl C4 } & 0.26 & 0.19 & 0.07 \\ \text { sdl C5 } & 0.31 & 0.18 & 0.14 \\ \text { sdl C6 } & 0.36 & 0.21 & 0.15\end{array}$

Static diameter spinal canal, cranial border

$\begin{array}{llll}\text { sdh C2 } & 0.64 & 0.44 & 0.20 \\ \text { sdh C3 } & 0.31 & 0.22 & 0.09 \\ \text { sdh C4 } & 0.27 & 0.18 & 0.09 \\ \text { sdh C5 } & 0.27 & 0.19 & 0.08 \\ \text { sdh C6 } & 0.32 & 0.22 & 0.10\end{array}$

Atlanto-axial distance in anteflexion (1) and retroflexion (2)

$\begin{array}{llll}\text { aa1 } & 0.87 & 0.50 & 0.37 \\ \text { aa2 } & 0.66 & 0.37 & 0.30\end{array}$




\section{Obsenver variability of the derived kinematic variables}

Table $V$ presents $\left(P_{\text {intratiner }}\right),\left(P_{\text {ind }}\right)$, and $\left(P_{\text {inte }}\right)$ of the derived variables.

Intra-observer variability of denved variables

The mean ( $\mathrm{P}_{\text {inria }}$ ) of the derived variables is 0.11 and is lower than the $\left(P_{\text {inm }}\right)$ of the basic variables which is 0.33 . The highest $\left(P_{\text {intar }}\right)$ values $(>0.2)$ are found for the sum of the disc heights in anteflexion [Sum dh 1], sum disc heights in retroflexion [Sum $\mathrm{dh2}$ ], sum translations of $\mathrm{C}_{0}-\mathrm{C}_{1}, \mathrm{C}_{1}-\mathrm{C}_{2}$, $\mathrm{C}_{2}-\mathrm{C}_{3}[\mathrm{Sm} \mathrm{TrC0}-2]$, and for the translation-rotation ratio of $\mathrm{C}_{0}$

Inter-observer variability of derived variables

The mean $\left(P_{\text {in }}\right)$ of the derived variables is 0.37 . The ratio variables show higher $\left(P_{\text {inter }}\right)$ values (mean 0.47) than the $\left(P_{\text {inter }}\right)$ of the sum variables (mean 0.26). The mean ( $\mathbb{P}_{\text {inter }}$ ) of the derived variables is higher than the $(P$ inter $)$ of the original variables $(0.14)$.

Total observer variability or variance of measurement noise of derived variables

The mean ( $\mathbf{P}_{\text {inter+inta }}$ ) is 0.48 meaning that approximately half of the total wariance of observations can be explained by measurement noise. Again, the highest (P)-values are found for the ratio variables, whereas sum variables only show high values for the sum translation in the upper cervical cluster [SmTrC0-2], the sum of $\mathrm{x}$-co-ordinates of the R-Centre $\mathrm{C}_{5}$ and $C_{6}$ with respect to $G_{7}[\operatorname{SmR} 7 \times 5-6]$, and the sum of the disc heights in ante- and retroflexion, [Sum dh l.] and [Sum dh2]. 
Table V: obsever tariobility of derived kinearatic wariables.

\begin{tabular}{llll}
\hline Sum variables & $P_{\text {inuratinter }}$ & $P_{\text {intra }}$ & $P_{\text {imper }}$ \\
\hline
\end{tabular}

Sum of respective variables within the individual motion segments of all measured levels

$\begin{array}{llll}\text { Sum ar } & 0.16 & 0.03 & 0.14 \\ \text { Sum dd1 } & 0.24 & 0.10 & 0.15 \\ \text { Sum dd2 } & 0.28 & 0.09 & 0.19 \\ \text { Sum dh1 } & 0.66 & 0.48 & 0.18 \\ \text { Sum dh2 } & 0.58 & 0.39 & 0.19 \\ \text { Sum sdh } & 0.34 & 0.12 & 0.22 \\ \text { Sum sdl } & 0.28 & 0.10 & 0.19 \\ \text { Sum tr } & 0.50 & 0.14 & 0.36\end{array}$

Sum rotation in clusters of segments
SmarCo-2
0.25
0.05
0.20
SmarC0-3
0.25
0.06
0.18
SmarC3-6
0.14
0.01
0.12

Sum $x$-co-ordinates $R$-centres $C_{7}$ in clusters of segments
SmR7 $\times 0-2$
0.17
0.05
0.12
SmP7 $7 \times 2-5$
0.14
0.04
0.10
SmR7 $\times 5-6$
0.69
0.03
0.66

Sum $y$-co-ordinates $R$-centres $C_{7}$ in clusters of segments
SmA7ya-2
SmR7y 2-5
SmR7y5-6
0.32
0.06
0.25
0.09
0.39
0.49
0.02
0.47

Sum translation in clusters of segments

$\begin{array}{llll}\text { SmTrC0-2 } & 0.83 & 0.32 & 0.51 \\ \text { SmTrC3-6 } & 0.38 & 0.06 & 0.33\end{array}$

Ratio variables $P_{\text {intratimer }} \quad P_{\text {intra }} \quad P_{\text {inter }}$

Ratio of segmental rotation at successive levels and sum rotation

$\begin{array}{llll}\text { arC1C0sr } & 0.22 & 0.03 & 0.19 \\ \operatorname{arC1C2sr} & 0.80 & 0.19 & 0.61 \\ \operatorname{arc2C} 3 \mathrm{sr} & 0.48 & 0.09 & 0.40 \\ \operatorname{arc} 3 \mathrm{C} 4 \mathrm{sr} & 0.60 & 0.05 & 0.55 \\ \operatorname{arc4C} 5 \mathrm{sr} & 0.26 & 0.05 & 0.21 \\ \operatorname{arc5C6sr} & 0.38 & 0.05 & 0.33 \\ \operatorname{arC6C7sr} & 0.63 & 0.10 & 0.52\end{array}$

Ratio of segmental rotation at one level and segmental rotation of the level below

$\begin{array}{llll}\operatorname{arC} 12 \mathrm{CO} 01 & 0.58 & 0.17 & 0.42 \\ \operatorname{arc} 23 \mathrm{C} 12 & 0.60 & 0.15 & 0.45 \\ \operatorname{arC} 34 \mathrm{C} 23 & 0.70 & 0.07 & 0.63 \\ \operatorname{arc} 45 \mathrm{C} 34 & 0.56 & 0.03 & 0.53 \\ \operatorname{arc56C45} & 0.46 & 0.05 & 0.41 \\ \operatorname{arc} 67 \mathrm{C} 56 & 0.54 & 0.11 & 0.43\end{array}$

Translation rotation ratios at successive levels

$\begin{array}{llll}\text { trara } & 0.87 & 0.33 & 0.54 \\ \text { trar1 } & 0.65 & 0.14 & 0.50 \\ \text { Irar2 } & 0.74 & 0.18 & 0.55 \\ \text { trar3 } & 0.56 & 0.06 & 0.50 \\ \text { trar4 } & 0.46 & 0.03 & 0.43 \\ \text { trar5 } & 0.63 & 0.12 & 0.51 \\ \text { tran6 } & 0.86 & 0.15 & 0.71\end{array}$




\section{DHSCUSSION}

The significance of a diagnostic procedure is, among other things, determined by the degree to which results can be reproduced.

An analysis of observer variation does provide some quality control of diagnostic procedures and enables comparison of different methods with respect to the reliability of the measurements. However, there seems to be no consensus about the conditions to be fulfilled for an analysis of obserwer variability to be valid. Designs vary widely and, to make matters worse, the results are presented quite differently, which makes comparison of these studies difficult (Wilmink et al., 1984; Saraste et al., 1985; Vanharante et al., 1985; Ogston et al., 1986; Berfelo, 1989; Amevo et al., 1991; Dvorak et al., 1992; Vortman, 1992; Ho et al., 1993). In some studies an analysis of observer variability is restricted to intra-observer variability; in others, the inter-observer variability of merely two observers is analysed (van Mameren et al., 1990; Dvorak et all., 1991).

\section{The intra-observer variability}

The intra-obsener variability is a random error resulting from the measuring procedure itself. Mean values of $\left(\mathrm{P}_{\text {intra }}\right)$ of single kinematic variables are equivalent to figures in comparable stuclies of the lumbar spine (Berfelo, 1989, 1993). In these studies, the error was mainly the result of the marking procedure. Reduction of the random error could be achieved by repeated marking. Because of the inconvenience involved, we did not choose this option. With regard to the intra-observer variability, measurements of the cervical spine proved to be as accurate as measurements of the lumbar spine. The $\left(P_{\text {imral }}\right)$ of the derived variables are even negligible. The impact of the measuring method is probably less in summation of variable values.

The effect of errors may also become less pronounced when averaging techniques are used (Amevo et al., 1991; van Mameren et al., 1992). 'This approach, however, introduces quite a different source of inaccuracy: the effect of crrors is climinished - true enough - but the averaging techniques also affect the values of the measured variables.

\section{The inter-observer variability}

The inter-obsenver variability is a random error that will be present when two or more observers measure a variable. In this study, the $\left(\mathrm{P}_{\mathrm{inter}}\right)$ of the disc height and atlanto-axial distance are, although acceptable, relatively high. Improvement of these figures might be expected when the comers of vertebral body and axis can be defined unequivocally. However, generally speaking, the overall mean value of $\left(\mathrm{P}_{\text {inter }}\right)$ in this study is negligible. Of the derived variables, it is mainly the ratio variables which show rather high but still acceptable $\left(\mathrm{P}_{\text {inter }}\right)$ values. 


\section{Total observer variability or variance of measurement noise}

The variance of measurement notse is composed of an intra- and an inter-observer factor. In 1989, in his measurements of the lumbar spine, Berfelo found $\left(\mathrm{P}_{\text {intertinua }}\right)$ to be approximately 0.80 . The present study uses the same techniques and standardisations as those used by Berfelo for processing, measuring and recording function $\mathrm{x}$-rays. The mean value for $\left(P_{\text {intertintrat }}\right)$ in the basic variables is 0.46 , and in the derived variables 0.48 , meaning that approximately half of the total variance of observations can be explained by variance of measurement noise. That the $\left(\mathrm{P}_{\text {imer }}\right.$ inseis $)$, being a proportion of the total variance of observations, is considerably smaller in the present study might be explained by the fact that the total variance of observations is larger for kinematic variables of the cervical spine compared to the lumbar spine.

The results demonstrate that the rotation centres of each vertebral body with respect to $\mathrm{C}_{7}$ can be determined more accurately than the commonly used rotation centres of the individual motion segments.

Panjabi (1979) and Pearcy et al. (1988) demonstrated that errors in determining the R-Gentres in individual motion segments increase exponentially when the angles of rotation become smaller than ten degrees. Panjabi et al. (1982) also pointed out that the variations of $x$-and $y$-coordinates due to observer variability can be looked upon as if normally distributed. Surprisingly, he found the variations of the $y$-co-ordinates to be larger than the variations of the $x$-co-ordinates, as is also true in this study. This unexpected difference might be explained by non-orthogonality between digitising surface and projection beam or by human inconvenience when working in a non-horizontal plane.

Disc height studies are often referred to as being inaccurate, and thus of limited value for clinical practice (Saraste et al., 1985; Andersson et al., 1981). These studies are almost exclusively related to the lumbar spine. The main reason for these inaccurate measurements is stated to be the distortion of the spine in radiographic depiction, due to deviations from the mid-sagittal plane on the one hand, and alterations in the spatial relationship between the x-ray tube, subject, and film between the two exposures on the other. Pope et al. (1977), however, demonstrated that disc height can be measured quite accurately, provided a technique is employed that compensates for these radiographic shortcomings. In this study, the anteflexion $x$-ray is mathematically corrected with respect to the retroflexion $x$-ray for photographic distortion of the wedge-shape and for differences in the magnification of the vertebral bodies (see chapter 5 : 'Present study design'). The results in this study of measurements of disc heights are quite acceptable: mean value for $\left(\mathbf{P}_{\text {inces+intra }}\right)=0.5$, meaning that this variable is as useful as the variables rotation and translation with respect to observer variability. 
The measurement of the adanto-axial distance shows a larger value: $\left(\mathbf{P}_{\text {inter }-\mathrm{ini}}\right)$ for the distance in anteflexion is 0.87 and in retroflexion 0.66 , respectively. This larger value shows that this complex part of the cervical spine is difficult to assess kinematically.

Studies assessing the reliability of measurements of the cervical spinal canal diameter are rare, despite the fact that much attention has been paid to the clinical manifestations of stenosis of the cervical spinal canal. Boijsen (1954) and Payne et al. (1957) drew attention to the wide range of normal variation, as did Burrows (1963) who performed measurements in 300 individuals to assess the limits of normal variation. Nordquist (1964) was one of the first authors to evaluate the sources of errors in a study on the sagittal diameter of the spinal cord and subarachnoid space in different age groups as well as in an experimental model, by processing the differences between observed and true values obtained by four observers. The total error was approximately $0.5-1.0 \mathrm{~mm}$ per observation. These absolute findings cannot be compared with the results of this study. Vanharante (1985) presents the inter-observer variability for measurements of the lumbar mid-sagittal diameter (at level $\left(\mathrm{L}_{3}\right),\left(\mathrm{L}_{4}\right)$, and $\left(\mathrm{L}_{5}\right)$ ) as a reliability coefficient $R_{\text {rel }}$ "The relation between $\left(\mathrm{R}_{\mathrm{red}}\right)$ and $\left(\mathrm{P}_{\text {intertintra }}\right)$ is given by the equation: $\left(R_{\mathrm{rel}}\right)=1-\left(\mathrm{P}_{\text {intertinura }}\right)$. Values of $\left(R_{\mathrm{rcc}}\right)$ in the study of Vanharante varied between 0.51 and 0.62 , being equivalent to $\left(\mathrm{P}_{\text {inter }}\right)$ value of 0.49 and 0.38 , respectively. The mean value of $\left(P_{\text {inter+inera }}\right)$ for measurements of the cervical mid-sagittal diameter in this study is 0.33 . This means that measurements of the lumbar and cervical mid-sagittal diameter are affected by observer variability to approximately the same extent.

The diameter of the cervical spinal canal can be measured as reliably as $\mathrm{R}$-Centres with respect to $\mathrm{C}_{7}$, and more precisely than disc height, rotation, translation, and atlanto-axial distance.

Côté et al. (1997) propagated the measurement of the lordotic curve of the cervical spine by measuring the angle between $C_{1}$ and $C_{7}$. In their study, three sets of $x$-rays were evaluated by three experienced observers. A reliability coefficient $\left(\mathrm{R}_{\mathrm{rel}}\right)$ of 0.94 was found, and it was concluded that rhis method provides reliable results. The equivalent of $\left(\mathrm{R}_{\mathrm{rel}}\right)$ of [Sum ar] in the present study is $1-\left(P_{\text {intertintral }}\right)=0.86$.

Dworak et al. (1991) introduced the translation/ rotation ratio. It was advocated because of the smaller error (intra-observer variance). Only the intra-observer variance was tested (5x). True enough, the intra-observer variance is small; however, reanalysing this derived variable, a high interobserver variance fraction was found. 


\title{
Chapter 7.
}

\section{Evaluation of diagnostic performances of kinematic variables}

\author{
INTRODUGTION
}

Kinematic studies of the spine are commonly evaluated with techniques of unwariate anabsis, meaning that the attention is focussed on the effect of one single variable on the mean values of different study groups. This approach has not resulted in the development of diagnostic tools with clinical significance for individual patients, as is demonstrated in the review of the literature (Chapter 3). For this reason, we called upon the logistic regression procedure, a technique of multivariate analysis, meaning that the effect of a combination of variables on the mean values of a number of different study groups is analysed. The next paragraphs describe the univariate and logistic regression procedures, as applied in this study, in more detail.

\section{Methods}

Function $\mathrm{x}$-rays of four different groups of individuals are analysed kinematically:

- healthy individuals $(\mathbf{n}=112)$

- patients suffering from cervical myelopathy $(n=25)$

- patients with a herniated disc at level $C_{5}-C_{6}(n=28)$

- patients with a herniated disc at level $\mathrm{C}_{6}-\mathrm{C}_{7}(\mathrm{n}=48)$

These groups are described in detail in Chapter 5 .

\section{Univariate analysis}

Significant differences between the patient groups with respect to age and gender are evaluated with a One Way Analysis of Variance (ANOVA) and the Pearson Chi-square test, respectively.

The effect of age and gender on the values of observations on the defined variables is evaluated by calculating the Pearson correlation coefficient, and using the Independent t-test, respectively.

Significant differences between the study groups with respect to the mean values of the basic and sum-variables are determined with a One Way Analysis of Variance and/or the least significant difference (LSD) test. The analysis of variance provides at so-called F-value, being the ratio of the mean square value between groups and the mean square value within groups of the respective variables. Referring this F-value to tables of the F-distri- 
bution with $(\mathrm{k}-1)$ and $(\mathrm{N}-\mathrm{k})$ degrees of freedom, provides the probability (p) that the groups will differ significantly $k$ is the number of groups, $N$ the number of subjects). Significant differences between the study groups with respect to the mean values of the ratio-variables are tested with the Kruskal Wallis test. All tests are performed with $\alpha=0.05$, double-sided.

\section{Lagistic regression procedure}

The purpose of this study is to evaluate the diagnostic significance of kinematic variables derived from anteflexion and retroflexion x-rays of the cervical spine. The number of defined variables is large ( $n=118$ ), so is the observer variability (see Chapter 6). We, therefore, resorted to a statistical technique, the so-called logistic regression procedure, which enables us to select a limited number of variables containing (nearly) all diagnostic information present in the study groups. The values of the selected variables allow one to calculate the diagnostic probability of a particular outcome being true or false. This dichotomy true versus false, can also be read as healthy versus patient or as melopathy versus hemiated disc etc.

Taking this dichotomy into account, we have categorised the patient groups as follows:

- the control group $(n=112)$ versus patient group $(n=101)$

- the patient group with cervical myelopathy $(n=25)$ versus patient group with a hemiated cervical disc $(\mathrm{n}=76)$

- the patient group with herniated disc at level $C_{5}-C_{6}(n=28)$ versus patient group with herniated disc at level $\mathrm{C}_{6}-\mathrm{C}_{7}(\mathrm{n}=48)$

- the control group $(n=112)$ versus patient group with herniated cervical disc $(n=76)$

- the control group $(n=112)$ versus patient group with cervical myelopathy $(\mathrm{n}=25)$

The values of eacl continuous variable are recoded and assigned to one of three equally sized categories or tertiles. low, median or high values. Next, the logistic regression coefficient is calculated for each tertile. "The value of the regression coefficient is proportional to the probability that the cvent we are looking for will actually happen. Thus, the tertile with the highest regression coefficiont contains the values of the variable relatat to the highest probability that the event will occur.

Selection of kinematic variables with diagnostic significance Using the logistic regression procedure in order to select variables with diagnostic significance poses two particular problems. The furst problem has to do with the possible relationship between several variables within the data set. Due to this potential collinearity, some variables will be considered, incorrectly, as having no diagnostic significance and vice-versa. In 
this situation, the logistic regression procedure will demonstrate arbitrary results, illustrated by extremely high coefficient values with extremely high standard deviations resulting in extremely high odds ratios. For this reason, an arbitrarily chosen threshold for the odds ratios is introduced: when the value of 10 is exceeded, the selection procedure stops.

The second problem can be described as data dredging. One might put all measured values of all variables of $\mathrm{G}_{0}$ down to $\mathrm{C}_{7}$ through the logistic regression procedure in one go. If one does this, the output might be the result of pure chance. To minimise this risk, we examine the data systematically, practising eight different strategies.

Strategy 1,2 and 3 deal with the basic kinematic variables and strategy 4 with the derived kinematic variables. Strategy 5 and 6 handle the basic and the derived kinematic variables together. Strategy 7 serves to check the results of strategies 1,2 and 3 with respect to the basic variables, while strategy 8 checks the resulis of strategy 4 with respect to the derived variables. The variables age and gender are included in all strategies.

Strategy 1: the data collection of all segments of each individual basic variable is clustered together. Each cluster is analysed using the logistic regression procedure (i.e. all values of the variable rotation, all values of the variable translation etc). Thus, we gain insight into the kinematic behaviour of the cervical spine: the motion segments, which do have diagnostic significance with respect to the tested variables, will become distinct.

Strategy 2: the Pearson correlation coefficient $(r)$ is used to identify a possible relationship between the basic variables. Variables interrelated by a high correlation coefficient $(r>0.7)$ contain approximately the same diagnostic information. If, for example, variable $\mathrm{A}$ at level

$C_{1}-C_{2}$ is interrelated with variable $B$ at levels $C_{1}-C_{2}, C_{2}-C_{3}$, and $C_{3}-C_{4}$ as shown by correlation coefficients higher than 0.7 , it is obvious that the diagnostic significance of these wariables is about the same. Subsequendy, a logistic regression procedure is used to identify the variable(s) with the highest diagnostic significance.

Strategy 3: the basic variables of the upper, middle, and lower cervical segments are clustered: cluster $\mathrm{C}_{0}-\mathrm{C}_{1}, \mathrm{C}_{1}-\mathrm{C}_{2}$, duster $\mathrm{C}_{2}-\mathrm{C}_{3}, \mathrm{C}_{3}, \mathrm{C}_{4}, \mathrm{C}_{4}-\mathrm{C}_{5}$ and cluster $\mathrm{C}_{3}-\mathrm{C}_{6}, \mathrm{C}_{6}-\mathrm{C}_{7}$, respectively. The values of all basic variables of each cluster are analysed with the logistic regression procedure.

Strategy 4: the derived variables, which are described earlier in this chapter, were analysed separately using the logistic regression procedure.

Strategy 5: the variables, which emanated from strategy 1 and from strategy 4 are analysed together using the logistic regression procedure.

Strategy 6: a low variance of the measurement noise with respect to the total variance, i.e. $\left(\mathrm{P}_{\text {intratinier }}\right)$, is related to high relliability; therefore, only basic and derived variables with a low value of $\left(\mathrm{P}_{\text {intratinter }}\right)$ are analysed $\left(P_{\text {intratinter }}<0.3\right)$ with the logistic regression procedure. 
Stralegy 7: differences between the four study groups are detemined using a One Way Analysis of Variance $(\alpha=0.05$ ). All basic variables are included in this procedure; 51 variables showed significanty different values between the study groups. These 5 ] variables are subsequenty analysed with the logistic regression procedure.

Stratggy 8: the same procedure as in strategy 7 is applied to the derwed variables; 19 wariables show significantly different values between the study groups. These 19 variables are also analysed with the logistic regression procedure.

All eight defined strategies are put into practice to differentiate primarily between healthy individuals and patients; and next to differentiate beween patients with a hemiated cervical disc and patients diagnosed as having a cervical myelopathy. A limited number of strategies is used to differentiate between patients with a herniated disc at level $\mathrm{C}_{5}-\mathrm{C}_{6}$ or at level $\mathrm{C}_{\mathrm{H}} \cdot \mathrm{C}_{7}$ for the following reasons. There appeared to be no significant difference in the performance of strategy 1, 2 and 3. For this reason, only strategy 1 is used to select basic variables with diagnostic significance. Strategy 4 serves to select derived wariables. Strategy 5 yields better results then strategy 6 and is therefore used to select a combination of basic and derived variables. Strategy 7 and 8 are both used as a final check.

Strategy 5 results in the selection of variables, which differentiate best between the control group and the combined patient groups. For this reason, strategy 5 was used to differentiate between the control group and herniated disc groups on the one hand, and the control group and cervical myelopathy group on the other.

The observed values of the selected subset of variables serve to calculate the diagnostic probability for an individual with respect to one of two diagnosis groups. The quality of this probabilistic diagnosis is presented by the Receiver Operating Characteristic (ROG) curve (vi.).

\section{ROG curves}

The sensivity of a diagnostic procedure is defined as the proportion of subjects with the disease that gives a positive test for this disease. A sensitive test will rarely miss subjects with the disease; it gives few false negative results. Specificity is expressed as the proportion of subjects without the disease who have a negative test. A specific test will rarely misclassify subjects without the disease as being diseased; it gives few false positive results. 
The logistic regression procedure provides a diagnostic probability. The sensitivity and specificity of the calculated diagnostic probability resulting from the logistic regression procedure in a particular strategy, is represented by a curve, the so-called recewer operating characteristic curve or $R O C$ curve. This curve is constructed by plotting the true positive rate (sensitivity) on the $y$-axis versus the false positive rate ( 1 -specificity) on the $\mathrm{x}$ axis. The discriminating power of a subset of variables, resulting from a particular strategy is thus represented by the $\mathrm{ROC}$ curve belonging to it. If the curve runs more or less diagonally from the lower left comer to the upper right corner, the strategy in question has selected poorly discriminating variables; if, however, the curve crowds toward the upper left corner, the chosen strategy performs well [see Fig. 54 .

A

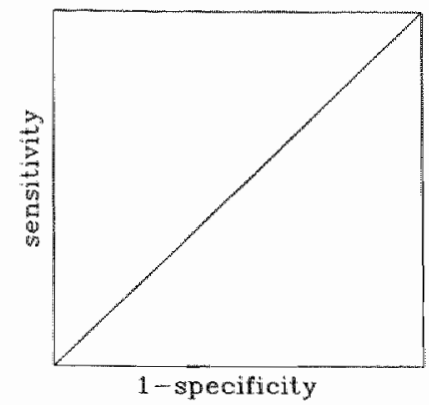

$\mathrm{B}$

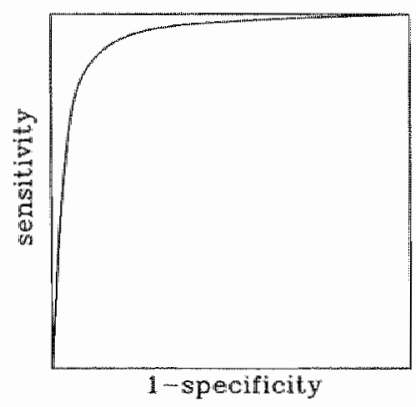

Fig. 54: A: pronly discriminating strategy

B: highly discriminating strategy

It is possible to compare the performances of different strategies by comparing the area below the line, which represents the ROG curve: a large area is associated with high performance and vice versa. Differences between areas under the ROC curves belonging to different strategies are tested using the method described by Hanley et al. (1983).

ROC curves of different strategies: comparing the areas under the curves

The diagnostic performance of different tests can be evaluated by comparing the area under the respective $\mathbb{R O C}$ curves. Doing so, one has to take into account the correlation between the two areas induced by the paired nature of the data. A correction for pairing is described by JA. Hanley and B.J. Mc Neil (1983). 
A general approach is to assess the 2 ratio:

$$
z=\frac{A l-A 2}{\sqrt{S e^{2}+S e^{2}-2 R S e+S e 2}}
$$

A/ and Sel represent the area under $\mathrm{ROC}$ curve and the estimated standard error of the first test.

A2 and 522 represent the area under $\mathrm{ROC}$ curve and the estimated standard error of the second test.

$R$ represents the estimated correlation between the area under $\mathrm{ROC}$ curve 1 and the area under $\mathrm{ROC}$ curve 2.

The value of $z$ is referred to tables of nomal distribution. Values above 1.96 are taken as evidence that the 'true' areas under the respective $\mathrm{ROC}$ curves are different.

For assessing the correlation $R$ between two $\mathrm{ROC}$ areas, the mean area $\left(\frac{A 1+A 2}{2}\right)$ is assessed.

Next, the correlation between the diseased patients of test 1 and test $2\left(r_{d}\right)$ and the non-diseased patients of test 1 and $2\left(\mathrm{r}_{n}\right)$ is assessed using the Kendall rau test.

The mean $x$ value $\left(\frac{x^{2}+y_{n}}{2}\right)$ is calculated.

For the correlation coefficient $R$ between the nwo curves, the reader is referred to Table I of the publication of J. A. Hanley and B.J. Mc Neil (1983). The correlation coefficient $R$ between two curves is in this Table presented as a function of the above-mentioned average correlation between ratings (mean $r$ ) and the averaged areas (mean area).

\section{Selection of strategies}

The results of all strategies were evaluated with respect to the discriminating performance of the selected subsets of variables. The strategy, which performed best, was finally selected, based on the following criteria:

- the selected subset of variables should demonstate (some) features which can be clinically explained, at least to some extent.

- the area under the ROC curve should be as large as possible, representing high sensitivity and specificity of the selected subset.

- small 95\% confidence interval of ROC curve area, meaning that the result with respect to the sensitivity and specificity of the selected variables, is less subject to chance.

- the selected variables should be measured as accurately as possible, as ascertained by a small observer variance. 


\section{Split-sample method}

This study aims to design a probabilistic diagnosis model of the cervical spine with respect to the four groups under study. The logistic regression procedure is used to define this model. To test the fit of this model to new data and assess its reliability, one has to conduct a new study. It is, however, also possible to split all observations at random into four groups. For three of the four groups (combined as training group), a probabilistic diagnosis model is laid down. This model is subsequently tested in the fourth group (test group). This procedure is repeated four times; each time a different group of the four becomes the test group, so that each patient is a test patient once. In this way, the split-sample method acts as a substitute for a new study. The number of subjects in the patient groups is rather small, rendering them unsuitable for the split-sample method. For this reason, we only tested our probabilistic diagnosis model for the control group versus the (combined) patient groups.

\section{RESULTS}

\section{Age}

The mean values, standard deviations, and minimum-maximum values for the age distribution within the study groups are presented in Table VI.

Table VI: descriphe statistics of the wariable Age within the stady groups (ANOVA: $\alpha=0.05, p=0.004)$.

\begin{tabular}{lrrrrr}
\hline & $N$ & Mean & S.D. & Min. & Max. \\
\hline Control group & 112 & 45.83 & 14.97 & 19 & 74 \\
Myelopathy & 25 & 55.56 & 15.25 & 30 & 80 \\
Herniated disc $\mathrm{C}_{5}-\mathrm{C}_{6}$ & 28 & 44.21 & 7.65 & 28 & 62 \\
Herniated disc $\mathrm{C}_{6}-\mathrm{C}_{7}$ & 48 & 44.83 & 9.34 & 27 & 71 \\
\hline
\end{tabular}

The $95 \%$ confidence intervals for the mean values of age of the control group and herniated disc groups show an overlap; these groups do not differ significantly from one another with respect to age. However, the mean value of age within the cervical myelopathy group is significantly higher as one might expect: the incidence of cervical myelopathy increases with age duc to developing spondylosis and spondylarthrosis which cause narrowing of the spinal canal.

Table VII summarises the variables at those levels of the motion segments, which show a significant correlation with age, for all study groups together. The control group shows about the same significant correlations.

The angles of rotation [ar] are negatively correlated with age at all lev- 
els (segments $\mathrm{C}_{0,}-\mathrm{C}_{1}$ and $\mathrm{C}_{1}-\mathrm{C}_{2}$ excepted), meaning that $[\mathrm{ar}$ decreases with increasing age. Mobility decreases with age. Obviously, decreasing values for the angle of rotation play an important role in this process.

Translation [tr] is found to correlate negatively with age but only at levels $\mathrm{C}_{2}-\mathrm{C}_{3}$ and $\mathrm{C}_{4}-\mathrm{C}_{5}$ : this finding might be due to chance.

The dynamic diameter in anteflexion [ $\mathrm{ddl}]$ is negatively correlated with age at levels: $\mathrm{C}_{2}-\mathrm{C}_{3}, \mathrm{C}_{3}-\mathrm{C}_{4}, \mathrm{C}_{4}-\mathrm{C}_{5}$, and $\mathrm{C}_{5}-\mathrm{C}_{6}$. This implies that the dynamic diameter of the cervical canal in the anteflexion posture decreases with increasing age.

The static diameter, both cranial and caudal, as measured in the different study groups, does not show a significant correlation with age.

Disc height in both anteflexion and retroflexion ([dh1] and [dh2], respectively) shows a negative correlation with age at levels $\mathrm{C}_{5}-\mathrm{C}_{6}$ and $\mathrm{C}_{60}-\mathrm{C}_{7}$ : at these levels, disc height decreases significantly with increasing age. This funding is in accordance with the every-day clinical observation that the earliest degenerative changes due to increasing age manifest themselves at these levels.

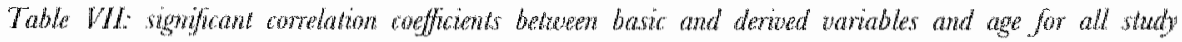
groups togeilier (Pearson comelation coefficient (o), $\alpha=0.05$ ).

\begin{tabular}{lclc}
\hline Basic variable & $\begin{array}{c}\text { Pearson correlation } \\
\text { coefficient }(r)\end{array}$ & Derived variable & $\begin{array}{c}\text { Pearson correlation } \\
\text { coefficient }(r)\end{array}$ \\
\hline ar C2C3 & -0.23 & Sum ar & -0.38 \\
ar C3C4 & -0.21 & SmarC3-6 & -0.41 \\
ar C4C5 & -0.32 & arC1C0sr & 0.17 \\
ar C5C6 & -0.34 & arC5C6sr & -0.17 \\
ar C6C7 & -0.28 & arC34C23 & 0.15 \\
tr C2C3 & -0.16 & arC67C56 & -0.15 \\
tr C4C5 & -0.17 & Sum tr & -0.22 \\
aa2 & -0.14 & SmTrC0-2 & -0.19 \\
& & & -0.16 \\
dd1 C2C3 & -0.21 & Sum dd1 & \\
dd1 C3C4 & -0.17 & & -0.19 \\
dd1 C4C5 & -0.14 & & \\
dd1 C5C6 & -0.21 & & \\
dh1 C5C6 & -0.33 & Sum dh1 & -0.21 \\
dh1 C6C7 & -0.27 & Sum dh2 & -0.17 \\
dh2 C5C6 & -0.27 & & \\
dh2 C6C7 & -0.26 & SmR7y2-5 & \\
yR7 C6 & -0.13 & SmR7y5-6 & -0.21 \\
yR7 C5 & -0.20 & & -0.18 \\
yR7 C4 & -0.25 & & \\
yR7 C3 & -0.14 & & \\
yA7 C2 & -0.18 & & \\
\hline
\end{tabular}

The atlanto-axial distance in retroflexion [aa2] decreases with increasing age. The laxidity of the ligaments involved, decreasing with age, controls this distance. 


\section{Gender}

Table VIII presents the gender frequency distribution within the study groups.

Table VIIL: gender distribution in the study groups.

\begin{tabular}{lrrrr} 
& Male & \multicolumn{3}{c}{ Fernale } \\
& \multicolumn{1}{c}{$n$} & $\%$ & \multicolumn{1}{c}{$n$} & $\%$ \\
\hline Control group & 52 & $46 \%$ & 60 & $54 \%$ \\
Myelopathy & 20 & $80 \%$ & 5 & $20 \%$ \\
Herniated disc $\mathrm{C}_{5}-\mathrm{C}_{5}$ & 15 & $54 \%$ & 13 & $46 \%$ \\
Herniated disc $\mathrm{C}_{6}-\mathrm{C}_{7}$ & 29 & $60 \%$ & 19 & $40 \%$ \\
Total & 116 & $54 \%$ & 97 & $46 \%$ \\
\hline
\end{tabular}

The cervical myelopathy group contains significantly more males than females composed to the control group (Pearson Chi-square test; $\alpha=0.05$ ). No significant difference in gender distribution is found in the other groups.

Variables at respective levels, which show significant differences between genders, are presented in Table IX for all study groups together.

Table IX: variables, which show significant differences between genders for all shady groups together. The gonder with the highest watue of the respective obsenation is mentioned (Independent Somples t-text; $\alpha=0.05$ ).

\begin{tabular}{|c|c|c|c|}
\hline Basic variables & gender & Derived variables & gender \\
\hline ar $\mathrm{C} 2 \mathrm{C} 3$ & femalle & Sum ar & temale \\
\hline ar $\mathrm{C} 4 \mathrm{C5}$ & female & Smarc3-6 & female \\
\hline $\operatorname{ar} \mathrm{C}_{5 \mathrm{C} 6}$ & female & ar $\mathrm{C} 4 \mathrm{C} 5 \mathrm{sr}$ & temale \\
\hline $\operatorname{tr} \mathrm{C}_{2} \mathrm{C} 3$ & female & Sum tr & temale \\
\hline or $\mathrm{C}_{3} \mathrm{C} 4$ & female & $\mathrm{SmTrCO} 2$ & female \\
\hline $\operatorname{tr} C 4 C 5$ & femalle & $\mathrm{SmTrC} 3-6$ & Temale \\
\hline ddI $\mathrm{ClC} 2$ & malle & & \\
\hline $\mathrm{dd} 1 \mathrm{C} 2 \mathrm{C} 3$ & male & & \\
\hline $\mathrm{dd} 2 \mathrm{C} 1 \mathrm{C2}$ & male & Sum dd2 & male \\
\hline $\mathrm{dd} 2 \mathrm{C} 2 \mathrm{C3}$ & male & & \\
\hline dd2 C5C6 & male & & \\
\hline dhe $C 4 C 5$ & female & Sum dh1 & female \\
\hline dhy C5C6 & female & & \\
\hline dh2 $C 3 C 4$ & female & Sum dhe & femalle \\
\hline dhe $C 4 C 5$ & female & & \\
\hline dh $2 \subset 5 C 6$ & femalle & & \\
\hline dh 2 C6C7 & femalle & & \\
\hline $\mathrm{sdh} \mathrm{C} 2$ & male & & \\
\hline soll $\mathrm{Cl}$ & male & & \\
\hline yR7 C4 & female & & \\
\hline y $R$ C $3 C 4$ & male & & \\
\hline
\end{tabular}


Females show significantly higher values for rotations [ar], translations $[t r]$, and for disc heights [dh] than males.

\section{Basic hinematic wariables; differences between the sudy groups}

The mean values of the basic kinematic variables at the successive levels are graphically presented in Fig. 1-13, Appendix II. The standard deviadions and the minimum-maximum values of the defined basic kinematic variables of each study group are also presented together with the p-values of the means of these variables.

Fifty-one of the 77 mean values of the basic kinematic variables show a significant difference between the groups. However, the $95 \%$ confidence intervals of almost all variables show a considerable overlap. This means on the one hand that kinematic studies may characterise groups of patients; on the other that the values of single kinematic variables themselves do not contribute to the probabilistic diagnosis of an individual patient.

Significant differences between the four study groups are determined with the lleast-significant difference test.

The mean values for the angles of rotation [ar] are significantly higher in the control group than in the patient groups at all levels but levels $\mathrm{C}_{0}-\mathrm{C}_{1}$ and $\mathrm{C}_{1}-\mathrm{C}_{2}$. (Fig. 1, Appendix II)

Fig. 2 (Appendix II) presents the mean values for translation [ur] within the study groups, and shows larger values in the control group than in the patient groups at levels $\mathrm{C}_{5}-\mathrm{C}_{6}$ up to and including $\mathrm{C}_{2}-\mathrm{C}_{3}$. The values at levels $\mathrm{C}_{0}-\mathrm{C}_{1}$ and $\mathrm{C}_{1}-\mathrm{C}_{2}$ are not significandy different; nor are the mean values at level $\mathrm{C}_{6}-\mathrm{C}_{7}$ albeit that the control group shows larger values than the patient groups.

The mean values for disc height in both the anteflexion posture [dhl] and netroflcxion posture [dh2] show a tendency to decrease from $\mathrm{C}_{2}-\mathrm{C}_{3}$ down to $\mathrm{C}_{6}-\mathrm{C}_{7}$ in all groups. The cervical myelopathy group shows significantly smaller values for [dh l] than the other groups ([*ig. 3-4, Appendix II). Other significant differences between the mean values of the groups are present at 3 levels in anteflexion and at 4 levels in retroflexion.

The mean values of the dynamic diameter in anteflexion [dd1] are significantly smaller in the cervical myelopathy group than in the control group at levels $\mathrm{C}_{2}-\mathrm{C}_{3}, \mathrm{C}_{3}-\mathrm{C}_{4}, \mathrm{C}_{4}-\mathrm{C}_{5}, \mathrm{C}_{5}-\mathrm{C}_{6}$, and $\mathrm{C}_{6}-\mathrm{C}_{7}$. In retroftexion [dd2], level $\mathrm{C}_{1}-\mathrm{C}_{2}$ is also included (Fig. 5-6, Appendix II).

The mean static diameter in the control group, measured cramially [sdh] is $16.4 \mathrm{~mm}$ and measured caudally [sdl] is $17.9 \mathrm{~mm}$. Both [sdh] and [sdl] 
show significant differences between the study groups at all levels level $\mathrm{C}_{1}$ excepted). The static diameter of the canal is smaller in patients with cervical myelopathy than in healthy individuals. In the group of patients presenting with cervical myelopathy, the smallest values for the static diameter are predominantly found at level $\mathrm{C}_{4}$; the mean value of $[\mathrm{sdh}]$ is 13.85 and of $[\mathrm{sdl}]$ is $15.05 \mathrm{~mm}$.

In the present group of patients with cervical myelopathy, the neurological level $\mathrm{C}_{5}$ was most frequently involved in the clinical syndrome, subsequently levels $\mathrm{C}_{6}, \mathrm{C}_{4}, \mathrm{C}_{3}, \mathrm{C}_{7}$, and $\mathrm{C}_{2}$ (frequency of involvement 20, $17,14,8,6$, and 2 times, respectively).

Significant differences between the mean values of the $x$-co-ordinates of the intersegmental R-Centres $[\mathrm{xR}]$ are present at only three of the seven levels $\left(\mathrm{C}_{3}-\mathrm{C}_{4}, \mathrm{C}_{4}-\mathrm{C}_{5}\right.$, and $\left.\mathrm{C}_{5}-\mathrm{C}_{6}\right)$; in addition, these differences are related to different pairs of study groups. The mean values of the $y$-co-ordinates $[y R]$ are significantly different at one level only: $\mathrm{C}_{4}-\mathrm{C}_{5}$. Therefore, it is not surprising that the graphs representing the $\mathrm{x}$ - and $\mathrm{y}$-co-ordinates of the intersegmental R-Centres in the study groups do not exhibit a distinct pattern (Fig. 9-10, Appendix. II). It would seem justified to attribute the differences between the groups, with respect to the $x$ - and $y$-co-ordinates of the intersegmental R-Centres, simply to chance.

In contrast to the $\mathrm{x}$-co-ordinates of the intersegmental $\mathrm{R}$-Centres $[\mathrm{xR}]$, the $x$-co-ordinates of the $\mathrm{R}$-Centres determined with respect to $\mathrm{C}_{7}$ (R-Centres$\mathrm{C}_{7}$ or $[\times \mathrm{R} 7]$ ) show significant differences between the groups at all but one level, i.e. $\mathrm{C}_{6}$ with respect to $\mathrm{C}_{7}$. The control group shows the lowest values at all levels: the values from $\mathrm{C}_{0}$ down to $\mathrm{C}_{5}$ are significantly lower than the values in the other groups. This means that the $\mathrm{R}$-Zero line of the control group, connecting the R-Centres- $C_{7}$, is less steep than the R-Zero lines of the other groups. In other words: patients are more inclined to an anteflexion posture than healthy individuals (Fig. 11, Appendix II). Wirh respect to the $y$-co-ordinates of the R-Cientres- $C_{7}$, three of the six vertebral bodies show significantly different mean values between the groups ([yR7 CO], [yR7 C.1] and [yR7 C3]) (Fig. 12, Appendix II).

The mean values of the atlanto-axial distances in the study groups show no significant differences.

The angles of rotation are correlated with disc heights [dh] ] and [dh2] at levels $\mathrm{C}_{4}-\mathrm{C}_{5}, \mathrm{C}_{5}-\mathrm{C}_{6}$, and $\mathrm{C}_{6}-\mathrm{C}_{7}$; level $\mathrm{C}_{3}-\mathrm{C}_{4}$ is only correlated to disc height [dh2]. The correlation coefficients range from 0.2 to 0.5 .

The correlation coefficients of the angle of rotation and dynamic diameter in anteflexion at levels $\mathrm{C}_{3}-\mathrm{C}_{4}, \mathrm{C}_{4}-\mathrm{C}_{5}, \mathrm{C}_{5}-\mathrm{C}_{6}$, and $\mathrm{C}_{6}-\mathrm{C}_{7}$ reach a 
statistically significant level (mean value of the coefficient is 0.3 ). No such correlation was found in retroflexion.

The correlation coefficients of transtation at levels $\mathrm{C}_{3}-\mathrm{C}_{4}, \mathrm{C}_{4}-\mathrm{C}_{5}, \mathrm{C}_{5}-\mathrm{C}_{6}$ : and $\mathrm{C}_{6}-\mathrm{C}_{7}$ on the one hand and the successive dynamic diameters in anteflexion on the other, also reach a degree of statistical significance mean value of the coefficient is 0.3 ).

A correlation between disc height, both in anteflexion [dhl] and in retroftexion [dh2], and translation is found at level $\mathrm{C}_{3}-\mathrm{C}_{4}, \mathrm{C}_{4}-\mathrm{C}_{5}$, and $\mathrm{C}_{5}$ $\mathrm{C}_{6}$. (Pearson correlation coefficients range from 0.24 to 0.29 ).

It would seem justified to conclude that a high mobility of the cervical spine would be accompanied by high values for the variables rotation, translation, and disc heights; as a consequence, dynamic diameters will have high values.

\section{Derived kinematic variables}

To characterise the cervical spine as an integral structure, so-called derived kinematic variables were defuned, i.e. the sum ariables, the clusters of aniables, and the ratio varables (see Chapter 5, 'Present study design', paragraph 'Methods', 'Definition of kinematic variables'). The means, standard deviations and the minimum-maximum values of the defined derived kinematic variables of each study group are presented in Appendix III. The calculated p-values for differences between the study groups with respect to the mean values are also presented.

\section{Sum variables}

All mean values of the sum variables show significant differences between the four study groups (least significant difference test). Table $\mathrm{X}$ presents the significantly different groups related to the successive variables. The numbers in the respective columns indicate the groups with significantly lower mean values than the group mentioned in the header.

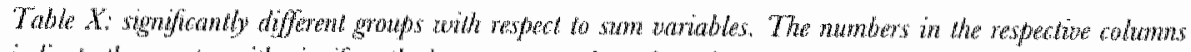

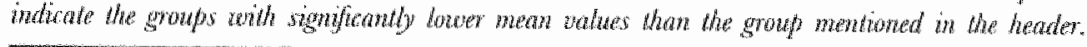

\begin{tabular}{|c|c|c|c|c|}
\hline Sum variables & $\begin{array}{l}\text { (1) Control } \\
\text { group }\end{array}$ & $\begin{array}{l}\text { (2) Cervical } \\
\text { myelopathy }\end{array}$ & $\begin{array}{l}\text { (3) Herniated } \\
\text { disc } C_{5} C_{6}\end{array}$ & $\begin{array}{l}\text { (4) Herniated } \\
\text { disc } C_{6}-C_{7}\end{array}$ \\
\hline Sum ar & $2-3-4$ & & & \\
\hline Sum tr & $2-3-4$ & & & \\
\hline Sum dh1 & 2 & & 2 & 2 \\
\hline Sum dh2 & $2-3-4$ & & & 2 \\
\hline Sum dd 1 & $2-3-4$ & & 2 & 2 \\
\hline Sum dd2 & $2-3$ & & 2 & 2 \\
\hline Sum sdh & $2-3-4$ & & 2 & 2 \\
\hline Sum sill & $2-3-4$ & & 2 & 2 \\
\hline
\end{tabular}


The mean value of the sum rotation [Sum ar] is significantly higher in the control group than in the patient groups; so is the sum translation [Sum tr]. These findings demonstrate a higher mobility in the control group than in the patient groups. The cervical myelopathy group shows significantly lower mean values for the sum of both the static and dynamic diameters as compared to the other groups. This patient group also shows significantly lower values for the sum disc heights than the other groups; a finding which complies with higher age as present in these subjects.

\section{Cluster variables}

The mean values of the kinematic variables in the four study groups are graphically presented in Appendix II, Fig. 1-13. From these graphs, distinct patterns stand out in different parts of the cervical spine. The respective collections of variables defining these patterns are represented by so-called cluster variables. Table XI presents the groups, which differ significantly with respect to these cluster variables (least significant difference test). The numbers in the respective columns indicate the groups with significantly lower mean values than the group mentioned in the header.

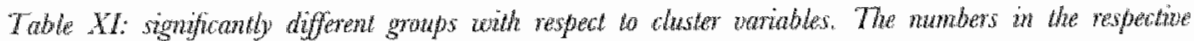

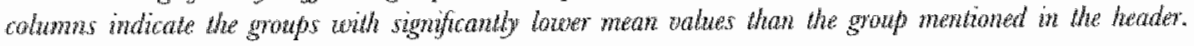

\begin{tabular}{|c|c|c|c|c|}
\hline Cluster variables & $\begin{array}{l}\text { (1) Contral } \\
\text { group }\end{array}$ & $\begin{array}{l}\text { (2) Cervical } \\
\text { myelopathy }\end{array}$ & $\begin{array}{l}\text { (3) Herniated } \\
\text { disc } C_{5}-C_{6}\end{array}$ & $\begin{array}{l}\text { (4) Herniated } \\
\text { disc } C_{6}-C_{7}\end{array}$ \\
\hline \multicolumn{5}{|l|}{ Smar CO-2 } \\
\hline \multicolumn{5}{|l|}{ Smar $\mathrm{CO}-3$} \\
\hline Smar C3-6 & $2-3-4$ & & & \\
\hline SmR7x 0-2 & & 1 & $t$ & 1 \\
\hline SmP7 $\times 2-5$ & & 1 & 1 & 1 \\
\hline $\operatorname{SmR7} \times 5-6$ & & & 1 & \\
\hline SmR7y $0-2$ & & 1 & 1 & 1 \\
\hline SmR7y 2.5 & & & 2 & 2 \\
\hline SmR7y 5-6 & 2 & & & \\
\hline $\mathrm{Sm} \pi \mathrm{r} \mathrm{CO}-2$ & $2-3$ & & & \\
\hline SmTr C3-6 & $2-3-4$ & & & \\
\hline
\end{tabular}

The analysis of cluster variables does not supply additional information as compared to the results of the basic variables and sum variables.

Ratio variables

Significant differences in the mean values of the defined ratio variables are few and non-systematically distributed in the groups (Kruskall-Wallis test): they can be regarded as resulting from pure chance. 
Selection of zanables with diagnostic significance using the lagistic regression procedure

Using all variables for diagnostic purposes is highly impractical, if possible at all. The logistic regression procedure is, therefore, used to select a limited number of variables, which contain (nearly) all diagnostic information present in the study groups.

The values of the selected variables serve to calculate the diagnostic probability of each patient for:

- the control group ( $n=112)$ or patient groups $(n=101)$

- the patient group with cervical myelopathy $(n=25)$ or patient groups with a herniated cervical disc $(n=76)$

- the patient group with herniated disc at level $\mathrm{C}_{5}-\mathrm{C}_{6}(n=28)$ or patient group with herniated disc at level $\mathrm{C}_{6}-\mathrm{C}_{7}(\mathrm{n}=48)$

- the control group $(n=112)$ or paticnt groups with herniated cervical disc $(n=76)$

- the control group $(n=112)$ or patient group with cervical myelopathy $(n=25)$

The subset of variables which produce the best ROC curve and thus shows the best performance in discriminating between a specific pair of groups, is finally selected to calculate the diagnostic probabilitics of each patient for these two groups.

\section{Control group versus patient groups}

All eight defined strategies are put into practice to differentiate between the control group on the one hand and the patient groups on the other. The resulting sulbsets of variables are presented in Table XIII.

Strategies 1, 3, and 5 yield subsets of variables which show about the same prognostic performance as is demonstrated by the area under the respective $\mathrm{ROC}$ curves $(93 \%)$; the area under the $\mathrm{ROC}$ curve belonging to the subset of variables selected by strategy 6 , is insignificantly smaller $(91 \%)$. The analysis of differences between the area under the ROC curves of strategy 5 and 6 is presented in Table XII.

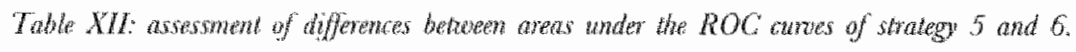

\begin{tabular}{ccc}
\hline Strategies & Area under the ROC-Curve & Se \\
\hline 5 & 0.93 & 0.017 \\
6 & 0.91 & 0.019 \\
\hline
\end{tabular}




\begin{tabular}{cccccccc}
\hline Strategies & $r_{\text {diseaser }}$ & $r_{\text {mon-diseased }}$ & mean $r$ & mean Area & $F$ & $z$-value & $P$-value \\
\hline 586 & 0.581 & 0.593 & 0.587 & 0.92 & 0.48 & 1.084 & 0.28 \\
\hline
\end{tabular}

The subsets of variables selected by strategies 1,5 , and 6 are characterised by relatively small observer variances and show greatest association with clinical perceptions. Based on the above-mentioned considerations, it was decided to use the subset of variables resulting from the logistic regression procedure in strategy 5 to discriminate between the control group and patient groups. The addition of the variables age and gender to the subset defined by strategy 5 does not change the relevant ROG curve, meaning that age and gender do not add to the discriminating perfomance of the selected subset.

The following subset is selectred:

- the ratio of the angle of rotation at level $C_{6}-C_{7}$ and at level $C_{5}-C_{6}$, i.e. [arC67C56]

The contours of the normal cervical spine appear as smooth curves in the ante- and retroflexion postures, thus demonstrating a proportionate distribution of rotations amongst the motion segments (Penning et al., 1966; Bechar et al., 1971; Wilmink, 1991). In this study, ratio values between 0.60 and 0.92 are accompanied by a high probability for normal kinematic behaviour of the cervical spine. Decreasing values of the angle of rotation at level $\mathrm{C}_{6}-\mathrm{C}_{7}$ with respect to the values of the angle of rotation at level $\mathrm{C}_{5}-\mathrm{C}_{6}$ will result in low ratio values, thus representing a higher probability for abnormal kinematic behaviour. $\mathrm{Ab}$ normal kinematic behaviour might also be expected when the angle of rotation at level $\mathrm{C}_{6}-\mathrm{C}_{7}$ shows extremely high values with respect to the angle of rotation at level $\mathrm{C}_{5}-\mathrm{C}_{6}$.

- sum rotation of segments $C_{6} C_{7}$ up to and including $C_{2} C_{39}$, i.e. /SmarC3-6] (Dvorak et al., 1993) is one of the few who studied kinematics of the cervical spine both in healthy individuals and in patients. He states that pathology is characterised by a decrease in mobility. The findings of the present study support this opinion; we found that decreasing values of sum rotations of motion segments $\mathrm{C}_{6}-\mathrm{C}_{7}$ up to and including $\mathrm{C}_{2}-\mathrm{C}_{3}$ go together with an increasing incidence of pathology (appendices 2 and 3 ). The variable [SmarC3-6] differentiates even better between the study groups than [Sum ar]; this is due to the fact that rotations in the upper cervical motion segments are more or less equal in the four study groups.

- static diameter spinal canal, caudal border, 2.e. [sdl CA]

The variable [sdl] demonstrates statistically significant differences beween the four study groups, but for level $\mathrm{C}_{1}$; these differences are most striking at level $\mathrm{C}_{4}$. Smaller values of [sdl] are accompanied by an increased probability for pathology. 
- sum of the manslations within the individual motion segments $C_{7}-C_{7}$ up to and including $\mathrm{C}_{i j}-\mathrm{C}_{j}$ i.e. [Sum $\left.\mathrm{b}\right]$

The wariable [Sum tr] shows statistically significant differences between the sudy groups. Decreasing values of sum transtations of the movion segments $\mathrm{C}_{6}-\mathrm{C}_{7}$ up to and including $\mathrm{C}_{0} \mathrm{C}_{1}$ are the result of decreased mobility. This decrease in mobility relates to abnomal kinematic behaviour.

- sum of $x$-co-ordinates of $R$-Centres of $C_{2}$ up to and including $C_{0}$ with respect to $\left.C_{7}, i . e . / 5 m R 7 \times 0-2\right]$

Increasing sum values of the $\mathrm{X}$-co-ordinates of $\mathrm{R}$-Centres with respect to $\mathrm{C}_{7}$ of $\mathrm{C}_{0}$ up to and including $\mathrm{C}_{2}$ are accompanied by a higher incidence of pathology; the line connecting the R-Centres, the so-called $\mathbb{R}$-Zero line, inclines to the anteflexion posture. Differences between the study groups are illustrated in Appendix II: these differences are most striking at the upper cervical levels.

- dynamic diameter in rebroplexion level $C_{6}-C_{7}$, i.e. [dd2 C6C7]

Decreasing values of the dynamic diameter in retroftexion at level $\mathrm{C}_{6}-\mathrm{C}_{3}$ increases the probability for pathology.

- transtation at level $C_{4}-C_{\text {, }}$, i.e. $[6 C A C 5]$

Statistically significant differences between the control group and patient groups with respect to intersegmental translation are most outstanding at levels $\mathrm{C}_{4}-\mathrm{C}_{5}$ and $\mathrm{C}_{5}-\mathrm{C}_{6}$. Low and extremely thigh values for iranslation at level $\mathrm{C}_{4}-\mathrm{C}_{5}$ are accompanied by an increased probability for pathology. Values between 0.05 and 0.09 comply with normal kinematic behaviour.

A summary of the strategies $1-8$ and resulting subsets of variables from it are presented in Table XIII.

On the basis of measured values of the selected subset of variables, al probabilistic diagnosis rule is defined. This rule serves to calculate the probabilistic diagnosis for each patient. A calculated diagnostic probability of $50 \%$ results in the numbers and pereentages of correcty allocated patients as presented in table XIV (see also: cut-of point $50 \%$ in the ROC curve of Fig. 55).

The sensivity of the selected subset with respect to the patient groups is the percentage of correctly allocated patients in the patient groups: $(84 / 101=83 \%)$, the specificity is the percentage of allocations to the control group which are correcty not allocated to the patient groups $(100 / 112-89 \%)$. The positwe diagnostic value of the selected subset with respect to the paticnt groups is the percentage of patients, which are corm rectly classified as patients $(84 / 96=88 \%$; the negatie diagnosto value is the percentage of subjects in the control group, correctly not classified as patients $(100 / \| 17=86 \%)$. 
Table WII: selected subse of wariables resulting from strategy I-8.

\section{Strategies}

$\begin{array}{llllllll}1 & 2 & 3 & 4 & 5 & 6 & 7 & 8\end{array}$

Vaniables

Levels

\begin{tabular}{|c|c|c|c|c|c|c|c|c|c|}
\hline \multirow{5}{*}{ Angles of rotation } & $\operatorname{arc} 2 \mathrm{C}_{3}$ & & & * & & & & \multirow{5}{*}{$*$} & \\
\hline & $\operatorname{arc} 3 \mathrm{C}_{4}$ & $*$ & & & & & & & \\
\hline & ar $C 5 C 6$ & * & * & * & & & & & \\
\hline & ar C67C56 & & & & * & * & & & * \\
\hline & Smar C3-6 & & & & * & $*$ & * & & * \\
\hline \multirow{2}{*}{ Tramslations } & $\operatorname{tr} 04 \mathrm{CS}$ & $*$ & & * & & * & 4 & & \\
\hline & Sum tr & & & & $*$ & * & & & * \\
\hline Disc heights & dh1 $\mathrm{C}_{2} \mathrm{C} 3$ & & * & & & & & & \\
\hline \multirow{3}{*}{$\begin{array}{l}\text { Dynamic diameters } \\
\text { in anteflexion }\end{array}$} & dd $1 \mathrm{C}_{1} \mathrm{C} 2$ & * & & * & & & \# & & \\
\hline & dd1 $\mathrm{C} 5 \mathrm{c} 6$ & * & & & & & & & \\
\hline & dd1 16607 & & * & & & & & & \\
\hline \multirow{2}{*}{$\begin{array}{l}\text { Dynamic diameters } \\
\text { in retroflexion }\end{array}$} & $\mathrm{dd} 2 \mathrm{C} 1 \mathrm{C} 2$ & $*$ & & * & & & & & \\
\hline & $\mathrm{dd} 2 \mathrm{C} 6 \mathrm{C} 7$ & * & & & & * & * & * & \\
\hline \multirow{3}{*}{$\begin{array}{l}\text { Cranial static } \\
\text { diameters }\end{array}$} & sdh $\mathrm{C} 2$ & & & * & & & & & \\
\hline & sdih $\mathrm{C} 4$ & $*$ & * & & & & & & \\
\hline & Sum sdh & & & & * & & & & \\
\hline \multirow{3}{*}{$\begin{array}{l}\text { Caudal static } \\
\text { diameters }\end{array}$} & sall Cl & & & & & & * & & \\
\hline & sdl $\mathrm{C}_{4}$ & & & * & & * & " & * & \\
\hline & Sum sdl & & & & & & & & $*$ \\
\hline \multirow{2}{*}{$\begin{array}{l}\text { P-Centres: } \\
\text { y-co-ordinate }\end{array}$} & yR $\mathrm{C} 2 \mathrm{C} 3$ & & & * & & & & & \\
\hline & $y R C 4 C 5$ & & & & & & & * & \\
\hline \multirow{2}{*}{$\begin{array}{l}\text { A-Centres-C7; } \\
x-c 0 \text {-ordinate }\end{array}$} & $x R 7 \mathrm{CH}$ & * & * & $*$ & & & & $*$ & \\
\hline & $S m P 7 \times 0-2$ & & & & * & * & $*$ & & *. \\
\hline
\end{tabular}

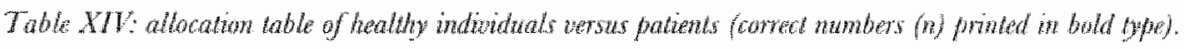

\begin{tabular}{lllll}
\hline & $\begin{array}{l}\text { Allocated } \\
\text { control group }(n)\end{array}$ & $\begin{array}{l}\text { Allocated } \\
\text { patient groups }(n)\end{array}$ & $\begin{array}{l}\text { Total } \\
\text { Correct } \\
\text { allocations }(\%)\end{array}$ \\
\hline True control group $(n)$ & 100 & 12 & 112 & $(100 / 112) 89 \%$ \\
True patient groups $(n)$ & 17 & 84 & 101 & $(84 / 101) 83 \%$ \\
\hline Total & 117 & 96 & 213 & $(184 / 213) 86 \%$ \\
\hline
\end{tabular}


The sensituity of the selected subset with respect to the control group is the percentage of correct allocations in the control group: $(100 / \| 12=89 \%)$; the specificity is the percentage of allocations to the patient groups which are correctly not allocated to the control group $(84 / 101=83 \%)$. The positive diagnostic value of the selected subset with respect to the control group is the percentage of correct allocations in the control group: $(100 / 117=86 \%)$; the negative diagnostic value is the percentage of correctly not allocated subjects in the patient groups $(84 / 96=88 \%)$.

Subjects are allocated on the basis of their calculated diagnostic probability, which will be different for each subject. One might expect that a high calculated diagnostic probability would go together with a high diagnostic value, but this is not a matter of course. Therefore, the relationship is presented between the calculated diagnostic probabilities at levels of 10-30-50-70- and 90\% and the corresponding diagnostic values, with the respective sensitivities and specificities.

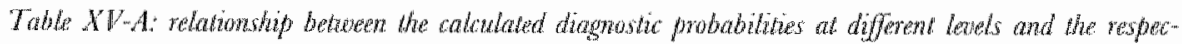

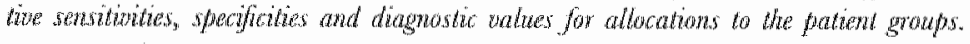

\begin{tabular}{lclll}
\hline $\begin{array}{l}\text { Calculated } \\
\text { diagnostic } \\
\text { probability }\end{array}$ & specificity & $\begin{array}{l}\text { positive } \\
\text { diagnostic } \\
\text { value }\end{array}$ & $\begin{array}{l}\text { negative } \\
\text { diagnostic } \\
\text { value }\end{array}$ \\
\hline $90 \%$ & $(48 \%) 48 / 101$ & $(98 \%) 110 / 112$ & $(96 \%) 48 / 50$ & $(68 \%) 110 / 163$ \\
$70 \%$ & $(75 \%) 76 / 101$ & $(96 \%) 107 / 112$ & $(94 \%) 76 / 81$ & $(81 \%) 107 / 132$ \\
$50 \%$ & $(83 \%) 84 / 101$ & $(89 \%) 100 / 112$ & $(88 \%) 84 / 96$ & $(86 \%) 100 / 117$ \\
$30 \%$ & $(92 \%) 93 / 101$ & $(76 \%) 85 / 112$ & $(78 \%) 93 / 120$ & $(91 \%) 85 / 93$ \\
$10 \%$ & $(98 \%) 99 / 104$ & $(52 \%) 58 / 112$ & $(65 \%) 99 / 153$ & $(97 \%) 58 / 60$ \\
\hline
\end{tabular}

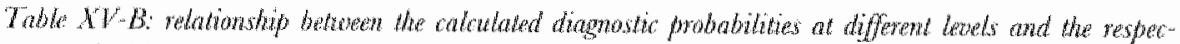

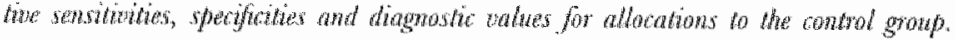

\begin{tabular}{lllll}
\hline $\begin{array}{l}\text { Calculated sensitivity } \\
\text { diagnostic } \\
\text { probability }\end{array}$ & specificity & $\begin{array}{l}\text { positive } \\
\text { diagnostic } \\
\text { value }\end{array}$ & $\begin{array}{l}\text { negative } \\
\text { diagnostic } \\
\text { value }\end{array}$ \\
\hline $90 \%$ & $(52 \%) 58 / 112$ & $(98 \%) 99 / 101$ & $(97 \%) 58 / 60$ & $(65 \%) 99 / 153$ \\
$70 \%$ & $(76 \%) 85 / 112$ & $(92 \%) 93 / 101$ & $(91 \%) 85 / 93$ & $(78 \%) 93 / 120$ \\
$50 \%$ & $(89 \%) 100 / 112$ & $(83 \%) 84 / 101$ & $(86 \%) 100 / 117$ & $(88 \%) 84 / 96$ \\
$30 \%$ & $(96 \%) 107 / 112$ & $(75 \%) 76 / 101$ & $(81 \%) 107 / 132$ & $(94 \%) 76 / 81$ \\
$10 \%$ & $(98 \%) 110 / 112$ & $(48 \%) 48 / 101$ & $(68 \%) 110 / 163$ & $(96 \%) 48 / 50$ \\
\hline
\end{tabular}


Tables XV-A, and $-\mathrm{B}$ are complementary due to the fact that a subject can only be allocated to one of the two groups. Therefore, from now on we will only present this information for one of the wo groups under discussion.

It is shown that increasing calculated diagnostic probabilities are indeed accompanied by a systematic increase of the specificities and positive diagnostic values on the one hand, and a systematic decrease in the sensitivities and negative diagnostic values on the other, thus demonstrating the added diagnostic value of the method at hand.

The relationship between the sensitivities and specificities of the calculated diagnostic probabilities resulting from the logistic regression procedure in a particular strategy, is represented by a so-called ROC curve (see Methods, ROG curve). The area under the curve is a quantified measure for the quality of the calculated diagnostic probabilities.

The area of the resulting ROC curve of strategy 5 is $93 \%$ of the total area (standard deviation $=0.02 ; 95 \%$ confidence interval $=0.90-0.97$ ).

The areas under the resulting $\mathrm{ROC}$ curves of the other strategies are: $93 \%$ (strategy 1), $87 \%$ (strategy 2), 93\% (strategy 3), $89 \%$ (strategy 4), $91 \%$ (strategy 6 ), $88 \%$ (strategy 7 ), and $90 \%$ respectively (stratcgy 8 ).

Frg. 5.5: ROC cunce representing the relationship between the sensitivities and specifictites of the calculated diagnestic probutitities for the patiment groups and the control group as reference. The calculated dugrgastic probabiaty hevels of $10 \%$, $30 \%, 50 \%, 70 \%$, and $90 \%$ are andicated by black dots.

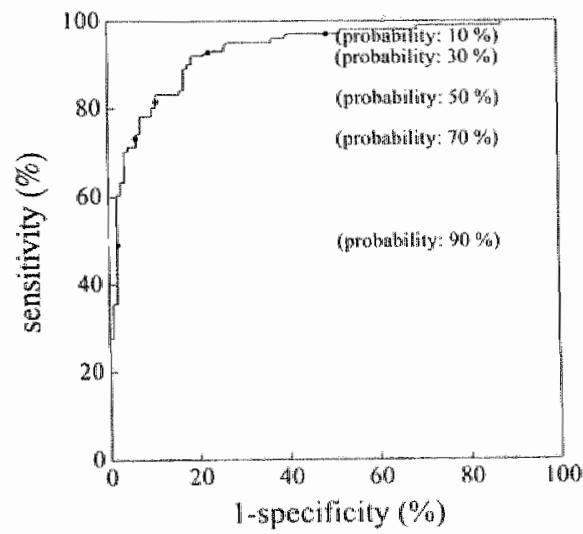

Cervical myelopathy group versus herniated cervical disc groups To differentiate between the cervical myelopathy group and the hemiated cervical disc groups, all eight strategies (with the addition of the variables age and gender) are evaluated (see paragraph 'Methods', 'Logistic regression procedure', 'Selection of kinematic variables with clinical significance). The subset of variables, which performed best, is selected to calculate the probabilistic diagnosis for each subject in these study groups.

Strategies 1, 3, 5 and 7 result in the selection of identical subsets of variables. The ROC curve belonging to it, shows an area of $83 \%$ which 
differs not significantly from the ROC curve areas resulting from strategy 4 and $8(89 \%$ and $91 \%$, respectively). The analysis of differences between the areas under the ROC curves of strategy 4 and 5 and of strategy 5 and 8 are presented in Table XVI.

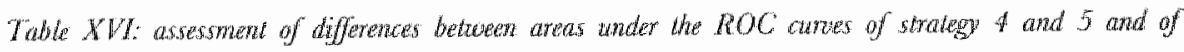
strategr 5 and $g$.

\begin{tabular}{lll}
\hline Strategies & Area under the ROC-curve & Se \\
\hline 4 & 0.89 & 0.04 \\
5 & 0.83 & 0.04 \\
8 & 0.91 & 0.03 \\
\hline
\end{tabular}

\begin{tabular}{llllllll}
\hline Strategies & $r_{\text {dissarsed }}$ & $r_{\text {ram-diseased }}$ & mean & mean Area & $R$ & $z$-value & $P$-value \\
\hline 485 & 0.209 & 0.088 & 0.149 & 0.86 & 0.12 & 0.213 & 0.831 \\
588 & 0.280 & 0.296 & 0.288 & 0.87 & 0.24 & 1.823 & 0.068 \\
\hline
\end{tabular}

All strategies except strategy 4 result in the selection of the variable age. The abserver variability in the measurements of variables selected by strategy 8 is smallest. For these reasons, the subset of variables resulting from strategy 8 is used to differentiate between the patient groups with a herniated cervical disc and the patient group with a cervical myelopathy.

The following subset of variablles is selected:

- age

In the present study, subjects in the cervical myelopathy group demonstrate a statistically significant higher age than the subjects in the other study groups. This is in agreement with reports from the literature, stating that the incidence of cervical myclopathy increases with age.

- the ratio of the angle of rotation at level $C_{5}-C_{6}$ and at level $C_{4} C_{5}$, i.e. $\operatorname{TarC56C45]}$

[ArC56C45], and to a lesser degree [arC67C56], are the only intersegmental rotation ratios which show statistically significant differences between the study groups. Ratio values of [ar C56C45] between 0.76 and 1.05 are associated with a high probability for cervical myelopathy. When rotation at level $\mathrm{C}_{5}-\mathrm{C}_{6}$ is small with respect to rotation at level $\mathrm{C}_{4}-\mathrm{C}_{5}(\mathrm{e} . \mathrm{g}$. ratio $<0.76)$, the probability for a herniated disc increases. In this situation, the smooth contour of the cervical spine will be lost and angulation at level $\mathrm{C}_{4}-\mathrm{C}_{5}$ may occur.

- sum of $y$-co-ordinates of $R$-Centres of $C_{2}$ up to and inchading $C_{0}$ with respect to $C_{7}$, i.e. $[\operatorname{Sin} R 7 y 0-2]$ 
The R-Zero line inclines to the anteflexion posture with increasing values of sum of $y$-co-ordinates of R-Centres of $\mathrm{C}_{2}$ up to and including $\mathrm{C}_{0}$ with respect to $\mathrm{C}_{7}$. This inclination to the anteflexion posture goes together with an increased probability for cervical myelopathy.

- sum disc heights of the segments $C_{6}-C_{7}$ up to and including $C_{2} C_{3}$ in anteftexion, i.e. [sum dhi]

The values of the variable sum disc heights show statistically significant differences between the study groups. Differences between subjects with cervical myelopathy and patients with a herniated disc are most pronounced in anteflexion: decreasing sum values of disc heights in anteffexion of segments $\mathrm{C}_{6}-\mathrm{C}_{7}$ up to and including $\mathrm{C}_{2}-\mathrm{C}_{3}$ increase the probability for cervical myelopathy. In retroflexion, disc heights in both groups are more or less the same (Appendix III).

- sum of superior static sagittal diameter of $C_{6}$ up to and including $C_{2}$, i.e. Fsum salhy It is obvious that decreasing values for the sum of superior static sagittal diameters of $\mathrm{C}_{6}$ up to and including $\mathrm{C}_{2}$ increase the chance of cervical myelopathy.

A summary of the strategies $1-8$ and selected subsets of variables resulting from it are presented in Table XVII.

Table XVII: selucted subset of variables resulhing from strategy, $1-8$.

\begin{tabular}{|c|c|c|c|c|c|c|c|c|c|}
\hline & \multicolumn{8}{|c|}{ Strategies } \\
\hline & & 1 & 2 & 3 & 4 & 5 & 6 & 7 & 8 \\
\hline Variables & Levels & & & & & & & & \\
\hline Age & & * & $*$ & * & & * & * & * & * \\
\hline Angles of rotation & ar $\mathrm{C} 56 \mathrm{C} 45$ & & & & “ & & & & $*$ \\
\hline Disc heights & $\begin{array}{l}\text { dh2 } \mathrm{C} 6 \mathrm{C} 7 \\
\text { Sum dhy }\end{array}$ & & * & & * & & & & * \\
\hline $\begin{array}{l}\text { Dynamic diameters } \\
\text { in anteflexion }\end{array}$ & dd1 $\mathrm{C} 5 \mathrm{C} 6$ & & & & & & * & & \\
\hline Cranial static & sdh $\mathrm{C} 3$ & • & * & * & & * & & * & \\
\hline diameters & Sum sidh & & & & * & & & & " \\
\hline $\mathrm{R}$-Centres-C7; & SmA7y $0-2$ & & & & * & & & & * \\
\hline$y$-co-ordinate & SmR7y $2-5$ & & & & . & & & & \\
\hline
\end{tabular}

Patients are allocated to the herniated cervical disc groups or cervical myelopathy group based on the calculated probabilistic diagnoses. A calculated diagnostic probability of $50 \%$ results in the following numbers and percentages of correctly allocated patients: 


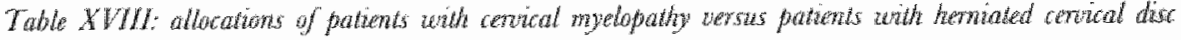
(comed numbers $(n)$ printed in bold bye).

\begin{tabular}{lllll}
\hline & $\begin{array}{l}\text { Allocated } \\
\text { herniated } \\
\text { cervical disc }(n)\end{array}$ & $\begin{array}{l}\text { Allocated } \\
\text { cervical } \\
\text { myelopathy }(n)\end{array}$ & Total & $\begin{array}{l}\text { Correct } \\
\text { allocations (\%) }\end{array}$ \\
\hline $\begin{array}{l}\text { True herniated } \\
\text { disc groups }(n)\end{array}$ & 72 & 4 & 76 & $(72 / 76) 95 \%$ \\
$\begin{array}{l}\text { True cervical } \\
\text { myelopathy group }(n)\end{array}$ & 8 & 17 & 25 & $(17 / 25) 68 \%$ \\
\hline Total & 80 & 21 & 101 & $(89 / 101) 88 \%$ \\
\hline
\end{tabular}

Table XIX presents the relationship between the calculated diagnostic probabilities at levels of $10,30,50,70$ and $90 \%$ and the diagnostic values belonging to them, with the respective sensitivities and specificities. The cervical myclopathy is the reference group, meaning that the probabilitics are primarily calculated for the patients in the herniated cervical disc groups. The complementary values for the cervical myelopathy group derive from this table and will, therefore, not be presented.

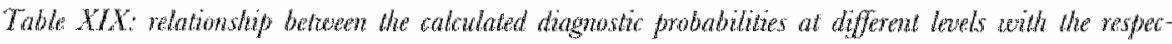

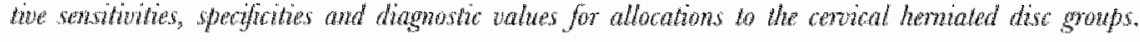

\begin{tabular}{lllll}
\hline $\begin{array}{l}\text { Calculated } \\
\text { diagnostic } \\
\text { prabability }\end{array}$ & spensitivity & & $\begin{array}{l}\text { positive } \\
\text { diagnostic } \\
\text { value }\end{array}$ & $\begin{array}{l}\text { negative } \\
\text { diagnostic } \\
\text { value }\end{array}$ \\
\hline $90 \%$ & $(61 \%) 46 / 76$ & $(96 \%) 24 / 25$ & $(98 \%) 46 / 47$ & $(44 \%) 24 / 54$ \\
$70 \%$ & $(92 \%) 70 / 76$ & $(72 \%) 18 / 25$ & $(91 \%) 70 / 77$ & $(75 \%) 18 / 24$ \\
$50 \%$ & $(95 \%) 72 / 76$ & $(68 \%) 17 / 25$ & $(90 \%) 72 / 80$ & $(81 \%) 17 / 21$ \\
$30 \%$ & $(97 \%) 74 / 76$ & $(60 \%) 15 / 25$ & $(88 \%) 74 / 84$ & $(88 \%) 15 / 17$ \\
$10 \%$ & $(100 \%) 76 / 76$ & $(28 \%) 7 / 25$ & $(81 \%) 76 / 94$ & $(100 \%) 7 / 7$ \\
\hline
\end{tabular}

The area of the resulting ROC curve is $91 \%$ of the total area (standard deviation $=0.03 ; 95 \%$ confidence interval $=0.84-0.97$ ).

The areas under the resulting $\mathrm{ROC}$ curves of the other strategies are: $83 \%$ (strategy $1,3,5$, and 7 ), $88 \%$ (strategy 2 ), $89 \%$ (strategy 4 ), and $84 \%$ respectively (strategy 6). 
Fig. 50. ROC cune representing the retation hith

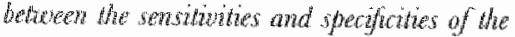

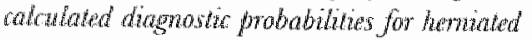
ariacal disc groups and the molopathy grous as referentice

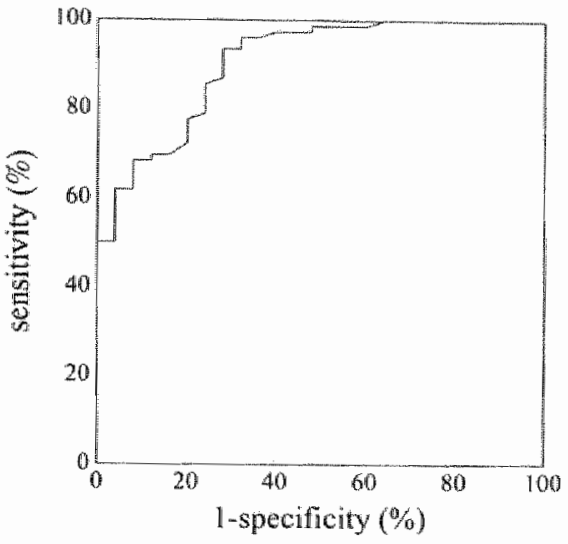

Patient group with herniated disc at level $\mathrm{C}_{5}-\mathrm{C}_{65}$ versus patient group with herniated disc at level $\mathrm{C}_{6}-\mathrm{C}_{7}$

To discriminate between patients with a herniated disc at level $\mathrm{C}_{5}-\mathrm{C}_{6}$ and patients with a hemiated disc at level $\mathrm{C}_{6}-\mathrm{C}_{7}$, we evaluate only the performance of a limited number of strategies used to differentiate between the control group and the patient groups on the one hand, and between the parients with a herniated cervical disc and cervical myelopathy on the other: i.e. strategies $1,4,5,7$ and 8 .

Placing only the derived variables at the disposal of the logistic regression procedure (see strategies 4 and 8) does not result in the selection of any variable. Strategy 1 results in the selection of a subset of three similar variables (all three referred to rotation centres within a motion segment), while strategy 7 results in the selection of 3 completely different variables, which are difficult to interpret (see Table XXI). The area under the ROC curve belonging to strategy $I$ is $84 \%$; this area cloes not differ significantly from the area under the ROC curve belonging to strategy $7(83 \%)$. The analysis of differences between the area under the $\mathrm{ROC}$ curves of strategy 1 and 7 is presented in Table XX.

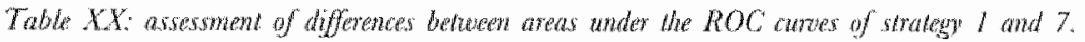

\begin{tabular}{lll}
\hline Strategies & Area under the ROC.Curve & Se \\
\hline 1 & 0.84 & 0.04 \\
7 & 0.83 & 0.05 \\
\hline
\end{tabular}

\begin{tabular}{llllllll}
\hline Strategies & $r_{\text {diseased }}$ & $r_{\text {nom disersed }}$ & mean $r$ & mean Area & $R$ & $z$-value & $P$-value \\
\hline 187 & 0.299 & 0.356 & 0.3275 & 0.835 & 0.28 & 0.1767 & 0.859 \\
\hline
\end{tabular}


It was decided to use the subset of variables resulting from strategy 1 to differentiate between the patient groups with a hemiated disc at tevel $\mathrm{C}_{5}$ $\mathrm{C}_{6}$ versus level $\mathrm{C}_{6}-\mathrm{C}_{7}$.

The following wariables are selected:

- ratation centre of segment $G_{6}-G_{7}$, y-co-ordinate, i. br C6C7)

The diagnostic probabillity for a herniated disc at level $\mathrm{C}_{5}-\mathrm{C}_{6}$ increas$\mathrm{Cs}_{3}$ and for therniated disc at level $\mathrm{C}_{6}-\mathrm{C}_{7}$ decreases, with increasing values of the $y$-co-ordinate of the $\mathrm{R}$-Centre of motion segment $\mathrm{C}_{6}-\mathrm{C}_{7}$ : the intersegmental $R$-Centre shifts upwards, which means that rotation of $\mathrm{C}_{6}$ increases with respect to translation.

- rotation centre of segment $C_{5} C_{6}$, x-comordinate, i.e. $[x R C .5 C 67$

The diagnostic probability for a hemiated disc at level $\mathrm{C}_{5}-\mathrm{C}_{6}$ increases with increasing values of the $x$-co-ordinate of the $R$-Centre of motion segment $C_{5}-C_{6}$, the intersegmental $R$-Centre shifts anteriorly, thus producing a relative retroflexion position of $\mathrm{C}_{5}$ with respect to $\mathrm{C}_{6}$. This relative retroffexion position will be visible as angulation at level $\mathrm{C}_{5}-\mathrm{C}_{6}$.

- rotation centre of segment $C_{3}-C_{4}, x$-co-ordinate, i.e. [xR C3CA]

The diagnostic probability for a hemiated disc at level $\mathrm{C}_{3}-\mathrm{C}_{6}$ increases with increasing values of the $x$-co-ordinate of the $R$-Centre of motion segment $\mathrm{C}_{3}-\mathrm{C}_{4}$. Increasing values of the $\mathrm{x}$-co-ordinate of the $\mathrm{R}$-Centre of motion segment $\mathrm{C}_{3}-\mathrm{C}_{4}$ will contribute to angulation at level $\mathrm{C}_{3}-\mathrm{C}_{4}$.

\section{Comprent:}

Vortman (1992) studied a group of patients $(n=21)$ with decreased disc height, spondylosis and spondylarthrosis at level $\mathrm{C}_{5}-\mathrm{C}_{6}$. He also found an anterior shift of the $\mathrm{R}-\mathrm{Centre} \mathrm{C}_{5}-\mathrm{C}_{6}$. This suggests that the noted anterior shift is rather aspecific. This finding supports our view that single kinematic variables are not diagnostically significant for indivicual patients.

A summary of strategies $1,4,5,7$ and 8 and the selected subsets of variables resulting from it are presented in Table XXI.

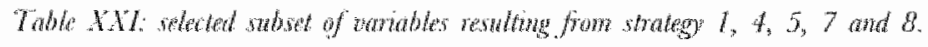

\section{Strategies}

14578

Variables

Levels

Angles of rotation

ar $\mathrm{C} 6 \mathrm{C} 7$

Dynamic diameters in retroflexion

F-Centres: $x$-co-ordinate

dd2 $\mathrm{C} 4 \mathrm{C5}$

$\times \mathrm{R} \mathrm{C} 3 \mathrm{C} 4$

$x R \mathrm{C} 5 \mathrm{C} 6$

A-Centres; y-co-ordinate

y $\mathrm{R} 6 \mathrm{C} 7$ 
The probabilistic diagnoses for the herniated disc groups $\mathrm{C}_{5}-\mathrm{C}_{6}$ and $\mathrm{C}_{6}-\mathrm{C}_{7}$ are calculated on the basis of these three variables. A calculated diagnostic probability of $50 \%$ results in the following numbers and percentages of correctly allocated patients.

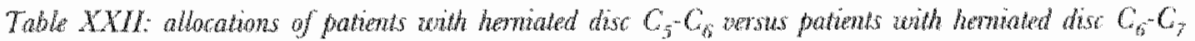
(comed nombers ( $n$ ) printed in bold type).

\begin{tabular}{lllll}
\hline & $\begin{array}{l}\text { Allocated } \\
\text { hemiated } \\
\text { disc } C_{5}-C_{6}(n)\end{array}$ & $\begin{array}{l}\text { Allocated } \\
\text { herniated } \\
\text { disc } C_{5}-C_{7}(n)\end{array}$ & Total & $\begin{array}{l}\text { Correct } \\
\text { allocations (\%) }\end{array}$ \\
\hline $\begin{array}{c}\text { True herniated } \\
\text { disc } \mathrm{C}_{5} \mathrm{C}_{6}(\mathrm{n})\end{array}$ & 20 & 8 & 28 & $(20 / 28) 71 \%$ \\
$\begin{array}{c}\text { True herniated } \\
\text { disc } \mathrm{C}_{6} \omega \mathrm{C}_{7}(\mathrm{n})\end{array}$ & 9 & 39 & 48 & $(39 / 48) 81 \%$ \\
\hline Total & 29 & 47 & 76 & $(59 / 76) 78 \%$ \\
\hline
\end{tabular}

Both the herniated disc groups are rather small hemiated disc $\mathrm{C}_{5}, \mathrm{C}_{6}$, $\mathrm{n}=28$; hernated disc $\mathrm{C}_{6}-\mathrm{C}_{7}, \mathrm{n}=48 \mathrm{y}$. This might explain why the percentage of correct allocations is somewhat lower than in the previous groups. Another reason might be that these two groups are quite similar: only the level of the herniated disc is diterent.

Table XXIII presents the relationship between the calculated diagnostic probabilities at levels of $10,30,50,70$ and $90 \%$ and the diagnostic values belonging to it, with the respective sensitivities and specifucities.

The patients with a herniated disc at level $\mathrm{C}_{5}-\mathrm{C}_{6}$ serve as reference, meaning that the probabilities are primarily calculated for the paticnts with a herniated disc at level $\mathrm{C}_{6}-\mathrm{C}_{7}$.

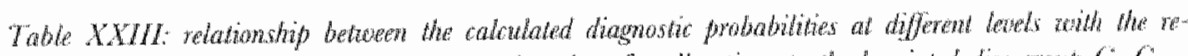

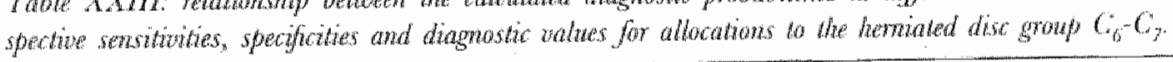

\begin{tabular}{lrrll}
\hline $\begin{array}{l}\text { Calculated } \\
\text { diagnostic } \\
\text { probability }\end{array}$ & specificity & $\begin{array}{l}\text { positive } \\
\text { diagnostic } \\
\text { value }\end{array}$ & $\begin{array}{l}\text { negative } \\
\text { diagnostic } \\
\text { value }\end{array}$ \\
\hline $90 \%$ & $(48 \%) 23 / 48$ & $(100 \%) 28 / 28$ & $(100 \%) 23 / 23$ & $(53 \%) 28 / 53$ \\
$70 \%$ & $(71 \%) 34 / 48$ & $(71 \%) 20 / 28$ & $(90 \%) 34 / 38$ & $(53 \%) 20 / 38$ \\
$50 \%$ & $(81 \%) 39 / 48$ & $(71 \%) 20 / 28$ & $(83 \%) 39 / 47$ & $(69 \%) 20 / 29$ \\
$30 \%$ & $(94 \%) 45 / 48$ & $(36 \%) 10 / 28$ & $(71 \%) 45 / 63$ & $(77 \%) 10 / 13$ \\
$10 \%$ & $(100 \%) 48 / 48$ & $(7 \%) 2 / 28$ & $(65 \%) 48 / 74$ & $(100 \%) 2 / 2$ \\
\hline
\end{tabular}

The area of the resulting $\mathrm{ROC}$ curve is $84 \%$ of the total area (standand deviation $=0.04 ; 95 \%$ confidence interval $=0.76-0.93)$. 


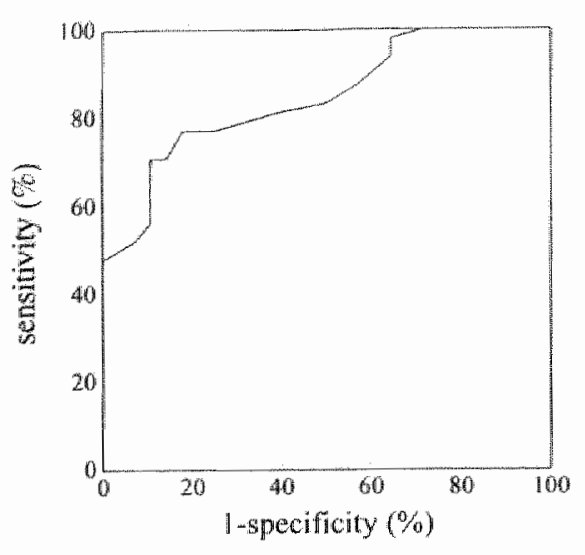

Fig. 57: ROC ande regresentiog the telationship betwerm the sensitivities and speciffoities of the calcuitated diagnoslic probabilities for hemiated cerwical disc group $C_{6} C_{3}$ and the hemiated dise group $C_{5} C_{t_{j}}$ as wefrence.

Control group versus herniated cervical disc groups

As explained in the paragraph 'Control group versus patient groups', strategy 5 is used for the selection of a subset of variables; this subset serves to calculate the probabilistic diagnoses for the control group versus the hemiated cervical disc groups. The addition of the variables age and gender to the subset defined by strategy 5 does not change the relevant ROG curve, meaning that age and gender do not add to the discriminating performance of the selected subset.

The following variables are sellected:

- the ratio of the angle of rotation at level $C_{6}{ }^{-} C_{7}$ and at level $C_{5} C_{6}$, i.e. [arc67C56]

Ratio values between 0.60 and 0.92 are associated with a high probability for normal kinematic behaviour of the cervical spine. Decreasing values of the angle of rotation at level $\mathrm{C}_{6}-\mathrm{C}_{7}$ with respect to the values of the angle of rotation at level $\mathrm{C}_{5}-\mathrm{C}_{6}$ will resule in low ratio values, thus representing a higher probability for a hemiated cervical disc. Abnormal kinematic behaviour might also be expected when the angle of rotation at level $\mathrm{C}_{6}-\mathrm{C}_{7}$ shows extremely high values with respect to the angle of rotation at level $\mathrm{C}_{5}-\mathrm{C}_{6}$.

- sam of $x$-co-ordinates of $R$-Centres of $C_{2}$ up to and including $C_{0}$ with respect to $C_{7}$, i.e. $[\operatorname{SmR} R \times 0-2]$

Increasing sum values of the $\mathrm{x}$-co-ordinates of $\mathrm{R}$-Centres with respect to $\mathrm{C}_{7}$ of $\mathrm{C}_{0}$ up to and including $\mathrm{C}_{2}$ are associated with a higher incidence of pathology, the line connecting the R-Centres, the so-called $\mathrm{R}$-Zero line, inclines to the anteflexion posture. Differences between the study groups are illustrated in Appendix II: these differences are most striking at the upper cervical levels. 
- translation at Level $C_{4}-C_{5}$, i.e. [o 6405$]$

Low and extremely high values for translation at level $\mathrm{C}_{4}-\mathrm{C}_{5}$ go together with an increased probability for a herniated cervical disc. Values between 0.05 and 0.09 comply with nomal kinematic behaviour.

- sum ratakion of segments $C_{6}-C_{7}$ up to and inchuding $C_{2}-C_{3}$, i.e. [SmarC3-6]

Decreasing values of sum rotations of motion segments $\mathrm{C}_{6}{ }^{-} \mathrm{C}_{7}$ up to and including $\mathrm{C}_{2}-\mathrm{C}_{3}$ are accompanied by an increasing incidence of pathology.

- disc height at level $C_{6} C_{7}$ in retrofterion, i.e. [dh2 G6C7]

Increasing disc heights in retrofexion at level $\mathrm{C}_{6}-\mathrm{C}_{7}$ decreases the probability of having a herniated cervical disc, especially at level $\mathrm{C}_{6-}$ G.

- dynamic diameter at level $\mathrm{C}_{1}-\mathrm{C}_{2}$ in anteflevion, ie. [ddl CIC2]

Increasing values of dynamic diameter in anteflexion at $l e v e l \mathrm{C}_{1}-\mathrm{C}_{2}$ increase the chance of having a herniated disc. The mean values for the dynamic diameters in retroflexion are significantly different in the respective study groups, contrary to the mean value of the dynamic diameters in anteflexion. For this reason it is unclear why the variable dynamic diameter $C_{1}-C_{2}$ in anteftexion is selected in this subset. Obviously, a combination of this variable with one or more variables from this subset does have diagnostic significance.

- dynamic diameter at level $\mathrm{C}_{2}, \mathrm{C}_{3}$ in anteflexion, ine [dd $\left.1 \mathrm{Ca} \mathrm{C}_{3}\right]$

The mean values of this variable are significantly bigher in the control group than in the other study groups. Thus, increasing values of the dynamic diameter in anteflexion at level $\mathrm{C}_{2}-\mathrm{C}_{3}$ go together with a decreasing probability of having a herniated cervical disc.

The calculated probabilistic diagnoses resulted in allocations as presented in Table XXIV.

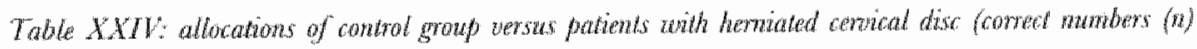
printed in bold tiste.

\begin{tabular}{|c|c|c|c|c|}
\hline & $\begin{array}{l}\text { Allocated } \\
\text { control } \\
\text { group }(n)\end{array}$ & $\begin{array}{l}\text { Allocated } \\
\text { herniated } \\
\text { disc groups }(n)\end{array}$ & Total & $\begin{array}{l}\text { Correct } \\
\text { allocations (\%) }\end{array}$ \\
\hline True contral group $(n)$ & 104 & 8 & 112 & $(104 / 112) 93 \%$ \\
\hline $\begin{array}{l}\text { True herniated } \\
\text { disc group (n) }\end{array}$ & 9 & 67 & 76 & $(67 / 76) \quad 88 \%$ \\
\hline Total & 113 & 75 & 188 & $(171 / 188) 91 \%$ \\
\hline
\end{tabular}


Table XXV presents the relationship between the calculated diagnostic probabilities at levels of $10,30,50,70$ and $90 \%$ and the corresponding diagnostic values, with the respective sensitivities and specificities.

The control group serves as reference, meaning that the probabilities are primarily calculated for the hemiated cervical disc groups.

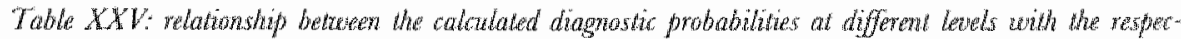

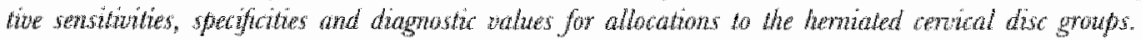

\begin{tabular}{lccll}
\hline $\begin{array}{l}\text { Calculated sensitivity } \\
\text { diagnostic } \\
\text { probability }\end{array}$ & specificity & $\begin{array}{l}\text { positive } \\
\text { diagnostic } \\
\text { value }\end{array}$ & $\begin{array}{l}\text { negative } \\
\text { diagnostic } \\
\text { value }\end{array}$ \\
\hline $90 \%$ & $(50 \%) 38 / 76$ & $(98 \%) 110 / 112$ & $(95 \%) 38 / 40$ & $(74 \%) 110 / 148$ \\
$70 \%$ & $(74 \%) 56 / 76$ & $(96 \%) 107 / 112$ & $(92 \%) 56 / 6 / 1$ & $(84 \%) 107 / 127$ \\
$50 \%$ & $(88 \%) 67 / 76$ & $(93 \%) 104 / 112$ & $(89 \%) 67 / 75$ & $(92 \%) 104 / 113$ \\
$30 \%$ & $(93 \%) 71 / 76$ & $(86 \%) 96 / 112$ & $(82 \%) 71 / 87$ & $(95 \%) 96 / 101$ \\
$10 \%$ & $(99 \%) 75 / 76$ & $(66 \%) 74 / 112$ & $(66 \%) 75 / 113$ & $(99 \%) 74 / 75$ \\
\hline
\end{tabular}

The area of the resulting ROC curve is $91 \%$ of the total area (standard deviation $=0.02 ; 95 \%$ confidence interval $=0.87-0.95$ )

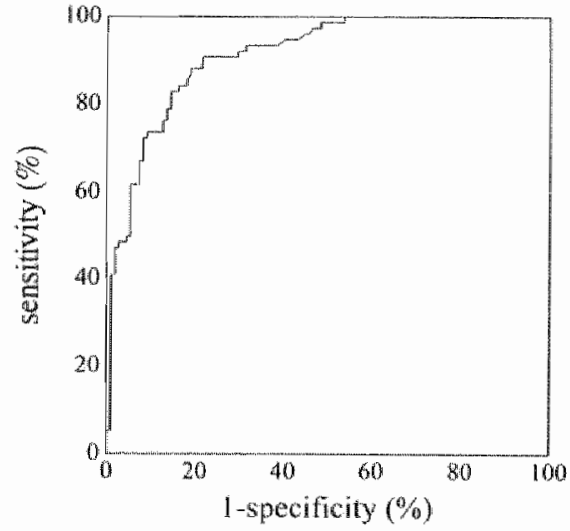

Fig. 59. ROC owne representing the retationship

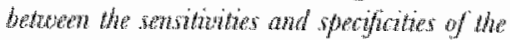
calculated tiagnostio probabilities for herniated cendel dise groups and the wontrol grouts as reference.

Control group versus cervical myelopathy group Strategy 5 is used to differentiate between the control group and the herniated disc groups; this strategy is used again to differentiate between the control group and the cervical myelopathy group. The addition of the variables age and gender to the subset defined by strategy 5 does not change the outcome, meaning that age and gender do not add to the discriminating performance of the selected subset. The following variables are selected: 
- sum rotation of segments $C_{6}-C_{7}$ up to and including $C_{2}-C_{3}$, i.e. [SmanC3-6] Decreasing values of sum rotations of motion segments $\mathrm{C}_{6}-\mathrm{C}_{7}$ up to and including $\mathrm{C}_{2}-\mathrm{C}_{3}$ are accompanied by an increasing incidence of pathology.

- disc height at level $C_{3}-C_{4}$ in retroflexion, i.e. [dh2C3C4]

Increasing values of disc height in retroflexion at level $\mathrm{C}_{3}-\mathrm{C}_{4}$ decreases the probability for cervical myelopathy.

- static diameter of the spinal canal at level $C_{4}$ and at level $C_{6}$ measured at the cranial border, i.e. [sdh C4] and [sth C6]

Decreasing values of the superior static diameter at level $\mathrm{C}_{4}$ and at level $\mathrm{C}_{6}$ increases the probability for cervical myelopathy. The study groups are significantly different at all levels, but most prominently at levels $\mathrm{C}_{4}$ and $\mathrm{C}_{6}$.

The calculated probabilistic diagnoses resulted in allocations as presented in Table XXVI.

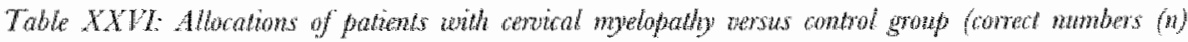
prinled in bold typel.

\begin{tabular}{|c|c|c|c|}
\hline $\begin{array}{l}\text { Allocated } \\
\text { control } \\
\text { group }(n)\end{array}$ & $\begin{array}{l}\text { Allocated cervical } \\
\text { myelopathy } \\
\text { group (n) }\end{array}$ & Total & $\begin{array}{l}\text { Corroct } \\
\text { allocations }(\%)\end{array}$ \\
\hline
\end{tabular}

$\begin{array}{lrrrr}\text { True control group }(n) & 108 & 4 & 112 & (108 / 112) 96 \% \\ \text { True cervical } & 5 & 20 & 25 & (20 / 25) 80 \% \\ \quad \text { myelopathy group }(n) & & & & \end{array}$

\begin{tabular}{lllll}
\hline Total & 113 & 24 & 137 & $(128 / 137) 93 \%$ \\
\hline
\end{tabular}

Table XXVII presents the relationship between the calculated diagnostic probabilities at levels of $10,30,50,70$ and $90 \%$ and the corresponding diagnostic values, with the respective sensitivities and specificities.

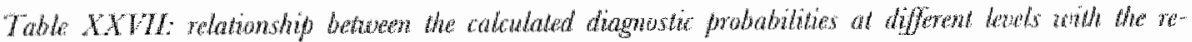

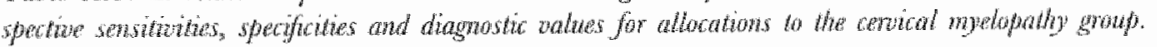

\begin{tabular}{lcccll}
\hline $\begin{array}{l}\text { Calculated } \\
\text { diagnostic } \\
\text { probability }\end{array}$ & & specificity & $\begin{array}{l}\text { positive } \\
\text { diagnostic } \\
\text { value }\end{array}$ & $\begin{array}{l}\text { negative } \\
\text { diagnostic } \\
\text { value }\end{array}$ \\
\hline $90 \%$ & $(28 \%)$ & $7 / 25$ & $(100 \%) 112 / 112$ & $(100 \%) 7 / 7$ & $(86 \%) 112 / 130$ \\
$70 \%$ & $(60 \%)$ & $15 / 25$ & $(99 \%) 111 / 112$ & $(94 \%) 15 / 16$ & $(92 \%) 111 / 121$ \\
$50 \%$ & $(80 \%)$ & $20 / 25$ & $(96 \%) 108 / 112$ & $(83 \%) 20 / 24$ & $(96 \%) 108 / 113$ \\
$30 \%$ & $(84 \%)$ & $21 / 25$ & $(92 \%) 103 / 112$ & $(70 \%) 21 / 30$ & $(96 \%) 103 / 107$ \\
$10 \%$ & $(88 \%)$ & $22 / 25$ & $(81 \%) 91 / 112$ & $(51 \%) 22 / 43$ & $(97 \%) 91 / 94$ \\
\hline
\end{tabular}




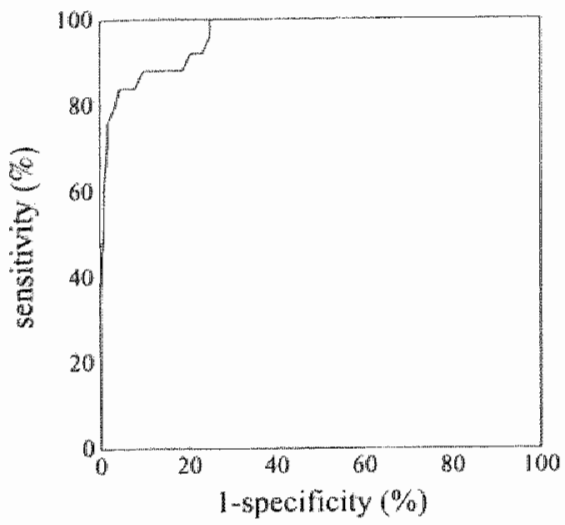

Fig. 59: ROC cunverefresenting the relationshifn

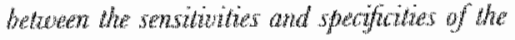
alculated diagnosic frobabilites for the myelopotsy group and the control growp as refrence.

The area of the resulting ROC curve is $96 \%$ of the total area (standard deviation $=0.02 ; 95 \%$ confidence interval $=0.93-0.99$ ).

\section{Split-sample method}

The calculated probabilistic diagnosis of each subject is partially based on observations on the same subject. The results will, therefore, show a bias. This bias makes it questionable whether conclusions can be generalised and applied to other patient samples. The most convincing way to assess the reliability of our model and resulting probabilistic diagnosis rules is to conduct a completely new study and test the model on new data. However, the reliability of the model can also be tested using a so-called splitsample method, which involves the following: all observations are randomly assigned to one of four groups. Three groups serve to provide the probabilistic diagnosis rule (training groups), which is subsequently tested in the fourth group (test group). This procedure is repeated four times; each time a different group of the four becomes the test group, so that each patient is a test paticnt exactly once. The resulting diagnostic allocations will be free of the above-mentioned bias and can be considered as representing the quality of allocations for future patients. The individual pattient groups are small and thus not suitable for the split-sample method. Therefore, only the diagnostic performance of the calculated probabilistic diagnosis rule discriminating between the control group on the one hand and the combined paticnt groups on the other is tested using the splitsample method.

Table XXVIII presents the subsets of variables selected from the complete groups, and the subsets selected from the training groups 1-4. 


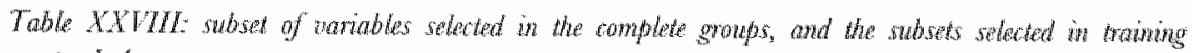
groupsis $1-4$.

\begin{tabular}{|c|c|c|c|c|}
\hline $\begin{array}{l}\text { Complete } \\
\text { groups }\end{array}$ & Training group 1 & Training group 2 & Training group 3 & Training group 4 \\
\hline $\operatorname{arc67C56}$ & $\operatorname{arc67C56}$ & $\operatorname{arc67C56}$ & $\operatorname{arc67C56}$ & \\
\hline Smarc3-6 & $\begin{array}{l}\text { Smarc3-6 } \\
\mathrm{R} 7 \times \mathrm{C}_{1}\end{array}$ & SmarC3-6 & SmarC3-6 & SmarC3-6 \\
\hline $\begin{array}{l}\text { SmR7 } \times 0-2 \\
\text { Sum tr } \\
\text { sdl } \mathrm{C} 4 \\
\text { dd } 2 \mathrm{C} 6 \mathrm{C7} \\
\operatorname{tr} \mathrm{C} 4 \mathrm{C5}\end{array}$ & $\begin{array}{l}\text { sdl } \mathrm{C} 4 \\
\text { dd } 2 \mathrm{C} 6 \mathrm{C} 7 \\
\operatorname{tr} \mathrm{C} 4 \mathrm{C} 5 \\
\text { dd } 1 \mathrm{C} 1 \mathrm{C} 2\end{array}$ & $\begin{array}{l}\text { SimA7 } \times 0.2 \\
\text { Sumtr } \\
\text { sdlc4 } \\
\text { dd2 C6C7 } \\
\text { dd1 } \mathrm{C} 1 \mathrm{Cz}\end{array}$ & $\begin{array}{l}\text { SmR7 } \times 0-2 \\
\text { Sum tr } \\
\text { sdl } \mathrm{C} 4 \\
\text { dd2 } \mathrm{C} 6 \mathrm{C} 7 \\
\text { tr } \mathrm{C} 4 \mathrm{C} 5\end{array}$ & $\begin{array}{l}\text { Sum tr } \\
\text { sdl } \mathrm{C} 4 \\
\text { dd } 2 \mathrm{C} 6 \mathrm{CP}\end{array}$ \\
\hline
\end{tabular}

The subset of variables, selected in each training group, serves to derive a probabilistic diagnosis rule. This rule is applied to the test group belonging to the training group. The resulting sensitivity, specificity, and diagnostic values of the calculated probabilistic diagnoses in the successive test groups are presented in Table XXIX.

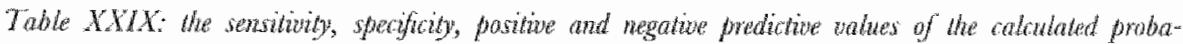
billitic diagnowes in the succerstive lest groups.

\begin{tabular}{|c|c|c|c|c|c|c|}
\hline \multirow{2}{*}{$\begin{array}{l}\text { Calculated } \\
\text { diagnostic } \\
\text { probability } \\
\text { All subjects }\end{array}$} & \multirow{2}{*}{$\frac{\text { sensitivity }}{(83 \%) 84 / 101}$} & \multicolumn{2}{|c|}{ specificity } & \multicolumn{2}{|c|}{$\begin{array}{l}\text { positive } \\
\text { diagnostic } \\
\text { value }\end{array}$} & \multirow{2}{*}{$\begin{array}{l}\begin{array}{l}\text { negative } \\
\text { diagnostic } \\
\text { value }\end{array} \\
(86 \%) 100 / 117\end{array}$} \\
\hline & & $(89 \%)$ & $100 / 112$ & $(88 \%)$ & $84 / 96$ & \\
\hline first sample & $(76 \%) 19 / 25$ & $(86 \%)$ & $24 / 28$ & $(78 \%)$ & $19 / 24$ & $(83 \%) 24 / 29$ \\
\hline second sample & $(80 \%) 20 / 25$ & $(86 \%)$ & 24/ 28 & $(83 \%)$ & $20 / 24$ & $(83 \%) 24 / 29$ \\
\hline third sample & $(80 \%) 20 / 25$ & $(86 \%)$ & $24 / 28$ & $(87 \%)$ & $20 / 23$ & $(80 \%) 24 / 30$ \\
\hline fourth sample & $(69 \%) 18 / 26$ & $(68 \%)$ & $19 / 28$ & $(72 \%)$ & $18 / 25$ & $(66 \%) 19 / 29$ \\
\hline
\end{tabular}

The sensicivity and specificity of the successive subsets are graphically presented in ROC curves; the areas under the curves range from $0.82-0.94$.

The selection of variables is consistent and obviously not solely the result of pure chance. This consistency also applies to the sensitivity, specificity, and diagnostic values of the calculated probabilistic diagnoses in the successive test groups. It can be concluded that the bias in our probabilistic diagnosis rule will have no major eflect on the probabilistic diagnoses of future subjects. 


\section{DISCUSSION}

\section{Age}

Degenerative changes of the spine, such as spondylosis and spondylarthrosis, increase with age, cause a narrowing of the spinal canal and are present in almost all individuals over 50 years of age (Nurick, 1972; ten Have, 1978). Due to these changes, especially in combination with an existing rarrow canal, the spinal cord may become compressed, thus inducing the clinical picture of cervical myelopathy. It is, therefore, not sur prising that the patients in the cervical myelopathy group are significantly older than the individuals in the other study groups.

The observation that the mobility of the spine decreases with increasing age has been demonstrated by numerous studies (Jones, 1960; Lind et al. 1989; Weh et al., 1990; Youdas et al, 1992; Braakman, 1994). Therefore, it is obwious that the variable sum rotation [Sum ar] displays a negative correlation with age (Pearson correlation coefficient; $r=-0.38$ ), as was also reported by Weh et al.(1990). Furthemore, the results of this study show that the age-related decrease in mobility with respect to angular rotation [ar] is most distinct at Jevel $\mathrm{G}_{5}-\mathrm{C}_{16}$ which shows the highest natural mobility. The angular rotations at levels $\mathrm{C}_{0}-\mathrm{C}_{\|}$and $\mathrm{C}_{1}-\mathrm{C}_{2}$ are not affected by age.

The variable sum translation. [Sum tr] is also negatively correlated with age (Pearson correlation coefficient; $r=-0.22$ ), although an age-related decrease of translation could only be demonstrated at levels $\mathrm{C}_{4}-\mathrm{C}_{5}$ and $\mathrm{C}_{2}-\mathrm{C}_{3}$.

A segmental disc height reduction related to age, is only seen at level $\mathrm{C}_{5}$. $\mathrm{C}_{i j}$ and to a lesser degrec at lovel $\mathrm{C}_{i_{3}} \mathrm{C}_{7}$. Thus, these reductions are rem sponsible for a decrease in the measured values of the sum dise heights variable in both antellexion [Sum dhl] and retroftexion [Sum dh2].

Anatomical changes due 10 age are often qualified as 'degenerative', especially when they manifest themselves in bony structures such as the spine. These alterations, however, are the result of natural processes and should, therefore, not be regarded as paihological. The development of spondylosis and spondylarthrosis, but also a decrease of angular rotation and a decrease of dise height with increasing age should, therefore, be considered as nomal "in spite of the unfavourable term "degeneration".

In the young, levels $\mathrm{C}_{5}-\mathrm{C}_{6}$ and $\mathrm{C}_{6}-\mathrm{C}_{7}$ show the highest mobility, probably due to differences in (the development of) the uncinate processes, as compared to the higher levels. (Sec Part I-Review-Anatomy-Vertebral segments and motion segment-Middle and lower cervical region-Unci- 
nate process and uncovertebral joints.) The prominent dynamic fonces acting at these levels are supposed to be responsible for the readily developing changes in this part of the cervical spine. These effects have also been described by Penning (1988), Kracmer et al.(1989) and Welh et al. (1990).

The diminishing nobility of the ageing spine also results in a decrease of the dynamic diameter of the spinal canal in anteflexion [dd 1] at all levels, with the exception of levels $\mathrm{C}_{1}-\mathrm{C}_{2}$ and $\mathrm{C}_{6}-\mathrm{C}_{7}$. This negative comratation with age (Pearson correlation coefficient; mean value $\mathbb{E}=-0.18$ ) is not lound for the dynamic diameter in retrofexion [dd 2]. This can be explained as follows. The dynamic diameter of the spinal canal is defined as the smallest distance between the cranial border of the spinal process of a vertebral body and the dorso-caudal angular point of the vertebral body above. Degenerative changes related to age result in a narrowing of the spinal canal, thus in a decrease of the dynamic diameter in remoflexion. This decrease, however, is counterbalanced by the reduced mobility of the spine: the retroflexion posture will be less pronounced, as will be the reduction in the dynamic diameter. In the anteflexion posture, on the other hand, both degeneration and decreased mobility reduce the dynamic diameter, thus establishing the (negative) correlation between the dynamic diameter in anteflexion and age. Age affects the dynamic diameter in anteflexion [dd 1] more than in retroflexion [dd 2]. The sum variables show the same pattern: only the sum of the dynamic diameters in anteflexion [Sum dd 1] is negatively comelated with age (Pearson correlation coefficient; $r=-0.19$ ).

The static diameter of the cervical spinal canal, both cranial and caudal, does not show a significant correlation with age in any of the study groups. These findings correspond to the results of a study by Burrows (1963). The higher incidence of cervical myelopathy in the older age groups might be due to several factors such as a decreasing dyamiz diameter in anteftion, or compression of the cord by soft tissue (hypertrophy of ligaments as a sign of ageing), or a localised rather than a generalised decrease in the diameter of the spinal canal. Penning et al.(1966) described the dynamic mechanism in play as a "pincer mechanism". A small shatic diameter acts as a predisposing factor.

\section{Gender}

The corvical myelopathy group contains significantly more males than females. This is in agreement with earlier studies (Clarke et al., 1956; Lees et al., 1963; de Graaff, 1982; Hamburger et al., 1994). In the present study, as in the studies of Woll et al. (1956), Payne et al.(1957) and Burrows (1963), it is demonstrated that the antero-posterior diameter of the 
cervical spinal canal in healthy individuals is wider in males than in females. These findings seem to be contradictory but can be explained as follows: when males have a narrow cervical spinal canal, they are apt to develop the clinical signs and symptoms of cervical myelopathy more readily than females, because they are more exposed to occupational trauma (Clarke et al., 1956; Nurick, 1972; Jensen et al., 1996). No significant difference in gender distribution was found in the other groups.

In the mid-cervical region, females demonstrate higher values for rotations, translations, and disc heights. These findings are in agreement with the reports of Dvorak et al.(1992) and Youdas et al. (1992).

The cervical canal diameter, both static and dynamic, is larger in males than in females. This is in agreement with the findings of Wolf et al.(1956), Payne et al.(1957) and Burrows (1963) and applies specifically to the dynamic diameter in retroflexion.

\section{Paradoxical liting}

Kracmer et al.(1989) described a peculiar movement of $C_{1}$ in healthy individuals: a paradoxical tilting of the atlas which consisted of retroflexion of $\mathrm{C}_{1}$ in relation to the line of McGregor during anteflexion of the cervical spine. This phenomenon was reported to occur in about $90 \%$ of subjects under the age of 20 (equally in males and females), to diminish with increasing age and finally to change into anteflexion. The present study, however, did not show any correlation between age and the measurements of kinematic variables at level $C_{1}$. The frequency distribution of age in the present control group is about the same as in the study group of Kraemer. We do not even find a difference in the measurements of kinematic variables at level $\mathrm{C}_{1}$ between individuals older versus younger than 40 years of age (Kendall's tau-b test). The instructions on how to perform the ante- and retroflexion manoeuvre are of the utmost importance: they might essentially determine the outcome. Kraemer describes that his instructions do not result in a 'natural' movement of the cervical spine. However, the instructions given in the present study aim to achieve maximal anteflexion and retroflexion as can also be observed in daily life.

\section{Basic kinematic variables}

\section{Angle of rotation}

Table XXX presents a summary of various studies with respect to the measured values for the angle of rotation at successive levels; mean age, gender distribution and a brief description of the instructions given to the subjects are also presented. 

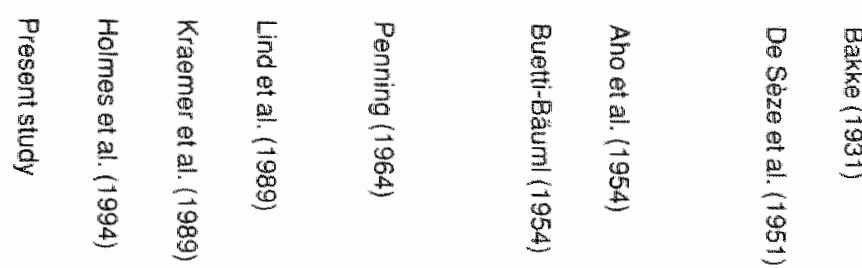

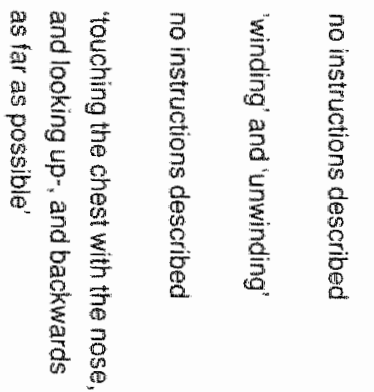

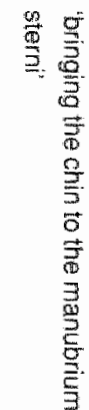

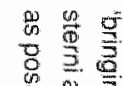

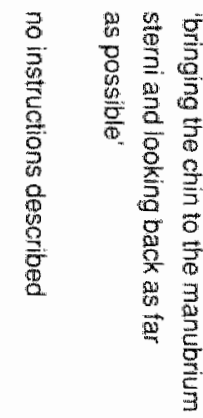

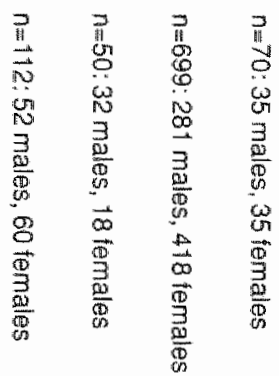

$\stackrel{9}{2} \stackrel{3}{5}$

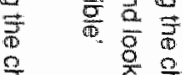

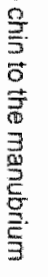

울

$\stackrel{0}{\circ} \vec{b}$

爱 焉

产

का

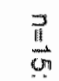

जा $\overrightarrow{0}$

롫

क्ष

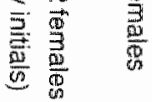

$\stackrel{\vec{i}}{=} \quad \frac{\overrightarrow{1}}{\omega}$

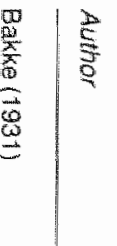

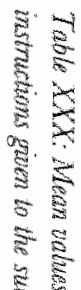

S.

5

온

s

농

哭

i

s

ह

.

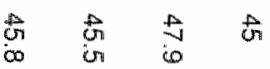

$\mathrm{B}$
$\mathrm{B}$
$\mathrm{N}$

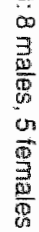

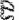

沗

se

है

管

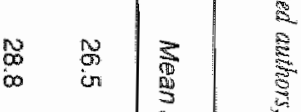

葴

$\vec{\omega} \quad \vec{\omega}$

$\overrightarrow{\vec{N}} \quad \begin{array}{ll}\vec{N} & \vec{\omega}\end{array}$

$\omega$

$\frac{8}{8}$

范

政

政

$=\frac{0}{100}$

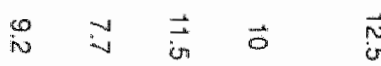

$\overrightarrow{0} \quad \vec{N}$

$\vec{c} \overrightarrow{0}) \vec{n}$

$\vec{\omega} \quad \begin{array}{llll}\vec{\omega} & \infty & \vec{\infty} & \vec{\infty}\end{array}$

$\vec{j} \overrightarrow{0}$

$\vec{D} \quad \vec{i} \quad \vec{\omega} \quad \vec{\omega} \quad \overrightarrow{0}$

$\frac{N}{0} \quad \frac{n}{0}$

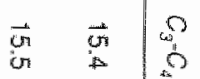

$\stackrel{0}{0}$

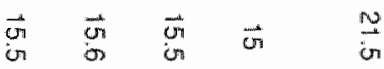

$\begin{array}{ll}N & N \\ U & 0\end{array}$

$\begin{array}{lll}0 & 0 \\ 0 & 0\end{array}$

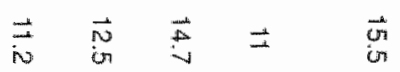

$\vec{\infty} \quad \overrightarrow{0}$

$\begin{array}{lll}\overrightarrow{4} & \vec{j} & 0 \\ \text { in } & 0 & 0\end{array}$

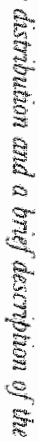


Most studies are confined to a limited number of subjects. The study of Kraemer et al, on the other hand, comprises 699 subjects. It is, therefore, regrettable that the instructions he gave to the subjects to anteflect and retroflect, differ essentially from what is customary. These instructions do not result in a natural movement, as mentioned by the author himself.

The results of the studies presented in Table XXX demonstrate that rotation is less at the upper levels and, with the exception of level $\mathrm{C}_{65}-\mathrm{C}_{7}$, increases downwards.

Significant differences between the study groups in the measured values of the angles of rotation are present at levels $\mathrm{C}_{2}-\mathrm{C}_{3}, \mathrm{C}_{3}-\mathrm{C}_{4}, \mathrm{C}_{4}-\mathrm{C}_{5}$, and $\mathrm{C}_{5}-\mathrm{C}_{6}$ : the mean values of these angles of rotation are significantly higher in the control group than in the patient groups. It can be concluded that a decrease in mobility is associated with a higher probability for pathology. Dvorak et al.(1993) studied three patient groups (total number $n=60$ ) characterised by degenerative changes, radicular symptoms, or symptoms after a whiplash trauma, and found only reduced walues for the angle of rotation at level $\mathrm{C}_{48}-\mathrm{C}_{7}$. Unfortunately the study groups are ill-defined, thus making it impossible to generalise the outcome.

\section{Translation}

Hadley (1956) and Penning (1964) studied a group of healthy individuals and reported that translation is most prominent at levels $\mathrm{C}_{4}-\mathrm{C}_{5}$ and $\mathrm{C}_{5}-\mathrm{C}_{6}$; our findings are in agreement with this report. The present study shows, furthermore, that the control group has significantly larger values for translation at levels $\mathrm{C}_{5}-\mathrm{C}_{6}$ up to and including $\mathrm{C}_{2}-\mathrm{C}_{3}$ than the patient groups. The patient groups themselves do not show mutually significant differences. This means that a decrease in translation is a pathological phenomenon.

\section{Dynamic diameter in anteflexion and retroflexion}

Penning (Penning et al., 1966 ) was the first to stress the importance of $x$ rays in retroflexion, specifically when contact pressure on the spinal cord is suspected to be the cause of myelopathic signs: he found the diameter of the cervical spinal canal to be smallest in this posture. The results of the present study support his opinion: the dynamic diameter is smaller in retrollexion [dd2] than in anteftexion [dd1], in all study groups. The difference between [ddl] and [dd2] diminishes at lower cervical levels. The study groups show significantly different values for the wo variables, [dd 1] and [dd 2], at all levels (see Appendix III).

\section{Disc height}

Disc height decreases with age. This decrease results in a restricted mobility of the spine as is also demonstrated by Jones (1960) and Ball et al.(1964). 
The elastic properties of the intervertebral discs enable remodelling of the spinal column and even more important, remodelling of the spinal canal. In anatomical terms: the facets run obliquely from postero-inferior to antero-superior, thus forcing a tilting of the vertebral bodies during movements. This tilting results in an increase in disc heights measured dorsally, combined with a decrease in disc heights measured ventrally during anteflexion (vice-versa in retroflexion). The length of the spinal column, measured anteriorly, thus decreases in anteflexion and increases in retroflexion, meaning that the values of disc heights in anteflexion [dh1] are generally smaller than in retroflexion [dh2]. The present study confirms these findings. Penning $(1960,1978)$, too, demonstrated that the spinal canal elongates in anteflexion. The author explained this phenomenon by the position of the R-Centres anterior to the spinal canal.

The present study demonstrates that this elongation, defined as the difference between [dh1] and [dh2], is most prominent in healthy individuals at level $\mathrm{C}_{5}-\mathrm{C}_{6}$. Colachis et al.(1965) reported similar findings.

\section{R-Gentre}

The positions of the intersegmental R-Centres as found in the present study, are comparable with those reported by Penning (1988) and Amevo et al.(1991). Significant differences between the study groups are present at levels which exhibit a high mobility: [xR C3], [xR C4], [yR C4], and [xR C5]. However, the measurements of these intersegmental R-Centres show large variances of observations, in the present study as well as in the studies of Penning and Amevo. The clinical significance of this variable is, therefore, limited, if present at all. To obtain information about the cervical spine as a complete structure, we define the variable R-Centre- $\mathrm{C}_{7}$, meaning that the R-Centre of each vertebral body is determined with respect to a common reference, being $C_{7}$. These $R$-Centres- $C_{7}$ are positioned in one co-ordinate system and can be inter-related, thus providing information about the cervical spine as a complete structure.

\section{R-Centre-C7}

The line connecting the successive R-Centres- $\mathrm{C}_{7}$, is called the $\mathrm{R}$-Zero line and represents the kinematic mid-position between the antcflexion and retroftexion posture. This R-Zero line is steeper in the patient groups than in the control group, meaning that the kinematic midposition in patients shifts into the direction of anteflexion. Furthermore, the herniated cervical disc groups show an unequal distribution of the $\mathrm{R}$-centres- $\mathrm{C}_{7}$ amongst the R-zero line, while this line is no longer straight but more or less broken (Appendix II, Figure 13).

The diameter of the spinal canal in our patients is compromised by the presence of a herniated disc or by spondylosis/arthrosis. In anteftexion, 
the diameter of the spinal canal is maximal; therefore, these patients will prefer an anteflexion posture to compensate for the pathological narrowing of the canal. Another reason might be found in the decrease of anterior disc heights in patients. This decrease results in a diminished cervical lordosis, thus inducing an anteflexion posiure.

The R-Zero line determined for the lumbar spine also shows this shift in the direction of anteflexion in the presence of a narrow spinal canal (Berfelo, 1989).

\section{Static diameter}

The mean values of the static diameters measured in this study from level $\mathrm{C}_{5}$ up to and including $\mathrm{C}_{3}$ are concordant with the mean values as presented in the literature (Wolf et al., 1956; Payne et al., 1957; Penning, 1960; Burrows, 1963; Crandall et al., 1966; Bechar et al., 1971).

In the group of patients presenting with cervical myelopathy, the smallest values for the static diameter are predominantly found at level $\mathrm{C}_{4}$; the mean value of $[\mathrm{sdh}]$ is 13.85 and of $[\mathrm{scll}]$ is $15.05 \mathrm{~mm}$. The mean values of the static diameter of $\mathrm{C}_{7}$ up to and including $\mathrm{C}_{4}$ in a group of patients with myelopathy as described by Payne et al.(1957) ranged from 14.1 to 15.0 mm. In a group of athletes with symptomatic developmental stenosis (Herzog ct al., 1990), values of 13.50 to 14.38 were measured. Crandall et al.(1966) noticed that mainly the neurological levels $\mathrm{C}_{4}$ and $\mathrm{C}_{5}$ were involved in the clinical syndrome of cervical myelopathy; at the corresponding anatomical levels, a diameter of approximately $13 \mathrm{~mm}$ was measured. In the present group of patients with cervical myelopathy, the neurological level $\mathrm{C}_{5}$ is most frequently inwolved in the clinical syndrome, subsequently levels $C_{6}, C_{1}, C_{3}, C_{7}$, and $C_{2}$ (frequency of involvement 20, 17, 14, 8, 6 , and 2 times, respectively). This finding is in agreement with the studies of Nordquist (1964) and Braakman et al. (1971) who noted that the free play for the spinat cord is smallest at level $\mathrm{C}_{5}$ (Fig. 7-8, Appendix II).

\section{Derived Rinematic variables}

Kincmatic studies of the spine are almost exclusively focussed on the properties of single segments of motion and have not resulted in the development of diagnostic tools with clinical significance for individual patients. For this reason the so-called denied kinematic variables are defined which acknowledge the notion that the spine behaves as an integrated structure.

\section{Sum variables}

The control group shows significantly higher mean values for both the sum rotations and sum manslations than the patient groups, meaning that the overall mobility is larger in the control group. A limitation in the range of motion is thus a sign of pathology. 
The other sum variables (sum disc heights, sum static diameters and sum dynamic diameters) show the following trend: the mean values in the control group are significantly larger than the mean values in the herniated disc groups, which in turn show significantly larger mean values than the cervical myelopathy group. The clinical picture of a herniated cervical disc has a subacute character: healthy individuals develop signs and symptoms within a few days or weeks, due to anatomical changes in one motion segment. Cervical myelopathy has a more chronic character. Usually, clinical signs and symptoms develop over the course of several months, sometimes even years, and are accompanied by anatomical changes on almost all levels.

It seems that sum variables provide the same information as basic variables on the kinematic behaviour of the cervical spine, be it that differences, if present at all levels, are better visualised.

\section{Cluster variables}

From the graphs representing the mean values of the kinematic variables in the four study groups, a few distinct patterns can be discerned in different parts of the cervical spine (Appendix II, Fig. 1-13). The respective collections of variables defining these patterns are presented by so-called cluster variables. First of all, it appears that the mean values for sum rotations and sum translations of levels $\mathrm{C}_{0}-\mathrm{C}_{3}$ are not significantly different in the four study groups, contrary to the mean values of sum rotations and sum translations of levels $\mathrm{C}_{3}-\mathrm{C}_{6}$ which are significantly larger in the control group. Secondly, it is demonstrated that the R-Zero lines of the patient groups incline to the anteflexion posture. However, both findings also result from an analysis of the mean values of basic kinematic variables.

From the above, it can be concluded that cluster variables do not provide new kinematic information, but merely phrase known findings difGerently.

\section{Ratio variables}

Van Mameren (1988) studied healthy individuals and reported more tilling (i.e. rotation) to be present in the caudal cervical segments than gliding (translation), and vice-versa in the cranial cervical segments. The present study confirms these findings. However, they apply equally to each of the patient groups; diagmostic significance is thus absent.

Dvorak (1993) introduced the ratio translation/rotation as kinematic variable because of its low observer variance. His study groups were small, illdefined, and not significantly different with respect to this variable. The present study is also unable to demonstrate clinically significant differences between the study groups.

In conclusion: ratio variables do not provide clinically significant kincmatic information. 


\section{Chapter 8. \\ General discussion}

Comparison of different studies with respect to observer variability is only possible when the analysing techniques and presentation of the results are standardised. A review of the literature shows that this ideal is far from being realised.

The determination of the reproducibility of measurements in biological systems only makes sense when the variations in measurements of a variable are related to the normal spread of that variable in the population. In other words: measurements in biological systems showing small changes with respect to the normal spread of a variable demonstrate high precision; and vice-versa. For this reason, it was decided to express the observer variability as a fraction $\left(\mathrm{P}_{\text {intertinua }}\right)$ of the total variance of an observation.

The variances of the observations on the newly defined variables $R$ Centre- $\mathrm{C}_{7}$, i.e. the $\mathrm{R}$-Centre of each vertebral body with respect to body $\mathrm{C}_{7}$, are considerably smaller than the equivalent values for observations on the customary intersegmental R-Centres. This might be one reason why these $\mathrm{R}$-Centres- $\mathrm{C}_{7}$, contrary to the customary intersegmental $\mathrm{R}$ Centres, are selected in the subsets of variables, which are used to derive a probabilistic diagnosis rule (see chapter 7: 'Evaluation of cliagnostic performance of kinematic variables'). For this reason, we advocate the use of the R-Centres- $\mathrm{C}_{7}$ in future kinematic studies.

The $R$-Centres- $\mathrm{C}_{7}$ can be determined as reliable as the cervical midsagittal diameter. In the evaluation of patients with cervical myclopathy the diagnostic significance of this variable is taken as a fact.

Measurements of rotation, translation, and disc height are equally subject to observer variability, meaning that, from this point of view, none of these variables is less precise than another in clinical practice.

As far as the clerived variables are concerned the values of the sumvariables rotation, diameter of the spinal canal, and $x$-co-ordinates of the $\mathrm{R}$-Zero line are less subject to observer variation than the sum variables conceming disc heights, translations, and $y$-co-ordinates of the R-Zero line. Of all variables the ratio variables, especially the translation/rotation ratios, are most subject to observer variability.

To improve upon the diagnostic significance of kinematics of the cervical spine, basic as well as derived variables are analysed; the combination of both these variables acknowledge the notion that the cervical spine be- 
haves as an integrated structure. Furthermore, a sophisticated statistical technique, the so-called logistic regression procedure, is used to analyse the huge collection of data. With this technique, it is possible to extract a limited subset of variables from the total number; this subset contains nearly all diagnostic information present. Based on the measurement values of this subset, a probabilistic diagnosis rule is formulated; this diagnosis rule serves to calculate the probabilistic diagnosis of individual subjects. The logistic regression procedure calculates the probability of a particular outcome being true or false. This dichotomy true versus false can also be read as control versus patient, hemiated disc versus myelopathy etc. From this it follows that the calculation of the diagnostic probabilities for indiviclual patients for each of the four study groups takes several steps. Firsi of all, one has to determine whether the subject belongs to the control group or to the patient groups. If belonging to the patient groups, further diagnostic differentiation is necessary: e.g. herniated disc versus myelopathy, etc.

The diagnostic probability is a priori $47 \%$. At a probability level of $50 \%$, a mean of $84 \%$ of the allocations to one of the studly groups is correct and $16 \%$ incorrect. At a level of $70 \%, 85 \%$ of all allocations are correct $(86 \%$ for the control group versus patient groups; $87 \%$ for the group of patients with a herniated disc versus the group of patients with cervical myelopathy; and $71 \%$ for the patient groups with a hemiated disc at two different levels). At a diagnostic probability level of $90 \%$ still $70 \%$ of the allocations are correct $74 \%$ for the control group versus patient groups; $69 \%$ for the group of patients with a herniated disc versus the group of patients with cervical myelopathy; and $67 \%$ for the patient groups with a hemiated disc at two different levels). (See chapter 'Evaluation of diagnostic performances of kinematic variables-Results', Table $\mathrm{XV}-\mathrm{A}, \mathrm{XV}-\mathrm{B}, \mathrm{XIX}$, and $\mathrm{XXIII}$.) It is also demonstrated that increasing values of the calculated diagnostic probabilities are accompanied by highcr positive diagnostic values meaning that the number of correct allocations to the 'non-reference' group increases.

Aho et at. (1955) described reduced mobility in advanced morphological changes in the cervical spine such as osteochondrosis and spondylarthrosis deformans. He also pointed at the unequal distribution of motion amongst the successive segments in pathological cases. Equal versus unequal distribution of motion in the cervical spine in pathological cases was also described by Veleanu et al.(1975). Unfortunately, no definition of the small patient group $(n=3)$ was given. Reduced motion in a small and hetcrogencous patient group $(n=6)$ was also described by Dimnet et al. (1982). Wackenheim (1975) described a very elegant technique to measure cervical spine motion (see 'Review of the literature'). Using this 
method, he could demonstrate a reduced overall mobility or a reduction of ante- or retroflexion in the presence of pathology. However, he did not present information about his patient groups.

In summary: previous studies suggest - but cannot prove beyond reasonable doubt - that reduced mobility and/or an unequal distribution of motion in the cervical spine is a sign of pathology.

Berfelo (1989, 1993) introduced the concept of a so-called $R$-zero line. This line connects the centres of rotation of each lumbar vertebral body with respect to the sacrum. In healthy individuals, this line is straight, while the distances between the successive centres of rotation are equal. "This means that the vertebral bodies are identically oriented with respect to the sacrum from a kinematic point of view, and that each motion segment contributes equally to motions of the lumbar spine. Patient groups exhibit specific configurations of the R-zero line: this line is no longer straight, shows a different inclination and the distances between the centres of rotation are no longer identical.

To enable the construction of a R-zero line for the cervical spine, the centres of rotation of each vertebral body (including $\mathrm{C}_{0}$ ) with respect to $\mathrm{C}_{7}\left(\mathrm{R}\right.$-Gentres $\left.\mathrm{C}_{7}\right)$ are determined. The line, connecting these centres of rotation is called the $\mathrm{R}$-zero line of the cervical spine.

The present study shows that the R-zero line of the cervical spine is straight in healthy individuals, meaning that all cervical vertebral bodies (including $\mathrm{C}_{0}$ ) are identically orientated with respect to $\mathrm{C}_{7}$. The distances between the rotation centres are identical in the lower and mid-cervical region, meaning that these motion segments contribute equally to motions of the cervical spine. The upper cervical segments show a higher mobility than the lower and mid cervical segments, meaning that the distances beiween the rotation centres of $\mathrm{C}_{0}$ and $\mathrm{C}_{1}$, and $\mathrm{C}_{1}$ and $\mathrm{C}_{2}$ respectively, are larger but they are still identically orientated with respect to $\mathrm{C}_{7}$. Patients characteristics as suggested in the above-mentioned studics could indisputably be proved in the present study. As shown by the sclected variables the patient groups show a characteristic R-zero line on the one hand and a reduction of mobility on the other. The R-zero line is more or less broken and follows a steeper course while the R-centres of the successive vertebral bodies with respect to $\mathrm{C}_{7}$ are unequally distributed along this line. This means that the cervical spine inclines to the anteflexion posture on the one hand while the overall mobility decreases in the patient groups.

Berfelo explained this steepening of the R-zero line as a sign of stenosis, resulting from compression of the content of the spinal canal. This compressing mechanism is present in both the cervical myelopathy group as well as in the hemiated cervical disc groups. The antero-posterior diameter of the cervical spinal canal increases in anteflexion, thus explain- 
ing the tendency of these patients to assume an anteflexion posture.

It is striking that the majority of the selected wariables which differentiate between healthy individuals and patients with a hernated cervical dise do not refer to the level of pathology: only two of the seven selected variables are directly related to the levels $\mathrm{C}_{5}-\mathrm{C}_{6}$ or $\mathrm{C}_{6}-\mathrm{C}_{3}$ ([arC67C56) and [dh2 $\mathrm{C} 6 \mathrm{C} 7]]$. It is obvious that pathology affects the kinematic behaviour of the cervical spine as a complete structure.

Local hypomobility as a result of a radicular disorder is described earher but may also be present in patients with degenerative changes of the spinal column (Dworak et al., 1993).

Boijsen (1954) was the first to measure the sagital diameter of the cervical spinal canal, not to diagnose pathological narrowing, but rather the opposite, pathological widening. It was Arnold (1955) who linked the clinical picture of cervical myelopathy to a narrow spinal canal. Since then, the diagnosis of cervical myelopathy still relies on various factors including measurement of the sagittal diameter of the spinal canal. The spinal cord casily becomes compromised and injured in a narrow canal. With the advent of MRI, these injuries are now visible as hyperintense intramedullary foci. Notwithstanding the presence of these intramedullary lesions, it is still mandatory to establish a narrow spinal canal as their cause. On the other hand, one has to bear in mind that a narrow spinall canal may also be present without any clinical signs or symptoms of cervical myelopathy. This means that one cannot solely rely on measurements of the spinal canal diameter.

The present study demonstrates that function $x$-rays of patients with cervical myelopathy are not exclusively characterised by a narrow spinal canal, but also by a decrease in rotation at level $\mathrm{C}_{6}-\mathrm{C}_{7}$ up to and including $\mathrm{C}_{2}-\mathrm{C}_{3}$ and by a decrease in disc height in anteftexion at the same levels. The decrease in disc heights in anteflexion results from degenerative changes of the intervertebral dises and is associated on the one hand with a diminished cervical lordosis, and on the other with a decrease in mobility, as is also reflected by the concomitant decrease of rotation.

The calculated diagnostic probabilities for the subjects allocated to the cervical myelopathy group are, thus, based on the measurement values of these three variables and not exdusively on the values of spinal canal diameter.

The calculated diagnostic probabilities and allocations of subjects to diagnosis groups are assigned on the basis of observations within the same diagnosis groups: subjects serve both as reference and as test subjects. To climinate this bias as much as possible, and to test the performance of the selected subset of variables, we used a so-called split-sample method. 
The patient groups are rather small: it is, therefore, not possible to apply the split-sample method to these groups individually. It is possible, however, to test the diagnostic performance of the probabilistic diagnosis rule discriminating between the control group on the one hand and all patient groups together on the other with the split-sample method.

The results demonstrate that the selection of variables is consistent and not the result of pure chance. "This consistency is also present in the sensitivity, specificity and diagnostic values of the calculated probabilistic diagnoses in the successive test groups. From this, it can be concluded that the bias, which is present in the current probabilistic diagnosis rule, will not essentially affect the quality of calculated probabilistic diagnoses of future subjects.

\section{RECOMMENDATIONS FOR FUTURE STUDIES}

- Clear definitions of kinematic variables, reference points and positions of co-ordinate systems on the one hand and standardisation of postures to be examined, measuring methods, and analysis of observer variability on the other are essential for the extension of the present kinematic knowledge.

- The rapid progress in the development of MRI techniques will make the conventional $\mathrm{x}$-ray techniques redundant and will enable the analysis of sequential images of the moving spine.

- Studying not only the preoperative images of patients groups as defined in the present study, but also comparing them with the postoperative images will further extend our kinematic knowledge of the cervical spine. 


\section{Chapter 9. \\ Conclusions}

Anteflexion and retroflexion $\mathrm{x}$-rays reflect the outcome of forces acting on the spine. The actual movements resulting from these forces, as well as the forces themselves, are not visualised. These limitations restrict the diagnostic significance of kinematic studies of function $x$-rays. However, qualitative descriptions of $\mathrm{x}$-rays are subject to the same limitations. The following questions are, therefore, raised in the introduction of this study:

1. Do kinematic studies of function $x$-rays of the cervical spine have clinical significance?

2. Do kinematic studies of function $x$-rays of the cervical spine contribute to the clinical diagnosis of individual patients?

Previous studies have clearly demonstrated that kinematic measurements on function $\mathrm{x}$-rays provide means to characterise groups of patients. These characteristics contribute to our understanding of functions of the cervical spine.

The present study also demonstrates the presence of some group characteristics. The distances between the $\mathrm{R}$-centres- $\mathrm{C}_{7}$ of the vertebral bodies $\mathrm{C}_{6}$ up to and including $\mathrm{C}_{3}$ are approximately equal in healthy individuals while the distances between the $R$-Centres- $C_{7}$ of bodies $C_{3}$ up to and including $\mathrm{C}_{0}$ are somewhat larger but also equal. This means that the motion segments in the indicated regions contribute equally to motions of the cervical spine in healthy individuals. The line, connecting these RCentres- $C_{y}$ is called the R-zero line. This line is straight in healthy individuals, meaning that all motion segments are identically orientated with respect to $\mathrm{C}_{7}$.

All patient groups are characterised by a decrease in mobility of the cervical spine. They are furthermore inclined to an anteflexion posture and to a decrease of cervical lordosis.

An unequal distribution of the R-Centres- $C_{7}$ is found along the $R$-Zero line, which is no longer straight. This means that the respective motion segments do not contribute equally to motion of the cervical spine, and also that these motion segments are not identically orientated with respect to $\mathrm{C}_{7}$ in these groups.

All groups demonstrate that the cervical spine behaves as an integrated structure: structural changes at one level affect the kinematic behav- 
iour of the other motion segments. A kinematic analysis of function x-rays of the cervical spine should, therefore, take into account all motion segments.

Thus far, kinematic studies have failed to demonstrate diagnostic significance for individual patients. (An exception has to be made for the measurements of the antero-posterior diameter of the spinal canal in patients presenting with clinical signs and symptoms of cervical myelopathy.

One reason for this might be that the variances of observations in the measurements of kinematic variables are large (as is demonstrated in an analysis of observer variability). Another reason might be that the attention is commonly focussed on the diagnostic performance of single kinematic variables.

The statistical technique of logistic regression was called upon to evaluate the diagnostic significance of function $x$-rays of the cervical spine for individual patients. This procedure enables the selection of a limited number of variables which, as a subgroup, contain nearly all diagnostic information that is present in the study groups.

The results of the logistic regression procedure demonstrate convincingly that kinematic studies of function x-rays of the cervical spine yield diagnostic information, which is clinically significant for individual palients. The results of the split-sample method demonstrate, furthermore, that the quality of calculated probabilistic diagnoses of future subjects will be about the same as in the present study, provided that the mixture of patient populations and methods of investigation remain the same. 


\section{Chapter 10. \\ Summary}

Neck pain, with or without neurological signs of spinal cord or nerve root compression is very common: about $30 \%$ of the population suffers from pain in the neck on at least one occasion during their working life. Imaging studics aim to depict the cause of the complaints, but quite often fail to do so. Frequently, morphological changes are found that may also be present in individuals without complaints and sometimes no abnormalitics are found at all. These studies are almost exclusively focussed on qualitative information. The present study focusses on the quantitative information provided by so-called function x-rays of the cervical spine: lateral $x$ rays made in maximal anteflexion and in maximal retrofiexion.

A computer-assisted measuring technique is developed to analyse kinematically the function $x$-rays of a group of healthy individuals $(n=112)$ and of three groups of patients: one group suffering from cervical myelopathy $(\mathrm{n}=25)$ and two groups suffering from a herniated cervical disc at level $\mathrm{C}_{5}-\mathrm{C}_{6}(\mathrm{n}=28)$, and at level $\mathrm{C}_{6}-\mathrm{C}_{7}$, respectively $(\mathrm{n}=48)$.

The present study focusses on two issues:

- are kinematic studies of the cervical spine clinically relevant

- do kinematic studies of the cervical spine have clinical significance for the individual patient

Chapter 2 elucidates some anatomical aspects of the cervical spine, which are considered relevant for the present study.

Chapter 3 discusses the results of imaging techniques commonly used for the diagnosis of patients with cervicobrachialgia.

Myelography and/or GT-myelography provide the best diagnostic information on patients with radiculopathy, but these procedures are invasive. MR imaging is a non-invasive alternative, but it often demonstrates the inability to make a distinction between a soft disc and a bony spur as the cause of nerve root compression. In these cases additional plain $x$-rays or CT are useful.

Plain $x$-rays predict the onset of spinal cord compression in cervical myelopathy when the AP diameter of the spinal canal is less than 12.5 $\mathrm{mm}$. When the cross-sectional area of the spinal cord is reduced by $30 \%$ or more, or when the cross-sectional area of the spinal cord is $60 \mathrm{~mm}^{2}$ or less on MR or CT-myelography, long tract signs will start to develop. Intramedullary areas with increased signal intensities on $\mathrm{T}_{2}$-weighted $\mathrm{MR}$ images indicate the region of maximal cord compression. 
Despite sophisticated $\mathrm{CT}$ and MR imaging techniques, which are mainly morphologically oriented, the cause of cervicobrachialgia remains unexplained in about $10-20 \%$ of the patients.

The kinematic behaviour of the cervical spine has been extensively studied in order to gather additional information. A review of these studies is presented in chapter 4 . The bentefits for the individual patient, however, are still scant if present at all. Therefore, function $x$-rays of the cervical spime are not used as a routine for diagnostic purposes. One reason why kinematic studies have not resulted in the development of diagnostic tools with clinical significance for individual patients might be that the attention is almost exclusively focussed on the properties of single segments of motion, disregarding the fact that the spine behaves as an integrated chain of motion segments and as a complete structure. Another reason might be found in the large variances of observations, which are mainly physiological.

The present study puts emphasis on the quantitative data obtained from function $x$-rays of the cervical spine. On both the anteflexion and retroflexion x-ray film, 43 predefined landmarks are identified and marked with a pencil. These markings serve to calculate the values of a large number of kinematic variables. A specific sofware programme was written to enable the present kinematic analyses.

Motion can be analysed in two different ways: the Cartesian method and the R-centre method.

The Cartesian method describes displacements in an $x-, y-z-c o-o r d i-$ nate system as rotations about and/or linear displacements along these axes. The R-centre method describes any displacement of a rigid body in one plane, though actually resulting from combined rotations and linear displacements, as if it results from pure rotation only about one axis perpendicular to that plane.

Acknowledging the concept of the cervical spine as a complete and integrated structure, a number of derived kinematic variables which pay tribute to this notion are defined $(n=39)$.

The concept of the $\mathrm{R}$-zero line is introduced. This line describes the kinematic mid-position of the cervical spine between anteflexion and retrollexion, representing the situation in which the cervical spine as at whole has consumed half the amount of rotations and linear displacements required to carry out the anteflexion-retroflexion manoeuve. The other derived variables are divided into sum-variables and ratio-variables. The sum-variables refer to summation of variables (summation of all segments of one variable or summation in clusters of several segments of that 
vamable). The ratio-variables refer to the ratio of segmental manstation and segmental rotation, respectively, and to the ratio of segmental rotation and summotation. In all, 77 basic variables and 39 derived variables are defined. The infuence of age and gender is also taken into account.

An obsenver variabilicy study has been carried out to evaluate the accuracy of the measurements and to identify different types of error (Chap(er 6).

Kinematic studies of the spine are commonly evaluated with techniques of unvariate analysis, meaning that the attention is focussed on the effect of one single variable on the mean values of different study groups. Differences between the patient groups with respect to age and gender and the effect of age and gender on the values of observations of the defined variables are analysed. Differences beween the study groups with respect to the values of observations of the respective variables are analysed $t o 0$. The correlations between the values of observations of the respective kinematic variables are calculated.

The logistic regression procedure, a technique of multivariate analysis, cuables us to select a limited number of variables containing (nearly) all diagnostic information present in the study groups. The values of the selected variables allow one to calculate the diagnostic probability of a particular outcome being rue or false. This dichotomy true versus false, can also be read as healthy versus patient or as myelopathy versus hernated dise etc. The values of each continuous variable are recoded and assigned to one of three equally sized categories or tertiles: low, median or high walues. Next, the logistic regnession coefficient is calculated for each tertile. Using the logistic regression procedure in order to select variables with diagnostic significance poses two particular problems. The first problem has to do with the possible collinearity betwoen several variables within the data set. To handle this problem an arbitrarily chosen threshold for the adds ratios is introduced: when the value of 10 is exceeded, the selection procedure stops. The second problem an be described as data dredging. One might put all measured values of all variables of $\mathrm{C}_{0}$ down to $C_{*}$ through the logistic regression procedure in one go. If one does this, the output might be the result of pure chance. To mimimise this risk, we examine the data systematically, practising eight different strategies. The results of all strategies are evaluated with respect to the discriminating performance of the selected subsets of variables. The strategy, which performed best, is finally selected.

The observed values of the selected subset of variables serve to calculate the diagnostic probability for an individual with respect to one of two diagnosis groups. The quality of this probabilistic diagnosis is presented by the Receiver Operating Characteristic (ROC) curve. 
The diagnostic probability is a priori $47 \%$. At a probability level of $50 \%$, $84 \%$ of the allocations to one of the study groups is correct. At a probability level of $70 \%, 85 \%$ of all allocations are correct. And at a diagnostic probability level of $90 \%$ still $70 \%$ of the allocations are correct. It is also demonstrated that increasing values of the calculated diagnostic probabilities are accompanied by higher positive diagnostic values meaning that the number of correct allocations to the 'non-reference' group increases.

All patient groups are characterised by a decrease in mobility of the cervical spine. They are furthermore inclined to an anteflexion posture and a decrease of cervical lordosis.

An unequal distribution of the R-Centres- $C_{7}$ is found along the R-Zero line, which is no longer straight. This means that the respective motion segments do not contribute equally to motions of the cervical spine, and also that these motion segments are not identically orientated with respect to $\mathrm{G}_{7}$ in these groups.

All groups demonstrate that the cervical spine behaves as an integrated structure: structural changes at one level affect the kinematic behaviour of the other motion segments. A kinematic analysis of function $\mathrm{x}$-rays of the cervical spine should, therefore, take into account all motion segments.

Finally, the results of the split-sample method demonstrate that the quality of calculated probabilistic diagnoses of future subjects will be about the same as presented in this study, provided that the mixture of patient populations and methods of investigation remain the same. 


\section{Samenvatting}

Pijn in de nek, al dan niet met tekenen van ruggemerg- of wortelcompressie is een veel voorkomende klacht. Gemiddeld 1 op de 3 mensen heeft gedurende zijn of haar arbeidsverleden wel eens last gehad van dit soort nekklachten. Beeldvormende technieken leveren een belangrijke bijdrage aan de klinische diagnostiek omdat hiermee zicht verkregen kan worden op de oorzaak van de klachten.

Diagnostische procedures zijn echter niet altijd bevredigend. De oorzaak kan gelegen zijn in het feit dat de verkregen beelden met name kwalitatief beoordeeld worden en nauwelijks kwantitatief.

In deze studie wordt een meetmethode geintroduceerd waarmee sagitale anteflexie- en retroflexie opnamen kwantitatief worden geanalyseerd. Deze opnamen zijn gemaakt van cen controle groep $(n=112)$ en van drie patiënten groepen $(n=101)$ : van patiënten met een cervicale myelopathy $(n=25)$, van patienten met een $H N P$ op het niveau $\mathrm{C}_{5}-\mathrm{C}_{6}(\mathrm{n}=28)$ en van cen groep patiënten met een $\mathrm{HNP}_{\mathrm{N}}$ op het niveau $\mathrm{C}_{6}-\mathrm{C}_{7}(\mathrm{n}=48)$.

Centraal in deze studie staan de volgende vragen:

- hebben kinematische studies van de halswervelkolom klinische betekenis

- hebben kinematische studies van de halswervelkolom diagnostische betekenis voor de individuele patiënt

De anatomische aspecten die voor deze studie relevant worden geacht zijn beschreven in hoofdstuk 2 .

In hoofdstuk 3 worden de beeldvormende technieken beschreven die bij patiënten met cervico-brachialgie gangbaar zijn.

Bij patiënten met radiculopathie wordt myelografie al dan niet gecombineerd met CT onderzoek beschouwd als onderzocks-modalitcit van cerste keuze. Dit onderzoek is echter invasief. MRI is cen niet-invasief alternatief. Echter, met MRI is het onderscheid tussen een benige of weke delen compressie moeilijk te maken. In die gevallen kan CT aanvullende informatie geven.

Cervicale myelopathie door compressie van het myelum wordi waarschijnlijk wanneer de AP diameter van het cervicalc kanaal op de gewone overzichrsfoto kleiner is dan $12,5 \mathrm{~mm}$. Lange baan verschijnselen ontstaan wanneer de oppervlakte van het myelum op dwars doorsnede- weergegeven met CT-myelografie of MRI-afneemt met $30 \%$ of meer, of wanneer 
dit oppervlak minder dan $60 \mathrm{~mm}^{2}$ bedraagt. Ter plaatse van de medullaire compressie kunnen intramedullaire gebieden ontstaan met verhoogde signaal intensiteit op de $\mathrm{T}_{2}$ gewogen MRI opname.

Ondanks deze moderne veclal morfologisch georiënteerde technieken kan in $10-20 \%$ van de patienten met een cervicobrachialgie geen oorzaak van de klachten worden aangetoond.

Funktiefoto's van de halswervelkolom kunnen de besproken statische beelden aanvullen. Het kinematisch gedrag van de halswervelkolom is uitgebreid bestudeerd (hoofdstuk 4). Ondanks de grote hoeveelheid data die deze studies hebben opgeleverd zijn de consequenties voor de individuele patiènt gering gebleven en spelen functiefoto's dus geen rol van betekenis in de klinische diagnostiek. Een van de redenen zou kunnen zijn dat kinematische studies zich doorgaans richten op het gedrag van afzonderlijke bewegingssegmenten. Hiermee gaat men voorbij aan het feit dat de wervelkolom zich gedraagt als één geheel van geintegreerde bewegingssegmenten. Een andere oorzaak ligt mogelijk in de grote natuurlijke variatie van kinematische grootheden en in de onnauwkeurigheid van de metingen.

De huidige studie legt de nadruk op de kwantitatieve informatie die verkregen kan worden door functiefoto's van de halswervelkolom kinematisch te analyseren met behulp van gecomputeriseerde methode. Op zowel de ante- als op de retroflexiefoto's worden 43 herkenningspunten volgens protocol gemarkeerd. Aan de hand van deze markeringen worden de waarden van een groot aantal variabelen bepaald. Het inlezen van de markeringen en het berekenen van de variabelen gebeurt met behulp van een computer die is voorzien van specifiels ontwikkelde software.

In hoofdstuk 5 worden een aantal afgeleide variabelen gedefinieerd. Deze variabelen berusten op het inzicht dat de cervicale wervelkolom beweegt als een geintegreerd geheel dat is samengesteld uit afzonderlijke bewegingssegmenten. Er zijn twee methoden om standveranderingen van een voorwerp in de rumte vast to leggen: de zgn. Cartesiaanse methode en de zgn. R-centrum methode. Met de Cartesiaanse methode worden standveranderingen vastgelegd in een $x-, y-$, en $z$ - coördinatenstelsel als rotaties rónd deze assen al dan niet gecombineerd met lineaire verplaatsingen lángs die assen. Met de R-centrum methode worden verplaatsingen beschreven van een lichaam in een wak alsof deze verplaatsingen uitsluitend het gevolg zijn van rotaties rond écn punt, het $\mathrm{R}$-centrum. De $\mathrm{R}$-centrum methode maakt het mogelijk een zogenaande $R$-nullijn te construeren. Deze lijn weerspiegelt de middenpositie van de halswervelkolom tussen anteflexie en retroflexie in. In die positie is de helf van alle rotaties en de helf van alle lineaire verplaatsingen uitgevoerd die nodig zijn om van anteflexie naar retroHexie te bewegen of vice versa. Andere afgeleide variabelen geven de som 
weer van een basale variabele met betrekking tot verschillende bewegingssegmenten te samen of geven de verhouding weer tussen lineaire verplatsing en rotatie op segmentaal niveau respectievelijk de verhouding tussen segmentale rotatie en somrotaties. In totaal worden 77 basale variabelen en 39 afgeleide variabelen gedefinieerd. Ook wordt gekeken naar de invloed van leeftijd en geslacht.

Om een indruk te krijgen over de reproduceerbaarheid van de meetresultaten is een zogenaamde 'observer variance" studie uitgevoerd (hoofdstuk 6).

In kinematische studies is het gebruikelijk om univariant analyses uit te voeren. Verschillen tussen de patiènten groepen met betrekking tot leeftijd en geslacht, en de invloed van leefijd en geslacht op de verschillende variabelen is geanalyseerd. Verder is nagegaan in hoeverre verschillen bestaan in waarden van afzonderlijke variabelen tussen de patiëntengroepen. Ook is de samenhang tussen de afzonderlijke variabelen bestudeerd door de correlatie-coefficienten te berekenen.

Behalve deze univariate analyses zijn ook multivariante analyses uitgevoerd, en wel met de statistische technick van logistische regressie. Met deze technick kan een selecte groep van variabelen worden geidentificeerd die - als groep - nagenoeg alle diagnostische informatie bevat die aanwezig is in de studiegroepen. Met behulp van die geselecteerde variabelen wordt vervolgens een z.g. regressie-vergelijking opgesteld. Deze regressie-vergelijking dient om de kans te berekenen of een bepaalde uitkomst waar is of niet waar (behoort een individu tot de controlegroep of tot: de patientengroep, tot de patienten met het klinisch beeld van cervicale myelopathie of hernia, tot patiënten met cen $\mathrm{HNP}_{\mathrm{C}_{5}}-\mathrm{C}_{6}$ of met een $\left.\mathrm{HNP}_{\mathrm{C}_{6}}-\mathrm{C}_{7}\right)$. Bij de uitvoer van deze procedure moet rekening gehouden worden met de invloed van extreem hoge of extreem lage meetwaarden wan de variabelen (uitbijters), met mogelijke collineariteit tussen de verschillende variabelen, en met missers die kunnen optreden wanneer grote hoevedheid variabelen tegelijk wordt geanalyseerd ("data dredging"). De meetwaarden van de varabelen worden daarom gerecodeerd in drie min of meer gelijke groepen van hoge, gemiddelde, en lage waarden. Verder wordt de procedure van selectie van variabelen afgebroken wanneer de bijbehorende odds ratios onbetrouwbaar hoog (or laag) worden (arbitrair gekozen grenswaarde van de odds ratio $=10$ ). De logistische regressie methode wordt stapsgewijs uitgevoerd. Variabelen worden allereerst op grond van een bepaalde strategie gegroepeerd: in totaal zijn acht strategieên gedefiniecrd en dus acht groepen van variabelen samengesteld. Deze ach groepen, of clusters, wan variabelen worden afzonderlijk geanalyseerd. Verwolgens worden de variabelen die uit deze clusters worden geselecteerd samengevoegd en aan een 
eindanalyse onderworpen. Met de regressie-coefficienten van de variabelen die in deze laatste analyse worden geselecteerd wordt een regressie-vergelijking ofwel 'probabilistic diagnosis rule' opgesteld. Met deze 'probabilistic diagnosis rule' worden voor ieder individu de kansen berekend te behoren bij de verschillende diagnose-categoriëen: hij wordt uiteindelijk toegewezen aan de diagnose-categorie waarvoor de hoogste kans is berekend. De diagnostische waarde wordt tevens uitgedrukt in de sensitiviteit, specificiteit en diagnostische waarde van een dergelijke berekende kans, en wordt grafisch weergegeven in zogenaamde ROC curven. Ook wordt nader ingegaan op de karakteristieken van de verschillende diagnose-groepen aan de hand van de meetwaarden van de uiteindelijk geselecteerde variabelen.

De kans om aan de correcte patienten-groep toegewezen te worden is a-priori $47 \%$. Bij een berekende kans van $50 \%$ blijkt $84 \%$ van de individuen correct toegewezen. Bij een berekende kans van $70 \%$ zijn $85 \%$ van de toewijzingen correct en bij een berekende kans van $90 \%$ zijn nog steeds $70 \%$ van alle toewijzingen juist. Tevens blijkt dat de positieve diagnostische waarde direct samenhangt met de grootte van de berekende kans op een bepaalde diagnose: deze stijgt wanneer de kans groter is, en neemt af bij kleinere kans.

De bestudeerde onderzoeksgroepen laten een karakteristiek kinematisch patroon zien. Bij gezonde individuen liggen de $\mathrm{R}$-centra- $\mathrm{C}_{7}$ van $\mathrm{C}_{6}$ tot en met $\mathrm{C}_{3}$ op gelijke afstand van elkaar. De afstanden tussen de $\mathrm{R}-$ centra- $\mathrm{C}_{\gamma}$ van $C_{3}$ tot en met $C_{0}$ zijn eveneens aan elkaar gelijk maar zijn iets groter dan de afstanden tussen de R-centra van $\mathrm{C}_{66}$ tot en met $\mathrm{G}_{3}$. Dit betekent dat de betreffende bewegingssegmenten gelijkelijk bijdragen aan bewegingen van de halswervelkolom. De lijn die de $\mathrm{R}$-centra- $\mathrm{C}_{7}$ verbindt wordt de $\mathrm{R}$-nullijn genoemd. Bij gezonde individuen is de $\mathrm{R}$-nullijn recht waaruit volgt dat de opeenvolgende bewegingssegmenten identiek georiënteerd zijm ten opzichte van $\mathrm{C}_{7}$. Alle patiènten-groepen tonen een verminderde mobiliteit waarbij de halswervelkolom neigt naar anteflexie en de cervicale lordose afnecmt. De R-nullijn is niet meer recht en de $\mathrm{R}$-centra- $\mathrm{C}_{7}$ zijn op ongelijke afstand van ellkaar gelokaliseerd op deze lijn.

De halswervelkolom gedraagl zich in de vier onderzoeksgrocpen als én geintegreerd geheel: structurele veranderingen op één niveau beinvloeden het kinematisch gedrag van de andere niveaus. Wanneer functiefoto's van de halswervelkolom dan ook worden gebruikt voor diagnostische doeleinden is het noodzakelijk om álle bewegingssegmenten kinematisch te analyseren.

De resultaton van de 'split sample' analyse tenslotte, tonen aan dat de rosultaten van de huidige studie reproduceerbaar zijn. 


\title{
Appendix I
}

\author{
GRAPHS
}

Age distribution

- Frequency tables

- Box plot

(Fig. 1- 4)

(Fig. 5)

Gender distribution

- Frequency table

(Fig. 6) 
Age distribution: frequency iables.

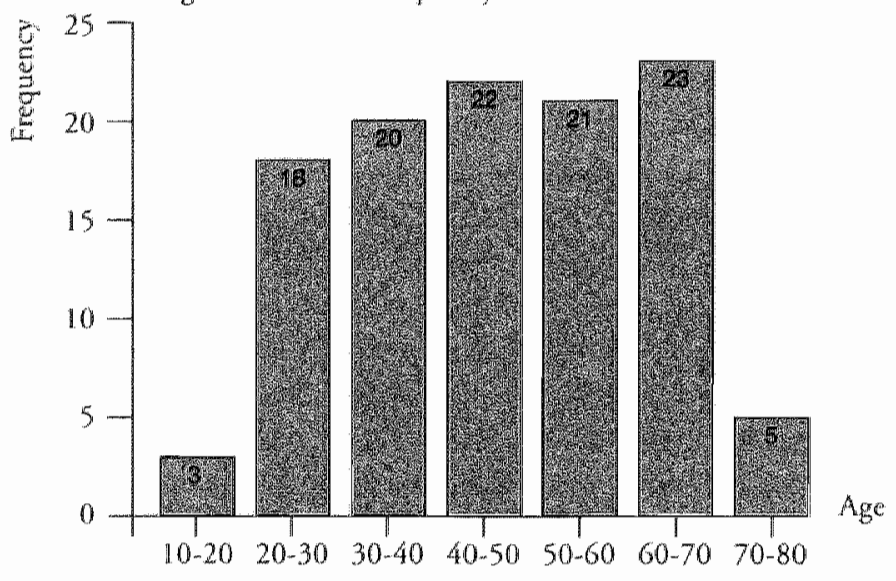

Srd. Dew $=14.97 \quad$ Mean $=46 \quad N=112.00$

Frg. 1: Control Group

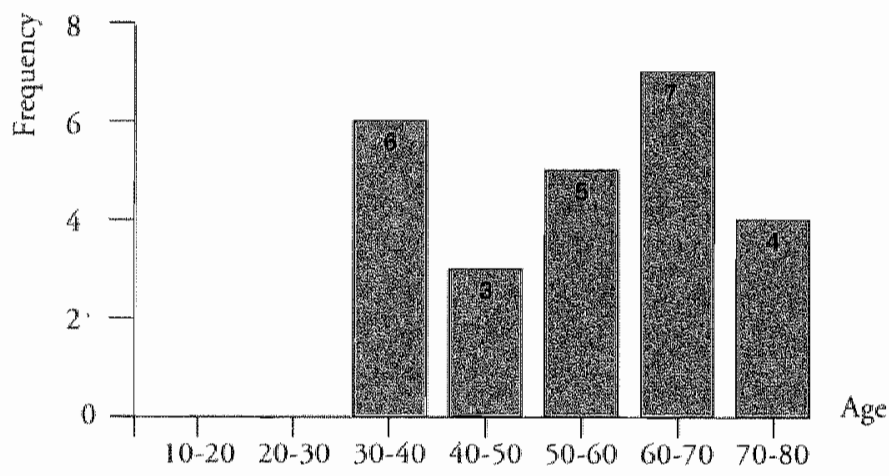

Sul. Dev. $=15.25 \quad$ Mean $=56 \quad \mathrm{~N}=25.00$

Fig. 2. Centon mprotopathy 


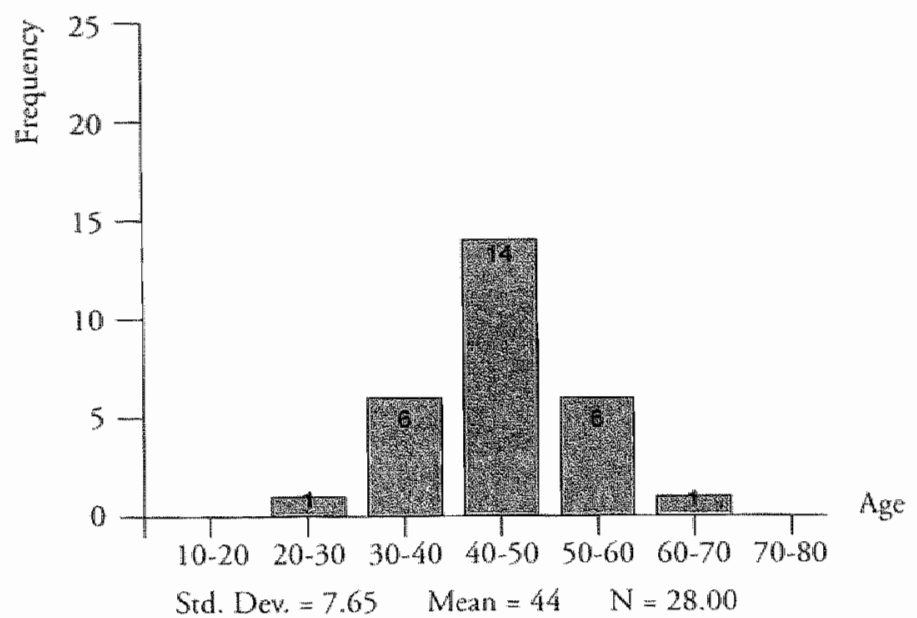

Fig. 3: Hemiated disc $C_{5}-C_{6}$

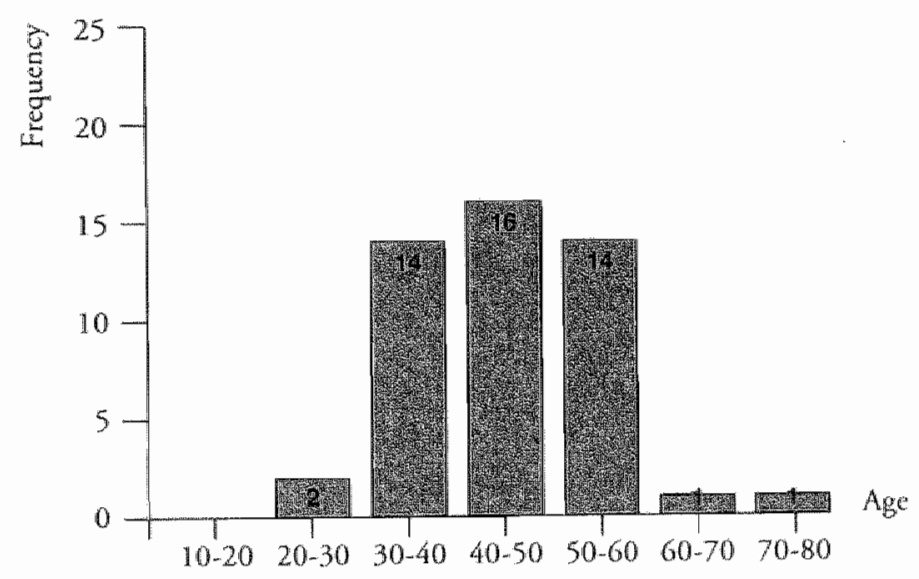

Sod. Dev $=9.34 \quad$ Mean $=45 \quad \mathrm{~N}=48.00$

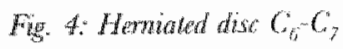




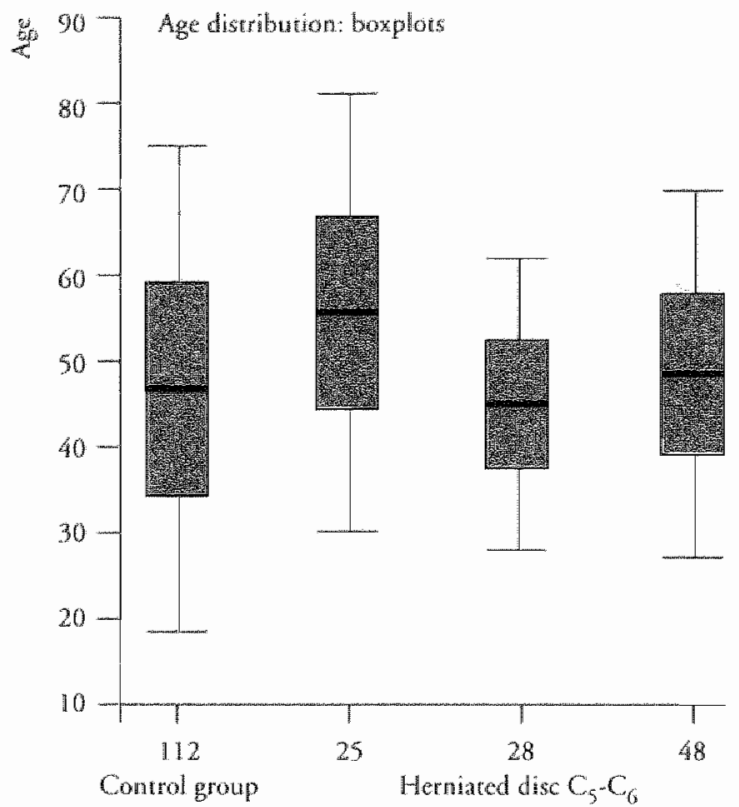

Cerwical myelopathy Herniated disc $\mathrm{C}_{6}-\mathrm{C}_{7}$

For. 5: Age disnibutw within the shady grotps

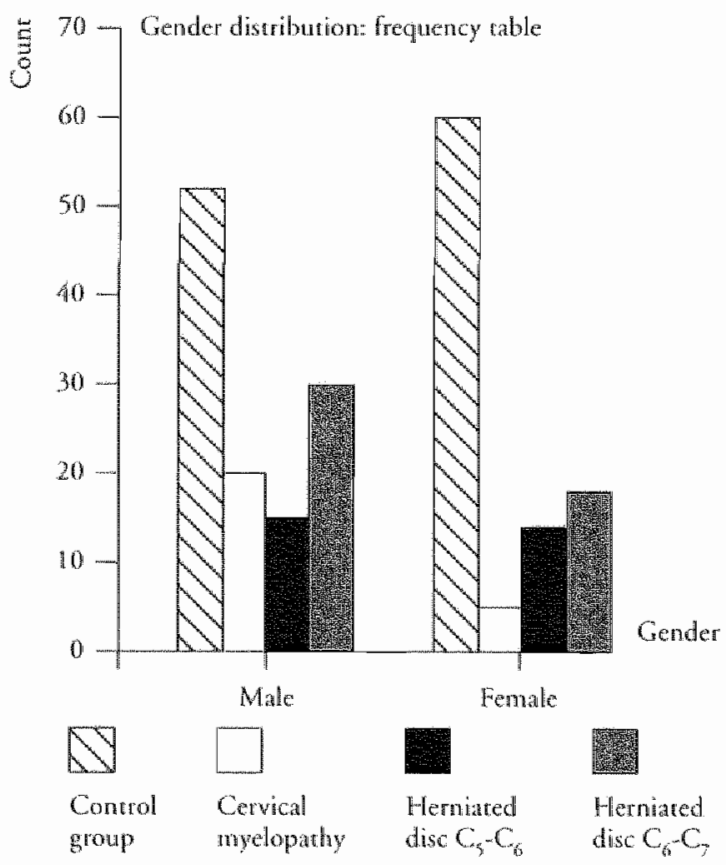

Fig. G. Gouder distribution in the stadty groups 


\section{Appendix II}

Angles of rotation

Translation

Disc heights in anteflexion

Disc heights in retroflexion

Dynamic diameters in anteflexion

Dynamic diameters in retroflexion

Cranial static diameters

Gaudal static diameters

R-Cientres: $\mathrm{x}$-co-ordinates

R-Cientres: y-co-ordinates

R-Centres-C7: $\mathrm{x}$-co-ordinates

R-Centres-C7: y-co-ordinates

R-Zero line in the study groups.

Atlanto-axial distance
(Fig. and table 1) (Fig. and table 2) (Fig. and table 3) (Fig. and table 4) (Fig. and table 5) (Fig. and table 6) (Fig. and table 7) (Fig. and table 8) (Fig. and table 9) (Fig. and table 10) (Fig. and table 11) (Fig. and table 12) (Fig. and table 13) (Table 14) 


\section{Angles of rolation}

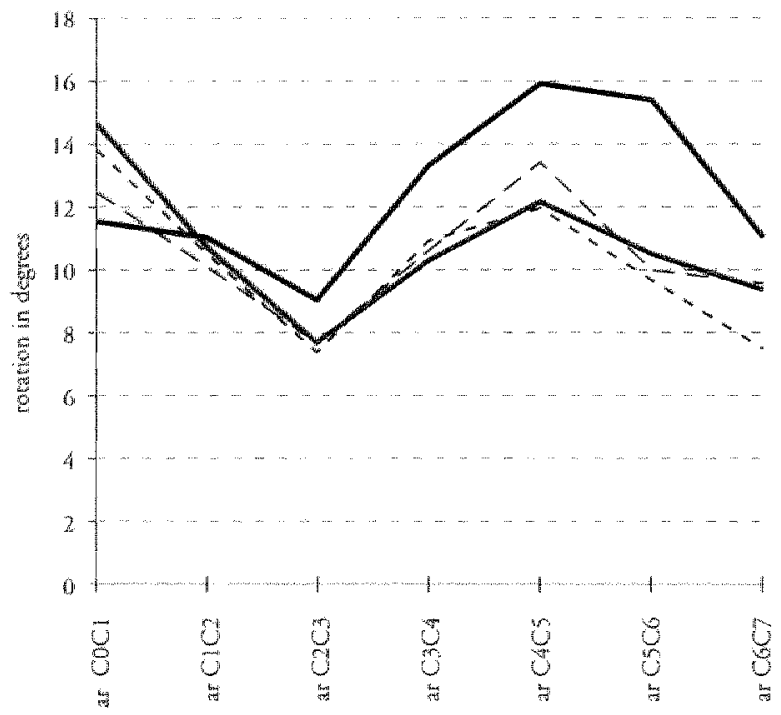

Control groutp

Cerwical myctopathy

- - - Herniated disc $\mathrm{C}_{5}-\mathrm{C}_{6,4}$

a.......... Hernated disc $\mathrm{C}_{6} \mathrm{C}_{\text {? }}$

Fig. I: mean values of angles of rotation at successine levels 


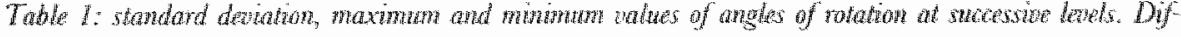

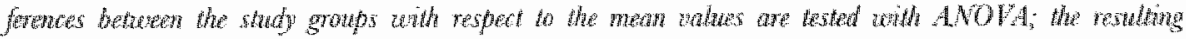
p-ralues are presented whe that colum.

\begin{tabular}{|c|c|c|c|c|c|}
\hline & & $S . D$ & $\min$. & $\max$ & p-value \\
\hline \multirow[t]{4}{*}{ ar $\mathrm{Cico}$} & Control group & 8.35 & -6.95 & 29.42 & $p=0.16$ \\
\hline & Cervical myelopathy & 5.82 & 5.38 & 28.04 & \\
\hline & Herniated disc $\mathrm{C}_{5} \cdot \mathrm{C}_{6}$ & 6.10 & -0.11 & 22.44 & \\
\hline & Herniated disc $\mathrm{C}_{6}-\mathrm{C}_{7}$ & 7.27 & -3.60 & 27.49 & \\
\hline \multirow[t]{4}{*}{ ar $\mathrm{C} 2 \mathrm{C} 1$} & Control group & 5.24 & -1.75 & 27.72 & $p=0.75$ \\
\hline & Cervical myelopathy & 4.48 & 3.52 & 21.58 & \\
\hline & Herniated disc $\mathrm{C}_{5}-\mathrm{C}_{6}$ & 4.90 & 0.96 & 22.85 & \\
\hline & Herniated disc $\mathrm{C}_{6}-\mathrm{C}_{7}$ & 4.25 & 2.23 & 24.26 & \\
\hline \multirow[t]{4}{*}{$\operatorname{ar} \mathrm{C} 3 \mathrm{C} 2$} & Contral group & 3.07 & 2.46 & 17.89 & $p=0.00$ \\
\hline & Cervical myelopathy & 3.15 & 0.63 & 14.33 & \\
\hline & Herniated disc $C_{5}-C_{6}$ & 2.67 & 3.55 & 12.77 & \\
\hline & Herniated disc $\mathrm{C}_{6}-\mathrm{C}_{7}$ & 3.23 & 1.31 & 13.39 & \\
\hline \multirow[t]{4}{*}{ ar $\mathrm{C} 4 \mathrm{C3}$} & Control group & 3.81 & 6.18 & 26.76 & $p=0.00$ \\
\hline & Cerwical myelopathy & 3.52 & 3.76 & 17.08 & \\
\hline & Herniated disc $\mathrm{C}_{5}-\mathrm{C}_{6}$ & 4.05 & 1.18 & 16.46 & \\
\hline & Herniated disc $\mathrm{C}_{6}-\mathrm{C}_{7}$ & 4.43 & 3.43 & 22.86 & \\
\hline \multirow[t]{4}{*}{ ar $\mathrm{C} 5 \mathrm{C} 4$} & Control group & 4.75 & 3.51 & 33.12 & $p=0.00$ \\
\hline & Cervical myelopathy & 4.92 & 2.22 & 19.76 & \\
\hline & Herniated disc $\mathrm{C}_{5}-\mathrm{C}_{6}$ & 5.23 & 1.54 & 23.15 & \\
\hline & Herniated disc $\mathrm{C}_{6}-\mathrm{C}_{7}$ & 4.48 & 2.17 & 18.66 & \\
\hline \multirow[t]{4}{*}{$\operatorname{ar} \mathrm{C} 6 \mathrm{C} 5$} & Control group & 4.94 & 0.97 & 27.40 & $p=0.00$ \\
\hline & Cervical myelopathy & 4.98 & -0.57 & 17.34 & \\
\hline & Herniated disc $\mathrm{C}_{5}-\mathrm{C}_{6}$ & 3.55 & 4.34 & 18.29 & \\
\hline & Hernated disc $\mathrm{C}_{6} \cdot \mathrm{C}_{7}$ & 5.21 & 1.78 & 21.99 & \\
\hline \multirow[t]{4}{*}{ ar $\mathrm{C} 6 \mathrm{C7}$} & Control group & 5.35 & 1.24 & 27.18 & $p=0.00$ \\
\hline & Cervical myelopathy & 4.82 & -1.26 & 18.74 & \\
\hline & Hermilated disc $\mathrm{C}_{5}-\mathrm{C}_{6}$ & 6.19 & -7.25 & 21.70 & \\
\hline & Herniated disc $\mathrm{C}_{6}-\mathrm{C}_{7}$ & 4.22 & -0.33 & 18.12 & \\
\hline
\end{tabular}




\section{Translation}

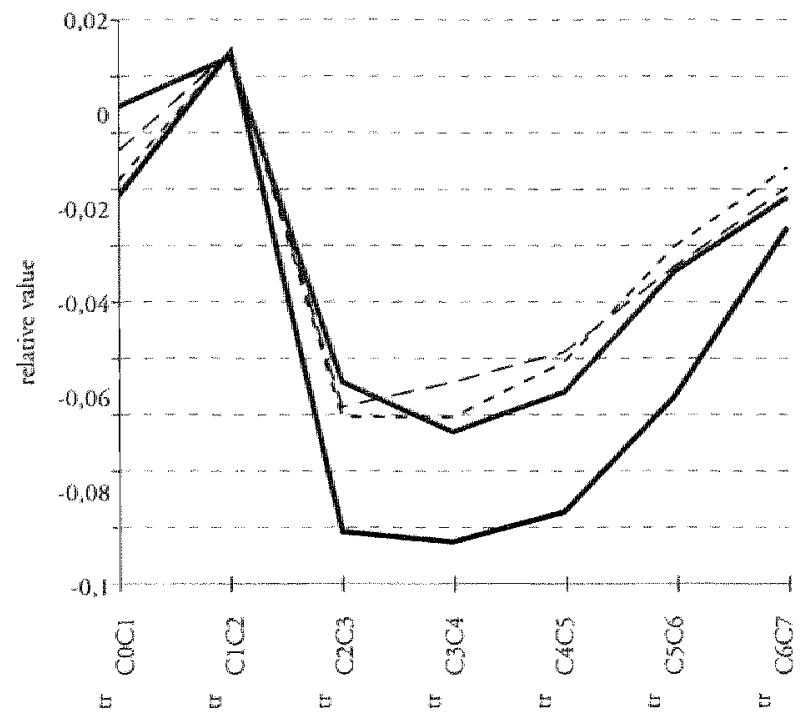

\section{Control group}

Cervical myelopathy

$-\ldots-$ - Hernated disc $\mathbb{C}_{5}-C_{6}$

Hernated disc $\mathrm{C}-\mathrm{C}$ ?

Pig. 2. mean walues of manslation at successio lowds 


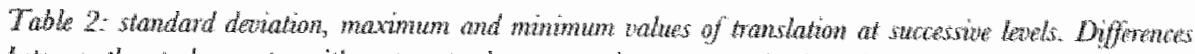

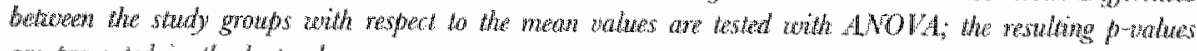
are presented in the last column.

\begin{tabular}{|c|c|c|c|c|c|}
\hline & & $S . D$ & $\min$ & max. & p-value \\
\hline \multirow[t]{4}{*}{ Ir $\mathrm{COC1}$} & Control group & 0.04 & -0.13 & 0.11 & $p=0.26$ \\
\hline & Cervical myelopathy & 0.04 & -0.11 & 0.06 & \\
\hline & Herniated disc $\mathrm{C}_{5}-\mathrm{C}_{5}$ & 0.03 & -0.07 & 0.04 & \\
\hline & Herniated disc $\mathrm{C}_{6} \cdot \mathrm{C}_{7}$ & 0.06 & -0.22 & 0.06 & \\
\hline \multirow[t]{4}{*}{$\operatorname{lrClC2}$} & Control group & 0.03 & -0.06 & 0.11 & $p=0.74$ \\
\hline & Cervical myelopathy & 0.04 & -0.07 & 0.11 & \\
\hline & Herniated disc $\mathrm{C}_{55} \mathrm{C}_{6}$ & 0.03 & -0.04 & 0.07 & \\
\hline & Herniated disc $\mathrm{C}_{6}{ }^{\circ} \mathrm{C}_{7}$ & 0.03 & -0.08 & 0.07 & \\
\hline \multirow[t]{4}{*}{$\operatorname{tr} \mathrm{C} 2 \mathrm{C} 3$} & Control group & 0.05 & -0.23 & 0.03 & $p=0.00$ \\
\hline & Cervical myelopathy & 0.05 & -0.20 & 0.01 & \\
\hline & Herniated disc $\mathrm{C}_{5}-\mathrm{C}_{15}$ & 0.05 & -0.16 & 0.07 & \\
\hline & Hernjated disc $\mathrm{C}_{10}-\mathrm{C}_{7}$ & 0.05 & -0.18 & 0.05 & \\
\hline \multirow[t]{4}{*}{$\operatorname{tr} \mathrm{C} 3 \mathrm{C} 4$} & Control group & 0.06 & -0.25 & 0.07 & $p=0.00$ \\
\hline & Cervical myelopathy & 0.04 & -0.19 & 0.02 & \\
\hline & Hermiated disc $\mathrm{C}_{5}-\mathrm{C}_{6}$ & 0.05 & -0.15 & 0.04 & \\
\hline & Herniated disc $\mathrm{C}_{6} \cdot \mathrm{C}_{7}$ & 0.05 & -0.15 & 0.02 & \\
\hline \multirow[t]{4}{*}{$\operatorname{tr} C 4 C 5$} & Control group & 0.05 & -0.22 & 0.05 & $p=0,00$ \\
\hline & Cervical myelopathy & 0.06 & -0.21 & 0.04 & \\
\hline & Herniated disc $\mathrm{C}_{\mathrm{g}}-\mathrm{C}_{\hat{6}}$ & 0.04 & -0.13 & 0.02 & \\
\hline & Herniated disc $\mathrm{C}_{6}-\mathrm{C}_{7}$ & 0.05 & -0.18 & 0.05 & \\
\hline \multirow[t]{4}{*}{ ti $\mathrm{C} 5 \mathrm{C6}$} & Control group & 0.05 & -0.20 & 0.05 & $p=0.00$ \\
\hline & Cervical myelopathy & 0.05 & -0.15 & 0.05 & \\
\hline & Herniated disc $\mathrm{C}_{5}-\mathrm{C}_{6}$ & 0.05 & -0.17 & 0.06 & \\
\hline & Herniated disc $\mathrm{C}_{6}-\mathrm{C}_{7}$ & 0.04 & -0.14 & 0.05 & \\
\hline \multirow[t]{4}{*}{$\operatorname{tr} 6607$} & Control giroup & 0.04 & -0.14 & 0.09 & $p=0.32$ \\
\hline & Cervical myelopathy & 0.05 & -0.12 & 0.06 & \\
\hline & Herniated disc $\mathrm{C}_{5}{ } \mathrm{C}_{6}$ & 0.04 & -0.16 & 0.08 & \\
\hline & Herniated disc $\mathrm{C}_{6}-\mathrm{C}_{7}$ & 0.04 & 0.15 & 0.09 & \\
\hline
\end{tabular}


Disc heights in anteftexion

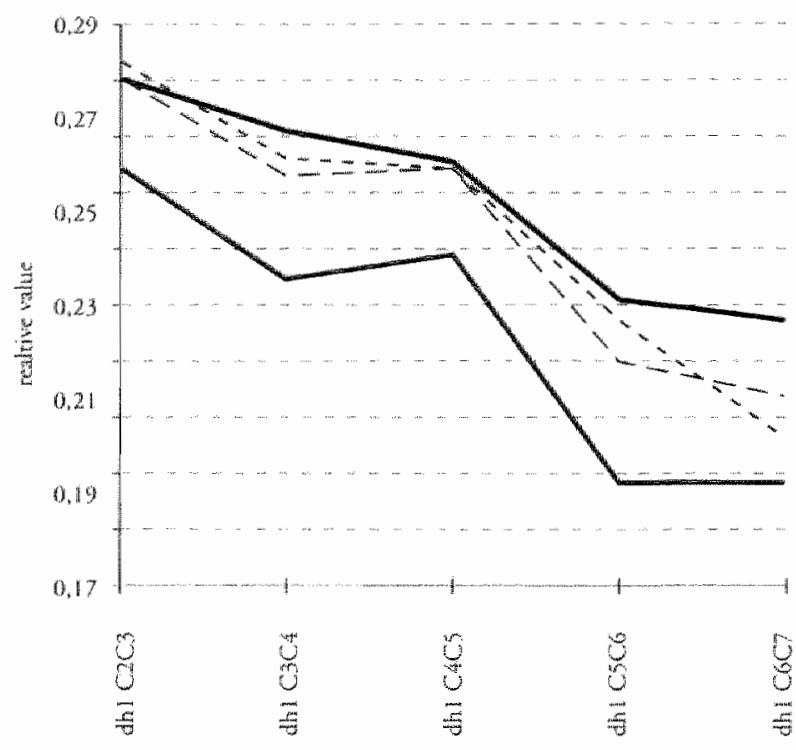

Control grous?

Cerrical motopatly

$-\ldots-\ldots$ Hernated disc $C_{y}-C_{b}$

Herniated diac $C_{0} \cdot C_{7}$

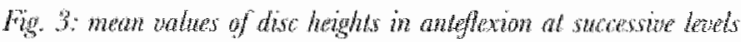




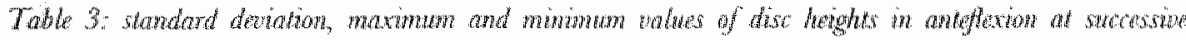

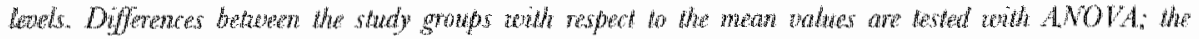
resulting $p$-solues are presented in the last columm.

\begin{tabular}{|c|c|c|c|c|c|}
\hline & & $S . D$ & $\min$ & $\max$ & p-value \\
\hline \multirow[t]{4}{*}{ dh1 $\mathrm{C} 3 \mathrm{C} 2$} & Control group & 0.04 & 0.16 & 0.36 & $p=0.18$ \\
\hline & Cervical myelopathy & 0.06 & 0.07 & 0.35 & \\
\hline & Herniated disc $\mathrm{C}_{5}-\mathrm{C}_{6}$ & 0.04 & 0.20 & 0.34 & \\
\hline & Herniated disc $C_{6} \cdot C_{7}$ & 0.05 & 0.19 & 0.36 & \\
\hline \multirow[t]{4}{*}{ dhi C4C3 } & Control group & 0.04 & 0.14 & 0.36 & $p=0.03$ \\
\hline & Cervical myelopathy & 0.06 & 0.11 & 0.38 & \\
\hline & Herniated disc $\mathrm{C}_{5}-\mathrm{C}_{6}$ & 0.05 & 0.13 & 0.35 & \\
\hline & Herniated disc $\mathrm{C}_{6}-\mathrm{C}_{7}$ & 0.04 & 0.16 & 0.40 & \\
\hline \multirow[t]{4}{*}{ dhy $\mathrm{C} 5 \mathrm{C} 4$} & Control group & 0.04 & 0.14 & 0.36 & $p=0.28$ \\
\hline & Cervical myelopathy & 0.05 & 0.13 & 0.32 & \\
\hline & Herniated disc $\mathrm{C}_{5}-\mathrm{C}_{6}$ & 0.05 & 0.16 & 0.37 & \\
\hline & Herniated disc $\mathrm{C}_{6}-\mathrm{C}_{7}$ & 0.05 & 0.04 & 0.33 & \\
\hline \multirow[t]{4}{*}{ dh1 C6C5 } & Control group & 0.05 & 0.05 & 0.34 & $p=0.01$ \\
\hline & Cervical myelopathy & 0.06 & 0.07 & 0.28 & \\
\hline & Herniated disc $\mathrm{C}_{5}-\mathrm{C}_{6}$ & 0.04 & 0.16 & 0.30 & \\
\hline & Herniated disc $\mathrm{C}_{16}-\mathrm{C}_{7}$ & 0.05 & 0.13 & 0.35 & \\
\hline \multirow[t]{4}{*}{ dh1 0706} & Control group & 0.05 & 0.04 & 0.37 & $p=0.01$ \\
\hline & Cervical myelopathy & 0.06 & 0.09 & 0.29 & \\
\hline & Herniated disc $\mathrm{C}_{5}-\mathrm{C}_{6}$ & 0.06 & 0.07 & 0.33 & \\
\hline & Herniated disc $\mathrm{C}_{6} \cdot \mathrm{C}_{7}$ & 0.04 & 0.12 & 0.30 & \\
\hline
\end{tabular}




\section{Disc heights in retroflexion}

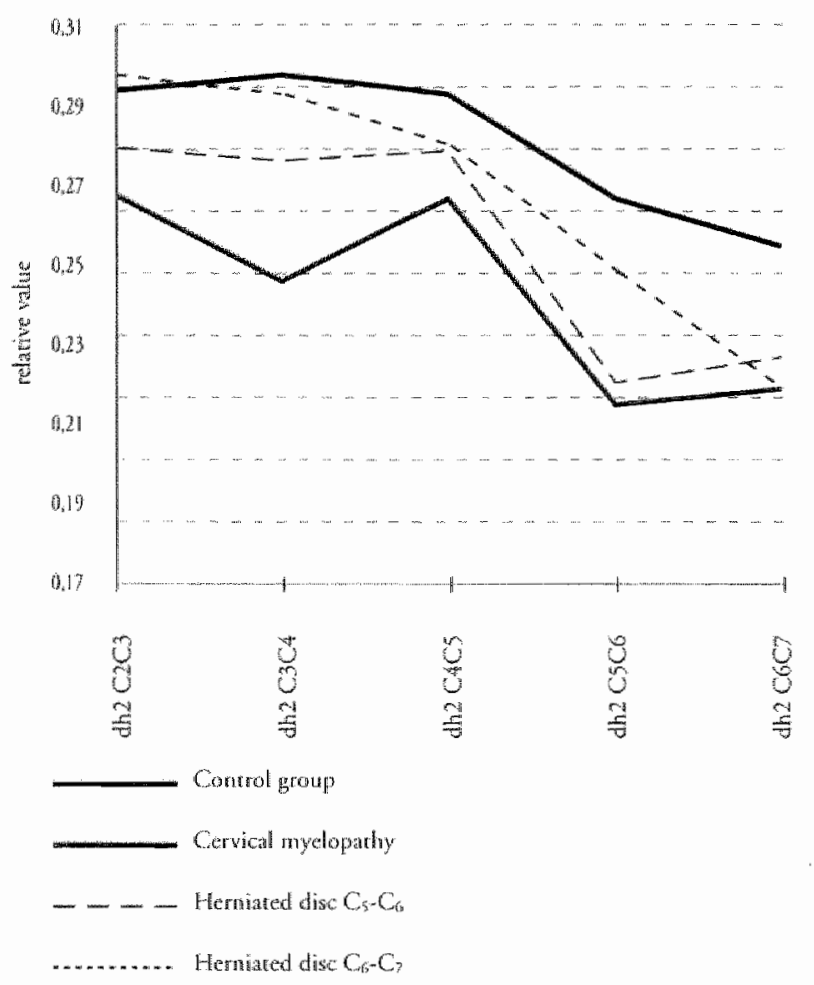

Figg. A: mean values of dise heights in wehwfexion at succersie levels 


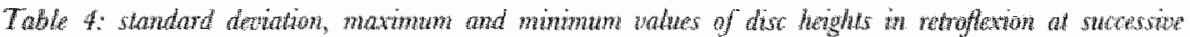

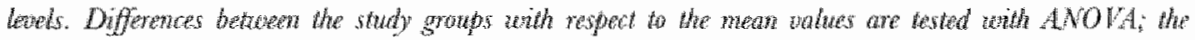
rendthg pondues are presented in the last coliwn.

\begin{tabular}{|c|c|c|c|c|c|}
\hline & & S.D. & min. & $\max$ & p-value \\
\hline \multirow[t]{4}{*}{ dhe $\mathrm{C}_{3} \mathrm{C} 2$} & Control group & 0.04 & 0.115 & 0.40 & $p=0.02$ \\
\hline & Cervical myelopathy & 0.07 & 0.08 & 0.40 & \\
\hline & Hernialed disc $\mathrm{C}_{5}-\mathrm{C}_{6}$ & 0.05 & 0.20 & 0.37 & \\
\hline & Herniated disc $\mathrm{C}_{6}-\mathrm{C}_{7}$ & 0.04 & 0.21 & 0.37 & \\
\hline \multirow[t]{4}{*}{ dh2 $\mathrm{C} 4 \mathrm{C} 3$} & Control group & 0.04 & 0.116 & 0.42 & $p=0.00$ \\
\hline & Cervical myelopatthy & 0.06 & 0.14 & 0.38 & \\
\hline & Herniated disc $\mathrm{C}_{5} \cdot \mathrm{C}_{6}$ & 0.05 & 0.16 & 0.37 & \\
\hline & Herniated disc $\mathrm{C}_{6}-\mathrm{C}_{7}$ & 0.05 & 0.19 & 0.41 & \\
\hline \multirow[t]{4}{*}{ dh2 $\mathrm{C5C} 4$} & Control group & 0.05 & 0.14 & 0.39 & $p=0.07$ \\
\hline & Cervical myelopathy & 0.05 & 0.17 & 0.38 & \\
\hline & Herniated disc $\mathrm{C}_{5}-\mathrm{C}_{6}$ & 0.05 & 0.18 & 0.35 & \\
\hline & Hernated disc $\mathrm{C}_{6} \cdot \mathrm{C}_{7}$ & 0.06 & 0.05 & 0.37 & \\
\hline \multirow[t]{4}{*}{ dhe C6C5 5} & Control group & 0.05 & 0.10 & 0.40 & $p=0.00$ \\
\hline & Cervical myelopathy & 0.06 & 0.11 & 0.32 & \\
\hline & Herniated disc $\mathrm{C}_{5}-\mathrm{C}_{6}$ & 0.04 & 0.10 & 0.31 & \\
\hline & Herniated disc $\mathrm{C}_{6}-\mathrm{C}_{7}$ & 0.05 & 0.15 & 0.36 & \\
\hline \multirow[t]{4}{*}{ dh2 $\mathrm{C7C6}$} & Control group & 0.06 & 0.05 & 0.38 & $\rho=0.00$ \\
\hline & Cervical myelopathy & 0.07 & 0.11 & 0.31 & \\
\hline & Herniated disc $\mathrm{C}_{5}-\mathrm{C}_{6}$ & 0.06 & 0.08 & 0.34 & \\
\hline & Herniated disc $\mathrm{C}_{6}-\mathrm{C}_{7}$ & 0.05 & 0.11 & 0.34 & \\
\hline
\end{tabular}




\section{Dynamic diameters in anteflexion}

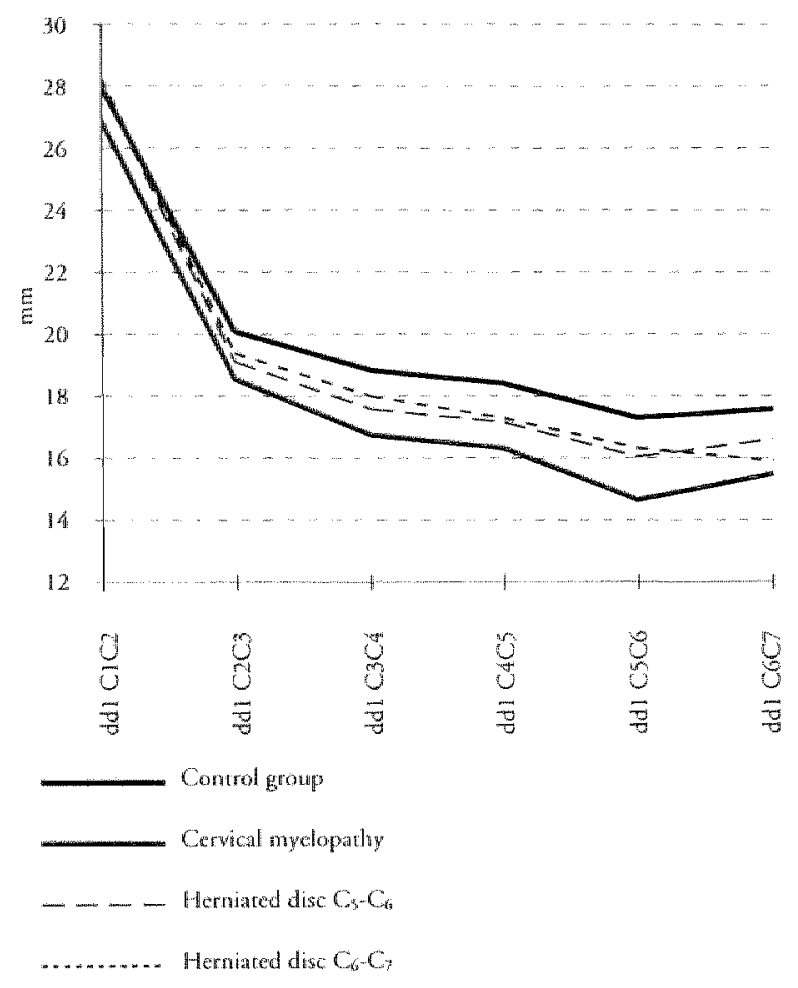

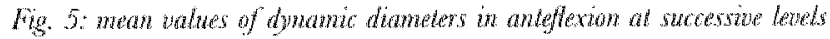




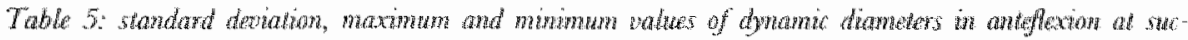

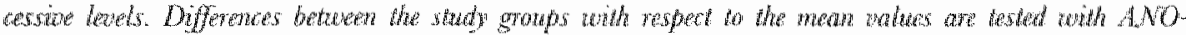

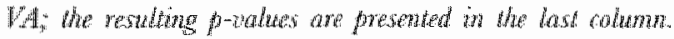

\begin{tabular}{|c|c|c|c|c|c|}
\hline & & $S . D$ & $\min$ & max. & p-value \\
\hline \multirow[t]{4}{*}{ dd $1 \mathrm{C} 2 \mathrm{Cl}$} & Control group & 3.37 & 19.52 & 43.62 & $p=0.27$ \\
\hline & Cervical myelopathy & 3.53 & 20.37 & 34.63 & \\
\hline & Herniated disc $\mathrm{C}_{5}-\mathrm{C}_{6}$ & 2.42 & 23.48 & 32.06 & \\
\hline & Herniated disc $\mathrm{C}_{6}-\mathrm{C}_{7}$ & 2.51 & 21.50 & 32.63 & \\
\hline \multirow[t]{4}{*}{ dd1 $\mathrm{CBC} 2$} & Control group & 1.84 & 45.68 & 24.50 & $p=0.00$ \\
\hline & Cervical myelopathy & 2.71 & 14.59 & 24.99 & \\
\hline & Herniated disc $\mathrm{C}_{5}-\mathrm{C}_{6}$ & 1.33 & 16.10 & 22.32 & \\
\hline & Herniated disc $\mathrm{C}_{6}-\mathrm{C}_{7}$ & 1.54 & 15.97 & 22.98 & \\
\hline \multirow[t]{4}{*}{ dd1 $\mathrm{C} 4 \mathrm{C} 3$} & Control group & 1.65 & 14.37 & 24.33 & $p=0.00$ \\
\hline & Cervical myelopathy & 2.65 & 11.97 & 22.05 & \\
\hline & Herniated disc $\mathrm{C}_{5}-\mathrm{C}_{6}$ & 1.70 & 14.38 & 21.39 & \\
\hline & Herniated disc $\mathrm{C}_{6}-\mathrm{C}_{7}$ & 1.56 & 15.18 & 21.65 & \\
\hline \multirow[t]{4}{*}{ dd $1 \mathrm{C} 5 \mathrm{C} 4$} & Control group & 1.69 & 14.24 & 23.93 & $p=0.00$ \\
\hline & Cervical myelopathy & 2.40 & 11.62 & 20.88 & \\
\hline & Herniated disc $\mathrm{C}_{5}-\mathrm{C}_{6}$ & 1.67 & 14.36 & 21.03 & \\
\hline & Hermiated disc $\mathrm{C}_{6}-\mathrm{C}_{7}$ & 1.61 & 13.42 & 20.74 & \\
\hline \multirow[t]{4}{*}{ dd $1 \mathrm{C6C5}$} & Control group & 1.52 & 13.63 & 21.52 & $p=0.00$ \\
\hline & Cervical myelopathy & 2.16 & 9.69 & 19.36 & \\
\hline & Herniated disc $C_{5}-C_{6}$ & 1.58 & 12.61 & 19.12 & \\
\hline & Herniated disc $\mathrm{C}_{6^{-}} \mathrm{C}_{7}$ & 1.73 & 12.43 & 19.53 & \\
\hline \multirow[t]{4}{*}{$\mathrm{dd} 1 \mathrm{C7C6}$} & Control group & 1.54 & 13.63 & 21.83 & $p=0.00$ \\
\hline & Cervical myelopathy & 1.56 & 12.62 & 19.20 & \\
\hline & Herniated disc $C_{5}-C_{6}$ & 1.66 & 14.18 & 19.58 & \\
\hline & Herniated disc $\mathrm{C}_{6}-\mathrm{C}_{7}$ & 1.37 & 1.2 .20 & 18.66 & \\
\hline
\end{tabular}




\section{Dymamic diameters in retroflexion}

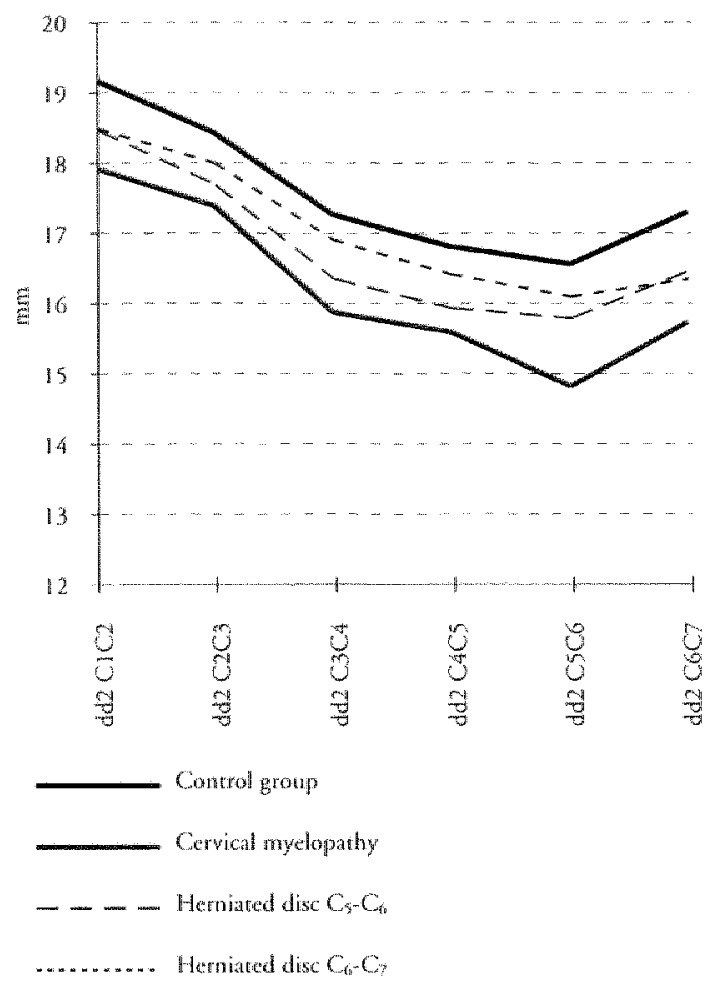

Fig. 6. mean values of dynamic diametors in retroflexion at sucessine lavels 
Table 6. standard deriation, maximum and minimum walues of dynama diameters is retroflexion at sus

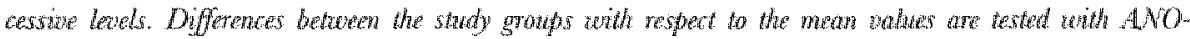
Wr the resuling p-values awe presented in the last colum.

\begin{tabular}{|c|c|c|c|c|c|}
\hline & & S.D. & $\min$. & $\max$ & $p$-value \\
\hline \multirow[t]{4}{*}{$\mathrm{dd} 2 \mathrm{C} 2 \mathrm{C} 1$} & Control group & 2.30 & 14.27 & 27.70 & $p=0.03$ \\
\hline & Cervical myelopathy & 2.24 & 1.4 .03 & 23.51 & \\
\hline & Herniated disc $\mathrm{C}_{5}, \mathrm{C}_{6}$ & 1.89 & 14.56 & 22.82 & \\
\hline & Herniated disc $\mathrm{C}_{3}-\mathrm{C}_{7}$ & 1.73 & 15.48 & 23.88 & \\
\hline \multirow[t]{4}{*}{ dd:2 $\mathrm{C} 3 \mathrm{C} 2$} & Control group & 1.68 & 13.96 & 21.85 & $p=0.03$ \\
\hline & Cervical myelopathy & 2.65 & 12.07 & 23.23 & \\
\hline & Herniated disc $\mathrm{C}_{5}-\mathrm{C}_{6}$ & 1.72 & 13.61 & 21.50 & \\
\hline & Herniated disic $\mathrm{C}_{6} \cdot \mathrm{C}_{7}$ & 1.54 & 14.49 & 21.09 & \\
\hline \multirow[t]{4}{*}{ dd2 $\mathrm{C} 4 \mathrm{C} 3$} & Control group & 1.59 & 12.27 & 20.72 & $p=0.00$ \\
\hline & Cervical myellopathy & 2.52 & 10.06 & 19.08 & \\
\hline & Herniated disc $\mathrm{C}_{5} . \mathrm{C}_{6}$ & 1.56 & 12.38 & 20.08 & \\
\hline & Hermiated disc $\mathrm{C}_{6}-\mathrm{C}_{7}$ & 1.56 & 13.35 & 20.53 & \\
\hline \multirow[t]{4}{*}{ dd $2 \mathrm{C} 5 \mathrm{C} 4$} & Control group & 1.54 & 12.41 & 20.28 & $p=0.00$ \\
\hline & Cervical myelopathy & 2.46 & 8.30 & 19.10 & \\
\hline & Herniated disc $\mathrm{C}_{5}-\mathrm{C}_{6}$ & 1.51 & 12.32 & 18.64 & \\
\hline & Herniated disc $\mathrm{C}_{6}{ }^{\prime} \mathrm{C}_{7}$ & 1.39 & 13.00 & 19.11 & \\
\hline \multirow[t]{4}{*}{ dd $2 \mathrm{C} 6 \mathrm{C} 5$} & Control group & 1.49 & 12.30 & 19.24 & $p=0.00$ \\
\hline & Cervical myelopathy & 2.19 & 8.55 & 18.68 & \\
\hline & Herniated disc $\mathrm{C}_{5}-\mathrm{C}_{6}$ & 1.86 & 11.21 & 18.08 & \\
\hline & Herniated disc $\mathrm{C}_{6}-\mathrm{C}_{7}$ & 1.60 & 11.90 & 18.85 & \\
\hline \multirow[t]{4}{*}{$\mathrm{dd} 2 \mathrm{C} 7 \mathrm{C} 6$} & Control group & 1.42 & 12.64 & 20.09 & $p=0.00$ \\
\hline & Cervical myelopathy & 1.64 & 11.10 & 17.67 & \\
\hline & Herniated disc $\mathrm{C}_{5}-\mathrm{C}_{6}$ & 1.83 & 12.30 & 18.34 & \\
\hline & Herniated disc $\mathrm{C}_{G}-\mathrm{C}_{7}$ & 1.50 & 10.90 & 18.61 & \\
\hline
\end{tabular}




\section{Cramial static diameter}

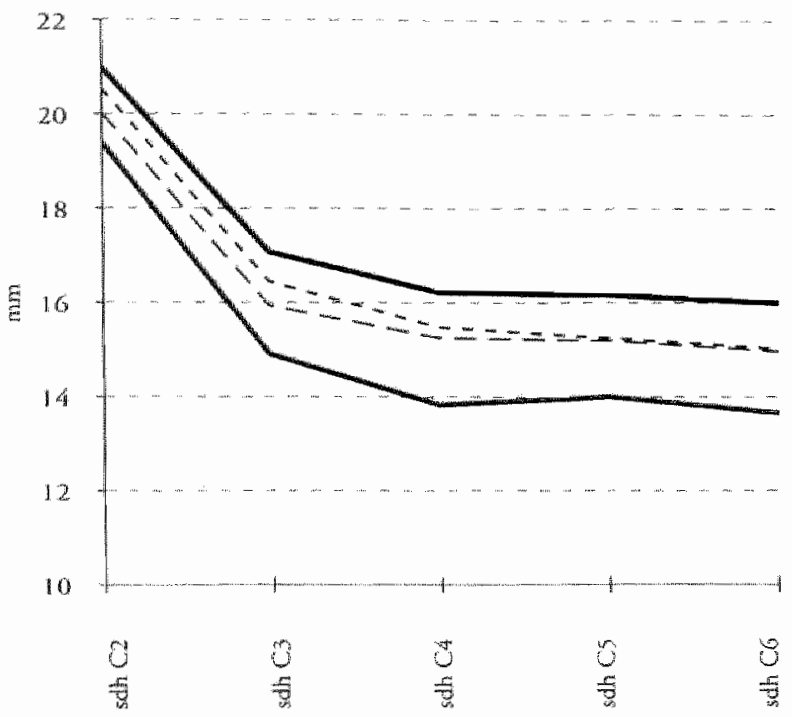

Contenol group

Cervical myelopathy

- _.... Herniared dise C $C_{5}-C_{4}$

Herniated disc $\mathrm{C}_{\mathrm{s}}+\mathrm{C}$ ?

Fig. 7: mean walues of crandal static diameders at successive levels 


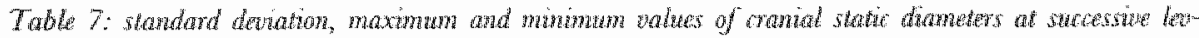

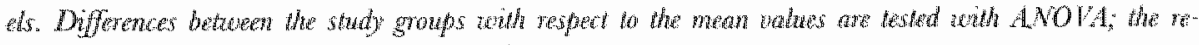
sulhing $p$-watues are presented in the last column.

\begin{tabular}{llllll}
\hline & & S.D & min. & max. & p-value \\
\hline \multirow{2}{*}{ sdh C2 } & Control group & 1.89 & 17.07 & 25.65 & $p=0.00$ \\
& Cervical myelopathy & 2.34 & 14.24 & 25.98 & \\
& Herniated disc $\mathrm{C}_{5}-\mathrm{C}_{6}$ & 2.11 & 15.58 & 25.45 & \\
& Herniated disc $\mathrm{C}_{6}-\mathrm{C}_{7}$ & 1.77 & 17.17 & 25.84 & \\
sdh C3 & Control group & 1.40 & 14.31 & 20.99 & $p=0.00$ \\
& Cervical myelopathy & 1.59 & 11.02 & 19.00 & \\
& Herniated disc $\mathrm{C}_{5}-\mathrm{C}_{6}$ & 1.34 & 12.91 & 19.70 & \\
sdh C4 & Herniated disc $\mathrm{C}_{6}-\mathrm{C}_{7}$ & 1.36 & 14.02 & 20.53 & \\
& Control group & 1.24 & 13.33 & 19.45 & $p=0.00$ \\
& Cervical myelopathy & 1.50 & 10.57 & 16.39 & \\
& Herniated disc $\mathrm{C}_{5}-\mathrm{C}_{6}$ & 1.46 & 11.82 & 18.40 & \\
& Herniated disc $\mathrm{C}_{6}-\mathrm{C}_{7}$ & 1.23 & 13.17 & 18.53 & \\
& Contral group & 1.35 & 13.26 & 20.16 & $p=0.00$ \\
& Cervical myelopathy & 1.80 & 9.99 & 17.73 & \\
& Herniated disc $\mathrm{C}_{5}-\mathrm{C}_{6}$ & 1.56 & 12.24 & 18.29 & \\
& Herniated disc $\mathrm{C}_{6}-\mathrm{C}_{7}$ & 1.21 & 12.61 & 18.72 & \\
& Control group & 1.28 & 12.88 & 19.22 & $p=0.00$ \\
& Cervical myelopathy & 1.48 & 10.46 & 15.68 & \\
& Herniated disc $\mathrm{C}_{5}-\mathrm{C}_{6}$ & 1.48 & 11.55 & 17.60 & \\
& Herniated disc $\mathrm{C}_{6}-\mathrm{C}_{7}$ & 1.33 & 12.58 & 18.40 & \\
& & & & &
\end{tabular}




\section{Caudal static diameter}

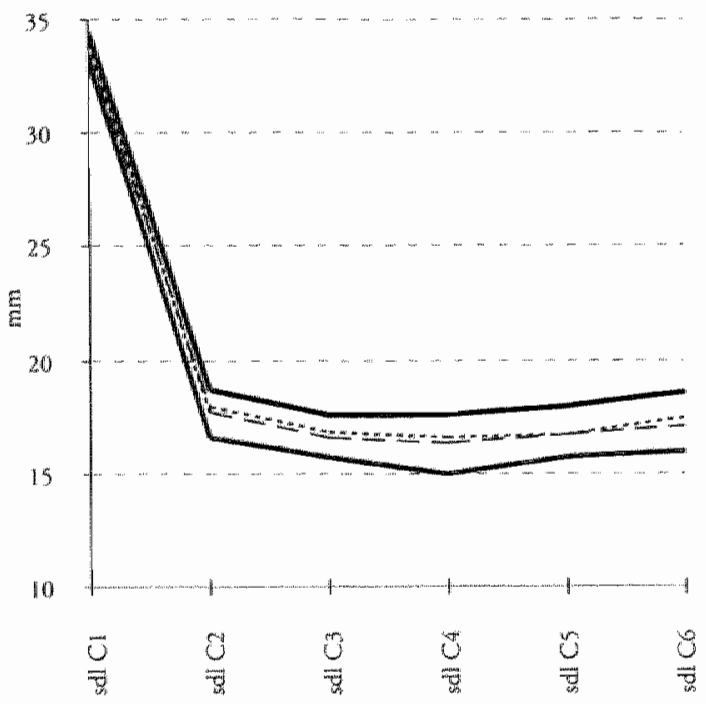

Control group

Corwical myeloparty

- - - Hernated disc $\mathrm{Cs}_{\mathrm{s}} \mathrm{C}_{6}$

Wernisted disc $\mathrm{C}_{\mathrm{E}}-\mathrm{C}_{7}$

Fog. 8: means walues of coudal static diameters at sucessine lewels 


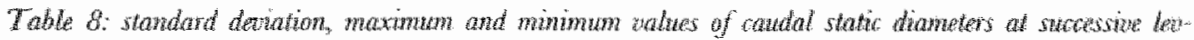

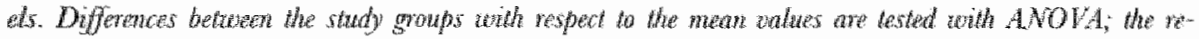
switing $p$-oalues are preserted in the last column.

\begin{tabular}{|c|c|c|c|c|c|}
\hline & & S.D. & min. & $\max$ & $\rho$-value \\
\hline \multirow[t]{4}{*}{ sdl CH } & Control group & 2.74 & 27.85 & 42.76 & $p=0.10$ \\
\hline & Cervical myelopathy & 2,47 & 29.51 & 39.81 & \\
\hline & Herniated disc $\mathrm{C}_{5}-\mathrm{C}_{6}$ & 2.23 & 29.76 & 37.37 & \\
\hline & Herniated disc $C_{6}-C_{7}$ & 2.11 & 28.57 & 38.19 & \\
\hline \multirow[t]{4}{*}{ sdll $\mathrm{C}_{2}$} & Control group & 1.60 & 15.07 & 22.50 & $p=0.00$ \\
\hline & Cervical myelopathy & 2.06 & 12.79 & 22.02 & \\
\hline & Herniated disc $C_{5}-C_{6}$ & 1.34 & 15.17 & 21.03 & \\
\hline & Herniated disc $\mathrm{C}_{\hat{6}}-\mathrm{C}_{7}$ & 1.52 & 15.22 & 21.06 & \\
\hline \multirow[t]{4}{*}{ sdl C3 } & Control group & 1.34 & 14.67 & 20.75 & $p=0.00$ \\
\hline & Cervical myelopathy & 1.93 & 12.04 & 19.61 & \\
\hline & Herniated disc $C_{5}-C_{6}$ & 1.35 & 13.16 & 19.33 & \\
\hline & Herniated disc $C_{6} \cdot C_{7}$ & 1.38 & 13.86 & 21.00 & \\
\hline \multirow[t]{4}{*}{ sdl: C4 } & Control group & 1.40 & 14.30 & 21.72 & $p=0.00$ \\
\hline & Cervical myelopathy & 1.88 & 11.39 & 18.27 & \\
\hline & Herniated disc $\mathrm{C}_{5}{ }^{\circ} \mathrm{C}_{6}$ & 1.44 & 13.69 & 19.04 & \\
\hline & Herniated disc $\mathrm{C}_{16}-\mathrm{C}_{\gamma}$ & 1.39 & 14.15 & 19.61 & \\
\hline \multirow[t]{4}{*}{ sdl $\mathrm{C5}$} & Control group & 1.72 & 14.64 & 23.19 & $p=0.00$ \\
\hline & Cervical myelopathy & 2.21 & 10.90 & 19.95 & \\
\hline & Herniated disc $\mathrm{C}_{5}-\mathrm{C}_{6}$ & 1.58 & 13.50 & 20.52 & \\
\hline & Herniated disc $\mathrm{C}_{6}-\mathrm{C}_{7}$ & 1.74 & 12.72 & 21.37 & \\
\hline \multirow[t]{4}{*}{ sdl C6 } & Control group & 2.06 & 14.71 & 24.03 & $p=0.00$ \\
\hline & Cervical myelopathy & 2.23 & 11.48 & 20.84 & \\
\hline & Herniated disc $\mathrm{C}_{5}-\mathrm{C}_{6}$ & 2.08 & 12.65 & 22.20 & \\
\hline & Herniated disc $\mathrm{C}_{6}-\mathrm{C}_{7}$ & 1.92 & 13.03 & 20.49 & \\
\hline
\end{tabular}




\section{R-Centres: $x$-comardinates}

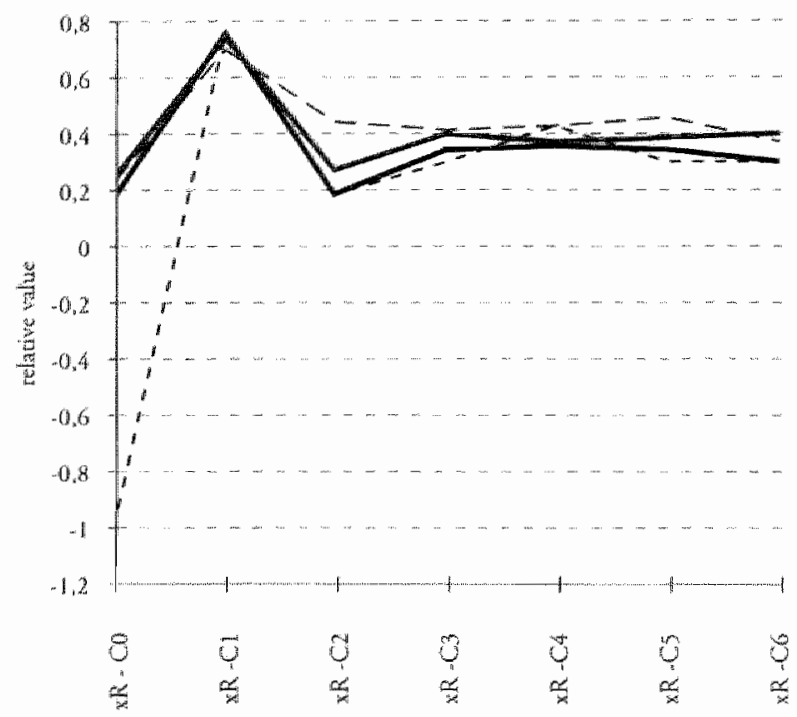

Controll group

Cervical myelopiathy

- $-\ldots$ Herniated dise $\mathrm{C}_{3}-\mathrm{C}_{6}$

......... Herrated dise $C_{6} C_{7}$

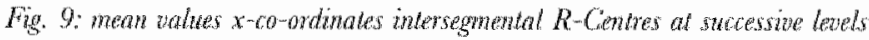




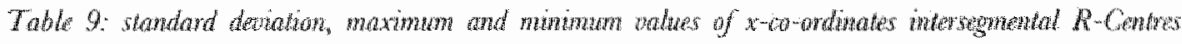

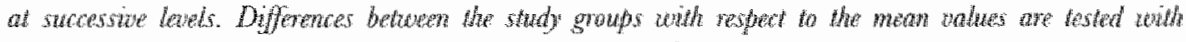
ANOVA: the rathing p-nalues are presented in the hast column.

\begin{tabular}{|c|c|c|c|c|c|}
\hline & & $S . D$ & $\min$ & $\max$ & p-value \\
\hline \multirow[t]{4}{*}{$x P C O C 1$} & Control group & 1.60 & -16.10 & 1.33 & $p=0.36$ \\
\hline & Cervical myelopathy & 0.58 & -1.80 & 1.15 & \\
\hline & Herniated disc $\mathrm{C}_{5}-\mathrm{C}_{6}$ & 0.55 & -1.47 & 1.06 & \\
\hline & Herniated disc $\mathrm{C}_{6}-\mathrm{C}_{7}$ & 8.33 & -53.43 & 9.12 & \\
\hline \multirow[t]{4}{*}{$x \mathbb{R}+\mathrm{C} 2$} & Control group & 0.41 & -0.70 & 268 & $\rho=0.83$ \\
\hline & Cervical myelopaihy & 0.62 & -1.16 & 2.83 & \\
\hline & Herniated disc $\mathrm{C}_{5}{ }^{-} \mathrm{C}_{6}$ & 0.29 & 0.14 & 1.27 & \\
\hline & Herniated disc $\mathrm{C}_{6}-\mathrm{C}_{7}$ & 0.42 & -0.03 & 2.96 & \\
\hline \multirow[t]{4}{*}{$x A \mathrm{C}_{2} \mathrm{C} 3$} & Control group & 0.46 & -1.42 & 1.31 & $p=0.10$ \\
\hline & Cervical myelopathy & 0.44 & -0.72 & 1.21 & \\
\hline & Herniated disc $\mathrm{C}_{5}-\mathrm{C}_{6}$ & 0.46 & -0.65 & 1.65 & \\
\hline & Herniated disc $\mathrm{C}_{6}-\mathrm{C}_{7}$ & 0.64 & -2.00 & 2.54 & \\
\hline \multirow[t]{4}{*}{$\times \mathrm{PlC} 3 \mathrm{C} 4$} & Control group & 0.17 & -0.16 & 0.77 & $p=0.02$ \\
\hline & Cervical myelopathy & 0.21 & 0.00 & 0.85 & \\
\hline & Herniated disc $\mathrm{C}_{5} \cdot \mathrm{C}_{6}$ & 0.24 & -0.12 & 1.12 & \\
\hline & Herniated disc $\mathrm{C}_{6}-\mathrm{C}_{\pi}$ & 0.16 & -0.07 & 0.71 & \\
\hline \multirow[t]{4}{*}{$\times \mathrm{RC} 4 \mathrm{C5}$} & Control group & 0.13 & 0.02 & 0.72 & $p=0.01$ \\
\hline & Cervical myelopathy & 0.21 & -0.12 & 0.70 & \\
\hline & Herniated disc $\mathrm{C}_{5}{ }^{\mu} \mathrm{C}_{6}$ & 0.19 & 0.07 & 0.81 & \\
\hline & Herniated disc $\mathrm{C}_{6}-\mathrm{C}_{7}$ & 0.16 & 0.07 & 1.02 & \\
\hline \multirow[t]{4}{*}{$x \mathrm{P} C 5 \mathrm{C} 6$} & Control group & 0.15 & -0.06 & 0.77 & $p=0.01$ \\
\hline & Cervical myelopathy & 0.22 & -0.11 & 0.84 & \\
\hline & Herniated disc $\mathrm{C}_{5}{ }^{-1} \mathrm{C}_{6}$ & 0.20 & 0.11 & 1.00 & \\
\hline & Herniated disc $\mathrm{C}_{6}-\mathrm{C}_{7}$ & 0.25 & -0.33 & 0.98 & \\
\hline \multirow[t]{4}{*}{$\times \mathrm{R} \mathrm{C6C7}$} & Control group & 0.24 & -0.41 & 1.08 & $p=0.51$ \\
\hline & Cervical myelopathy & 0.28 & -0.07 & 1.41 & \\
\hline & Herniated disc $C_{5}-C_{6}$ & 0.48 & -1.73 & 1.04 & \\
\hline & Herniated disc $\mathrm{C}_{6}-\mathrm{C}_{2}$ & 0.49 & -2.44 & 0.85 & \\
\hline
\end{tabular}




\section{R-Centres: y-co-ordinates}

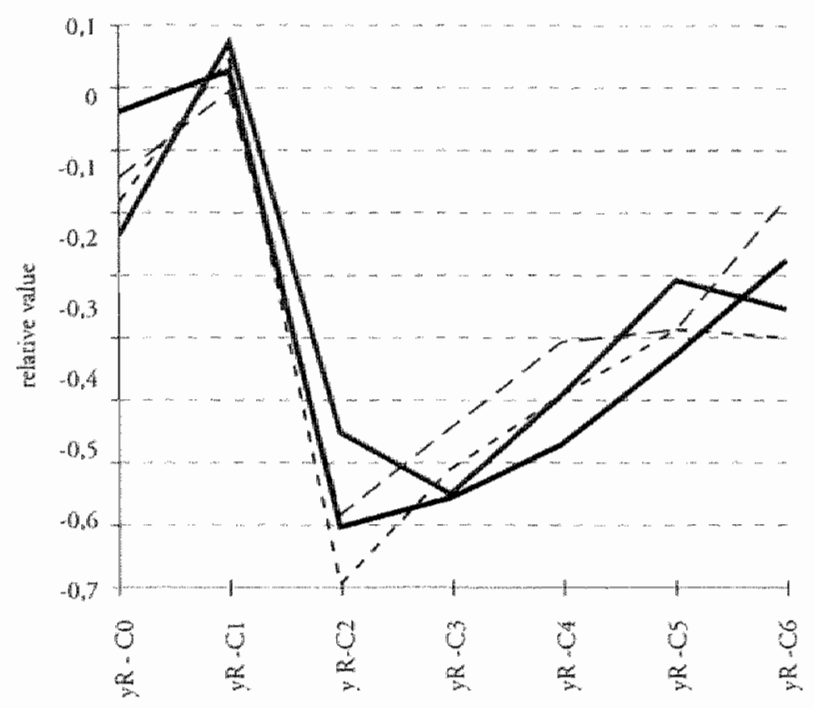

Control group

Cervical myelopatiy

- - - Herniated disc $\mathrm{C}_{5}-\mathrm{C}_{4}$

Hemiared disc $\mathrm{C}_{6} \mathrm{C}$.

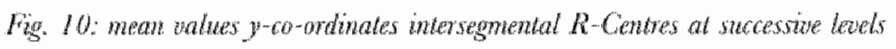




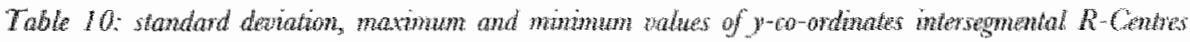

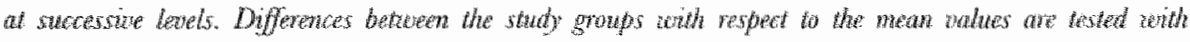

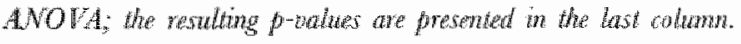

\begin{tabular}{|c|c|c|c|c|c|}
\hline & & S.D. & $\min$. & $\max$ & p.value \\
\hline \multirow[t]{4}{*}{ yR COC1 } & Control group & 1.32 & -1.09 & 11.41 & $p=0.81$ \\
\hline & Cervical myelopathy & 0.37 & -0.98 & 0.25 & \\
\hline & Herniated disc $\mathrm{C}_{5}-\mathrm{C}_{6}$ & 0.39 & -1.01 & 1.22 & \\
\hline & Herniated disc $\mathrm{C}_{6}-\mathrm{C}_{7}$ & 0.60 & -1.89 & 2.47 & \\
\hline \multirow[t]{4}{*}{$y \mathrm{R} \mathrm{ClC2}$} & Control group & 0.18 & -0.65 & 0.34 & $p=0.63$ \\
\hline & Cervical myelopathy & 0.23 & -0.72 & 0.54 & \\
\hline & Hermiated disc $\mathrm{C}_{5}-\mathrm{C}_{6}$ & 0.25 & -1.00 & 0.42 & \\
\hline & Herniated disc $\mathrm{C}_{16}-\mathrm{C}_{7}$ & 0.24 & -0.99 & 0.61 & \\
\hline \multirow[t]{4}{*}{$y R \mathrm{COC}$} & Contral group & 0.56 & -2.36 & 1.69 & $p=0.72$ \\
\hline & Cervical myelopathy & 0.48 & -1.52 & 1.20 & \\
\hline & Herniated disc $\mathrm{C}_{5}-\mathrm{C}_{6}$ & 0.44 & -1.92 & 0.41 & \\
\hline & Herniated disc $\mathrm{C}_{6}-\mathrm{C}_{7}$ & 1.26 & 8.00 & 2.57 & \\
\hline \multirow[t]{4}{*}{ yR C3C4 } & Contral group & 0.26 & -1.34 & 0.16 & $p=0.33$ \\
\hline & Cervical myelopathy & 0.25 & -1.08 & -0.16 & \\
\hline & Herniated disc $\mathrm{C}_{5}-\mathrm{C}_{6}$ & 0.26 & -1.20 & 0.08 & \\
\hline & Herniated disc $\mathrm{C}_{6}-\mathrm{C}_{7}$ & 0.31 & -1.59 & 0.29 & \\
\hline \multirow[t]{4}{*}{$y \cap C 4 C 5$} & Control group & 0.19 & -1.00 & -0.03 & $p=0.00$ \\
\hline & Cervical myelopathy & 0.18 & -0.73 & 0.02 & \\
\hline & Herniated disc $\mathrm{C}_{5}-\mathrm{C}_{6}$ & 0.23 & -0.67 & 0.41 & \\
\hline & Herniated disc $\mathrm{C}_{6}-\mathrm{C}_{7}$ & 0.24 & -1.06 & 0.13 & \\
\hline \multirow[t]{4}{*}{$y \mathbb{R C} 5 \mathrm{C6}$} & Control group & 0.17 & -0.87 & 0.05 & $p=0.43$ \\
\hline & Cervical myelopathy & 0.41 & .0 .95 & 1.09 & \\
\hline & Herniated disc $\mathrm{C}_{5}-\mathrm{C}_{6}$ & 0.27 & -1.12 & -0.01 & \\
\hline & Herniated disc $\mathrm{C}_{6}-\mathrm{C}_{7}$ & 0.43 & -1.97 & 0.52 & \\
\hline \multirow[t]{4}{*}{ yP C6C7 } & Control group & 0.28 & -1.18 & 0.69 & $p=0.38$ \\
\hline & Cervical myelopathy & 0.26 & -0.89 & 0.03 & \\
\hline & Herniated disc $\mathrm{C}_{5}-\mathrm{C}_{6}$ & 0.38 & -0.76 & 1.45 & \\
\hline & Herniated disc $\mathrm{C}_{6} \cdot \mathrm{O}_{7}$ & 0.95 & -6.23 & 0.66 & \\
\hline
\end{tabular}


R-Centres- $C_{7} ; x$-comordinates

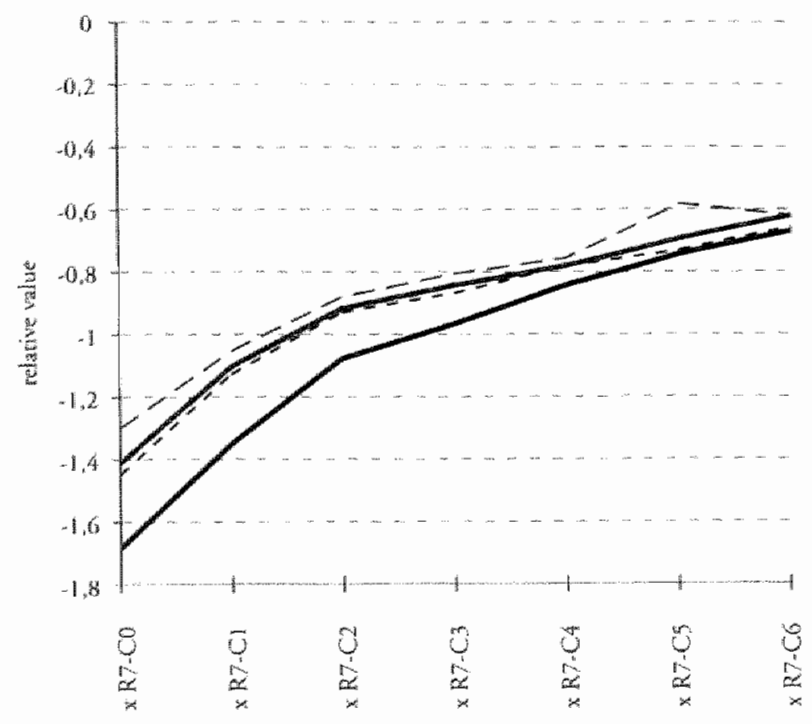

Concral group

Cervical myelopathy

- $-\ldots$ Hemiated dise $\mathrm{Cg}+\mathrm{C}$

an a........ Herniated diso $C_{6}+C_{j}$

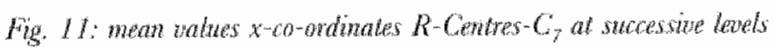




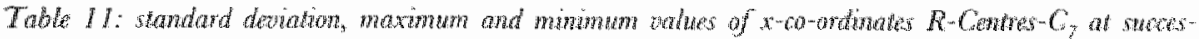

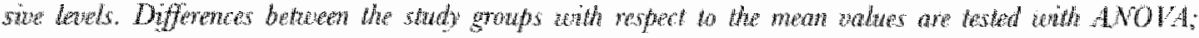

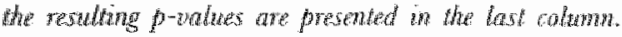

\begin{tabular}{|c|c|c|c|c|c|}
\hline & & S.D. & min. & $\max$ & $p$-value \\
\hline \multirow[t]{4}{*}{$\times \mathrm{R7} \mathrm{CO}$} & Control group & 0.45 & -3.17 & -0.67 & $p=0.00$ \\
\hline & Cervical myelopathy & 0.48 & -2.65 & 0.52 & \\
\hline & Herniated disc $\mathrm{C}_{5}-\mathrm{C}_{6}$ & 0.50 & -2.06 & 0.13 & \\
\hline & Herniated disc $\mathrm{C}_{6}-\mathrm{C}_{7}$ & 0.53 & -3.24 & -0.19 & \\
\hline \multirow[t]{4}{*}{$x R 7 \mathrm{CI}$} & Control group & 0.31 & .2 .26 & -0.53 & $p=0.00$ \\
\hline & Cervical myelopathy & 0.36 & -2.01 & -0.52 & \\
\hline & Herniated disc $\mathrm{C}_{5}-\mathrm{C}_{6}$ & 0.38 & -1.81 & 0.11 & \\
\hline & Herniated disc $\mathrm{C}_{6} \cdot \mathrm{C}_{7}$ & 0.40 & -2.83 & -0.34 & \\
\hline \multirow[t]{4}{*}{$\times \mathrm{A7} 7 \mathrm{C2}$} & Control group & 0.21 & -1.66 & -0.52 & $\rho=0.00$ \\
\hline & Cervical myelopathy & 0.26 & -4.61 & 0.35 & \\
\hline & Herniated disc $\mathrm{C}_{5}-\mathrm{C}_{6}$ & 0.28 & -1.44 & -0.20 & \\
\hline & Hermiated disc $\mathrm{C}_{6}-\mathrm{C}_{7}$ & 0.26 & -1.87 & -0.32 & \\
\hline \multirow[t]{4}{*}{$\times \mathrm{R7} \mathrm{C3}$} & Contral group & 0.18 & $-1,40$ & -0.48 & $p=0.00$ \\
\hline & Cervical myelopathy & 0.18 & -1.31 & -0.49 & \\
\hline & Herniated disc $\mathrm{C}_{5}-\mathrm{C}_{6}$ & 0.23 & -1.29 & -0.33 & \\
\hline & Herniated disc $\mathrm{C}_{6}-\mathrm{C}_{7}$ & 0.22 & -1.71 & -0.35 & \\
\hline \multirow[t]{4}{*}{$x R 7 \mathrm{C} 4$} & Control group & 0.14 & -1.20 & -0.44 & $\rho=0.01$ \\
\hline & Cervical myelopathy & 0.15 & -1.22 & -0.55 & \\
\hline & Herniated dise $\mathrm{C}_{5}-\mathrm{C}_{6}$ & 0.21 & -1.31 & -0.40 & \\
\hline & Herniated disc $\mathrm{C}_{6}{ }^{-} \mathrm{C}_{7}$ & 0.18 & -1.44 & -0.33 & \\
\hline \multirow[t]{4}{*}{$\times R 7 C 5$} & Control group & 0.13 & -1.02 & -0.28 & $p=0.00$ \\
\hline & Cervical myelopathy & 0.14 & -1.10 & -0.47 & \\
\hline & Herniated disc $\mathrm{C}_{5}-\mathrm{C}_{6}$ & 0.41 & -1.03 & 1.34 & \\
\hline & Herniated disc $\mathrm{C}_{6}-\mathrm{C}_{7}$ & 0.20 & -1.43 & -0.30 & \\
\hline \multirow[t]{4}{*}{$x R 7 C 6$} & Contral group & 0.24 & -1.33 & 0.10 & $p=0.85$ \\
\hline & Cervical myelopathy & 0.21 & -0.99 & -0.18 & \\
\hline & Hemniated disc $\mathrm{C}_{5}-\mathrm{C}_{10}$ & 0.52 & -2.92 & 0.05 & \\
\hline & Herniated disc $\mathrm{C}_{6}{ } \mathrm{C}_{7}$ & 0.28 & -1.41 & -0.05 & \\
\hline
\end{tabular}




\section{R-Centres-Cy'y-omordinates}

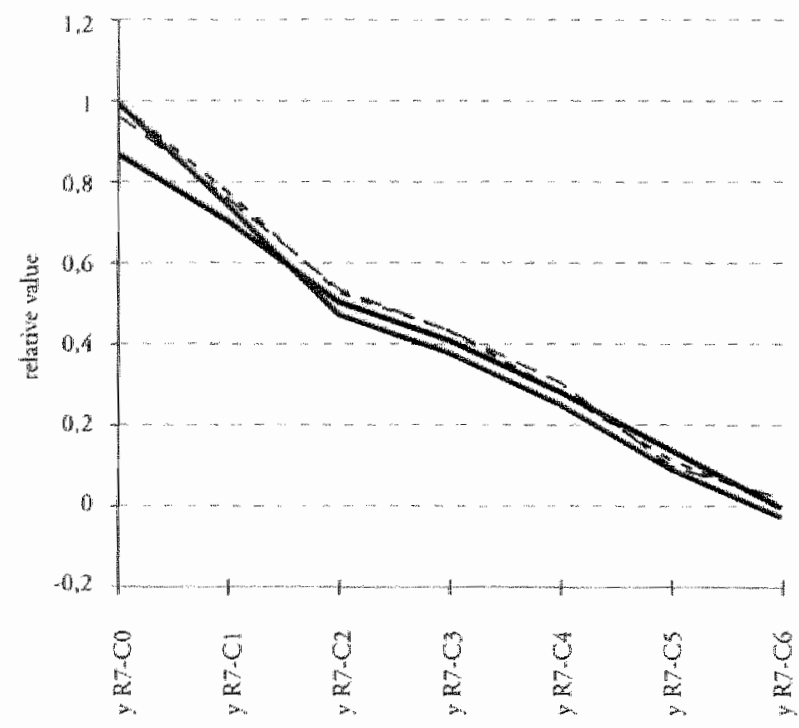

Concrol grotap

Cerwical myelopathy

- - Mentared disc $\mathrm{C}_{5}-\mathrm{C}_{\mathrm{O}}$

Herninucet dire $\mathrm{C}_{6}+\mathrm{C}_{\text {? }}$

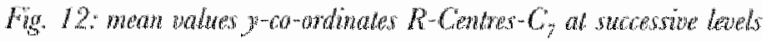




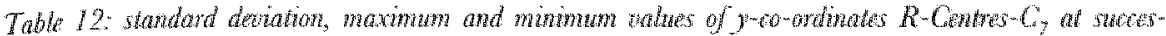

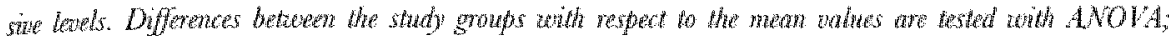
the resulting forolues are presented in the last columw.

\begin{tabular}{|c|c|c|c|c|c|}
\hline & & S.D. & $\min$. & $\max$ & prvalue \\
\hline \multirow[t]{4}{*}{ yค7 CO } & Control group & 0.16 & 0.47 & 1.23 & $\rho=0.00$ \\
\hline & Cervical myelopathy & 0.17 & 0.75 & 1.35 & \\
\hline & Herniated disc $\mathrm{C}_{5}{ }^{\mu} \mathrm{C}_{6}$ & 0.23 & 0.45 & 1.60 & \\
\hline & Herniated disc $\mathrm{C}_{6}-\mathrm{C}_{7}$ & 0.22 & 0.17 & 1.43 & \\
\hline \multirow[t]{4}{*}{ yA7 C1 } & Control group & 0.10 & 0.49 & 0.96 & $p=0.01$ \\
\hline & Cervical myelopathy & 0.12 & 0.45 & 0.94 & \\
\hline & Herniated disc $\mathrm{C}_{5}-\mathrm{C}_{6}$ & 0.18 & 0.49 & 1.24 & \\
\hline & Herniated disc $\mathrm{C}_{6}-\mathrm{C}_{7}$ & 0.14 & 0.37 & 1.08 & \\
\hline \multirow[t]{4}{*}{ yR7 C2 } & Control group & 0.08 & 0.32 & 0.79 & $p=0.06$ \\
\hline & Cervical myelopathy & 0.08 & 0.34 & 0.62 & \\
\hline & Herniated disc $\mathrm{C}_{5}-\mathrm{C}_{6}$ & 0.10 & 0.40 & 0.85 & \\
\hline & Herniated disc $\mathrm{C}_{6}{ }^{{ } \mathrm{C}_{7}}$ & 0.10 & 0.27 & 0.73 & \\
\hline \multirow[t]{4}{*}{$y / 7763$} & Control group & 0.07 & 0.20 & 0.57 & $p=0.02$ \\
\hline & Cervical myelopathy & 0.06 & 0.28 & 0.52 & \\
\hline & Herniated disc $\mathrm{C}_{5}{ }^{\circ} \mathrm{C}_{6}$ & 0.10 & 0.27 & 0.78 & \\
\hline & Herniated disc $\mathrm{C}_{6}-\mathrm{C}_{7}$ & 0.07 & 0.30 & 0.61 & \\
\hline \multirow[t]{4}{*}{$y R 7 C 4$} & Control group & 0.06 & 0.11 & 0.43 & $\rho=0.05$ \\
\hline & Cervical myelopathy & 0.05 & 0.18 & 0.36 & \\
\hline & Herniated disc $\mathrm{C}_{5}-\mathrm{C}_{6}$ & 0.11 & 0.15 & 0.71 & \\
\hline & Herniated disc $\mathrm{C}_{6}-\mathrm{C}_{7}$ & 0.07 & 0.07 & 0.47 & \\
\hline \multirow[t]{4}{*}{ y/7 C5 } & Control group & 0.05 & -0.01 & 0.28 & $p=0.09$ \\
\hline & Cervical myelopathy & 0.12 & .0 .38 & 0.37 & \\
\hline & Hermiated disc $\mathrm{C}_{5}-\mathrm{C}_{6}$ & 0.19 & -0.81 & 0.28 & \\
\hline & Herniated disc $\mathrm{C}_{6}-\mathrm{C}_{7}$ & 0.09 & -0.11 & 0.34 & \\
\hline \multirow[t]{4}{*}{ YA7 C6 } & Control group & 0.08 & .0 .42 & 0.21 & $p=0.20$ \\
\hline & Cervical myelopathy & 0.09 & .0 .24 & 0.21 & \\
\hline & Herniated disc $\mathrm{C}_{5}-\mathrm{C}_{6}$ & 0.11 & -0.22 & 0.32 & \\
\hline & Herniated disc $\mathrm{C}_{6} \cdot \mathrm{C}_{7}$ & 0.10 & .0 .24 & 0.32 & \\
\hline
\end{tabular}


R-Zero lines

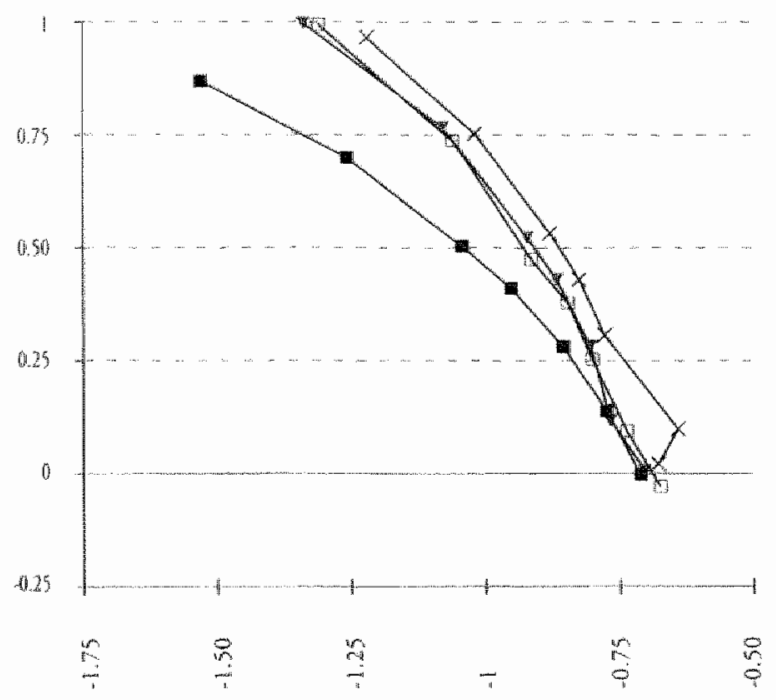

1 Control group

- D Cervical myetopathy

K Hentared disc $\mathrm{C}_{3} \times \mathrm{C}_{6}$

$\longrightarrow$ Hernatad disc $\mathrm{C}_{4} \mathrm{C}$,

Nog. I3: R-Zuro lines in the study groups (nubject facing to whe right side) 


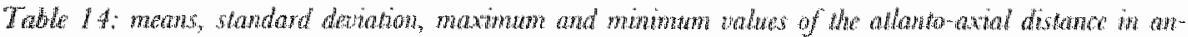

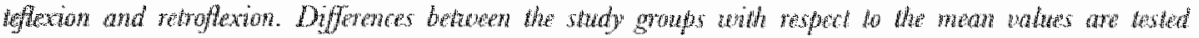
wath ANOVA: the resultang p-iadues are presented in the last collom.

\begin{tabular}{|c|c|c|c|c|c|c|}
\hline & & Mean & $S . D$ & main. & $\max$ & $p$-value \\
\hline \multirow[t]{4}{*}{ aail } & Control group & 1.69 & 0.70 & 0.04 & 4.36 & 0.58 \\
\hline & Cervical myelopathy & 1.49 & 0.69 & 0.50 & 3.08 & \\
\hline & Herniated disc $\mathrm{C}_{5}-\mathrm{C}_{6}$ & 1.62 & 0.93 & 0.13 & 3.46 & \\
\hline & Herniated disc $\mathrm{C}_{5}-\mathrm{C}_{7}$ & 1.73 & 0.81 & 0.06 & 3.99 & \\
\hline \multirow[t]{4}{*}{ aaz } & Control group & 1.04 & 0.74 & 0.02 & 3.06 & 0.79 \\
\hline & Cervical myelopathy & 0.97 & 0.77 & 0.03 & 2.47 & \\
\hline & Herniated disc $\mathrm{C}_{5}-\mathrm{C}_{6}$ & 1.11 & 0.56 & 0.23 & 2.52 & \\
\hline & Herniated disc $\mathrm{C}_{6}-\mathrm{C}_{7}$ & 1.13 & 0.71 & 0.03 & 2.88 & \\
\hline
\end{tabular}





\section{Appendix III}

TABLES

Sum variables; differences between study groups ( $\mathrm{p}$-values/Anova), means, standard deviations, minimum-, and maximum values (Table I)

Ratio variables; differences between study groups ( $\mathrm{p}$-value/Kruskal Wallis test), means, standard deviations, minimum-, and maximum values (Table il) 


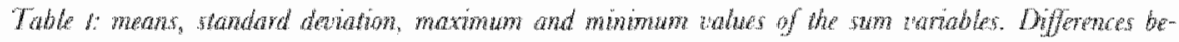

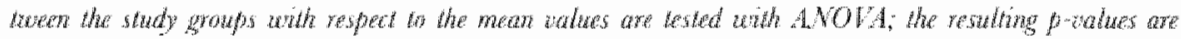
preserned in the last colleytrit.

Mean

S.D.

$\min$.

max. p-value

\begin{tabular}{|c|c|c|c|c|c|c|}
\hline \multirow[t]{4}{*}{ Sumi ar } & Control group & 88.13 & 16.82 & 40.94 & 126.54 & $p=0.00$ \\
\hline & Cervical myelopathy & 75.97 & 18.75 & 30.27 & 122.65 & \\
\hline & Herniated disc $\mathrm{C}_{5}-\mathrm{C}_{6}$ & 74.44 & 17.28 & 37.58 & 106.85 & \\
\hline & Herniated disc $\mathrm{C}_{6} \cdot \mathrm{C}_{7}$ & 72.31 & 14.84 & 44.71 & 103.00 & \\
\hline \multirow[t]{4}{*}{ Sum did 1} & Control group & 120.25 & 8.88 & 98.48 & 142.10 & $p=0.00$ \\
\hline & Cervical myelopathy & 108.65 & 11.64 & 86.78 & 131.17 & \\
\hline & Herniated disc $C_{5}-C_{6}$ & 114.87 & 6.75 & 102.99 & 131.49 & \\
\hline & Herniated disc $\mathrm{C}_{6}-\mathrm{C}_{7}$ & 115.35 & 7.91 & 96.79 & 129.98 & \\
\hline \multirow[t]{4}{*}{ Sum ddd2 } & Control group & 82.34 & 6.58 & 65.22 & 101.11 & $p=0.00$ \\
\hline & Cervical myelopathy & 74.34 & 9.27 & 52.75 & 89.05 & \\
\hline & Herniated disc $\mathrm{C}_{5}-\mathrm{C}_{6}$ & 78.53 & 6.59 & 66.74 & 96.52 & \\
\hline & Herniated disc $\mathrm{C}_{6}-\mathrm{C}_{7}$ & 80.60 & 6.10 & 69.58 & 94.56 & \\
\hline \multirow[t]{4}{*}{ Sum dh1 } & Control group & 1.26 & 0.16 & 0.82 & 1.73 & $p=0.00$ \\
\hline & Cervical myelopathy & 1.12 & 0.20 & 0.63 & 1.40 & \\
\hline & Herniated disc $\mathrm{C}_{5}-\mathrm{C}_{6}$ & 1.22 & 0.16 & 0.89 & 1.57 & \\
\hline & Herniated disc $\mathrm{C}_{6}-\mathrm{C}_{7}$ & 1.23 & 0.15 & 0.94 & 1.47 & \\
\hline \multirow[t]{4}{*}{ Sum dhe } & Control group & 1.41 & 0.17 & 0.90 & 1.87 & $p=0.00$ \\
\hline & Cervical myelopathy & 1.22 & 0.18 & 0.86 & 1.55 & \\
\hline & Herniated disc $\mathrm{C}_{5}-\mathrm{C}_{6}$ & 1.28 & 0.15 & 0.95 & 1.64 & \\
\hline & Herniated disc $\mathrm{C}_{6}-\mathrm{C}_{7}$ & 1.34 & 0.16 & 1.02 & 1.64 & \\
\hline \multirow[t]{4}{*}{ Sum sdh } & Control group & 86.65 & 6.24 & 72.74 & 101.34 & $p=0.00$ \\
\hline & Cervical myelopathy & 75.91 & 7.61 & 58.00 & 89.71 & \\
\hline & Herniated disc $\mathrm{C}_{5} \cdot \mathrm{C}_{6}$ & 81.54 & 6.64 & 69.49 & 99.42 & \\
\hline & Herniated disc $\mathrm{C}_{6} \mathrm{C}_{7}$ & 82.94 & 5.71 & 71.27 & 97.09 & \\
\hline \multirow[t]{4}{*}{ Sum sdl } & Control group & 90.48 & 6.82 & 75.27 & 108.10 & $p=0.00$ \\
\hline & Cervical myelopathy & 79.30 & 8.51 & 59.29 & 93.37 & \\
\hline & Herniated disc $\mathrm{C}_{5}-\mathrm{C}_{6}$ & 84.86 & 6.42 & 74.12 & 97.78 & \\
\hline & Herniated disc $\mathrm{C}_{6}-\mathrm{C}_{7}$ & 85.17 & 6.13 & 74.33 & 100.26 & \\
\hline \multirow[t]{4}{*}{ Sum tr } & Control group & -0.36 & 0.16 & -0.83 & -0.04 & $p=0.00$ \\
\hline & Cervical myelopathy & -0.22 & 0.15 & -0.54 & 0.04 & \\
\hline & Herniated disc $\mathrm{C}_{5}+\mathrm{C}_{6}$ & -0.21 & 0.12 & -0.55 & -0.02 & \\
\hline & Herniated disc $\mathrm{C}_{6} \cdot \mathrm{C}_{7}$ & -0.23 & 0.13 & -0.55 & 0.05 & \\
\hline \multirow[t]{4}{*}{ SimarCO-2 } & Control group & 22.86 & 10.25 & +.59 & 45.22 & $p=0.50$ \\
\hline & Cervical myelopathy & 25.58 & 7.40 & 12.68 & 39.29 & \\
\hline & Herniated disc $C_{55} C_{B}$ & 22.76 & 8.85 & 0.85 & 42.74 & \\
\hline & Herniated disc $\mathrm{C}_{6}-\mathrm{C}_{7}$ & 24.46 & 8.96 & -1.31 & 39.73 & \\
\hline
\end{tabular}




\begin{tabular}{|c|c|c|c|c|c|c|}
\hline \multirow[t]{4}{*}{$\mathrm{SmarCO}-3$} & Control group & 32.01 & 10.58 & 7.60 & 56.65 & $p=0.80$ \\
\hline & Cervical myelopathy & 33.32 & 9.12 & 17.94 & 50.73 & \\
\hline & Herniated disc $\mathrm{C}_{5}-\mathrm{C}_{6}$ & 30.56 & 9.91 & 4.78 & 48.90 & \\
\hline & Herniated disc $\mathrm{C}_{6}-\mathrm{C}_{7}$ & 31.92 & 9.49 & 0.72 & 50.14 & \\
\hline \multirow[t]{4}{*}{ SmarC3-6 } & Control group & 56.12 & 12.73 & 31.80 & 82.05 & $p=0.00$ \\
\hline & Cervical myelopathy & 42.64 & 13.69 & 12.33 & 71.92 & \\
\hline & Herniated disc $\mathrm{C}_{5}{ } \mathrm{C}_{6}$ & 43.88 & 13.52 & 10.52 & 71.02 & \\
\hline & Herniated disc $\mathrm{C}_{6}-\mathrm{C}_{7}$ & 40.39 & 11.68 & 15.14 & 66.73 & \\
\hline \multirow[t]{4}{*}{$S m R 7 \times 0-2$} & Control group & -3.02 & 0.74 & -5.41 & -1.20 & $p=0.00$ \\
\hline & Cervical myelopathy & -2.50 & 0.82 & -4.66 & -1.04 & \\
\hline & Herniated disc $\mathrm{C}_{5}{ }^{\circ} \mathrm{C}_{6}$ & -2.34 & 0.88 & -3.81 & 0.02 & \\
\hline & Herniated disc $\mathrm{C}_{6}-\mathrm{C}_{7}$ & -2.56 & 0.91 & -6.07 & -0.54 & \\
\hline \multirow[t]{4}{*}{$S m R 7 \times 2-5$} & Control group & -2.88 & 0.52 & -4.18 & -1.44 & $p=0.00$ \\
\hline & Cervical myelopathy & -2.52 & 0.57 & -4.14 & -1.39 & \\
\hline & Herniated disc $\mathrm{C}_{5}-\mathrm{C}_{6}$ & -2.42 & 0.70 & -3.84 & -1.15 & \\
\hline & Herniated disc $\mathrm{C}_{6}-\mathrm{C}_{7}$ & -2.56 & 0.65 & -5.02 & -1.03 & \\
\hline \multirow[t]{4}{*}{$\operatorname{SmR} 7 \times 5-6$} & Control group & -1.41 & 0.34 & -230 & -0.18 & $\rho=0.15$ \\
\hline & Cervical myelopathy & -1.31 & 0.30 & -1.98 & -0.84 & \\
\hline & Herniated disc $\mathrm{C}_{5}-\mathrm{C}_{6}$ & -1.20 & 0.80 & -3.95 & 1.39 & \\
\hline & Herniated disc $\mathrm{C}_{6} \cdot \mathrm{C}_{7}$ & -1.38 & 0.43 & -2.52 & -0.51 & \\
\hline \multirow[t]{4}{*}{ SinR7y0-2 } & Control group & 1.57 & 0.24 & 1.01 & 2.18 & $\rho=0.00$ \\
\hline & Cervical myelopathy & 1.74 & 0.28 & 1.23 & 2.27 & \\
\hline & Herniated disc $\mathrm{C}_{5} \times \mathrm{C}_{6}$ & 1.73 & 0.40 & 0.95 & 2.84 & \\
\hline & Herniated disc $\mathrm{C}_{6}{ }^{-1} \mathrm{C}_{7}$ & 1.77 & 0.34 & 0.54 & 2.51 & \\
\hline \multirow[t]{4}{*}{ SmP7y2-5 } & Control group & 1.20 & 0.20 & 0.66 & 1.74 & $p=0.02$ \\
\hline & Cervical myelopathy & 1.12 & 0.17 & 0.81 & 1.46 & \\
\hline & Herniated disc $\mathrm{C}_{5}, \mathrm{C}_{6}$ & 1.28 & 0.29 & 0.85 & 2.34 & \\
\hline & Herniated disc $\mathrm{C}_{6}-\mathrm{C}_{7}$ & 1.25 & 0.21 & 0.75 & 1.68 & \\
\hline \multirow[t]{4}{*}{ SmR7 $75-6$} & Control group & 0.14 & 0.12 & -0.42 & 0.41 & $p=0.24$ \\
\hline & Cervical myelopathy & 0.07 & 0.19 & -0.49 & 0.58 & \\
\hline & Herniated disc $\mathbb{C}_{5} \cdot C_{65}$ & 0.13 & 0.25 & -0.79 & 0.60 & \\
\hline & Herniated disc $\mathrm{C}_{6}-\mathrm{C}_{7}$ & 0.13 & 0.17 & -0.23 & 0.56 & \\
\hline \multirow[t]{4}{*}{ SmTrCo-2 } & Control graup & -0.09 & 0.08 & -0.28 & 0.10 & $p=0.01$ \\
\hline & Cervical myelopathy & -0.04 & 0.07 & -0.26 & 0.07 & \\
\hline & Herniated disc $\mathrm{C}_{5}{ }^{-} \mathrm{C}_{69}$ & -0.06 & 0.07 & -0.18 & 0.09 & \\
\hline & Herniated disc $\mathrm{C}_{6}-\mathrm{C}_{7}$ & -0.07 & 0.08 & -0.25 & 0.09 & \\
\hline \multirow[t]{4}{*}{ SmTrC3-6 } & Control group & -0.26 & 0.14 & -0.68 & 0.01 & $p=0.00$ \\
\hline & Cervical myelopathy & -0.18 & 0.12 & -0.43 & 0.04 & \\
\hline & Herniated disc $\mathrm{C}_{5}{ }^{-} \mathrm{C}_{66}$ & -0.16 & 0.12 & -0.51 & 0.01 & \\
\hline & Herniated disc $\mathrm{C}_{6}-\mathrm{C}_{7}$ & -0.16 & 0.10 & -0.43 & 0.02 & \\
\hline
\end{tabular}




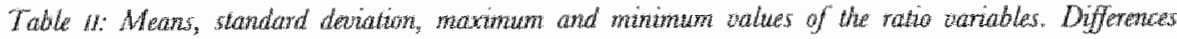

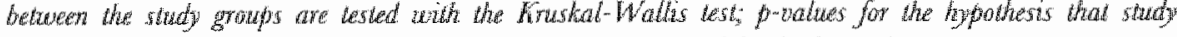
groups belong to poprtations with the same median are presented in the last oolumn.

Ratio variables

arcocise Control group

Cervical myelopathy

Herniated disc $\mathrm{C}_{5}-\mathrm{C}_{6}$

Herniated disc $\mathrm{C}_{6}-\mathrm{C}_{7}$

$\operatorname{arC} 12 \mathrm{C} 01$ Control group

Cervical myelopathy

Herniated disc $\mathrm{C}_{5}-\mathrm{C}_{16}$

Herniated disc $\mathrm{C}_{6} \cdot \mathrm{C}_{7}$

arC 1 C2ss Control group

Cervical myelopathy

Hermiated disc $\mathrm{C}_{5}-\mathrm{C}_{6}$

Hermiated disc $\mathrm{C}_{6} \cdot \mathrm{C}_{7}$

arC23C12 Control group

Cervical myelopathy

Herniated disc $\mathrm{C}_{5}-\mathrm{C}_{6}$

Herniated disc $\mathrm{C}_{6}-\mathrm{C}_{7}$

arC2C3sr Control group

Cervical myelopathy

Herniated disc $\mathrm{C}_{5}-\mathrm{C}_{6}$

Herniated disc $\mathrm{C}_{6}{ } \mathrm{C}_{7}$

arC34C23 Control group

Cervical myelopathy

Herniated disc $\mathrm{C}_{5}{ }^{2} \mathrm{C}_{6}$

Herniated disc $\mathrm{C}_{6}-\mathrm{C}_{7}$

arC3C4sr Control group

Cervical myelopathy

Herniated disc $\mathrm{C}_{5}-\mathrm{C}_{6}$

Herniated disc $\mathrm{C}_{6}-\mathrm{C}_{7}$

arC45C34 Control group

Cervical myelopathy

Herniated disc $\mathrm{C}_{5} \times \mathrm{C}_{6}$

Herniated disc $\mathrm{C}_{6}-\mathrm{C}_{7}$

arC4C5sr Contral group

Cervical myelopathy

Herniated disc $\mathrm{C}_{5}-\mathrm{C}_{6}$

Herniated disc $\mathrm{C}_{\mathbb{B}}-\mathrm{C}_{\text {? }}$

$\operatorname{arC} 56045$ Contral group

Mean S.D. min. max. p-value

$\begin{array}{lll}0.13 & 0.09 & -0.09\end{array}$

0.20

0.17

0.19

$-0.22$

0.84

0.61

0.78

0.13

0.14

0.14

0.15

1.19

0.82

1.11

0.85

0.11

0.10

0.11

0.10

$\$ .66$

2. 118

1.51

1.72

0.15

0.14

0.14

0.15

1.27

1.23

1.44

1.25

0. 18

0.16

0.18

0.17

1.03
0.07

0.08

0.10

10.83

0.42

1.92

1.58

0.06

0.05

0.07

0.06

1.72

0.45

0.96

0.65

0.04

0.03

0.03

0.04

0.85

3.91

0.87

0.89

0.04

0.04

0.05

0.05

0.46

0.52

0.76

0.77

0.05

0.05

0.07

0.06

0.52
13.38

0.61

0.55

0.31

0.68

0.07

0.06

0.03

0.06

0.34

0.47

0.18

0.13

0.04

0.05

0.03

0.04

0.03
0.33

0.38

0.34

0.41

16.56

1.70

2.97

5.96

0.35

0.26

0.34

0.27

2.11

4.17

3.99

0.25

0.14

0.16

0.19

5.65

$p=0.00$

$p=0.92$

$p=0.24$

$p=0.42$

$p=0.42$

20.54

4.63

4.96

0.34

0.23

0.25

0.28

2.55

2.59

3.53

4.97

0.32

0.31

0.37

0.38

5.33

$p=0.44$

$p=0.39$

$p=0.41$

$p=0.12$

$p=0.00$ 


\begin{tabular}{|c|c|c|c|c|c|c|}
\hline & Cervical myelopathy & 0.92 & 0.50 & -0.03 & 299 & \\
\hline & Herniated disc $\mathrm{C}_{5}-\mathrm{C}_{6}$ & 0.98 & 0.94 & 0.33 & 4.24 & \\
\hline & Herniated disc $\mathrm{C}_{56} \cdot \mathrm{C}_{7}$ & 0.92 & 0.71 & 0.10 & 4.73 & \\
\hline \multirow[t]{4}{*}{$\operatorname{arcsc6sr}$} & Control group & 0.18 & 0.05 & 0.01 & 0.35 & $p=0.00$ \\
\hline & Cervical myelopathy & 0.13 & 0.05 & -0.01 & 0.20 & \\
\hline & Herniated disc $C_{5^{\prime}} \mathrm{C}_{6}$ & 0.14 & 0.04 & 0.07 & 0.20 & \\
\hline & Hermiated disc $\mathrm{C}_{6}-\mathrm{C}_{7}$ & 0.13 & 0.06 & 0.02 & 0.27 & \\
\hline \multirow[t]{4}{*}{$\operatorname{arc67C56}$} & Control group & 0.89 & 1.52 & 0.11 & 15.78 & $p=0.02$ \\
\hline & Gervical myelopathy & 0.62 & 2.49 & -10.46 & 5.05 & \\
\hline & Herniated disc $\mathrm{C}_{5}-\mathrm{C}_{6}$ & 0.94 & 0.76 & -1.67 & 2.97 & \\
\hline & Herniated disc $\mathrm{C}_{6}-\mathrm{C}_{7}$ & 1.04 & 0.77 & -0.03 & 3.58 & \\
\hline \multirow[t]{4}{*}{$\operatorname{arc607sm}$} & Control group & 0.12 & 0.05 & 0.02 & 0.28 & $p=0.14$ \\
\hline & Cervical myellopathy & 0.12 & 0.05 & -0.02 & 0.18 & \\
\hline & Herniated disc $\mathrm{C}_{5}-\mathrm{C}_{6}$ & 0.12 & 0.08 & -0.14 & 0.23 & \\
\hline & Herniated disc $\mathrm{C}_{66}-\mathrm{C}_{7}$ & 0.10 & 0.05 & 0.00 & 0.26 & \\
\hline \multirow[t]{4}{*}{$\operatorname{trar} 0$} & Control group & 0.00 & 0.03 & -0.02 & 0.25 & $p=0.37$ \\
\hline & Cervical myelopathy & 0.00 & 0.00 & -0.01 & 0.01 & \\
\hline & Herniated disc $\mathrm{C}_{5}-\mathrm{C}_{6}$ & 0.01 & 0.03 & -0.01 & 0.18 & \\
\hline & Herniated disc $\mathrm{C}_{6}-\mathrm{C}_{7}$ & 0.00 & 0.00 & -0.01 & 0.01 & \\
\hline \multirow[t]{4}{*}{ Irar 1} & Control group & 0.00 & 0.01 & -0.01 & 0.03 & $p=0.96$ \\
\hline & Cervical myelopathy & 0.00 & 0.00 & -0.01 & 0.01 & \\
\hline & Herniated disc $\mathrm{C}_{5}-\mathrm{C}_{6}$ & 0.00 & 0.01 & -0.03 & 0.02 & \\
\hline & Herniated disc $\mathrm{C}_{6} \cdot \mathrm{C}_{7}$ & 0.00 & 0.00 & -0.01 & 0.01 & \\
\hline \multirow[t]{4}{*}{$\operatorname{trar} 2$} & Control group & -0.01 & 0.01 & -0.03 & 0.00 & $p=0.05$ \\
\hline & Cervical myelopathy & -0.01 & 0.01 & -0.03 & 0.00 & \\
\hline & Herniated disc $\mathrm{C}_{5} \cdot \mathrm{C}_{6}$ & -0.01 & 0.01 & -0.02 & 0.02 & \\
\hline & Herniated disc $\mathrm{C}_{\mathrm{B}}-\mathrm{C}_{7}$ & -0.01 & 0.01 & -0.05 & 0.02 & \\
\hline \multirow[t]{4}{*}{$\operatorname{trar} 3$} & Control group & -0.01 & 0.00 & -0.02 & 0.01 & $p=0.21$ \\
\hline & Cervical myelopathy & -0.01 & 0.00 & .0 .02 & 0.00 & \\
\hline & Herniated disc $\mathrm{C}_{5}-\mathrm{C}_{6}$ & -0.01 & 0.01 & -0.04 & 0.01 & \\
\hline & Herniated disc $\mathrm{C}_{B_{0}}-\mathrm{C}_{7}$ & -0.01 & 0.01 & -0.03 & 0.00 & \\
\hline \multirow[t]{4}{*}{$\operatorname{trar} 4$} & Control group & -0.01 & 0.00 & -0.02 & 0.01 & $p=0.07$ \\
\hline & Cervical myelopathy & 0.00 & 0.00 & -0.01 & 0.01 & \\
\hline & Herniated disc $\mathrm{C}_{5}-\mathrm{C}_{6}$ & 0.00 & 0.00 & -0.01 & 0.00 & \\
\hline & Herniated disc $\mathrm{C}_{5}-\mathrm{C}_{7}$ & 0.00 & 0.00 & -0.01 & 0.01 & \\
\hline \multirow[t]{4}{*}{$\operatorname{trar} 5$} & Control group & 0.00 & 0.00 & -0.02 & 0.00 & $p=0.07$ \\
\hline & Cervical myelopathy & 0.00 & 0.02 & -0.02 & 0.07 & \\
\hline & Herniated disc $\mathrm{C}_{5}-\mathrm{C}_{6}$ & 0.00 & 0.01 & -0.02 & 0.01 & \\
\hline & Herniated disc $\mathrm{C}_{6}{ } \mathrm{C}_{7}$ & 0.00 & 0.01 & -0.04 & 0.01 & \\
\hline \multirow[t]{4}{*}{$\operatorname{trar} 6$} & Control group & 0.00 & 0.01 & -0.03 & 0.02 & $p=0.68$ \\
\hline & Cervical myelopathy & 0.00 & 0.01 & .0 .02 & 0.01 & \\
\hline & Herniated disc $\mathrm{C}_{5}-\mathrm{C}_{6}$ & 0.00 & 0.01 & -0.02 & 0.02 & \\
\hline & Herniated disc $\mathrm{C}_{6}-\mathrm{C}_{7}$ & 0.00 & 0.02 & -0.09 & 0.12 & \\
\hline
\end{tabular}





\section{References}

Adams P, Davies GT, Sweetran PM.

Obsever error and measurements of the metacarpal.

BrJ Radiol $1969 ; 42: 192-7$.

Aho A, Vartiainen O, Salo 0 .

Segmentary anteromposterior mobility of the cervical spine.

Ann Med Int Fenniace 1955;44:287-99.

Altman DG.

Practical statistics for medical research.

London: Chapman and Hall, 1991.

Amevo B, Macintosh JE, Worth D, Bogduk N.

Instantaneous axes of rotation of the typical cerwical motion segrnents: T. an empirical study of technical errors.

Clinical Bromechanics 1991;6:31 6 .

Amevo B, Worth D, Bogduk N.

Instantaneous axes of rotation of the typieal cervical motion segments: II. optimization of iechnicall errors.

Clinical Biomechanics $1991 ; 6: 38-446$.

Anderson JA.

Shoulder pain and tension neck and their relation to work.

Scand J Work Emiron Health 1984;10:435-41.

Anderson N, Ekström T.

Ober die Beweglichkeit der Wirbulsüulc.

Morphol Jahrb 1940;85:135-85.

Andersson $G B$, Schuliz $A$, Nathan $A$, Irstam L.

Roengenographic measurement of lumbar intervertebral disc height.

Spine 1981;6:154-8.

Arlen i

'Die paradoxe Kippbewegung des Atlas' in der Funktionsdiagnostik der Halswirbelsäuls. Man Med 1977;15:16-21.

$\operatorname{Arlen} \mathrm{A}$

Messverfahren zur Erfassung von Statik und Dynamik der Halswirbelsăule in der sagitualen Ebene.

Man Med 1970;16:25-34. 
Arnold $J \mathrm{~J} \mathrm{~J}$.

The clinical marifestations of spondylochondrosis (spondylosis) of the cervical spine.

Amn Surg 1955;141:872-89.

Babin E.

La mesure du diametre sagitual du canal cervical chez l'adulte.

Scm Hôp $1970 ; 6,2739-42$

Badami JP, Noman D, Barbaro NM, Cann CE, Weinstein PR, Sobel DF.

Metrixamide CT myelography in cervical myelopathy and radiculopathy: cortelation with conventonal myelography and surgical fondings.

AJR Am J Roentgenol 1985; 144:675-80.

Bakke SN.

Röngenologische Beobachtungen über die Bewegungen der Wirbelsäule.

Acta Radiol Suppl 1931:13.

Ball. J, Meijers KA.

On cervical mobility.

Ann Rheum Dis 1964,23:429-38.

Bechar M, Front D, Bormstein B, Matz S.

Cervical myelopathy caused by narrowing of the cervical spinal canal. The walue of $x$-ray examination of the cervical spinal column in extension.

Clin Radiol 1971;22:63-8.

Begg AC, Falconer MA.

Plain radiography in intraspinal protrusion of lumbar intervertebral disks: a correlation with operative findings.

Brit J Surg 1949;36:225-39.

Berfelo MW.

Kinematics of the lumbar spine [dissertation].

Rotandam Erasmus University, 1989.

Berfolo MW.

The R-zero line; a new kinernatio concept of the lumbar spine.

Eur Spine 1993;2:89-94.

Boden SD, McCowin PR, Davis DO, Dina TS, Mark AS, Wiesel S.

Abnormal magnetic-resonance scans of the cervical spine in asymptomatic subjects. A prospective investigation.

J Bono Joint Surg Am $\llbracket 990 ; 72: 1178-84$.

Bovin G, Schrader $H$, Sand $T$.

Neck pain in the general population.

Spine 1994;19:1307-9.

Boijsen E.

The cerwical spinal canal in intraspinal expansive processes.

Acta Radiol 1954:42:101 15. 
Boreadis Borden AG, Rechtman AM, Gershon-Cohen J.

The nomal cervical lordosis.

$\mathbb{R}$ adiology 1960;74-806-9.

Brataman R.

Nekletsels. Een studie over stompe laag cervicale tratmata [dissertation].

Amsterdam: State University, 1967.

Braakman R.

Management of cerwical spondylotic myelopathy and radiculopathy.

J Neurol Neunosurg Psychiatry 1994:57:257-63.

Braakman R, Penning $L$.

Radiography, unctional anatomy, biomechanics.

In: Braakman $R$, Penning $L$, editors Injurjes of the cervical spine.

Amsterdam: Excerpta Medica, 1971.3-30.

Braakman R, Penning $L_{\text {in }}$

Borderline of nomaliry, definitions, pitalls.

In: Brakman $R$, Penning $\mathbf{l}$, editors. Injuries of the cervical spine.

Amsterdam: Excerpta Medica, 1971:31-52.

Brown RH, Burstein AH, Nash CL, Schock CC.

Spinal analysis using a three-dimensional radiograplic technique.

J Bromech 1976;9:355-65

Brown BM, Schwartz RH, Frank E, Blank NK.

Preoperative evaluation of cenvical radiculopathy and myelopathy by surface-coil MR imaging.

AVR Am JRoentgenol 1988;151:1205-12.

Buetti-Bäuml C.

Funktionelle Röntgendiagnostik der Halswirbelsäule.

Stuttgart: Thieme, 1954 .

\section{Burrows HR.}

The sagital diameter of the spinal canal in cervical spondylosis.

Clin Radiol 1963;14:77-86.

Chen $1 H$, Vasavada A, Panjabi MM.

Kinematics of the cervical spine canal: changes with sagittal plane loads.

J Spinal Disord 1994;7:93-101.

Chiarello $\mathrm{CM}$, Savidge R.

Interater reliability of the Cybex EDI-320 and fluid gonometer in nomats and patients with low back pain.

Arch Phys Med Rehabil 1993;74:32-7.

Clarke E, Robinson PK.

Cervical mycloparhy: a complication of cervical spondylosis.

Brain 1956; $79.483-510$. 


\section{Colachis SC.Jr, Surom BR.}

Radiographic sudies of cevical spine motion in nomal subjects: fliexion and hyperextension.

Aroh Phys Med Rehabil $1965,46 \% 753,60$.

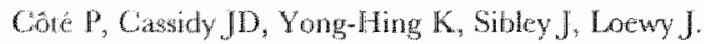

Apophysial join degeneration, dise degeneration, and sagital curve of the cervical spine.

Can they be measured reliably on radiographs?

Spine 1997:22,85964.

Crandall PH, Batzdor U.

Cervicat spoladylotic myelopathy.

J Nourosurg $1966,25,57-66$.

Gusick JF.

Pathophysology and treatment of cervical spondylotic myelopathy.

Clin Netrosurg 1991; 37:661-81.

Danicls DL, Grogan JP, Johansen JG, Meyer GA, Willams AL, Haughton VM.

Cervical radiculopathy: computed tomography and myelograplay compared.

Radiology 1984;151:109-13.

Deyo RA, Haselkorn J Holiman R, Kent DL.

Designing studies of diagnostic tests for low back pain of radiculopathy.

Spine 1994;19 (18 Suppl:20575-2065S.

Doyo RA, Me Nish LM, Gone $\mathbb{R O} 3 \mathrm{~d}$.

Observer varability in the inteppetation of lumbar spine radiographs.

Arthritis Rheum $1905 ; 28: 1066-70$.

Dicthelm L.

Rontgendiagnostik der Wirbelsäule.

Handbuch der Medizinischer Radiologic, Teil I.

Berlin: Springer-Verlag, 1974

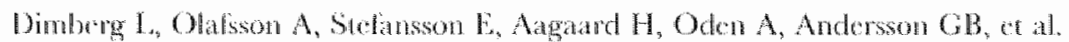

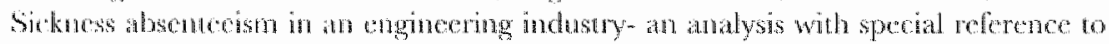
absence for neck and upper exuremity symptoms.

siond J Sor Med 1989;17:77-84.

Dimned. Pasquet A, Kang MH, Panjabi MM.

Gevical spine motion in the sagital plane: kincmatic and goometric parameters.

I of Bioned 1,982;15:959-69.

Dituma: 0 .

Rontgenstudien zur Mechanologie der Wobelsätale.

2. Orhop Chir Einshliest Heitgym Massage 1931;55:321-51.

Dupus PR, Yong-Hing K, Cassidy JD, Kirkaldy Willis WH.

Radiologie diagnosis of degenerative hmbar spinal instability.

Spine 1985; 10:262-76. 
Dworak J, Animes JA, Panjabi M, Loustalo D, Bonomo M. Age and gender related nomal motion of the cervical spine. Spine 1992,17(10 Suppl)3935-398S.

Dvorak J, Froeblich D, Perning L, Batunganner H, Panjabi MM.

Functional radiographic diagnosis of the cervical spine: flexion/cetension.

Spine $1988 ; 13: 748-55$

Dvorak, J, Panjabi MM, Novotny JE, Antimnes JA.

In wivo flexion/extension of the nomal cervical spine.

J Orthop Res 1991:9:828-34.

Drorak J, Panjabi MM, Grob D, Novony JE, Anumes.JA.

Clinical valictation of functional flexion/extension radiographs of the cervical spine.

Spine 1993;18:120-7.

Elward JF:

Motion in the vertebral column.

Am.J Roengenol 1939;42:91-9.

Espersen JO, Kosteljanez $\mathrm{M}$, Halaburt $\mathrm{H}$, Miletic $\mathrm{T}$.

Predictive whe of radiculography in patients with lumbago-sciatica.

A prospective study (Pan II).

Acta Neurochir Wien $1994 ; 73: 213-21$.

Fick $\mathbb{R}$.

Handbuch der Anatomie und der Mechanik der Gelenke.

Jenat: Gustav Fischer Verlag, 1904.

Fielding IW.

Cineroentgenograplyy of the normal cervical spine.

J Bone Joint Surg Am 1957;39:1280-8.

Ficlding JW.

Normal and selected abnomat motion of the cervical spine from the second cervical vernebra to the soventh cervical vertobra based on cinerocntgenography.

J Bone Join Surg Am 1964; $46: 1779-81$.

Fineman S, Borrelli W. Rubinstein BM, Epstein $\mathrm{H}$, Jacobson $\mathrm{HC}$.

The cervical spine: transformation of the nomal lordotic pattern into a linear paticen in the neutral posture. A roentgenographic demonstration.

J Bone Joint Surg Am 1963;45:1179-83, 1206.

Fletcher RH, Fetcher SW, Wagner EH.

Cinical Epidemiology. The esentials.

Batlimore: Williams \& Wilkins, 1996.

Fox AJ, Lin JP, Pinto RS, KrichedII.

Myclographic cervical nerve root deformites.

Radiology $1975 ; 116: 355-61$. 
Fricdenherg $Z \mathrm{ZB}$, Miller WT.

Degenerative disc disease of the cervical spine. A comparative study of asymptomatic and symptomatic patients.

J Bonc Joint Sure Am 1963;45:1171-8.

Frymoyer JW, Phillips RB, Newberg AH, MacPherson BV.

A comparative anatysis of the interpretations of lumbar spinal radiographs by

chropractors and medical doctors.

spine $1986 ; 11: 10204$.

Fijiwara $K$, Yonenobu K, Ebara $S$, Yamashia $K$, Ono $K$.

The prognosis of surgery for cenval compression myelopathy. An analysis of the factors involved.

J Bone Joine Surg Br 1969;71,393-8.

Garfin SR, Rydevik BL, Brown RA

Compressive neuropathy of spinal nerve roots. A mechanical or biological problem?

Spinc 1991;16:162-6.

Gatand LH.

Studies on the accuracy of diagnostic procedures

Arr J Roentgenol 1:959,82:25-39.

Gay RE.

The curve of the cervical spine: wriations and significance.

J Manipulative Physiol Ther 1993;16:591-4.

Gore DR, Sepic SB, Gardner GM.

Roentgenographic findings of the cervical spine in asymptomatic people.

Spine $1986,11: 521-4$.

Gratl R de:

Gervicalle spondylogene myelopathie [dissertattion].

Vtredt: State: Uniwersity, $198 \%$.

Gracowetsky S, Fathan $H_{\text {. }}$

"The optimum spine.

Spine 1986;11:543-73.

Gutrothen $\mathrm{a}$.

Pinführung in die statisch funktonelle Röngendiagnostik der Wirbelsăte unter besonderer Berücksichtigung der Koplgelonke und Halswirbelsäule.

Wiblsululo Forsch Prax 1956;1:70-2.

\section{Gumann $C_{x}$.}

Funktonello Pathologie and Klintk der Wirbelsäule. Pand 1. Die Halswirbelsäule. Die

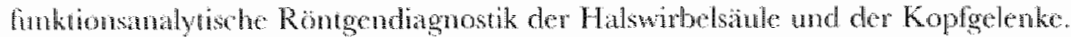

Stutgart: Gustaw Fischer Vertag, 1981

Hadicy l.A.

"The spine Anatomicomadiographic siudies. Dewolopment and the cervical region. Springheld: Chates $\mathrm{C}$. Thomas, 1956. 


\section{Hagelstam L.}

Retroposition of the lumbar vertebrac.

Acta Chir Scand Supj $1949 ; 143$.

Hall MC.

Luschka's joint.

Springield: Charles C.Thomas, 1965.

Hamburger C, Lanksch W, Oeckler R, Bachmama C.

The treatment of spondylotic cervical myelopathy by ventral discectomy, Long tem results on 121 patients.

Neurosurg Rev 1994;17:247-52.

Hanley JA, McNeil BJ.

A method of companing the areas under receiver operating characteristic curves derived from the same cases. Radiology 1983;148:839-43.

Harrison DD, Janik TI, Troyanowich SJ, Holland B.

Comparisons of lordotic cervical spine curvatures to a theoretical ideal model of the static sagitial cervical spine.

Spine $1996,21: 667-75$

Have $\mathbb{H}$ ten.

Voor-achterwaartse beweeglijkheid en afwijkingen van de thalswervelkolom [dissertation].

Leiden: State University, 1978.

Herzog RJ, Wiens $[J$, Dillingham MF; , Sontag MJ.

Normal cervical spine morphometry and cervical spinal stenosis in asymptomatic

professional football players. Plain film radiography, muliplanar compuced tomography, and magnetic resonance imaging.

Spine 1991;16 (6 Suppl):178S-186S.

Hirsch $\mathrm{C}$, Nachemson A.

The rellatbility or lumbar dise surgery.

Clin Onhop 1963;19:199-95.

Ho EK, Upadhyay SS, Chan FL, Hsu LG, Leong JC.

New methods of measuring vertidrat rotation from compued tomographic scans. An intrabserver and interobserver study on girls with scoliosis.

Spine $1993 ; 18: 1173-7$.

Holmes A, Wang $\mathrm{G}$, Han ZH, Dang GT.

The range and nature of Hexion-extersion motion in the cervical spine.

Spine 1994:19:2505-10.

Hughes Jr.

Pathology of the spinat cond.

London: Lloyd Luke, 1978.

Huli L.

Cervical, dorsal and lumbar syndromes.

Thesis.

Acta Orthop Scand Suppl 1954:17. 
Hussar AE, Guller EJ.

Correlation of pain and the roentgenographic findings of spondylosis of the cervical and lumbar spine.

An J Med Sci 1956;232:518-27.

Iai H, Moniya $\mathbb{H}$, Goto 5 , Takahashi $K$, Yamagata M, Tamaki T.

Threedimensional motion analysis of the upper cenvical spine during axial rotation.

Spine $1993 ; 18: 2388-92$.

Jensen MV, Twichsen F, Orhede $\mathrm{E}$.

Prolapsed cervical intervertebral disc in male professional drivers in Denmark, 1981-1990.

A longitudinal study of hospitalizations.

Spine 1996:21:2352-5.

Jirout J.

The mobility of the cervical spinal cord under nomal conditions.

Br.J Radiol 1959,32:744-51.

Jones MD.

Cineradiographic studies of the normal cervical spine.

Calif Med $₫ 960 ; 93: 293-6$.

Junghanns $\mathrm{H}$.

Hexenschuss im Rïcken (Lumbago) und Ausstrahlschmerz in Am und Bein (Brachiatgrie, Ischialgiel.

Ärd Forsch 1951;5:3934-402.

Junghanns $H_{\text {. }}$

Die 'funktionelle Röngenuntersuchung' der Halswirbelsäule.

Fortschn Geb Röntgenstrahten 1952;76:591-4.

Keessen W.

Stiffess properties of the lumbosacral joint in the sagittal plane: a radiological in vivo assessment folisertation.

Utredu: State University, 1988

Kcosen W, During I, Becker TW, Goudfrooij $H$, Crowe A.

Recondings of the movemen at the interverebral segment LS-S1: atechnique for the determitation of the movement in the L.5mSI spinal segment by using three specified posiural positions.

Spine 1984;9:83-90.

Klcinbaum DG, Kupper LL, Muller KE.

Applied regression analysis and other multivariable methods.

Belmont: Duxbury Press, 1980.

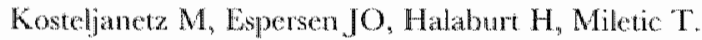

Predictive value of clinical and surgical findings in patients with lumbago-sciatica.

A prospecive sudy (Part l).

Acta Neurochir Wien $198+73367-76$. 
Kotike FJ, Mundale MO.

Range of mobility of the cervical spine.

Arch Phys Med Rehabil 1959;40:379-82.

Kraemer M, Patris A.

Radio-functional analysis of the cervical spine using the Arten method. A study of 699 subjects.

Part One: Methodology.

J Neuroradiol $1989 ; 16: 48-64$.

Kraemer M, Patris A.

Radio-functional analysis of the certical spine using the Arten method. A study of 699 subjects.

Part Two: Paradoxical tilung of the atlas.

Neuroradiol $1989 ; 16: 65-74$.

Kubo Y, Waga S, Kojima T, Matsubara T, Kuga Y, Nakagawa X.

Microsurgical anatomy of the lower cervical spine and cond.

Neurosurgery $1994 ; 34: 895-902$.

Lamberts $\mathrm{H}$.

Morbicity in general practice. Diagnosis related information from the monitoring project.

Urecht: Huisartsenpers, 1984.

[ang].

Klinische Anatomic der Halswirbelsäule.

Stutigart: Georg Thicme Verlag, 1994.

Larsson EM, Holtas S, Cronquist S, Brandt L.

Comparison of myelography, CT myelography and magnetic resonance imaging in cervical spondylosis and disk hemiation. Pre-and postoperative findings.

Acta Radiol 1989;30:233-9.

Law MD Jr, Bemhardi M, White AA $3 \mathrm{~d}$.

Exaluation and managenent of cervical spondylotic myelopathy.

J Bone Joint Surg An 1994;76:1420-33.

Lamence JS.

Dise degeneration. Its frequency and retationship to symptoms.

Ann Rhew Dis 1969:28:121-38.

Lee S, Hanis KG, NassilJ, Goel VK., Clark CR.

In vivo kinematics of the cervical spine. Part I: Dewelopment of a roentgen

stereophotogrammetric technique using metallic markers and assessment of its accuracy.

J Spinal Disord 1998;6:522-34.

Lee S, Harris KG, Goel VK, Glark CR.

Spinal motion after cervical fusion. In vivo assessment with roentgen

stercophotogrammetry.

Spine 1994:19:2336-42. 
Lees $F$, Turner JW.

Naural history and progrnosis of cervical spondlylosis.

Br Med J 1963;2:1607-10.

Lenshock CH.

Functioned röntgenonderzock bij aandoeningen van de halswervelkolom.

Ned Tujdschr Genceskd 1958;102:1718-19.

Lewit $\mathbb{K}$, Krausovid.

Messungen von Vor- und Rückbeuge in den Kopfgelenker.

Fortschr Geb Rontgenstr NukJearmed 1963;99.538-42.

Lind B, Sihlbom H, Nordwall A, Malchau $\mathrm{H}$.

Normal range of motion of the cervical spine.

Arch Phys Med Rehabil 1989;70:692-5.

Lochl WY.

Measurement of spinal posture and range of spimal movement.

Ann Phys Med 1967;9:103-10.

Lovet RW.

A contribution to the study of the mechanics of the spine.

Am J Anail $1903 ; 2 \times 457.62$.

Lunsford LD, Bissonette DJ, Zorub DS.

Anterior surgery for cervical disc disease. Part 2: Treament al cervical spondytonic myclopathy in 32 cases.

J Neurosurg 1980:53:12-9.

Lysell E.

Motion in the cervical spine. An experimental study on autopsy specimens.

Acta Orthop Scand 1969; Suppl 123.

Mameren $\mathbb{H}$ van.

Motion paterns in the eservical spine [dissertation].

Mastrich: State University Limbung, 1988.

Mamenen $\mathrm{H}$ van, Drukker ل, Sanches $\mathrm{H}$, Benrsgens J.

Gervical spine motion in the sagital plane (1) range of moton of actually performed movenents, an x-my cinematographic study.

Eur d Morphol 1990,28:47-68.

Mameren H van, Sanches H, Beurgens J. Drukker J.

Cervical spine motion in the sagital plane. II. Position of segmental averaged

instantancous centers of rotation- a cineradiographic study.

Spine 1992;17:476-4:

Mayer TG, "Tencer AF, Kristoferson S, Mooney V.

Use of noninvasive techmiques for quantification of spinal range of-motion in normal subjects and chronic low-back dystunction patients.

Spine 1984; $95880-95$ 
Mehalic TF; Pezzut RT, Applebaum BI.

Magnetic resonance imaging and cervical spondylotic myelopathy.

Newrosurgery 1990:26:217-27.

Milette PC, Fontaine S, Lepanto L, Breton G.

Radiating pain to the lower exirenities caused by lumbar disk rupture without spinal neve root involvement.

ANR An J Neuroradiol 1995;16:1605-13.

Mumenthater $\mathrm{M}$.

Diseases affecting mainly the spinal cond; nonneoplastic spinal cond compression.

In: Mumenthaler M, editor. Neurology.

Stutgant: George Thicme Verlag, 1990:181-233.

Mumenthater $\mathrm{M}$.

Spinal radicular syndromes.

In: Mumenthaler M, editor. Neurology.

Stutgant: Goorge Thieme Verlag, 1990:373.87

\section{Nachemson A.}

Towards a better understanding of low-back pain: a revicw of the mechanics of the lumbar disc.

Rheumatol Rehabil 1975;14:129-43.

\section{Nordquist L.}

The sagitual diameter of the spinal cond and subarachnoidal space in different age groups. Acta Radiol Supp! 1964; 227.

\section{Nurick S.}

The pathogenesis of the spinal cond disorder associated with cervical spondylosis.

Brain 1972,95:87-100.

Nurick S.

The natural history and the results of surgical treatmont of the spinal cord disonder associated with cervical spondylosis.

Brain 1972;95:101-8.

Ogton NG, King G], Gerzbein SD, Tilo M, Kapatsouri A

Centrode pattems in the lumbar spine. Bascline sudies in nomal subjects.

Spine $1986 ; 11: 591-5$.

Parjabi MM.

Centers and angles of rotation of body joints: a sudy of crors and optimization.

J Bromech 1979;12:9\|1-20.

Panjabi MM, Goel VK, Walter SD, Schick S.

Earors in the center and angle of rotation of a jomt: an experimental study.

J Biomech Eng 1982;104:232-7.

\section{Panjabi MM, Krag MH, Goel VK.}

A technique for measurement and description of three-dimensional six degree-of-frectom motion of a body joint with an application to the human spine.

J Biomech 1981;14:447-60. 
Panjabi M, White AA 3 d.

A matherwatical approach for theedimensional analysis of the mechanics of the spine.

J Biomech 197\&:4:203:11.

Pavlow H, Torg. IS, Robie B, Jahre C.

Crevical spinal stenosis: determination with wertebral body ratio method.

Radiology 1987;164:771-5.

Payne EE, Spilane JD.

The cerval spine: an anatomico-pathological study of 70 specimens (using a special technique) wilh particular reference to the problem of corvical spondylosis.

Brain 1957,80:571-96.

Peancy MJ, Bogduk N.

Instantaneous axes of rotation of the lumbar intervertebral joints.

Spine $1988 ; 13: 1033-41$.

Penning $\mathbb{L}$.

Functioneel röngenonderzock bij degeneratieve en tratmatiscthe andoeningen der laagcervicale bewegingsegmonten [dissertation].

Groningen: State University, 1960.

Penuing L.

Nonpathologic and pathologic relatonship between the lower cenical vertebrae.

Am J Roentgenol Radium Ther Nucl Mcd \$964:91:1036-50.

Penning L.

Normal movements of the cervical spine.

AJR Am ] Roentgenol 1978;130:317-26.

Penning l..

Differences in anatomy, motion development and aging of the upper and lower cervical dise segments.

Clin Bomednanics 1988;3:37.47.

Penning L, Wilmink JT, Woerden HH wan, Knol L.

G myelographe findings in degenerative disorders of the cervical spine: clinical signilicance.

AJNR Am J Netromadiol 1986;7: $196-27$

Pensinge L, Kwatag l'van der.

Büomechanical aspecis of spondylotic myelopathy.

Acta Radiol Diagn Stockh 1966;5:1090-103.

Plamondon A, Gagnon M.

Errors in simulated vertobral monons using Candan Euler angles with a least squares method.

J Biomodt Eng 1992;1 14:26022.

Pope MH, Hanley EN, Matteri RF, Wilder DG, Frymoyer JW.

Measurement of interyeteblal dise space height.

Spine $1977,2: 282-7$. 
Reul. I, Girvers B, Weis J, Thon A.

Assessment of the narrow cervical sphat canal a prospective comparison of MRI, myelography and CT-myelography.

Neuroradiology $1995,37: 187-91$.

Robinson ME, OConnor PD, Shirtey FR, Mac Millan M.

Intrasubject reliability of spinal range of motion and velocity deternined by video motion analysis.

Plyys Ther 1993;73:626-31.

\section{Rolinder SD.}

Motion of the lumbar spine wilh special reference to the stabilixing effect of posteriot fusion. An experimental study on autopsy specimens.

Acta Orthop Scand 1966; Suppl 90:1-144.

Roozmon P, Gracovetsky SA, Gouw G], Newnan N.

Examining motion in the cervical spine. II. Characterization of coupled join moton using an opto-elcotronic device to track skin makers.

J Biomed Eng 1993;1.5:13-22.

Rosenberg P.

The R-center method. A new method for analyzing vertebral motion by $x^{-1}$ wys.

J Am Ostropath Assoc 1955,55:103-11.

\section{Ruggien PM.}

Cervical madiculopathy.

Neuroimaging Clin N Am 1995:5:349-66.

Saraste H, Broström LA, Aparisi T, Axdiorph G.

Radiographic measurement of the lumbar spine. A dinical and experimental sudy in man.

Spine 1985; 10:236-41.

\section{Schoulen $\mathrm{H}$.}

Klinische statisack: een praktische inteding in methodologic en analyse.

Houtem: Bohn Stafleu van Loghum, 1995.

Solnultz $A B$.

Mechanies of the human spince.

Applied mechanics reviews 1974 ; nowembe: $1487-97$.

Selvik $G$

A roentgen sereophotogrammetric method for the sudy of the kinematieg of the sketeral system [dissertation].

Lund: Medicinskat fakulteten, 1974.

Seze $\$$ de, Djizm A, Abdelmoula $\mathrm{M}$.

Ende radiologique de la dynamique cervicale dans le plan sagital (Une comtrilution wadio-physiologique à l'ètude pathogénique des anthroses cevicalesj).

Revue du Rhumatisme 1951;3:1 11-6. 
Sobel DF, Barkovich $\mathrm{N}$, Munderlon $\mathrm{SH}$.

Merizamide myelography and postmyelographic computed tomography: comparative adequacy in the cervical spine.

ANR Arn J Neuroradiol 19845:385-90.

Spierings EL, Braakman R.

The management of os odontoideum. Analysis of 37 cases.

J Bone Joint Surg $\mathrm{Br} \quad 1982,64422-8$.

Slokes IA, Bewins TM, Lunn RA.

Back surface curvature and rneasurement of lumbar spinal motion.

Spine $1987 ; 12: 355-61$.

Stokes IA, Frymoyer JW

Segmental moton and insubility.

Spine 1987;12:688-91.

Teresi LM, Lufkin RB, Reicher MA, Mofit BJ, Vinuta FV, Wilson GM, ct al. Asymptomatic degenerative disk disease and spondylosis of the cervical spine: MR imaing.

Radiology $1987 ; 164: 83-8$.

Troup JD, Hood CA, Chapman AE.

Measurements of the sagittal nobility of the lumbar spine and hips.

An Phys Med 1968:9:308*21.

Vanharanta H, Korpi J; Heliovara M, Troup JD.

Radiographic measurements of Uumbar spinal canal size and their relation lo back mobility.

Spine $1985 ; 10: 461-6$

Veleanu C, Klepp HJ.

Relationships between the vertebral paraneters $\mathrm{C}_{2}-\mathrm{C}_{4}$ during movement of the centical "vertebral units" in the saghat plane.

Neuroradiology $1975 ; 10 ; 173-6$.

Virchow H.

Die saginal-hexonsehe Bewcgung der mensehlichen Halswirbelsăde.

Arch Orthop Unlallichir 1928;26:1-42.

Vorman 13.

Bewegingsentra van de lagere halswervelkolom [disseriation].

Groningen: Statc Universily, 1992.

Wackenheim $A$.

Une mélhode de notation de l'epreuve radiodynamique de Acxion-extension cervicale.

J Med Suasb $1975 ; 5: 25-9$

Weh L, Rüuker H.

Funkionsanalysen der Halswirbelsäule bei Gesunden.

Radiologe 1990;30-87.91. 
White A $3 d$, Panjabi MM.

The basic knematics of the human spine. A reviow of past and curent knowledge. Spint $1978 ; 3: 12-20$.

Whice AA 3d, Panjabi MM.

Clinicad biomechanics of the spine.

Toronto: J.B. Lippincott Company, 1978.

Wilmink JT.

Biomechanics of the cervical spinal region.

Procedings 1 st Refresher Course of the ESMR; 1991; Zunch. Udine Edizioni die

Centatro, 1991:33-3.

Wilmink JT, Penning L, Burg W van dèn.

Rolk of stenosis of spinal canal in $L_{4} L_{5}$ nore root compresion assessed by llexionextcnsion myelography.

Neuroradiology $1984,26: 173-131$.

Wumink JT, Roukema Jo Burg W van den.

Enect of i.v. contrast administration on inimaspinal and paraspinal tissues: a CT spudy. 2. Visual assessment.

AJNR Am J Neuroradiol 1988;9:191-3.

Woll BS, Khinani M, Malis L.

The sagival diameter of the bony corvical spinal canal and its signifucance in cervical spondylosis.

J Me Sinai Hosp New York 1956;23:283-92.

Yerushalmy J, Harkness JT, Cope JH, Kennedy BR.

The role of duat reading in mass radiography.

Am Rev Tuberc 1950;61:4,4:3-64.

Yone $\mathrm{K}$, Sakou T, Yanase $\mathbf{M}$, Ijiri $\mathrm{K}$.

Preoperative and postoperative magnetic resonance inage evaluations of the spinal cord in corvical myclopathy.

Spine 1992;77(10 Suppl):\$388-\$392

Youdas JW, Garret TR, Sumun VJ, Bogand CL, Haliman HO, Catrey JR.

Normal range of motion of the cervical spinc: an initial gontometric study.

Phys Ther 1992;72:770-80.

Yu YL, du Boulay GH, Stevens JM, Kendall $\mathrm{BE}$.

Computed tomography in expical spondylocic myclopathy and radiculopathy; visualisation of strectures, mevelographic comparison, cord measurements and finical unility.

Neuroradiology $1986,28: 221-36$ 

The final Chapter annot be antiten unit those responsible for the murder are brought to justice"

\section{ACKNOWLEDGEMENTS}

De volgende personen hebben een bijdrage geleverd aan dit proefschnif:

Promotie commissie:

Prof dr J.T. Wilmink, neuroradioloog, promotor, hoofd promoticcommissie

Prof. dr ir. P.A. van de Brandt, epidemioloog, promotor

Dr M.W. Berfelo, neurochirurg, compromotor

Beoordelings commissie:

Prof dr.J.M.J.P. van der Linden (voonzitter)

Prof. dr E.A.M. Beuls

Prof. dr R. Braakman

Prof. dr ir. J.D.F. Habbema

Dr H. van Mameren

De paranimfen:

Dr G. Blaauw en dhr. J. de Groen

Ondersteuning soffuare-antweikkeling:

Ir. J.M. Seroo, ir. H. Schouten (C.T.T. software), ir. F. Regtien

Adries statistische bewerkingen:

Ir. A.G.H. Kessels, dr H,J.A. Schouten

Verzamelen patienten data:

Mevr. C. Ramaekers-Ramakers, mej. M. Palmen, mej. K. van Eijsden, en mevr. A. Pecters van Oppen (secretaressen Neurochirurgie Atrim Heerlen) dr M.W. Berfelo, dr G. Blaaw en G.H.J.J. Spincemaille (Academisch Neurochirurgisch Centrum Limburg)

Bijdrage totstandkoming contrale groep:

Dhr. H.Hofmans (Epilepsie Centrum Kempenhaege), dhr. C. van der Linden (Scholengemeenschap de Berkenschutse), mevr. A. Purnot Roebroeks, dhr. en mevr. Baar, dhr. Slangen (Hoge school Heerlen sectic fysiotherapie), dhr. J. de Groen, Dr C. Pons (revalidatie arts Hoensbroek), mevr. G. van Rijn (hoofdlaborante Hoensbroek), mej. Y. Mikkers, Dr A. Scherbier en P. Barthelomeus (Skillslab Universitei Maastrichi) 


\section{Regeling werotor:}

Portiers/chauffeurs Epilopsic Centrum Kempenhaeghe en chaufeurs scholengomeenschap de Berkenschutse

\section{Cantrole groep:}

Leerkrachten van de scholengemeenschap de Berkenschutse, verpleckkundigen Epilcpsic Centrum Kempenhacghe, $\mathbb{E H B O}$ kadergroepsleden Limburg, studenten Universiteit Maastricht, sudenten Hoge school Heerlen sectie fysiotherapie, personcel Revalidatie Centrum Hoensbroek, Simulatic patiénten Skillslab-Universiteit Maastricht, werknemers Aannemers Bedriff. J. de Groen, chaufleurs Epilepsie Centrum Kempenhaeghe en scholengemeenschap de Berkenschutse, familie on bekenden.

\section{Ronigen opramen:}

C. Verstege en H. Engashoven (neurotadiologen Atrium Heerlen), P. Hofmans (radioloog Academisch Zilekenhuis Maastricht), mej. M. Wensink, en mej H. Kwikken (rontgentaboranten Arrum Heerlen, mevr. G. van Rjin (hoofdlaborante Revalidatie Centrum Hoensbroek), dhr. Lewis (hoofdlaborant Arrium Heerlen)

De motingen woor de obserwer variance studie werden werth doo: Dr M.W. Berfelo (neurochirurg), C. Versteege (neuroradioloog), H. Engelshoven (ncuroradioloog), mej. I.M.L. Majoie (studente Genecskunde), ir. J.M. Seroo

\section{Becommentariang teksiden:}

Ir. A.G.H. Kessels, prof dr R. Brathman, dr G. Blaauw, JI.C. Oudenarden

Compulas engelse tewt:

Mevr. B. Vollers King

\section{Contedies literatuating:}

Mej. M. Wetzeds (bibliohekanesse Antum Heerlen)

\section{En tot slot:}

"Live to write, write to live" moet vaker gecombineerd worden met

"Live to ride, ricle no live" 